PAULO ROGÉRIO PALO

AVALIAÇÃO DA EFICÁCIA DE MODELOS DE SIMULAÇÃO HIDRÁULICA NA OBTENÇÃO DE INFORMAÇÕES PARA DIAGNÓSTICO DE PERDAS DE ÁGUA. 
PAULO ROGÉRIO PALO

\section{AVALIAÇÃO DA EFICÁCIA DE MODELOS DE SIMULAÇÃO HIDRÁULICA NA OBTENÇÃO DE INFORMAÇÕES PARA DIAGNÓSTICO DE PERDAS DE ÁGUA.}

Dissertação apresentada à Escola Politécnica da Universidade de São Paulo para a obtenção do título de Mestre em Engenharia

São Paulo - SP 
PAULO ROGÉRIO PALO

\section{AVALIAÇÃO DA EFICÁCIA DE MODELOS DE SIMULAÇÃO HIDRÁULICA NA OBTENÇÃO DE INFORMAÇÕES PARA DIAGNÓSTICO DE PERDAS DE ÁGUA.}

Dissertação apresentada à Escola Politécnica da Universidade de São Paulo para a obtenção do título de Mestre em Engenharia

Área de concentração:

Saneamento

Orientador:

Prof. Dr. Kamel Zahed Filho 
Este exemplar foi revisado e alterado em relação à versão original, sob responsabilidade única do autor e com a anuência de seu orientador.

São Paulo, de setembro de 2010.

Assinatura do autor

Assinatura do orientador

FICHA CATALOGRÁFICA

Palo, Rogério Paulo

Avaliação da eficácia de modelos de simulação hidráulica na obtenção de informações para diagnóstico de perdas de água / P.R. Palo. -- ed.rev. -- São Paulo, 2010. $169 \mathrm{p}$.

Dissertação (Mestrado) - Escola Politécnica da Universidade de São Paulo. Departamento de Engenharia Hidráulica e Sanitária.

1. Perdas de água 2. Distribuição de água 3. Modelos mate máticos I. Universidade de São Paulo. Escola Politécnica. Depar-tamento de Engenharia Hidráulica e Sanitária II. t. 
Dedico este trabalho aos meus pais:

Sr. Agostinho Palo (in memoriam) e Sra. Marina Rodrigues Palo 


\section{AGRADECIMENTOS}

Ao Professor Doutor Milton Tomoyuki Tsutiya (in memoriam), pelos conselhos e orientações.

Ao Professor Doutor Kamel Zahed Filho, por dar continuidade à orientação deste trabalho, por sua dedicação, incentivo, análise cuidadosa, e cujas contribuições trouxeram melhorias inegáveis a este trabalho.

Aos Doutores José Rodolfo Scarati Martins e Renato Zambon, pela análise e valorosas contribuições a este trabalho em sua fase de qualificação.

Aos Professores do curso de Pós Graduação, em especial ao Professor Doutor Podalyro Amaral de Souza, pelos ensinamentos transmitidos e apoio ao longo do curso.

Aos funcionários do Departamento de Engenharia Hidráulica - PHD, pela atenção e colaboração durante todo o curso.

À Sabesp, na pessoa do superintende Eng. Francisco Paracampos, e do Departamento de Engenharia, na pessoa da gerente Élide Patella, pela oportunidade de desenvolver este trabalho. Ao meu gerente Eng. Fábio Denapoli, pela compreensão e apoio durante todo o trabalho.

Ao Eng. José Luiz Lorentz, Eng.João Alberto Favero, e Eng ${ }^{\underline{a}}$ Simone Previatelli que me apoiaram ao inicio deste trabalho.

A amiga Eng ${ }^{\mathrm{a}}$ Débora Soares Melato e ao amigo $\mathrm{Tecg}^{\circ}$ Genival Abdias Carvalho, pela ajuda e apoio.

Ao amigo Tecgํㅗำ Maurício Suzumura, pela ajuda e apoio na realização dos ensaios de campo e nas trocas de experiências diárias.

As equipes de técnicos da Divisão de Controle de Perdas Centro e da Divisão de 
Cadastro Técnico Centro, que se empenharam na execução dos ensaios de campo e me apoiaram durante todo o trabalho.

Ao Polo de Manutenção Vila Prudente na pessoa do gerente EngํAmarildo Miguel, pelo apoio nas obras de adequação do distrito de medição e controle.

A minha esposa Mônica Nobuco Shirayama Palo, pelo apoio, pela paciência e companheirismo.

Também a todos os amigos, colegas e profissionais que contribuíram direta ou indiretamente para a realização deste trabalho. 
"As pessoas não são nobres desde o nascimento, mas se enobrecem através de suas ações. As pessoas não são medíocres desde o seu nascimento, mas tornam-se assim através de suas ações. Se existem alguma diferença entre as pessoas, então essa diferença está somente nas suas realizações." Dr. Daisaku lkeda 


\section{RESUMO}

Atualmente a avaliação das perdas de água, nos sistemas de distribuição, é feita com base em equações empíricas, que utilizam informações, agrupadas e totalizadas, de uma área. Isto torna necessária sua subdivisão em frações cada vez menores, na busca da fração mais crítica. Neste trabalho, é apresentada uma avaliação da eficácia do uso de modelos de simulação hidráulica na obtenção das informações necessárias para a elaboração de um diagnóstico de perdas de água, com uma metodologia prática para o uso de modelos com este objetivo. Apresenta uma classificação dos trechos de rede em três categorias $\mathrm{A}, \mathrm{B}$ e $\mathrm{C}$, que facilita a priorização dos trechos mais críticos facilitando a análise por meio de gráficos de pareto e mapas temáticos. Demonstra que a adoção da simulação hidráulica no estudo das causas de perdas de água, nos sistemas de abastecimento, é uma ferramenta eficaz e permitirá às empresas de saneamento, uma melhoria na gestão operacional, que garante a sustentabilidade da empresa, a economia dos recursos humanos, econômicos, e principalmente, os hídricos.

Palavras Chave: Perdas de água, Distribuição de água, Modelos matemáticos, Algoritmos Genéticos, Calibração de Modelo, Simulação Hidráulica, Ensaio de Campo. 


\begin{abstract}
Currently water losses evaluation in distribution systems, is based on empirical equations using information, grouped and totaled, covering whole area. Thus, becomes necessary to subdivide the area into smaller and smaller fractions, searching for the most critical part. This study presents, the effectiveness evaluation of the hydraulic simulation models, use to obtain the information necessary in elaboration diagnosis of water losses, with a practical methodology for using models for this purpose. Shows a pipe classification in three categories A, B and C, it's began possible analyses with pareto graphics and thematic maps. Demonstrates that hydraulic simulation adoption is an effective tool in the study of water loss in supply systems. It will allow companies an operational management improvement, ensuring the sustainability of the business and economics of human, financial, and especially, water resources.
\end{abstract}

Keywords: water losses, water distribution, mathematical models, genetic algorithms, model calibration, hydraulic simulation, experimental test. 


\section{LISTA DE ILUSTRAÇÕES}

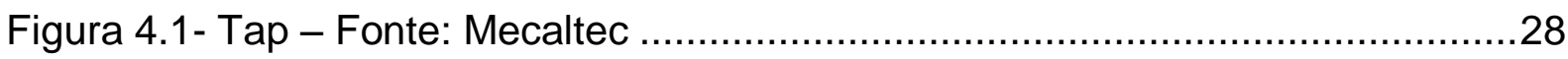

Figura 4.2 - Tipos de vazamentos - Tardelli Filho (2006) …...................................28

Figura 4.3 - Componente de Perdas Reais. Fonte: Thornton et al. (2008) adaptada 30 Figura 4.4 - Componentes de Perdas Aparentes - Fonte: Thornton et al. (2008) adaptada .33

Figura 4.5 - Estruturação para definição de ações para redução de perdas Farley et al. (2003) adaptada. .35

Figura 4.6 - Relação do custo operacional e perdas Fonte: Farley et al. (2003) adaptada .37

Figura 4.7 - NEP para Perda Aparente Fonte: Thornton et al.(2008) adaptada .......37

Figura 4.8 - Ciclo "PDCA" - Adaptado de Tardelli Filho (2006)..............................40

Figura 4.9 - Exemplo dos elementos do modelo hidráulico. (EPANET2, 2009) .........47

Figura 4.10 - Uma possível seqüência de etapas para a utilização de um aplicativo simulador hidráulico. (Walski et al., 2003) adaptada. .51

Figura 4.11 - Alguns Equipamentos utilizados na coleta de dados .........................53

Figura 4.12 - Espaços de codificação e de solução ……………...........................56

Figura 4.13 - Questões na codificação e decodificação (Ribeiro, 2005) Adaptada ...56

Figura 4.14 - Ciclo dos AGs Gen e Cheng (1997) apud Ribeiro (2005) ...................58

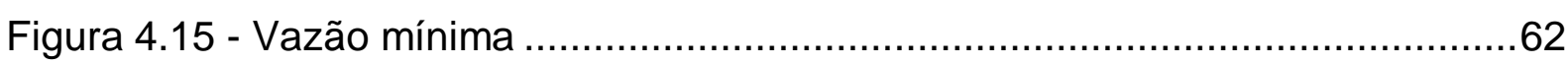

Figura 4.16 - Diagrama do Balanço Hídrico IWA.................................................64

Figura 4.17 - Exemplo de gráfico de Pareto(Silva, 2002) ....................................71

Figura 5.1 - Consumo horário desagregado por pontos de utilização fonte: (Barreto, 2008)

Figura 5.2 - Gráfico de fator horário obtido do estudo de (Barreto, 2008) ...............80

Figura 5.3 - Agrupamento de demandas nas junções por área de influência.............81

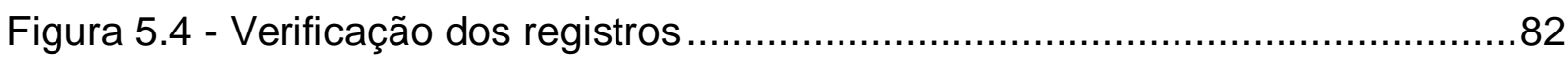

Figura 5.5 - Detecção de vazamentos (geofone eletrônico) ………..........................82

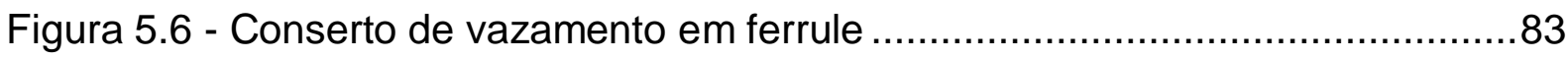

Figura 5.7 - Esquema de nivelamento geométrico - Fonte: (Jelinek, 2010)..............83

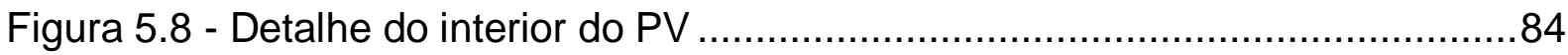

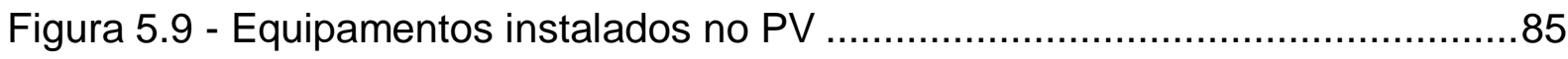


Figura 5.10 - Fechamento e lacração dos registros .85

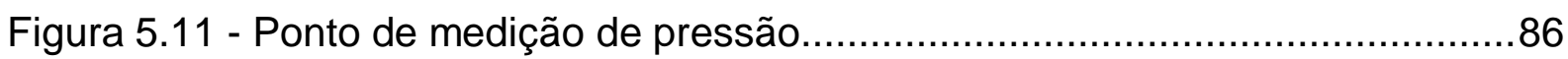

Figura 5.12 - Esquema do ensaio da rugosidade absoluta ..................................87

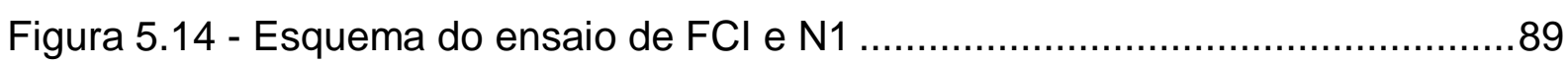

Figura 5.13 - Exemplo de gráfico com valores de $f$ calculados ..............................88

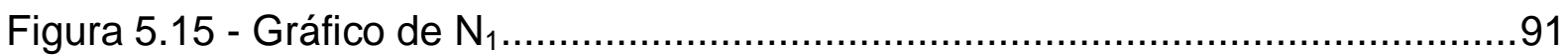

Figura 5.16 - Instalação de registrador de pressão ............................................92

Figura 5.17 - Exemplo de gráfico com a faixa de probabilidade dos valores............93

Figura 5.18 - Junções inseridas para representar os registradores eletrônicos

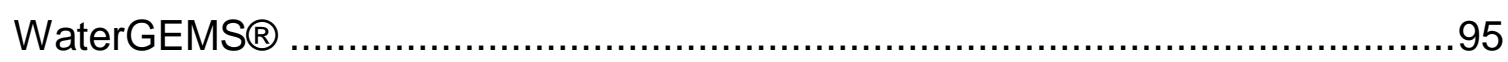

Figura 5.19 - Esquema da estratificação da vazão simulada ..................................97

Figura 5.20 - Esquema do balanço de vazões ………........................................

Figura 5.21 - Exemplo da avaliação das pressões ..............................................100

Figura 5.22 - Exemplo de mapa feito no ArcView® Versão 3.2 ….........................102

Figura 6.1 - Localização geográfica do DMC Fonte: Google Maps (2009) ..............103

Figura 6.2 - Altimetria do distrito de medição e controle (DMC) ….........................104

Figura 6.3 - Amostra da rede existente no $\mathrm{DMC}$ material $\mathrm{F}^{\circ} \mathrm{F}^{\circ} \mathrm{e}$ idade de 48 anos 105

Figura 7.1 - Gráfico comparativo da vazão medida e simulada..............................116

Figura 7.2 - Comparação entre valores horários medidos e simulados...................117

Figura 7.3 - Gráfico comparativo dos valores L-02 ……...............................118

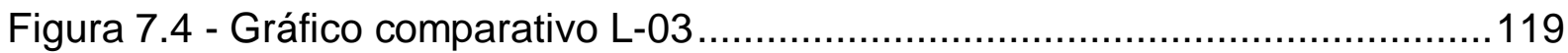

Figura 7.5 - Valores do registrador L03 simulados corrigidos pelo fator $k=1,28 \ldots \ldots .119$

Figura 7.7 - Gráfico de Pareto da porcentagem de perda total por trecho..............128

Figura 7.8 Gráfico de Pareto da perda total e extensão de rede acumuladas.........129

Figura 7.9 Gráfico de Pareto Perda aparente x Núm. de ligações acumuladas ......129

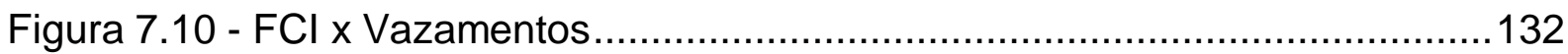

Figura 7.11 - Perda por quilometro (L/km) ................................................133

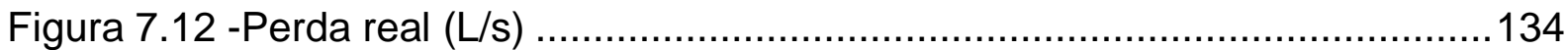

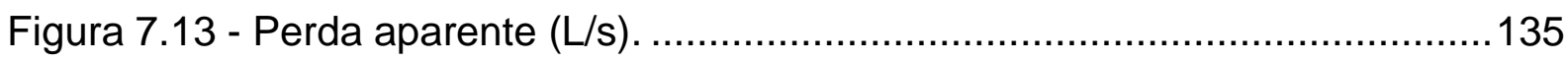

Figura 7.14 - FCl x Vazamentos x Perdas ...................................................136 


\section{LISTA DE TABELAS}

Tabela 4.1 - Histórico da calibração de modelos hidráulicos....................................41

Tabela 4.2 - Histórico da calibração de modelos considerando vazamentos .............45

Tabela 4.3 - Elementos comuns em modelagem (Walski et al., 2003) ......................47

Tabela 4.4 - Terminologia dos AGs (Ribeiro, 2005) ….......................................55

Tabela 4.5 - Valores de referência IWA - (Lambert et al., 1998) Adaptada ................66

Tabela 4.6 - Perda real anual inevitável - (Lambert et al., 1998) Adaptada ..............67

Tabela 5.1 - Valores do fator horário obtido de (Barreto, 2008) ...............................79

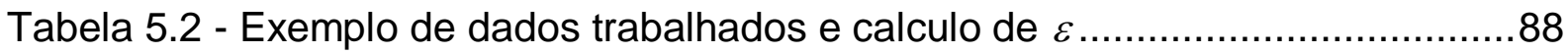

Tabela 5.3 - Exemplo de dados coletados em campo .........................................93

Tabela 5.4 - Exemplo de resultado da avaliação da incerteza .................................93

Tabela 5.5 - Exemplo de planilha de junções.......................................................95

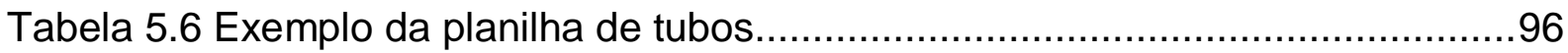

Tabela 5.7 - Exemplo de tabulação de resultados ……..........................................99

Tabela 6.1 - Dados fornecidos pelo controle sanitário Fonte:(Sabesp, 2009) .........106

Tabela 6.2 - Resumo dos valores médios e as 12 horas......................................110

Tabela 7.2 - Trechos com vazamentos comprovados ........................................126

Tabela 7.3 - Trechos com vazamentos não comprovados ...................................126 


\section{LISTA DE ABREVIATURAS E SIGLAS}

\begin{tabular}{|c|c|}
\hline ABENDE & Associação Brasileira de Ensaios Não Destrutivos \\
\hline ABNT & Associação Brasileira de Normas Técnicas \\
\hline AG (AGs) & Algoritmo Genético (plural) \\
\hline AWWA & American Water Works Association \\
\hline BABE & Bursts and Background Estimates \\
\hline $\mathrm{BH}$ & Balanço Hídrico \\
\hline DMC & Distrito de Medição e Controle \\
\hline EPI (EPIs) & Equipamento de Proteção Individual (plural) \\
\hline FAVAD & Fixed and Variable Area Discharge \\
\hline $\mathrm{FCl}$ & Fator de Condição de Infraestrutura \\
\hline FND & Fator Noite/Dia \\
\hline IBGE & Instituto Brasileiro de Geografia e Estatística \\
\hline IPDT & Índice de Perdas na Distribuição Total \\
\hline IWA & International Water Association \\
\hline MASP & Metodologia de Análise para a Solução de Problemas \\
\hline $\mathrm{N}_{1}$ & Coeficiente exponencial da relação vazão/pressão \\
\hline NEP & Nível Econômico de Perdas de água \\
\hline NPSH & Abreviação em Inglês de "Net positive suction head" \\
\hline$P$ & Pressão média de operação \\
\hline PDCA & Sigla em Inglês de "Plan, Do, Check and Action" \\
\hline PV & Poço de Visita \\
\hline Q & Vazão \\
\hline RMSP & Região Metropolitana de São Paulo \\
\hline Sabesp & Companhia de Saneamento Básico do Estado de São Paulo \\
\hline TAP & Nome em inglês para dispositivo que permite tirar água de um tubo \\
\hline VMN & Vazão Mínima Noturna \\
\hline VRP & Válvula Redutora de Pressão \\
\hline
\end{tabular}




\section{LISTA DE SÍMBOLOS}

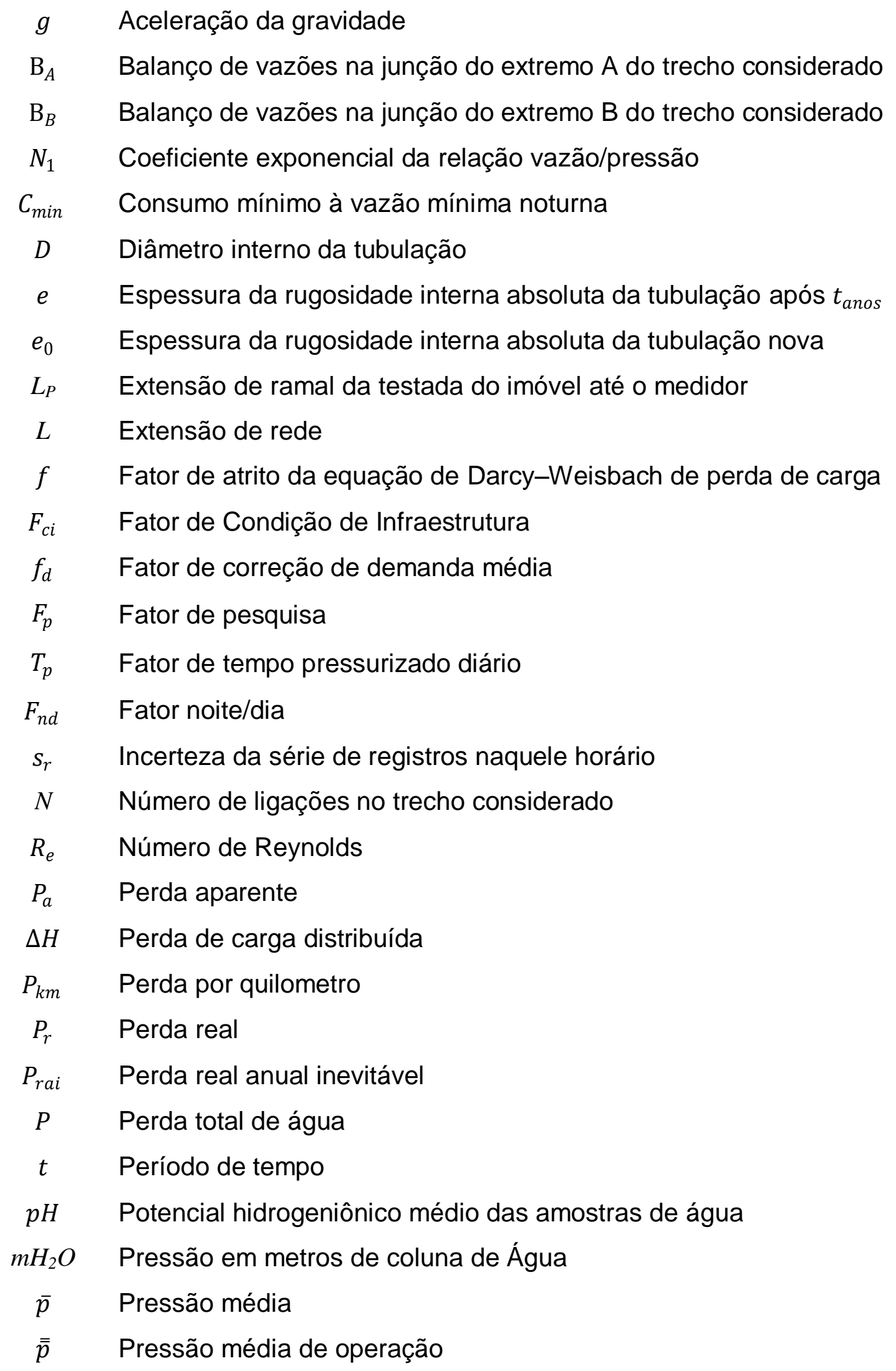




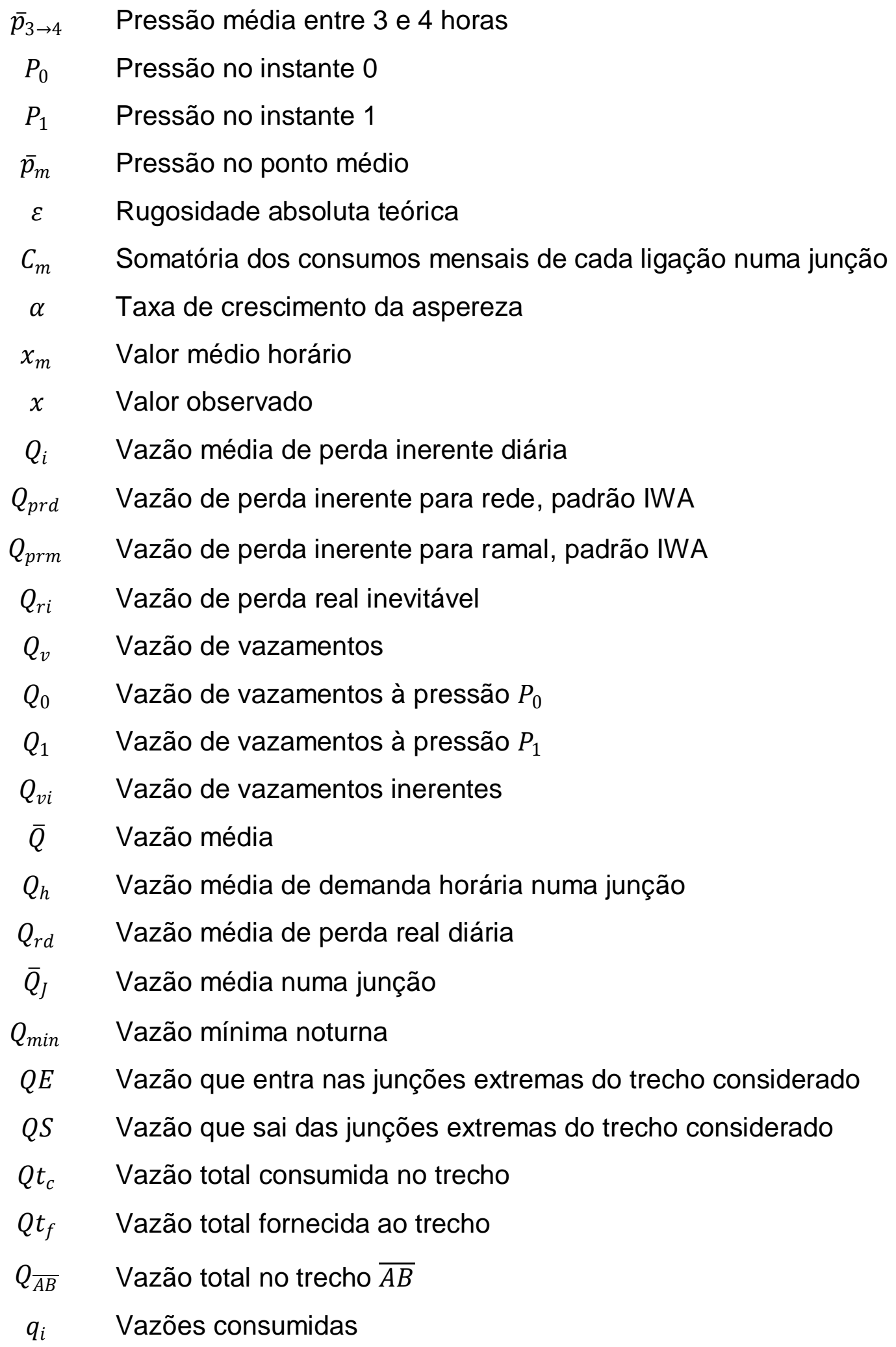




\section{SUMÁRIO}

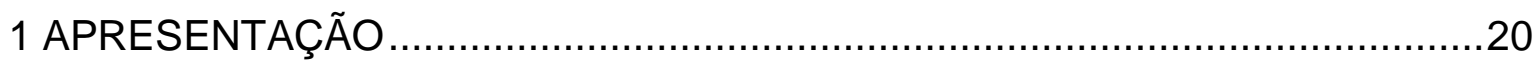

2 INTRODUÇÃO

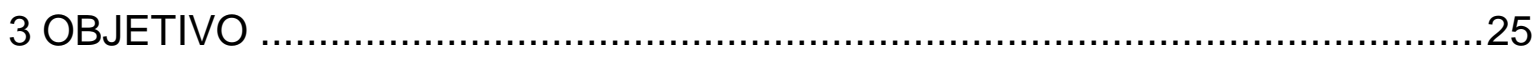

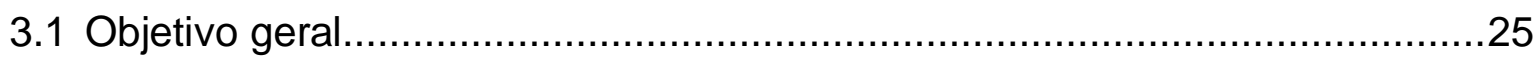

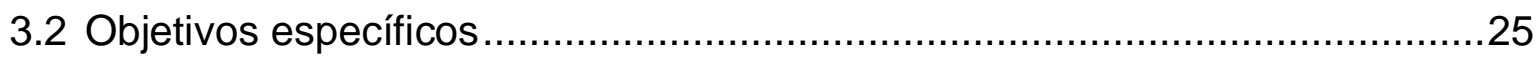

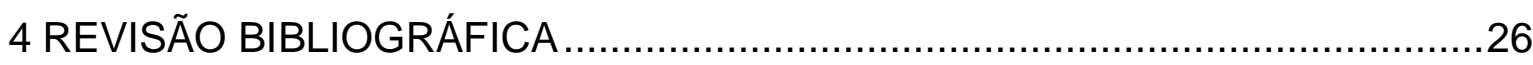

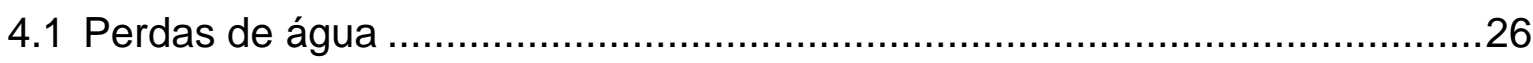

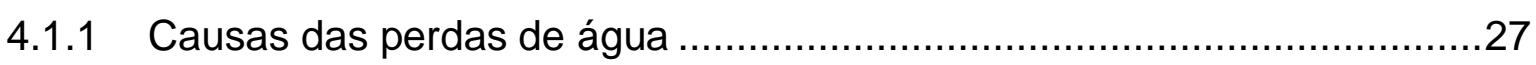

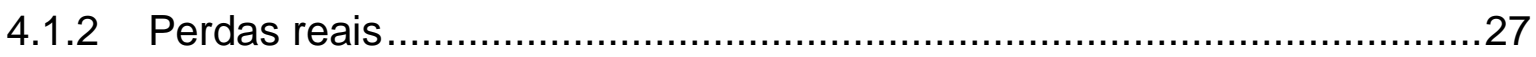

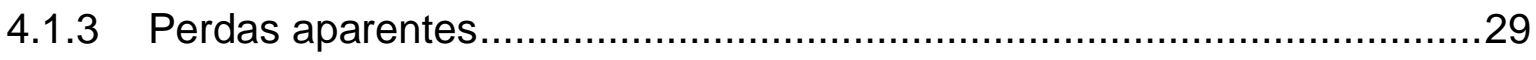

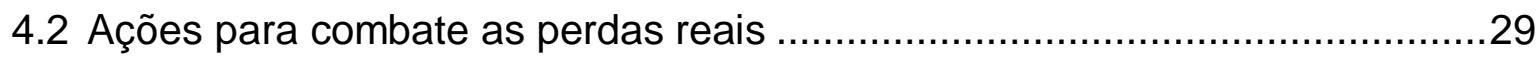

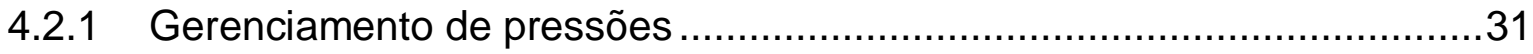

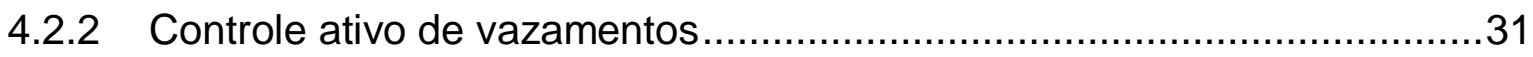

4.2.3 Reparo de vazamentos, melhoria da técnica e de materiais......................31

4.2.4 Manutenção e reabilitação da infraestrutura. ...........................................31

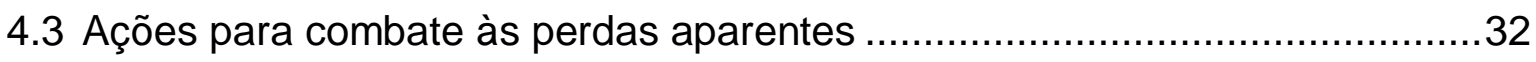

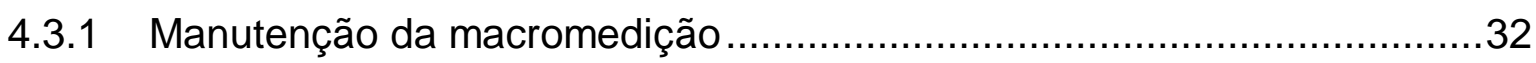

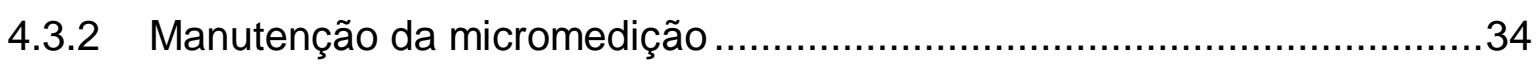

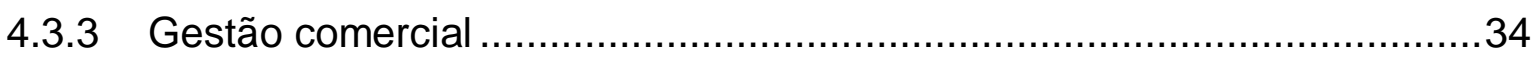

4.3.4 Elaboração de um programa de controle de perdas ................................35

4.4 Modelagem matemática de sistemas de distribuição de água ........................40

4.4.1 Montagem da topologia da rede no modelo ............................................46

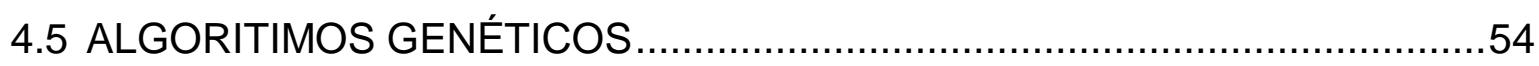

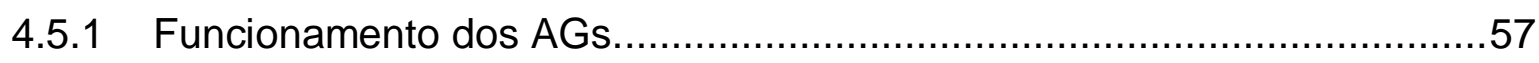

4.6 Modelagem matemática de perdas de água............................................59

4.6.1 Método "Fixed and Variable Area Discharge" (FAVAD) ............................60 


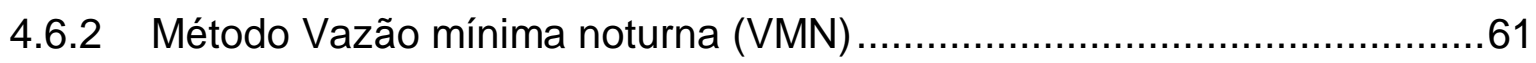

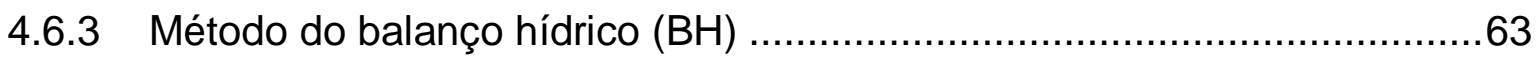

4.7 Métodos de avaliação de volume perdido ...................................................

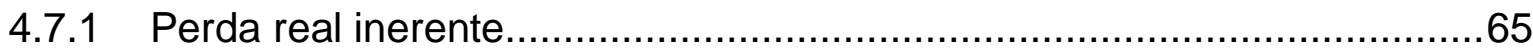

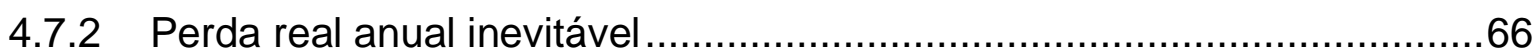

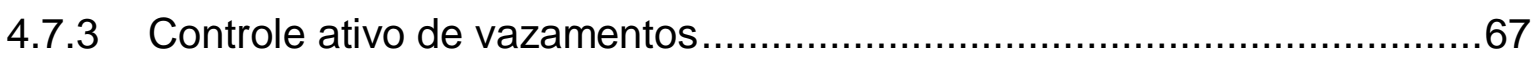

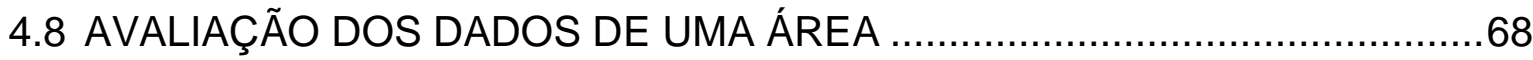

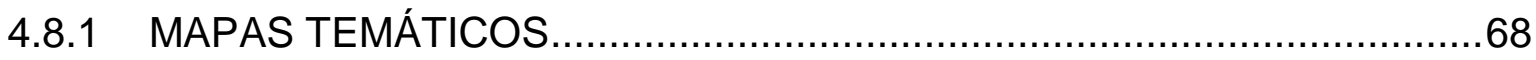

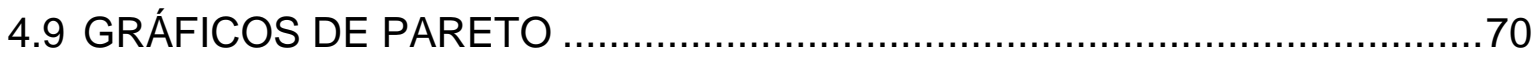

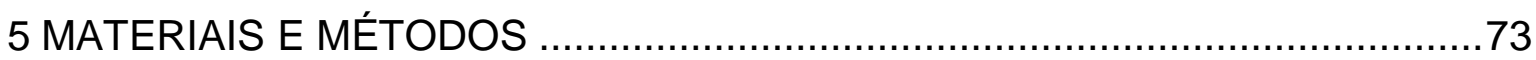

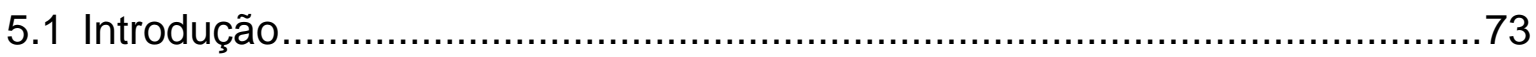

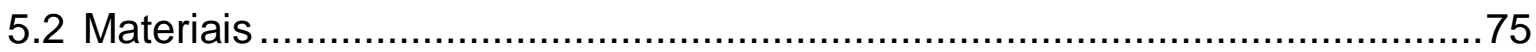

5.2.1 Microcomputadores e aplicativos utilizados .........................................

5.2.2 Construção do modelo no aplicativo de simulação hidráulica....................75

5.2.3 Ensaios e medições de campo ...........................................................76

5.2.4 Tratamento de dados, simulação e análise .............................................77

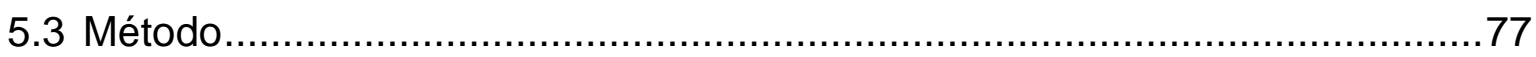

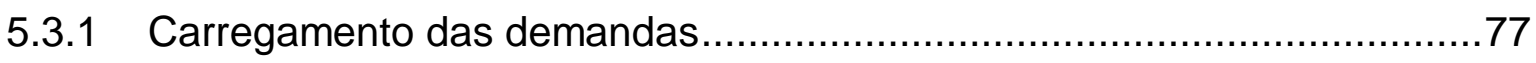

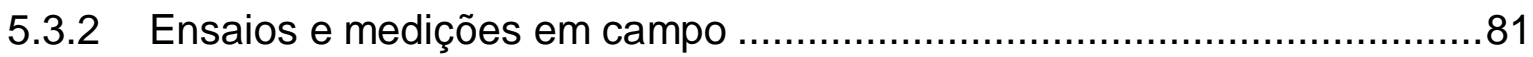

5.3.3 Tratamento dos dados coletados e determinação das incertezas .............92

5.3.4 Calibração do modelo com uso da ferramenta "Darwin Calibrator"............94

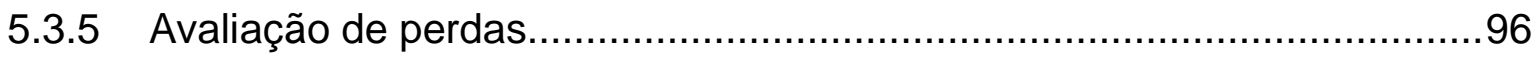

5.3.6 Análise da eficácia dos resultados no diagnóstico de perdas de água .....98

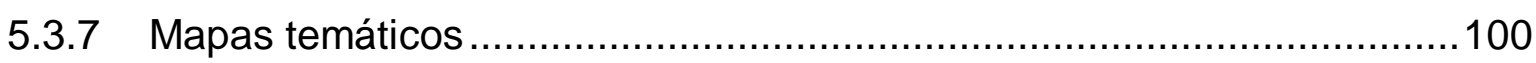

6 ESTUDO DE CASO - APLICAÇÃO EM UM DISTRITO DE MEDIÇÃO E

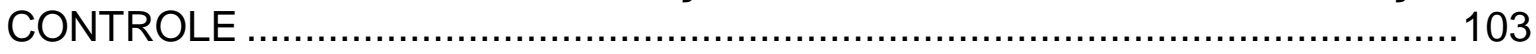

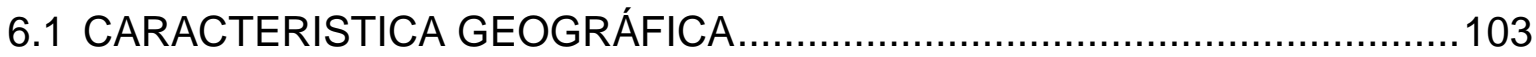

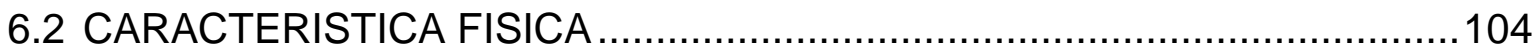

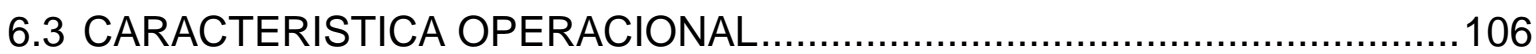


6.4 ENSAIOS DE CAMPO.

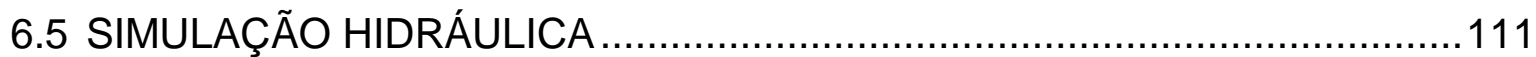

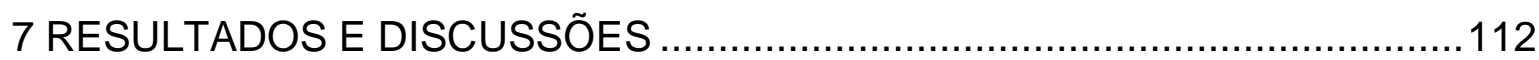

7.1 AS DIFICULDADES E AS SOLUÇÕES ADOTADAS .................................112

7.1.1 Dificuldade na coleta de dados de campo ……....................................113

7.1.2 Dificuldade de realização de ensaios de campo ...................................113

7.1.3 Falha na estanqueidade da área ...................................................115

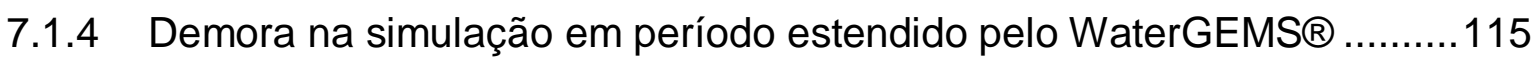

7.2 COMPARATIVO ENTRE AS GRANDEZAS MEDIDAS E SIMULADAS .......115

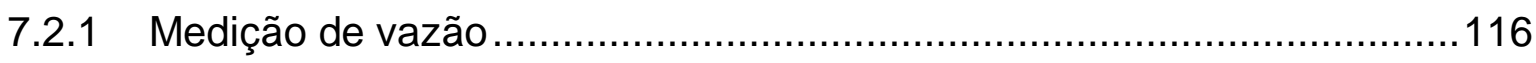

7.2.2 Medição de pressão......................................................................117

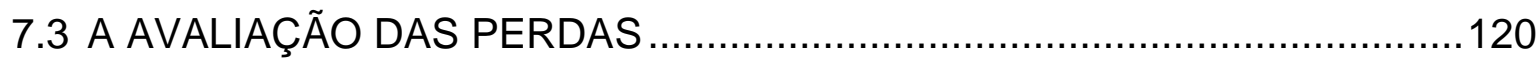

7.4 DISCUSSÃO SOBRE O USO DOS RESULTADOS NO DIAGNÓSTICO DE

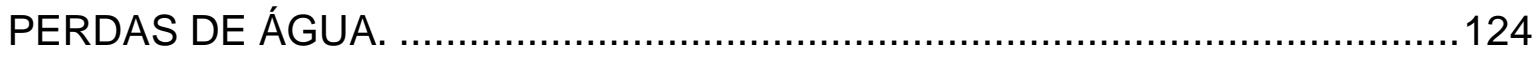

7.4.1 Comprovações na previsão de vazamentos. .......................................126

7.4.2 As pressões simuladas com as medidas no sistema real. ......................126

7.4.3 A vazão fornecida simulada e a medida na entrada do sistema real. .....127

7.4.4 A rugosidade absoluta teórica e a obtida no ensaio de campo................127

7.4.5 Análises com gráficos de Pareto..........................................................128

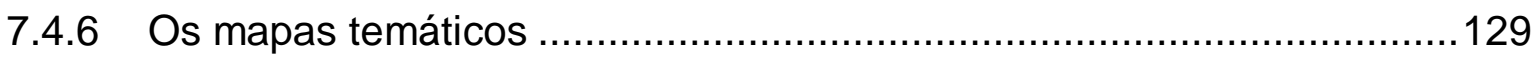

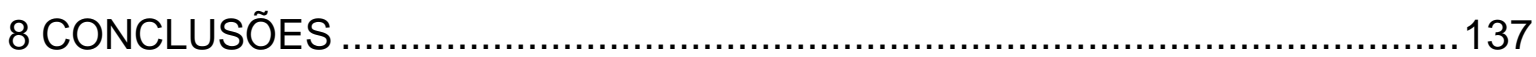

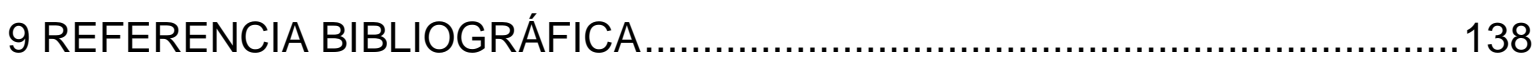

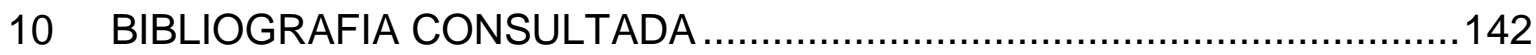

APÊNDICE A - CÁCULO DA INCERTEZA DA MEDIÇÃO ........................... 143

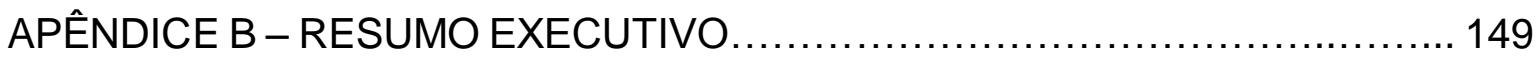

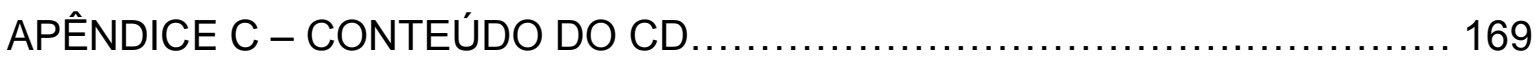




\section{APRESENTAÇÃO}

O autor é formado em engenharia civil e trabalha na Companhia de Saneamento Básico do Estado de São Paulo - Sabesp há dezessete anos. Nos últimos anos desenvolve seus trabalhos na Divisão de Controle de Perdas Centro. Com o conhecimento e a experiência adquiridos na vivência cotidiana de atividades relacionadas a redução das perdas de água, e no uso de softwares de simulação hidráulica, viu na modelagem matemática, de sistemas de distribuição de água, uma possível ferramenta para auxiliar no diagnostico operacional e de perdas em uma determinada área. $\mathrm{Na}$ atualidade, as perdas são avaliadas por equações empíricas cujos dados são anualizados, ou seja, totalizados por ano. Isto é feito para diluir o efeito da sazonalidade no abastecimento, e a diferença entre os períodos de leitura do volume fornecido e o consumido na área. Desta forma a avaliação de uma área, sem ou com menos de um ano de dados históricos, é demorada, uma vez que os valores devem ser considerados em períodos completos de 12 meses, e ao mesmo tempo, imprecisa, pois o resultado representa o passado da área e abrange a sua totalidade. É necessária a repetição da avaliação em partes cada vez menores na busca da fração mais crítica.

Surgiu então a ideia de desenvolver este trabalho, que avalia a eficácia da aplicação de modelos de simulação hidráulica apoiado em dados de campo, para o diagnóstico operacional e de perdas em uma área. A simulação do comportamento hidráulico do abastecimento, obtida com a utilização de amostragem dos dados reais medidos em campo, fornece resultados por trecho de rede, o que permite priorizar e direcionar as ações nos trechos onde haverá redução significativa de perdas, sem a necessidade de subdividir a área e repetir a avaliação, trazendo os melhores resultados. As perdas são geradas por fatores: físicos, comportamentais e ambientais. Estes influem diretamente nos valores medidos no sistema de abastecimento real. Na simulação, estes fatores estão implícitos nos dados de campo que são utilizados pelo algoritmo genético para representar o comportamento do sistema real. Desta forma, torna-se premente saber qual é o grau de confiança apresentados pelos resultados obtidos da simulação para a avaliação da área em estudo. 
A eficácia da simulação hidráulica é avaliada pela comparação entre os vazamentos detectados e os resultados obtidos na simulação hidráulica, cujo comportamento hidráulico foi aproximado por meio de algoritmo genético.

Este trabalho contribui para a adoção da simulação hidráulica no estudo das causas de perdas de água nos sistemas de abastecimento, bem como demonstra como selecionar os trechos, nos quais os investimentos em ações de redução de perdas reais ou aparentes, ou ambas, trarão a melhor relação custo-benefício.

A utilização dos modelos de simulação hidráulica, com o enfoque dado neste trabalho, permitirá as empresas de saneamento, uma gestão operacional que busca a excelência na distribuição de água. Esta busca tem a redução de perdas, como um dos pontos de maior destaque, pois está relacionada à: redução de despesas, investimentos assertivos, e manutenção preventiva. Estas ações garantem a sustentabilidade da empresa e economia dos recursos hídricos. 


\section{INTRODUÇÃO}

A modelagem matemática ou computacional tem evoluído significativamente com o aumento da capacidade e da velocidade de processamento dos computadores, que permitiram a manipulação de uma grande quantidade de dados e a realização de series de cálculos com grande velocidade e precisão. $\mathrm{O}$ uso de modelos matemáticos teve com isso uma arrancada significativa, o que permitiu o desenvolvimento e aplicação em diversas áreas.

Junto da evolução tecnológica da modelagem matemática, o combate às perdas de água tornou-se ação indispensável para todas as companhias de saneamento, pois como já foi amplamente divulgado, a escassez de recursos hídricos é uma realidade nos grandes centros urbanos, como a Região Metropolitana de São Paulo (RMSP).

Entretanto, no combate às perdas, são necessárias ações com um alto custo em sua execução, por exemplo, a revitalização da infraestrutura, a instalação de válvulas redutoras de pressão, a detecção e consertos de vazamentos, dentre outras. Para tanto, é imprescindível que haja uma definição acertada das áreas onde a aplicação de ações de combate a perdas, trará os bons resultados que justificam e viabilizam o investimento com a redução dos volumes perdidos.

Nos dias de hoje, com o acelerado crescimento dos centros urbanos, torna-se premente acompanhar este ritmo na adoção das medidas. Para isso, é indispensável um bom diagnóstico de perdas, que apresente informações que subsidiem a seleção mais precisa de ações, a serem aplicadas na a área em estudo.

Para o diagnóstico de perdas, são realizadas várias atividades, envolvendo um número significativo de profissionais. Entre elas, fazem parte os ensaios de campo, que visam obter o valor de algumas das variáveis necessárias para o conhecimento do sistema em estudo. Determinados valores são de fácil obtenção, enquanto que outros possuem um alto grau de complexidade, pois são dependentes de fatores diversos, tais como: hidráulicos, geográficos e comportamentais. Como exemplo, pode-se citar a demanda 
horária que é influenciada pelo clima, costumes e hábitos dos clientes. O ensaio de campo é um trabalho demorado e regularmente incorre na necessidade de intervenções na rede de distribuição, e no abastecimento, o que pode gerar incômodos aos clientes. Por exemplo, nos testes para a determinação do fator de condição da infraestrutura $\left(F_{c i}\right)$, é necessário o fechamento de todas as ligações, durante a execução do teste, ou seja, por um período aproximado de oito horas, e contar com a mobilização de técnicos e ajudantes.

Um modelo matemático representa ou interpreta simplificadamente a realidade, apresenta uma visão ou cenário baseado nas informações coletadas em campo. Assim, a aplicação dos modelos permite o estudo do comportamento hidráulico nos mais diversos cenários, e a análise em situações nas quais é impossível testar ou medir as diversas soluções possíveis. Evita gastos maiores na criação de modelos experimentais ou a aplicação de profissionais para testes em campo, ou em extensos cálculos analíticos.

A aplicação de modelos matemáticos no saneamento básico está bastante disseminada e se desenvolve rapidamente. Existem aplicativos para a simulação hidráulica como, por exemplo, WaterCAD da Haestad Methods, que em Agosto de 2004, fundiu-se a Bentley Systems, e o EPANET da U.S. Environmental Protection Agency. Eles oferecem aos profissionais maior rapidez na execução dos modelos e análises com maior nível de detalhamento.

Com a simulação hidráulica, são obtidos resultados que permitem avaliar e conhecer o comportamento hidráulico do sistema. A criação de cenários atuais e futuros demonstram quais ações trarão o maior retorno financeiro e operacional, mesmo sem se ter executado as ações planejadas.

$\mathrm{Na}$ montagem da topologia da rede de distribuição feita no modelo, tem-se necessariamente que coletar várias informações da área, o que por si só, ajuda no conhecimento e caracterização da área em estudo, auxiliando no diagnóstico de perdas. As informações técnicas e as comerciais são coletadas e inseridas na topologia do modelo. Por exemplo, do cadastro técnico são obtidos os materiais e idades das 
tubulações e do comercial os consumos mensais por tipo de cliente.

Comensurando a obtenção de informações para o cálculo das perdas de água, através de modelos de simulação hidráulica e dos métodos tradicionais, no primeiro a aquisição é com mais rapidez e menor investimento de recursos, tanto financeiros quanto humanos, o que nos dias atuais representa uma grande vantagem.

No Brasil, a preocupação com a redução das perdas teve início na década de 1970, e há poucas publicações nacionais sobre o assunto. Internacionalmente, a redução de perdas se iniciou no século XIX. Um marco importante foi à criação da Força Tarefa de Perdas de Água (Water Loss Task Force) da International Water Association (IWA) em 1996, em Londres (Inglaterra), cujo objetivo é desenvolver e promover as melhores práticas internacionais em gerenciamento de perdas de água. Como referências internacionais de melhores práticas em perdas, destacam-se o Japão e a Inglaterra.

A modelagem hidráulica pode simular a operação do sistema, e assim presumir as informações necessárias para o cálculo das perdas. Proporciona a elaboração do diagnóstico das perdas de água e o direcionamento de ações nos trechos mais críticos. Possibilita a análise e avaliação das condições operacionais do sistema em estudo, proporcionando detectar desvios da realidade causados por alterações das condições operacionais (fechamentos de registros, alteração de demandas, novos empreendimentos, etc.), com a aproximação do comportamento hidráulico por meio de algoritmo genético com parâmetros levantados em campo. Desta forma, o comportamento do sistema real é reproduzido, o que permite a elaboração do diagnóstico operacional do sistema.

O modelo pode apoiar as estratégias de investimento por meio de uma análise de custo benefício, apoiada nos resultados simulados. Isto porque aplicando os resultados na elaboração de gráficos de Pareto e mapas temáticos, facilitam a identificação de trechos de rede nos quais são necessárias, a detecção de vazamentos ou recuperação estrutural. O modelo permite o cálculo das variáveis necessárias para estimar as perdas pelo método da IWA, o que permite comparar os resultados na área em estudo com outras áreas estudadas internacionalmente. 


\section{OBJETIVO}

\subsection{Objetivo geral}

O presente trabalho tem por objetivo, avaliar a eficácia da utilização de modelos de simulação hidráulica de sistemas de abastecimento, apoiados em levantamentos de dados hidráulicos de campo, na obtenção de informações para elaboração do diagnóstico de perdas de um sistema de distribuição de água.

\subsection{Objetivos específicos}

- Demonstrar a eficácia na obtenção de informações para diagnóstico de perdas por meio de modelos de simulação hidráulica.

- Apresentar uma metodologia para o uso de modelos de simulação hidráulica, na obtenção de informações para a elaboração de um diagnóstico de perdas. 


\section{REVISÃO BIBLIOGRÁFICA}

Neste capítulo serão apresentados os seguintes tópicos:

- Perdas de água:

- Definição, causas e tipos;

- Ações para combate às perdas reais de água;

- Ações para combate às perdas aparente de água;

- Elaboração de um plano de perdas;

- Nível econômico de perdas;

- Modelagem matemática de sistema de distribuição de água;

- Algoritmos genéticos;

- Modelagem matemática de perdas de água;

- Método FAVAD;

- Método da Vazão Mínima Noturna;

- Método do Balanço Hídrico.

- Método de avaliação do volume perdido;

- Perda real inerente;

- Perda real inevitável;

- Mapas temáticos;

- Gráficos de Pareto.

\subsection{Perdas de água}

Segundo Alegre et al. (2006), as perdas de água é o volume referente à diferença entre a água entregue ao sistema de abastecimento e os consumos autorizados, medidos e não medidos, faturados ou não faturados. As perdas de água se dividem em dois grupos:

a) A perda real corresponde ao volume de água produzido que não chega ao consumidor final devido à ocorrência de vazamentos nas adutoras, redes de distribuição e reservatórios, bem como de extravasamentos em reservatórios setoriais (Tardelli Filho, 2006). 
b) A perda aparente são volumes efetivamente consumidos que por algum motivo não foram contabilizados pela companhia de saneamento (Tardelli Filho, 2006).

\subsubsection{Causas das perdas de água}

A perda de água é entendida pela maioria das pessoas como sendo vazamentos nas tubulações de distribuição. Entretanto, a perda de água acontece em diversas situações, e para seu entendimento, é necessário conhecer as várias causas que as produzem.

\subsubsection{Perdas reais}

As causas mais comuns das perdas reais segundo a AWWA (1999) são:

- Materiais de má qualidade ou com defeito de fabricação, seja nas juntas ou na vedação ou ainda apresentar bordas e superfície irregulares.

- Rompimento da tubulação devido ao assentamento em base irregular contendo pedras em contato com os tubos falta de uma vedação efetiva nas juntas, danos causados por tráfego pesado ou ainda deflecção excessiva nas juntas.

- Erros operacionais, excesso de pressão, abertura ou fechamento rápido de válvulas causando transiente hidráulico.

- Corrosão interna devido a agentes agressivos na água ou externa devido à falta ou insuficiência de proteção contra corrosão ou solo e/ou lençol freático agressivo.

- Vazamentos em componentes dos elementos da tubulação como válvulas, ventosas, hidrantes, etc. Que se dividem em:

- Danos acidentais ou deliberados a hidrantes e tap (nome em inglês para dispositivo que permite tirar água de um tubo ou barril, utilizado também para a inserção de medidores, ver Figura 4.1).

Os vazamentos são classificados segundo a ABENDE (2003), em:

- Vazamentos visíveis;

- Vazamentos não visíveis.

Os vazamentos não visíveis são ainda subdivididos em detectáveis e não detectáveis 
(ou inerentes). A Figura 4.2 apresenta os tipos de vazamentos e as ações para eliminálos ou reduzi-los (Tardelli Filho, 2006).

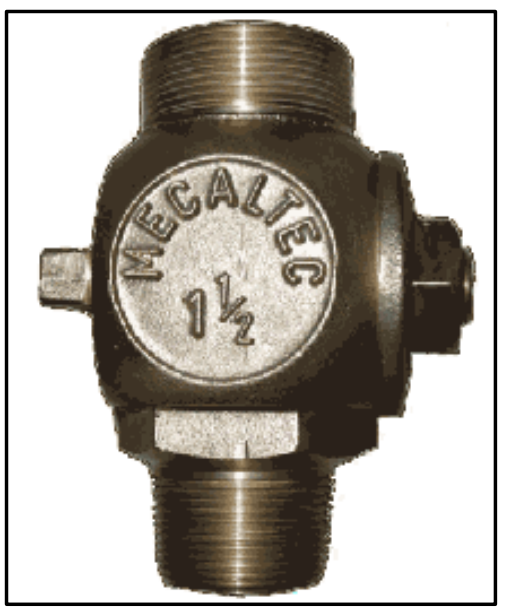

Figura 4.1- Tap - Fonte: Mecaltec

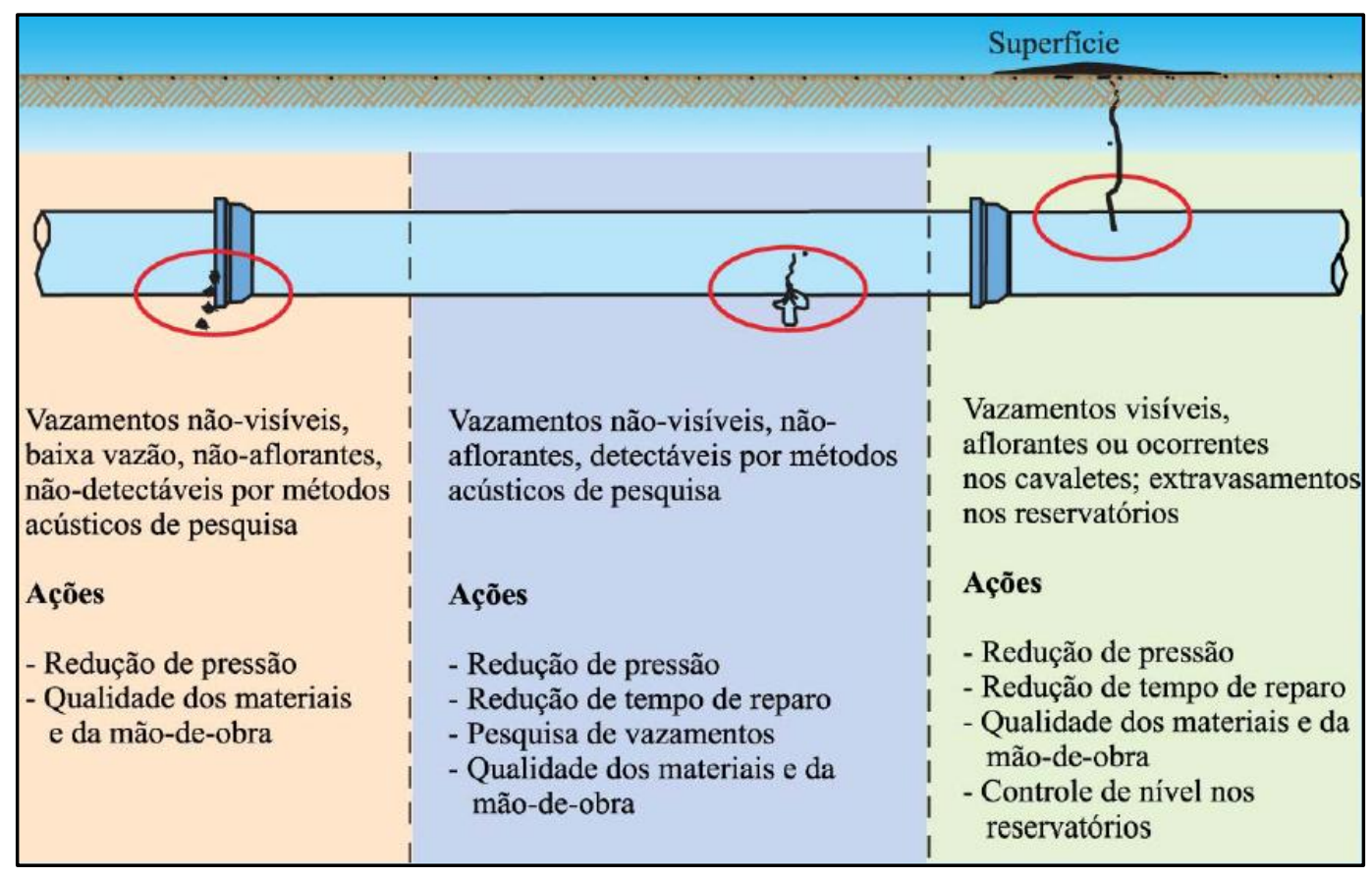

Figura 4.2 - Tipos de vazamentos - Tardelli Filho (2006)

Em cada sistema de abastecimento o número e a importância relativa destes três componentes de perdas reais (vazamentos visíveis, não visíveis e inerentes) apresentam características diferentes, e não há situação normal para análise. Fatores como condições físicas do terreno, solo, topografia, material das tubulações e pressão de operação da rede afetam a proporção entre as parcelas de perdas responsáveis por cada tipo de vazamento (Farley et al., 2003). 


\subsubsection{Perdas aparentes}

Segundo Tardelli Filho (2006), as causas das perdas aparentes são:

- Erros dos medidores de vazão: todo medidor de vazão possui uma incerteza na medida apresentada, expressa geralmente em porcentagem. Essa incerteza é definida dentro de uma faixa de trabalho. Se o medidor estiver operando fora desta faixa de trabalho, as incertezas em sua medição podem ser maiores do que o previsto. Existem outros fatores que geram erros nos medidores, por exemplo, a instalação inadequada, a descalibração, o dimensionamento inadequado, a má avaliação da faixa de trabalho, problemas físicos na instalação do elemento primário ou do secundário e problemas na coleta ou transmissão dos dados.

- Erros de cadastro comercial: relaciona-se ao registro da ligação na companhia de saneamento. Ele contém todas as informações que caracterizam o uso da água, localização da ligação, tipo de ligação, etc. Se o cadastro comercial possuir erros, a avaliação dos consumos fica prejudicada. É de suma importância mante-lo sempre atualizado e com informações confiáveis.

- Ligações clandestinas: são ligações existentes sem cadastro comercial.

- Fraudes: são ligações existentes com cadastro comercial, porém com alguma irregularidade em seu consumo, ou seja, o volume medido não corresponde ao volume real consumido. Isso pode acontecer por meio de "by pass" no cavalete, manipulação do hidrômetro, entre outras ações.

- Uso Irregular de Hidrantes: constitui o uso inadequado de hidrantes por pessoas ou empresas que abastecem caminhões-pipa para uso próprio ou comercial.

\subsection{Ações para combate as perdas reais}

Segundo Lambert et al. (1998), a condição da infraestrutura da rede de distribuição de água é claramente um dos fatores que determinam o volume de perdas reais no sistema de distribuição. Alguns pontos devem ser observados desde os estudos de concepção do sistema para reduzir as perdas: 
- Escolha adequada do material do tubo, levando em consideração a qualidade da água e as condições do solo ao redor da tubulação;

- Obedecer às especificações na execução do serviço, obedecendo aos limites definidos em projeto para o assentamento, no torque no aperto das juntas roscadas e nos parafusos de flanges;

- Cuidados de transporte e manuseio dos tubos quando em transporte ou estocado;

- Qualidade na execução de reparos na tubulação e em suas juntas;

- Controle de pressão: quando a tubulação entra em carga, fica sujeita a esforços repetitivos de pressão, o que potencializa o surgimento de vazamentos tanto nas juntas como por rompimentos.

Cada sistema de abastecimento possui características próprias que definem quais ações proporcionarão redução de perdas e manutenção a um nível aceitável (Tardelli Filho, 2006). No combate as perdas reais existem basicamente quatro principais componentes ilustrados na Figura 4.3, que são: Gerenciamento de pressões, Controle Ativo de Vazamentos, Rapidez e Qualidade no Reparo de Vazamentos e Melhoria da Técnica e Materiais, Manutenção e Reabilitação da Infraestrutura.

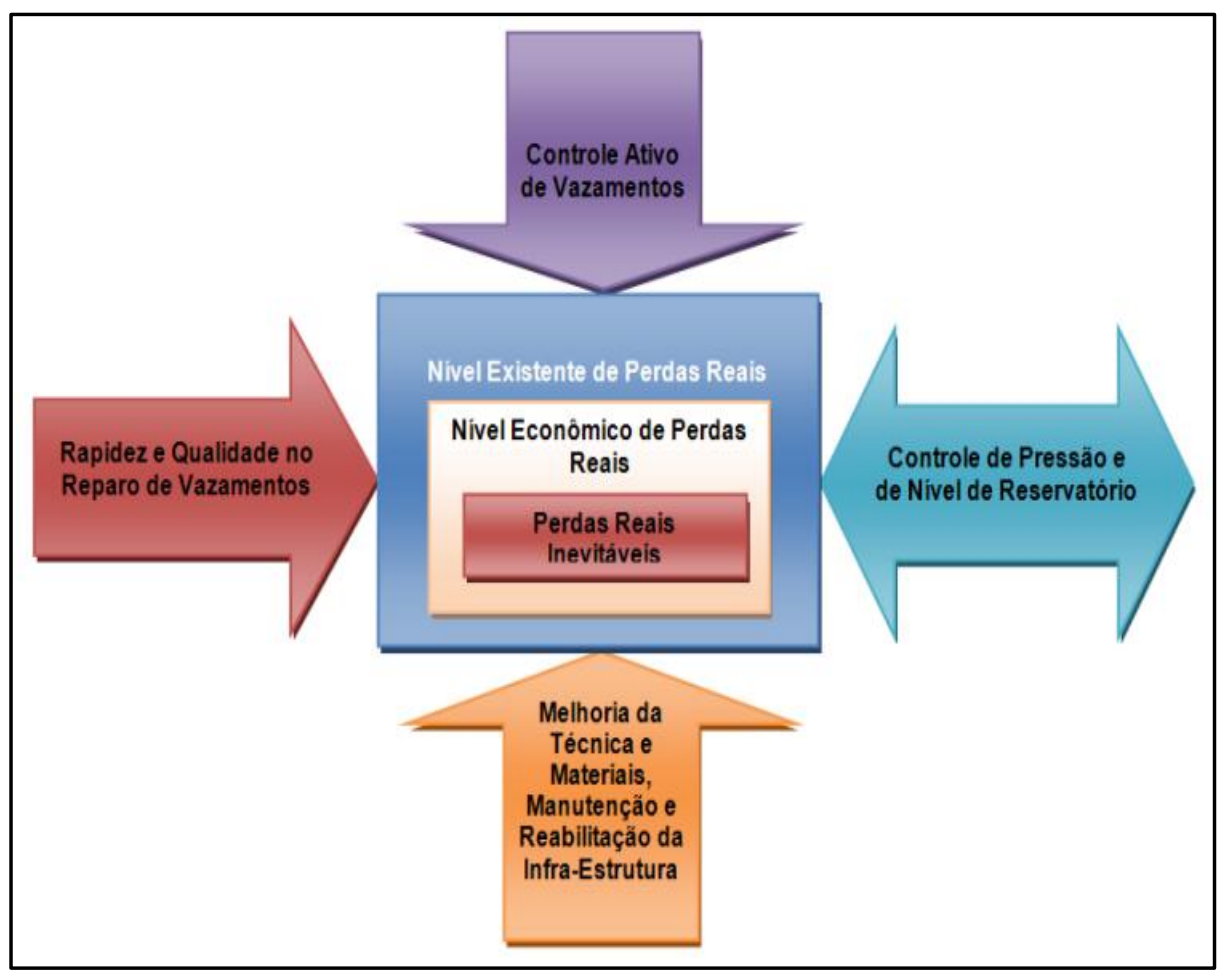

Figura 4.3 - Componente de Perdas Reais. Fonte: Thornton et al. (2008) adaptada 


\subsubsection{Gerenciamento de pressões}

A pressão é um dos principais fatores que influenciam o número e a vazão de vazamentos. A operação com níveis de pressão que atendam aos mínimos especificados para as horas de consumo máximo representa um bom referencial para se balizar. Devem atender às exigências das normas quanto à mínima e máxima pressão, que atualmente são 10 e $50 \mathrm{mH}_{2} \mathrm{O}$, respectivamente. As alternativas que se ajustam a esta situação são: setorização, o emprego de válvulas redutoras de pressão (VRP) e "boosters", desde que bem especificados e operados. Estes apresentam elevada relação custo benefício, além de grande flexibilidade para se adaptar às variações de demandas que ocorrem diariamente em uma área.

\subsubsection{Controle ativo de vazamentos}

O Controle Ativo de Vazamentos representa a ação sistemática desenvolvida no sentido de localizar os vazamentos não visíveis, através de métodos acústicos de pesquisa. $O$ principio básico de detecção acústica é ouvir o ruído do vazamento.

\subsubsection{Reparo de vazamentos, melhoria da técnica e de materiais.}

É um fator de alta responsabilidade da companhia de saneamento possuir uma infraestrutura e logística tal que permita corrigir o problema no menor prazo possível. $E$ que seja viável do ponto de vista econômico. As bases para a definição de metas relativas ao intervalo de tempo entre a identificação do vazamento e o seu conserto mudam de local para local, dependendo da extensão de rede, quantidade de vazamentos, condições internas das companhias e também de fatores externos. $O$ tempo normalmente adotado pelas companhias está entre 10 e 24 horas, em sistemas com boa gestão operacional.

\subsubsection{Manutenção e reabilitação da infraestrutura.}

Considera se, em projeto, que a vida útil das redes de distribuição seja, em geral, de 50 anos. Para os ramais, é adotado um tempo de vida útil bem menor já que eles estão sujeitos a mais fatores agressivos que as tubulações. A manutenção e reabilitação da 
infraestrutura se fazem por meio de duas ações básicas que segundo Tardelli Filho (2006) são:

- Troca de Rede: geralmente exigindo métodos de execução não destrutivos. Pode ter dois objetivos:

$\checkmark$ Melhoria das condições hidráulicas da tubulação, substituindo trechos com elevada incidência de incrustações;

$\checkmark$ Melhoria das condições estruturais da tubulação, substituindo trechos com elevada incidência de vazamentos.

- Reabilitação de tubulações: feita por meio da limpeza e revestimento da rede. $\mathrm{Na}$ maioria das vezes, tem por objetivo melhorar as condições hidráulicas, ou seja, procura-se garantir o escoamento com a menor perda de carga, em redes cujas condições estruturais (físicas) sejam satisfatórias.

\subsection{Ações para combate às perdas aparentes}

As perdas aparentes produzem uma variação no volume contabilizado pelas companhias de saneamento, seja no volume macromedido quanto no micromedido. Requerem ações especiais, pois são oriundas de fatores que possuem características relacionadas à metodologia de medição dos volumes e gestão comercial. As ações básicas na redução de perdas aparentes são apresentadas na Figura 4.4, que são: manutenção da macro e micro medição, gestão comercial, redução de fraudes e qualificação da mão de obra.

\subsubsection{Manutenção da macromedição}

A macromedição é fundamental numa companhia de saneamento, pois subsidiam dados importantes para o diagnóstico operacional, quantificação de dosagens de produtos químicos, e indicadores qualitativos e quantitativos da companhia.

É importante ter no sistema de abastecimento pontos de medição ("Tap" ou registro de derivação) que serão utilizados em:

a) Medições em distritos de medição e controle (DMC), que são áreas da rede de distribuição obtida pelo fechamento permanente de válvulas limítrofes, na qual a 
quantidade de água que entra ou sai é medida (IWA, 2007). Na NBR 12.218 é denominado como Setor de Medição. No caso de fechamento temporário de válvulas limítrofes para obtenção de dados (ensaios de campo), é denominado DMC temporário, devendo ser menor que o DMC permanente, mas garantindo uma vazão mínima que permita sua medição através de medidores fixos ou portáteis (IWA, 2007);

b) Trabalhos de calibração "in loco" dos macromedidores. A manutenção periódica dos macromedidores (especialmente os deprimogêneos) é muito importante para garantir a confiabilidade nas leituras obtidas. Grande parte da imprecisão dos medidores se dá por falhas na manutenção (90\%), e o restante resulta de problemas na instalação do mesmo (10\%). A calibração do medidor já se faz necessário logo no inicio de operação e posteriormente deve ser feita periodicamente com uma frequência mínima anual.

Segundo Tardelli Filho (2006), a calibração "in loco" com pitometria incorpora uma imprecisão da ordem de $2 \%$.

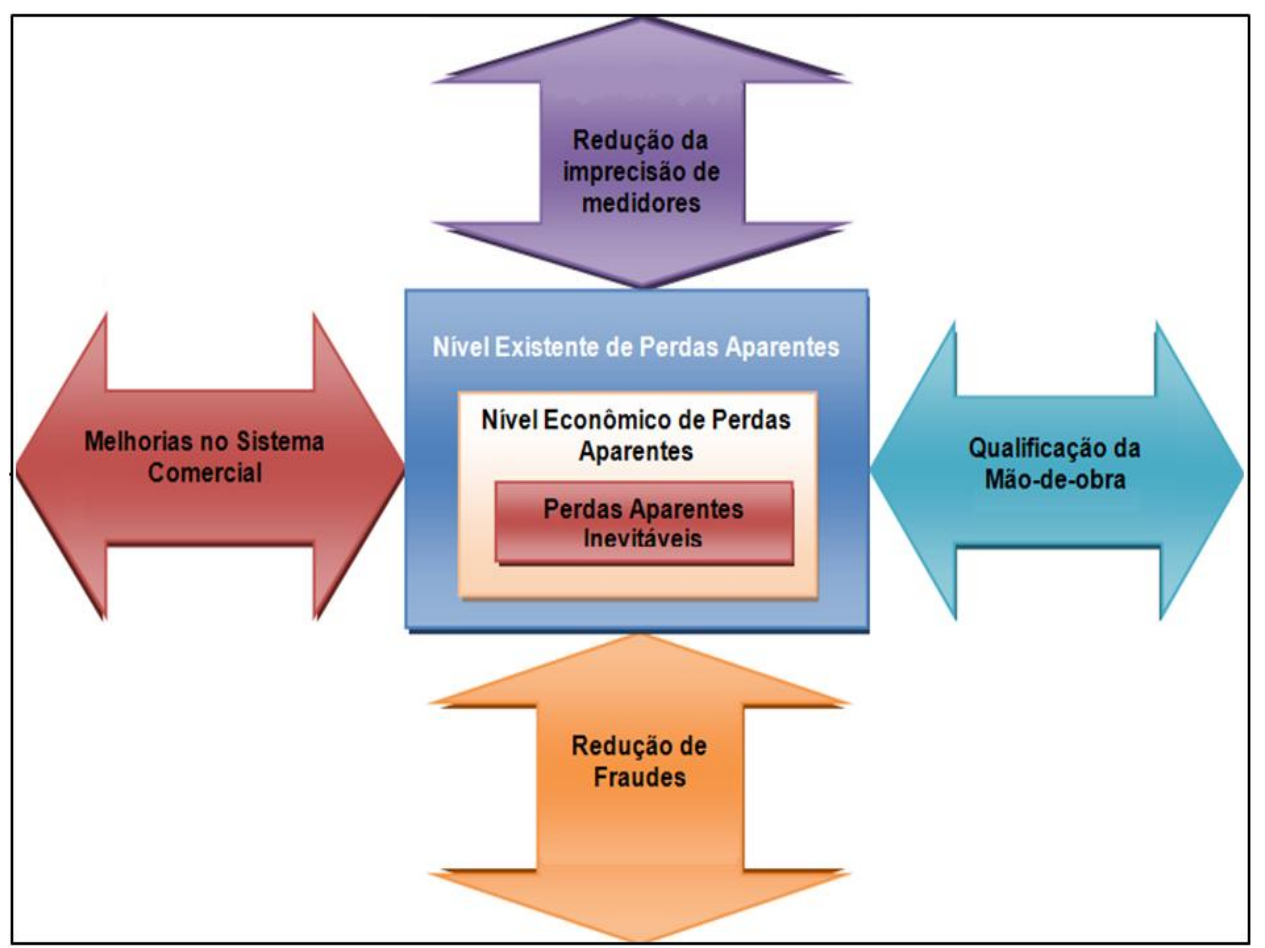

Figura 4.4 - Componentes de Perdas Aparentes - Fonte: Thornton et al. (2008) adaptada 


\subsubsection{Manutenção da micromedição}

A troca de Hidrômetros é de grande importância na redução de perdas aparentes. $O$ envelhecimento do hidrômetro ocasiona perda gradativa da precisão da medição e aumenta a perda aparente. Há três situações básicas para a troca:

a) Manutenção corretiva: a prioridade deve ser dada à manutenção corretiva, uma vez que neste caso não há leitura e o consumo fica estimado pela média histórica;

b) Manutenção preventiva: realizada quando os medidores atingem o limite de sua vida útil;

c) Adequação: a adequação dos hidrômetros à faixa de consumo é uma ação muito importante, e deve ser avaliada através da comparação do perfil de consumo da ligação levantado com os parâmetros nominais do hidrômetro, principalmente para os de grande capacidade.

Outro fator a ser avaliado, é a verificação da inclinação do hidrômetro, que é negligenciada na maioria das companhias de saneamento, gerando um fator de submedição que poderia ser evitado (Tardelli Filho, 2006).

\subsubsection{Gestão comercial}

A redução de perdas requer investimentos no gerenciamento da micromedição, avaliação de consumos públicos e prédios próprios, pesquisa de fraudes, gestão de grandes consumidores, pesquisa de vazamentos e formação e manutenção de equipe dedicada ao controle de perdas (Gomes et al., 2007).

A gestão comercial diz respeito a atividades voltadas a recuperação de perdas aparentes, segundo Fontanazza, Freni, \& La Loggia (2009), a perda aparente e causada por fraudes e erros na contabilização dos volumes consumidos autorizados, faturados e não faturados (medidos e estimados). Farley \& Trow (2003), apresentam a perda aparente como sendo consumos ilegais e erros de medição.

O cadastro comercial é uma fonte de informações importantes sobre os tipos de clientes, da manutenção e troca dos hidrômetros, e combate às ligações inativas, ações que atacam diretamente às perdas aparentes. 
Segundo Tardelli Filho (2006), a gestão comercial compreende as seguintes atividades:

a) Cadastramento apropriado de novas ligações;

b) Procura de falhas no cadastro comercial, para eliminar ligações inativas, clandestinas e fraudes;

c) A atualização cadastral do tipo de ocupação do imóvel (residencial, comercial, público ou industrial), o que reflete também na política tarifária;

d) Combate às fraudes que deve ser constante, pois uma vez que se demonstre fragilidade nesta ação o numero de fraudadores tende a aumentar;

e) Manutenção e troca dos hidrômetros.

A perda aparente possui outro fator importante além dos já descritos, pois o faturamento dos volumes de esgoto coletado é feito a partir do volume de água consumido. Assim para cada unidade de perda aparente recuperada, equivale a duas unidades no faturamento.

\subsubsection{Elaboração de um programa de controle de perdas}

Farley et al. (2003) propuseram uma estruturação geral para a definição de estratégias de redução de perdas (ver Figura 4.5).

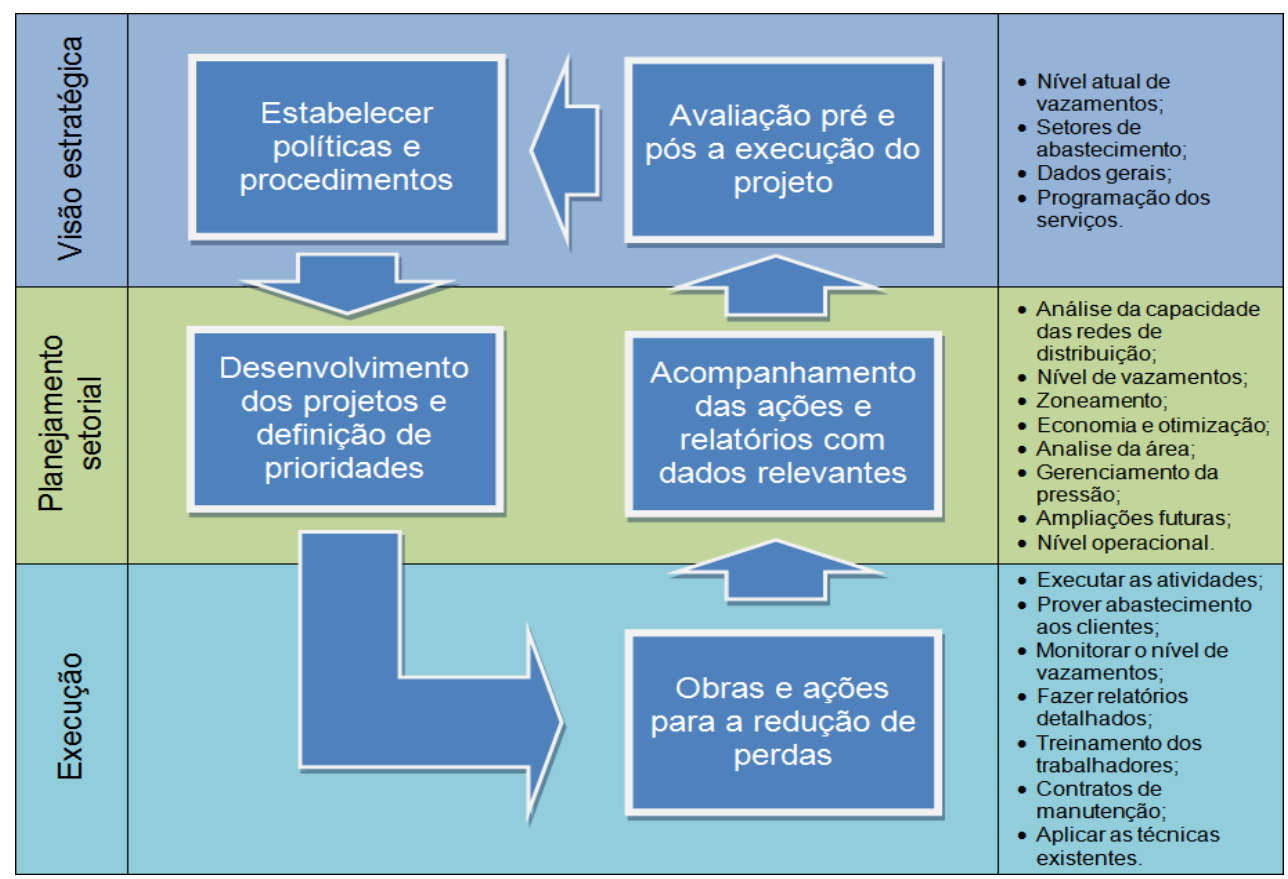

Figura 4.5 - Estruturação para definição de ações para redução de perdas Farley et al. (2003) adaptada. 
Baixar as perdas de água é a busca de todas as companhias de saneamento. Contudo, sempre haverá as perdas inevitáveis, causadas pelos vazamentos não detectáveis (ou inerentes).

Para chegar a esse nível de perdas é necessário um grande aporte financeiro que se torna inviável do ponto de vista econômico. Assim, o programa de perdas visa atingir o nível economicamente viável, através da avaliação de ações espacializadas, integradas e sequenciais, buscando os melhores resultados.

Segundo Farley et al. (2003) o mais importante na definição de uma estratégia de combate aos vazamentos é definir qual o nível de perdas se deseja atingir e por quanto tempo é possível mante-lo.

Segundo Tardelli Filho (2006), a importância deste processo está em que as decisões devem ser tomadas baseadas em indicadores e análises criteriosas dos resultados, como definidora das ações. O início de qualquer programa pressupõe o conhecimento do problema a enfrentar.

Para isso, serão necessários levantamentos de campo e estimativas para se chegar aos números representativos de cada setor, que definirão as linhas de ação mais adequadas para cada caso. Para todos os setores, existe um nível de perdas o qual é economicamente aceitável que é chamado nível econômico de perdas (NEP).

Muito tem sido escrito sobre a teoria do NEP, que consiste na avaliação do custo para reduzir um metro cúbico de perda, e o custo equivalente do metro cúbico de água. $\mathrm{E}$ também sobre os métodos para estimar seu valor.

O NEP deve ser avaliado levando em conta a perda real e a aparente. A Figura 4.6, apresenta a relação entre os custos operacionais e das perdas reais de um modo geral.

Quanto menor a perda, mais onerosa fica a detecção de vazamentos, pois o número de vazamentos detectáveis diminui e são necessários esforços maiores e mais tecnologia para encontrá-los. 


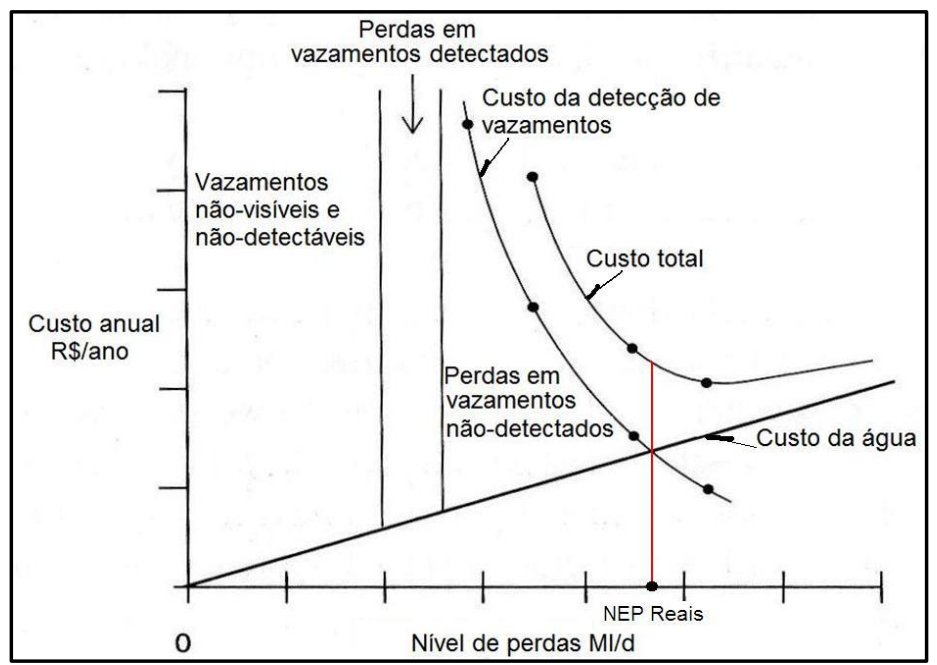

Figura 4.6 - Relação do custo operacional e perdas Fonte: Farley et al. (2003) adaptada

A perda aparente deve ser avaliada de maneira semelhante. Thornton et al. (2008), apresenta o NEP de perdas aparente como a igualdade dos custos das ações de combate as perdas aparentes e o custo da produção da água aplicado ao volume recuperado, ou seja, que começa a ser medido após a execução da ação (Figura 4.7).

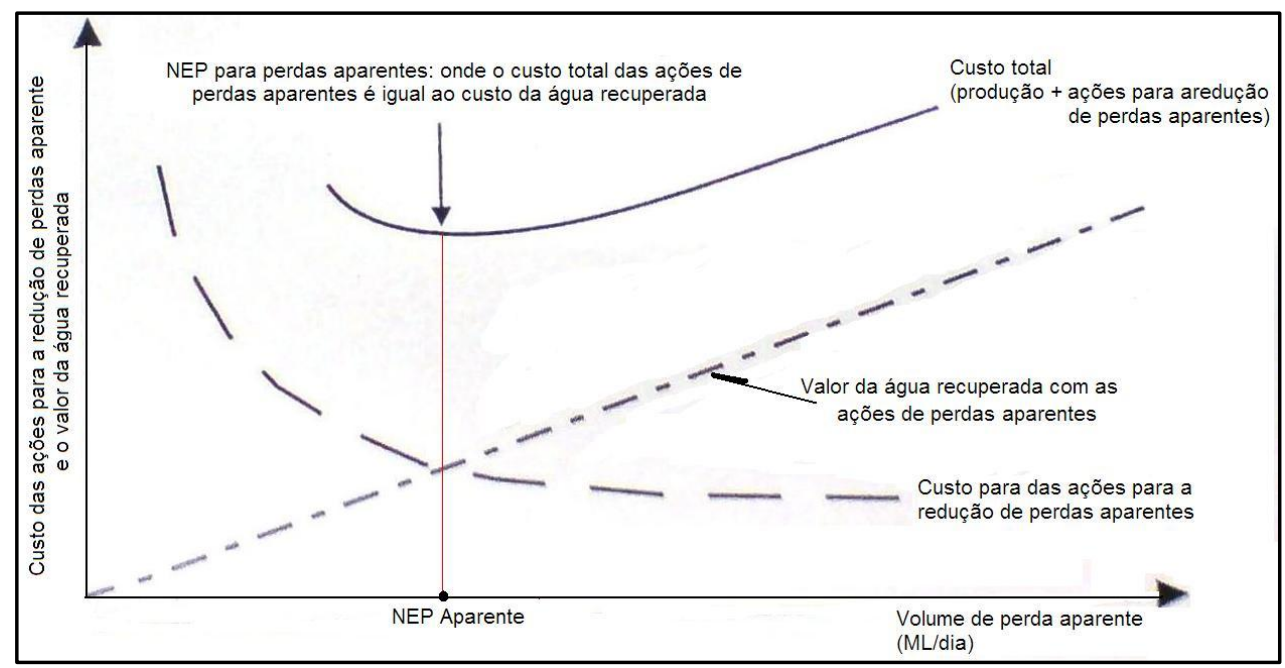

Figura 4.7 - NEP para Perda Aparente Fonte: Thornton et al.(2008) adaptada

Abaixo alguns pontos destacados por Farley et al. (2003) cuja análise deve ser desenvolvida na avaliação do NEP.

- Não existe um único NEP. O NEP varia com o tempo e depende de fatores como: frequência de vazamentos, sazonalidade no abastecimento e melhoria nas condições da infraestrutura. 
- Investimentos no controle de pressão, divisão em DMCs e o uso de telemetria que agiliza a detecção de vazamentos.

- O valor econômico da água varia com o tempo e a quantidade disponível. Pode aumentar quando a quantidade pronta para o tratamento é insuficiente para atender à demanda. E pode reduzir quando novos mananciais e estações de tratamento entram em operação. $O$ custo de operação também muda com o passar do tempo, devido à variação da qualidade da água, ou ainda devido a mudanças nas regulamentações, tornando as atuais práticas obsoletas.

- Novas técnicas de detecção de vazamentos aumentam a eficiência na pesquisa de vazamentos não visíveis, resultando na mudança do NEP. Dependendo do método utilizado para a detecção de vazamentos, podem-se obter valores diferentes para o NEP. Por exemplo: a utilização regular do controle ativo de vazamentos, ou a observação frequente da vazão mínima noturna (VMN) em DMCs.

- Na estimativa do NEP é imprescindível utilizar dados, informações e regras operacionais de cada área e do planejamento operacional de cada empresa de saneamento. Entretanto, antes que um significativo trabalho para a redução de perdas tenha sido concluído e os dados necessários para a estimativa de custos e efeitos sejam coletados, é impossível fazer uma suposição precisa do NEP. Assim, o cálculo do NEP estará num estágio aproximado, sendo necessários vários anos para uma determinação precisa.

- Metas para a redução de perdas baseadas no NEP devem ser específicas e dinâmicas.

É importante diferenciar duas situações do programa de perdas:

1. Quando é estabelecida uma meta de redução de perdas a um patamar definido.

2. Quando é necessário manter o nível de perdas atingido.

Estes dois estágios podem ocorrer simultaneamente numa mesma organização. Em uma zona são necessárias ações para a redução de perdas, e em outra, ações para a manutenção do nível alcançado.

Farley et al. (2003), expõem quatro pontos principais para a elaboração de um programa para a redução de perdas: 
1. Entender o ponto de partida: é essencial para definir a estratégia de combate à perda, compreender as fontes e níveis atuais das perdas.

2. Executar testes de campo com o intuito de: demonstrar os benefícios da redução de perdas para a organização, aplicação de novas tecnologias e coletar dados para análise e definições de ações.

3. Estabelecer recursos financeiros: qualquer programa de perdas necessita de um aporte financeiro para sua execução. Mesmo demonstrando os aspectos econômicos da redução de perdas, é necessário fundamentá-los com base no período de retorno do investimento, em alguns casos calculado para um período de 20 anos.

4. Destacar os benefícios que serão alcançados com a redução das perdas:

a. Melhora na distribuição, pois com a redução das perdas a vazão excedente (antes perdida), passa a abastecer o sistema, diminuindo a produção e os gastos com bombeamento.

b. Redução na frequência de novos vazamentos, gerando economia nos reparos.

c. Redução nas reclamações dos clientes, pois com um gerenciamento adequado de pressões, é garantido o abastecimento de todos.

d. Aumento da organização dos trabalhos: o programa de perdas proporciona um conhecimento detalhado das zonas de abastecimento e com a redução dos vazamentos é possível melhorar as estratégias de consertos e a detecção de vazamentos.

e. Redução na produção de água, gerando economia de produtos químicos, energia e depósitos de lodos (resíduos finais do processo de tratamento da água).

f. Economia de recursos hídricos, com a redução de perdas é possível postergar investimentos na captação de água em outros mananciais.

Com a avaliação dos resultados obtidos na execução do programa de perdas elaborado, são definidas novas ações e melhorias no processo. Isto permite a aplicação do método de melhoria contínua da qualidade ou "PDCA" sigla do inglês "Plan, Do, Check and Action". A Figura 4.8 apresenta a sequencia da aplicação do método.

No planejamento, é feita a criação dos padrões de trabalhos juntamente com a lógica de decisão em cada etapa do plano. Na execução, os padrões de trabalhos são postos em 
ação, gerando os comandos que atuam no processo de combate às perdas reais ou aparentes.

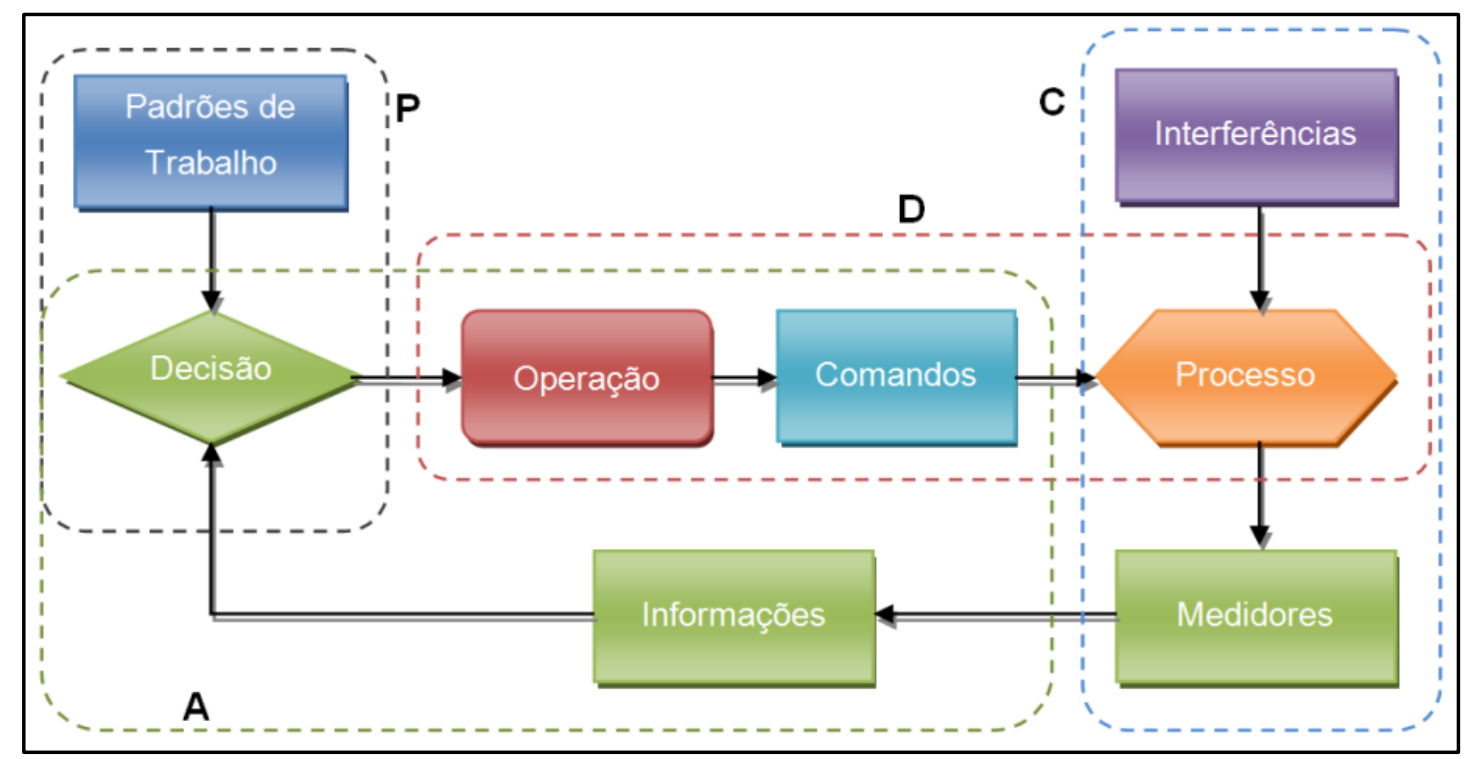

Figura 4.8 - Ciclo "PDCA" - Adaptado de Tardelli Filho (2006)

$\mathrm{Na}$ avaliação dos resultados do processo, são levantadas as interferências e as medições. Com a avaliação, é feita a análise geral do programa de perdas e são tomadas decisões que geram alterações na operação e assim modificam os processos. O programa de perdas, uma vez iniciado, deve ser contínuo, pois ao diminuir o nível de perdas fica difícil mantê-lo e um esforço maior é requerido para reduzi-lo ainda mais.

\subsection{Modelagem matemática de sistemas de distribuição de água}

Um modelo matemático é uma representação (ou interpretação), simplificada da realidade de um sistema (ou fragmento deste), segundo uma estrutura de conceitos teóricos e experimentais. A modelagem matemática ou computacional trata da aplicação de modelos matemáticos à análise, compreensão e estudo da fenomenologia de problemas físicos complexos, e a aplicação de modelos já desenvolvidos, para a simulação, previsão e projeções temporais e espaciais, nas áreas de engenharia, ciências exatas, biológicas, humanas, economia e ciências ambientais. Permite criar modelos computacionais para situações nas quais é impossível testar ou medir as diversas soluções possíveis ou o custo para a criação de modelos experimentais ou a solução analítica é inviável (Rios, 1982). 
Em Teoria de modelos um modelo é uma estrutura composta por um conjunto universo e por constantes, relações e funções definidas neste conjunto universo (Rios, 1982).

No caso da simulação de sistemas de distribuição de água, as leis físicas que regem o fenômeno de escoamento do fluido sob pressão, são utilizadas para este fim. Os modelos de simulação hidráulica são baseados no equacionamento das variáveis envolvidas no processo: vazões nos trechos de rede e pressões nos nós entre trechos consecutivos. A análise pode ser realizada em regime permanente de escoamento ou com variações de vazões e pressões ao longo do tempo. Geralmente os modelos que utilizam o regime permanente, baseiam-se na equação da continuidade nos nós e a equação da energia ao longo dos trechos. O sistema de equações obtido é resolvido por meio de linearizações sucessivas, pelo processo de Hardy-Cross ou NewtonRaphson (Carrijo, 2004).

Até o início da década de 80, os aplicativos desconsideravam os vazamentos nas suas avaliações hidráulicas. A Tabela 4.1, mostra alguns métodos criados ao longo do tempo para simular os sistemas de distribuição de água, e um resumo de suas principais características. Os trabalhos apresentados na Tabela 4.1, limitam a calibração do modelo a coeficientes de rugosidade, demandas e diâmetros, não consideram perdas por vazamentos e demandas dependentes das pressões no modelo (Soares, 2003).

O combate aos vazamentos constitui uma tarefa contínua que se inicia na fase de concepção do projeto da rede, estendendo-se por toda a sua vida útil.

Tabela 4.1 - Histórico da calibração de modelos hidráulicos.

\begin{tabular}{|c|c|c|}
\hline Ano & Autor / Autores & Proposição \\
\hline 1986 & ORMSBEE \& WOOD & $\begin{array}{l}\text { - Propuseram método explicito de calibração de rede de distribuição } \\
\text { de água. O processo é formulado em termos de fatores de atrito e } \\
\text { de uma reformulação das equações governantes do escoamento, e } \\
\text { que são resolvidas explicitamente para determinadas situações } \\
\text { operacionais. Métodos explícitos, conhecidos como analíticos ou } \\
\text { diretos, resolvem um sistema de } n \text { equações não lineares com } n \\
\text { incógnitas, sendo que para cada incógnita é requerido à medição de } \\
\text { vazão ou pressão. }\end{array}$ \\
\hline
\end{tabular}


Tabela 4.1 - Histórico da calibração de modelos hidráulicos.

\begin{tabular}{lll}
\hline Ano & Autor / Autores & Proposição \\
\hline 1989 ORMSBEE & - Desenvolve método matemático implícito para calibração de redes \\
& de distribuição de água. O método utilizou um algoritmo de \\
& otimização não linear juntamente com uma rede complexa, \\
& ajustando os parâmetros do modelo para diversas condições de \\
& carga em regime permanente, e para período estendido. Os \\
& melhores resultados foram obtidos com o uso de duas etapas para a \\
& calibração: na primeira os valores de rugosidade calibrados em \\
& regime permanente (elevada perda de carga), e na segunda a \\
& distribuição da demanda foi calibrada baseada em condições no \\
& período estendido (baixa perda de carga).
\end{tabular}

- Desenvolveram um algoritmo explicito para determinar diretamente

1990 BOULOS \& WOOD as variáveis. Oferecendo uma boa base para a determinação de valores ótimos para os parâmetros de projeto, operação e calibração. Para a resolução simultânea foi utilizado o método de Newton-Raphson, para a linearização dos termos não lineares.

BOULOS \&

ORMSBEE

C

1991

LANSEY \& BASNET

\& TUMBIOLO

1994

DATTA \&

SRIDHARAN
- Aperfeiçoaram o método explicito proposto por ORMSBEE \& WOOD em 1986, estendendo para que diversos testes, sob diferentes condições de contorno, fossem considerados.

- Apresentou uma aproximação similar a de ORMSBEE (1989), segundo a qual o algoritmo de programação não linear incorporou um modelo de simulação hidráulica. O método pode ser aplicado tanto no regime permanente quanto no período estendido para a calibração de coeficientes de rugosidade, abertura de válvulas e demandas nos nós.

- Apresentam uma metodologia para a avaliação dos coeficientes de rugosidade de tubulações de uma rede de distribuição de água utilizando dados de vazão e pressão em determinados pontos de observação. Os autores utilizaram uma matriz de sensibilidade para a determinação da rede de amostragem e concluem que o melhor período para a obtenção dos dados é o noturno.

- Apresentaram um método de calibração de coeficientes de rugosidade baseado na solução do problema inverso, expresso como a minimização dos quadrados das diferenças dos valores computados e observados, incluindo pesos nos desvios dos valores na função objetivo. A vantagem apontada foi a aplicação do método para diferentes condições de demanda com variado número de medidas de pressão e vazão. 
Tabela 4.1 - Histórico da calibração de modelos hidráulicos.

\begin{tabular}{|c|c|c|}
\hline Ano & Autor / Autores & Proposição \\
\hline 1996 & SRIDHARN \& RAO & $\begin{array}{l}\text { - Propuseram um método baseado em DATTA \& SRIDHARAN } \\
\text { (1994), para calibração com uma metodologia melhorada para a } \\
\text { determinação dos pesos. Esta baseada na variância dos valores de } \\
\text { pressões e vazões observados e simulados, com uma sistemática } \\
\text { de dois passos para o procedimento de adoção dos pesos. }\end{array}$ \\
\hline 1997 & SAVIC \& WALTERS & $\begin{array}{l}\text { - Emprega algoritmos genéticos como método de busca no processo } \\
\text { de otimização. O método proposto foi utilizado para a calibração dos } \\
\text { coeficientes de rugosidade da rede e os resultados comparados } \\
\text { com aqueles obtidos de procedimentos de tentativa e erro, } \\
\text { apresentando a dominância total dos algoritmos genéticos sobre } \\
\text { estes últimos. }\end{array}$ \\
\hline 1998 & WALTERS & $\begin{array}{l}\text { - Utiliza os algoritmos genéticos em seus trabalhos para a } \\
\text { determinação das rugosidades absolutas. }\end{array}$ \\
\hline 1999 & $\begin{array}{l}\text { GRECO \& } \\
\text { DEL GIUDICE }\end{array}$ & $\begin{array}{l}\text { - Apresentam um método de calibração dos coeficientes de } \\
\text { rugosidade, com o auxilio de uma matriz de sensibilidade para } \\
\text { otimização não linear, alem de pacotes computacionais para } \\
\text { simulação hidráulica. }\end{array}$ \\
\hline & $\begin{array}{l}\text { De SCHAETZEN et } \\
\text { al. }\end{array}$ & $\begin{array}{l}\text { - Avaliou alem da rugosidade absoluta, os diâmetros das tubulações } \\
\text { e as demandas nos nós. }\end{array}$ \\
\hline 2000 & GAMBALE & $\begin{array}{l}\text { - Avaliou os algoritmos genéticos na calibração de modelos de redes } \\
\text { de distribuição de água. São realizados estudos quanto a influencia } \\
\text { dos operadores genéticos e do número de pontos monitorados na } \\
\text { determinação dos coeficientes de rugosidade de uma rede } \\
\text { hipotética. O autor evidenciou a robustez dos algoritmos genéticos e } \\
\text { a necessidade de uma rede de amostragem otimizada para a } \\
\text { calibração. }\end{array}$ \\
\hline
\end{tabular}

- Estudo comparativo dos métodos para calibração apresentados por WALSKI (1983), BHAVE (1988) e BOULOS \& WOOD (1990). E para

CHEUNG este último trabalho propõe melhorias na metodologia como generalização do método, antes restrito apenas a uma rede da literatura, e a inclusão de um simulador hidráulico proposto por 2001 SOUZA (1994).

- Propõe uma técnica de calibração de modelos de rede de distribuição de água, visando à determinação das demandas nodais, RIGHETTO rugosidades absolutas e diâmetros das tubulações. O modelo hidráulico empregado baseia-se no método dos nós e na técnica dos elementos finitos, sendo cada trecho da rede considerado como 
Tabela 4.1 - Histórico da calibração de modelos hidráulicos.

\begin{tabular}{|c|c|c|}
\hline Ano & Autor / Autores & Proposição \\
\hline & & $\begin{array}{l}\text { um elemento, em que cada um destes interage diretamente com os } \\
\text { nós de suas extremidades. }\end{array}$ \\
\hline & BRDYS et al. & $\begin{array}{l}\text { - Desenvolve um algoritmo para a calibração dos coeficientes de } \\
\text { rugosidade utilizando técnica de linearizações sucessivas em duas } \\
\text { e três dimensões para a solução do problema não linear e não } \\
\text { convexo. Houve a descrição das incertezas dos parâmetros } \\
\text { utilizados no modelo. }\end{array}$ \\
\hline & LANSEY & $\begin{array}{l}\text { - Desenvolveu um procedimento em três etapas para calibração, que } \\
\text { considerava a incerteza nos valores observados e simulados e } \\
\text { proporciona o grau de incerteza na solução final. }\end{array}$ \\
\hline \multirow{3}{*}{2002} & $\begin{array}{l}\text { LINGIREDDY \& } \\
\text { ORMSBEE }\end{array}$ & $\begin{array}{l}\text { - Utilizam algoritmos genéticos para a avaliação de rugosidades } \\
\text { absolutas e demandas. }\end{array}$ \\
\hline & $\begin{array}{l}\text { KAPELAN, SAVIC \& } \\
\text { WALTERS }\end{array}$ & $\begin{array}{l}\text { - Desenvolvem um método híbrido, operando no regime transiente. A } \\
\text { proposta é utilizar um método de busca global, útil para a } \\
\text { "varredura" do espaço de busca, mas que oscila em torno da } \\
\text { solução ótima. Alem da determinação da rugosidade absoluta, o } \\
\text { método também é útil para a detecção de vazamentos. }\end{array}$ \\
\hline & MALLICK et al. & $\begin{array}{l}\text { - Desenvolveram uma metodologia para quantificar o impacto } \\
\text { introduzido no modelo devido a simplificação deste na escolha de } \\
\text { setores com coeficientes de rugosidade homogêneos. O método } \\
\text { determina o melhor número de tubulações em setor, e o número de } \\
\text { setores o qual a rede deve ser dividida, em função da idade, tipo de } \\
\text { material, diâmetro e localização das tubulações. }\end{array}$ \\
\hline
\end{tabular}

Fonte: (Soares, 2003) adaptada

Considerando que, de uma maneira geral, em uma rede de distribuição de água, tanto os vazamentos quanto as demandas dependem das pressões variáveis no tempo e no espaço, há a necessidade da previsão do comportamento das redes nas mais diversas condições operacionais. Tais previsões só podem ser realizadas a contento com o suporte de modelos matemáticos que descrevam adequadamente as leis físicas que regem o escoamento no interior dos condutos, bem como as demandas e os vazamentos, especialmente se a parcela relativa a estes últimos for expressiva (Gomes et al., 2007).

A influência das perdas nos custos finais de operação foi estudada por Colombo \& 
(Farley et al., 2003). Os autores demonstraram que os custos dependem de vários fatores que incluem o regime da demanda, a distribuição espacial das perdas e a complexidade do sistema (Carrijo, 2004).

Até 1994, havia poucos estudos disponíveis de modelagem de perdas. Segundo Farley et al. (2003), existiam alguns fatores que dificultavam a modelagem de perdas, eram eles:

- O desconhecimento sobre o processo dos vazamentos;

- O conhecimento empírico somente do relacionamento entre a ocorrência de vazamentos e a pressão;

- A perda era considerada como uma entidade única, desconhecendo suas componentes.

Alguns trabalhos foram apresentados para a inclusão dos vazamentos e demandas dependentes da pressão. A Tabela 4.2, contém um resumo de algumas propostas de métodos de cálculos e de suas principais características.

Tabela 4.2 - Histórico da calibração de modelos considerando vazamentos

\begin{tabular}{lll}
\hline Ano & Autor / Autores & Proposição \\
\hline & & Empregaram um processo de dois passos para a calibração. \\
& Primeiro é a estimativa dos parâmetros no modelo (inclusive os \\
& vazamentos) para um dado conjunto de medidas de pressão. A \\
& seguir as válvulas são abertas para a aquisição de um novo \\
& TUCCIARELLI \& & conjunto de medidas. O problema inverso é então resolvido, e o \\
TERMINI & procedimento é novamente repetido até que haja convergência. A \\
& desvantagem principal do método é o grande esforço computacional \\
& necessário para a inversão de duas matrizes da função objetivo \\
& para cada conjunto de medidas (resistências das válvulas). \\
\hline TUCCIARELLI, & Utilizou o método de busca simulated annealing, o processo foi \\
CRIMINISI \& & empregado em uma rede real com medidas de pressões e vazões \\
TERMINI & na função objetivo. Possibilitou a quantificação do total de \\
& vazamentos em diversos setores da rede, com a possibilidade de \\
& utilizar dados relativos a testes noturnos. \\
\hline
\end{tabular}

- Apresenta metodologia para a calibração de coeficientes de

2000 AINOLA et al.

rugosidade considerando as perdas por vazamentos no modelo, baseado na setorização da rede de distribuição de água quanto a 
Tabela 4.2 - Histórico da calibração de modelos considerando vazamentos

\begin{tabular}{ll}
\hline Ano Autor / Autores & Proposição \\
\hline & coeficientes de rugosidade e perdas por vazamentos similares. Na \\
& primeira etapa dos cálculos é a distribuição das perdas de água com \\
& a utilização de uma formulação empírica, que leva em consideração \\
& o comprimento, idade, diâmetro e material das tubulações, alem da \\
& pressão atuante. A seguir os coeficientes de rugosidade são \\
& estimados através da minimização de uma função objetivo que leva \\
& em consideração as pressões medidas e calculadas. \\
- Propuseram um método interativo para a calibração em termos de \\
rugosidade absoluta e parâmetros do modelo pressão x vazamento \\
de setores da rede de distribuição de água da cidade de São Carlos, \\
SP, Brasil. Primeiro passo consiste em determinar as rugosidades \\
absolutas das tubulações e no segundo passo os parâmetros de \\
vazamentos utilizando a rotina computacional desenvolvida por \\
CALIMAN (2002). Os dados de campo foram obtidos de ensaios \\
noturnos de campo, em setores com elevada taxa de vazamentos. \\
Os autores propõem um estudo sobre a posição e status das \\
válvulas na rede, pois tais componentes podem comprometer a \\
operação do sistema. A ferramenta de busca apoia-se nos \\
algoritmos genéticos e operadores inerentes da técnica.
\end{tabular}

Fonte: (Soares, 2003) adaptada

\subsubsection{Montagem da topologia da rede no modelo}

A modelagem matemática de sistemas de abastecimento de água envolve uma série de abstrações. Primeiro as tubulações e equipamentos reais são representados graficamente nas plantas cadastrais do sistema de distribuição de água. As informações das demandas e os dados técnicos são levantados. Então, as plantas, as informações e os dados são convertidos em modelos que simulam o fenômeno de transporte da água nas tubulações, demonstrando o comportamento do sistema de distribuição em determinada condição de operação. Para aprimorar o resultado, é feita a calibração do modelo, obtendo dados de campo em pontos arbitrários do sistema, que são carregados no modelo (Walski et al., 2003).

Montar, calibrar e utilizar um modelo matemático de um sistema de distribuição de água pode parecer um imenso trabalho logo de inicio, mas qualquer trabalho pode ser 
facilmente executado se dividido em etapas.

No início da modelagem, é necessário definir qual é o propósito para o qual se está modelando o sistema de distribuição, as intervenções de médio e longo prazo, e o planejamento das coletas das informações de cadastro e de campo.

Um modelo matemático é uma representação da realidade sendo que, quanto melhor for a qualidade da informação, melhor serão os resultados (Thornton et al., 2008).

A concepção de rede é fundamental para construção de um modelo de distribuição de água. A rede contém vários componentes de um sistema, e define como estes elementos estão interligados Figura 4.9.

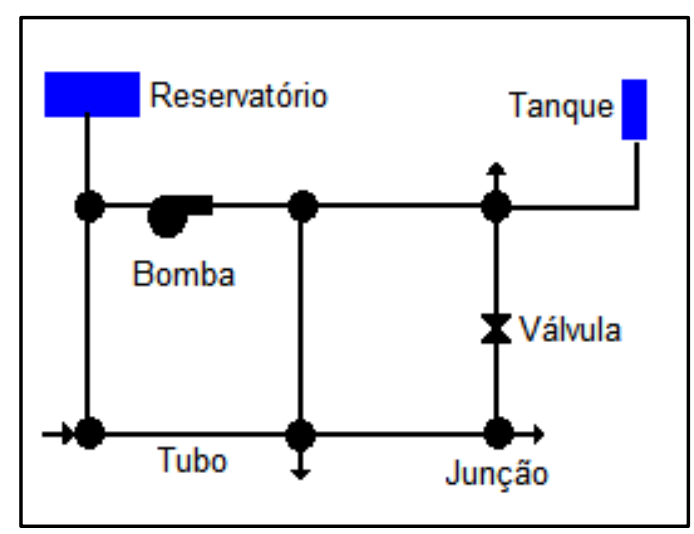

Figura 4.9 - Exemplo dos elementos do modelo hidráulico. (EPANET2, 2009)

A rede é composta de nós, os quais representam características de um local específico dentro do sistema, e de linhas retas, que definem as relações entre os nós, ver Tabela 4.3.

Tabela 4.3 - Elementos comuns em modelagem (Walski et al., 2003)

\begin{tabular}{lll}
\hline Elemento & Tipo & Função no modelo \\
\hline Reservatório & Nó & Prover água ao sistema. \\
\hline Tanque & Nó & $\begin{array}{l}\text { Estoca o excesso de água do sistema e devolve nos } \\
\text { horários de pico de consumo. }\end{array}$ \\
\hline Junção & Nó & Retira ou coloca vazão de água no sistema. \\
\hline Tubulação & Linha & Conduz água de uma junção a outra. \\
\hline Bombas & Nó ou linhas & $\begin{array}{l}\text { Aumenta a carga hidráulica para sobrepor desníveis } \\
\text { geométricos ou perda de carga. }\end{array}$ \\
\hline Válvulas de Controle & Nó ou linhas & $\begin{array}{l}\text { Controla a pressão ou vazão no sistema de acordo com } \\
\text { critérios definidos. }\end{array}$ \\
\hline
\end{tabular}




\section{Reservatórios}

O reservatório representa um ponto na borda do modelo, capaz de fornecer ou receber água em grande quantidade. Ele é um fornecedor ou receptor infinito, teoricamente mantedor de vazões de entrada ou saída do sistema durante todo o período de tempo. Reservatórios são utilizados no modelo como sendo fontes de água, onde a carga hidráulica é dada por valores diversos das geradas pelas demandas do sistema. Lagos, represas, poços profundos e até estações de tratamento de água são usualmente representados por reservatórios. Também na modelagem, o fornecimento de água entre sistemas de abastecimentos podem ser considerados como reservatório fornecedor para um e receptor para o outro.

Para um reservatório, duas informações são necessárias: a cota altimétrica do nível da água e a qualidade da mesma. Por definição, o reservatório não estoca água, assim nenhuma informação quanto ao volume disponível é necessária.

\section{Tanques}

Um tanque de reservação também é um ponto da borda do modelo. Difere de um reservatório, pois sua carga hidráulica varia de acordo com o consumo de água. Os tanques possuem volumes limitados que podem ser repostos ou consumidos durante 0 período de tempo. Os tanques existem na maioria dos sistemas de distribuição, e sua representação no modelo é geralmente bem fiel ao seu comportamento real.

Numa modelagem estática, o tanque se comporta identicamente a um reservatório, uma vez que o fluxo de água é calculado com sua carga hidráulica constante. Já numa modelagem em tempo estendido, existe a variação de sua carga hidráulica.

\section{Juncões}

Junções são mais do que simples conexões entre trechos da rede. Definem a posição de demandas do sistema de abastecimento, podendo esta ser um consumo ou um fornecimento de água do sistema. Pode-se utilizar uma junção no final de um trecho, para ser utilizado como uma descarga ou um consumo localizado. As junções conectam trechos da topologia da rede que representam as tubulações. Nas tubulações reais, as conexões ocorrem por meio de juntas entre os diversos tubos que compõem a tubulação, e os consumos se distribuem ao longo deles. A importância das junções na topologia é devida a simplificação causada no modelo, pois concentram nas as demandas existentes, sem afetar os resultados dos cálculos. A característica física 
definida numa junção é sua cota geométrica. Este atributo parece simples de ser atribuído, porém existem algumas considerações a serem observadas. Isto porque a pressão é determinada pela diferença entre a carga hidráulica calculada e a cota geométrica, assim atribuir o valor correto da cota geométrica é imprescindível.

\section{Tubulacõos}

As tubulações conduzem a água de um ponto a outro dentro da rede de distribuição. Os tubos, de aço e ferro fundido, são fabricados em comprimentos em torno de 6 metros, e são montados em série formando a tubulação. Na tubulação, existem várias conexões, como cotovelos ou curvas, que causam variações de direção ou válvulas que controlam a vazão em determinados trechos de rede. Para a modelagem, trechos individuais de rede e suas conexões podem ser combinados em um único trecho, tendo as mesmas características, ou seja, material, diâmetro, etc. O comprimento total entre uma junção e outra representa o percurso completo da água, mas não necessariamente em linha reta. O diâmetro da tubulação utilizado é seu diâmetro interno, ou seja, a distância de um ponto interno até seu diametralmente oposto na da parede interna. Este valor difere do diâmetro nominal, pois a medida exata depende da classe de pressão e material do tubo.

\section{Perda de carga}

As tubulações possuem uma rugosidade que causa uma perda de carga distribuída ao longo de sua extensão. Com o passar do tempo, envelhecem e com isso essa rugosidade pode aumentar, pois podem ocorrer incrustações e corrosão das paredes do tubo.

\section{Bombas}

As bombas são elementos que adicionam energia, ao sistema de modo a aumentar a carga hidráulica. A bomba é empregada para possibilitar que o fluxo de água na tubulação vença as perdas de carga e diferenças de cotas geométricas. A menos que o sistema seja totalmente operado por gravidade, as bombas fazem parte integrante do sistema de abastecimento. Nos sistemas de abastecimento de água, o tipo de bomba mais frequentemente utilizado é a centrífuga. Uma bomba centrífuga tem um motor que é conectado a um rotor que impulsiona a água pela tubulação. A energia mecânica de rotação impulsiona a água na tubulação aumentando a carga hidráulica. 
As características físicas das bombas necessárias para a modelagem são obtidas a partir da sua curva característica. Os parâmetros necessários são: altura manométrica, eficiência, potência e o NPSH (Net positive suction head) requerido.

A curva da altura manométrica representa o fornecimento de energia ao sistema para vencer o desnível geométrico e as perdas de carga. As outras curvas são utilizadas para determinar consumo de energia, requisitos do motor e avaliação da cavitação.

\section{Válvulas}

As válvulas são elementos utilizados para controle operacional e delimitações de áreas de abastecimento (setores, distritos de medição e controle, etc.) e sua operação é definida segundo as regras operacionais do sistema de abastecimento. Estas informações entram no modelo de simulação hidráulico em cada trecho de rede nos elementos obtidos no levantamento planialtimétrico. A seguir, são citados alguns tipos de válvulas: bloqueio, controle de vazão, controle, mantenedora de pressão, nível, redução de pressão, retenção e ventosas.

Existem aplicativos desenvolvidos para simulação hidráulica, baseados nos equacionamentos teóricos que representam as leis físicas do comportamento dos fluídos em condutos forçados, cujas características devem ser estudadas e entendidas para obtenção de resultados significativos e otimizados. A Figura 4.10 apresenta uma possível sequencia de etapas para a utilização de um aplicativo simulador hidráulico.

Na etapa um é feita a seleção e aprendizado do aplicativo, no qual a simulação será feita. Nesta etapa é necessário um treinamento eficaz, pois o bom conhecimento dos recursos e dos dados de entrada do aplicativo permite um aproveitamento pleno do mesmo, além de imprimir maior velocidade à criação do modelo.

Na etapa dois é realmente executada a simulação, e o primeiro passo é selecionar uma área discreta do sistema de abastecimento, e estudar suas características para conhecê-la suficientemente bem, proporcionando um bom domínio do comportamento, do consumo e das variáveis físicas e temporais envolvidas no transporte da água pelas tubulações. Todos os dados serão carregados no aplicativo. 


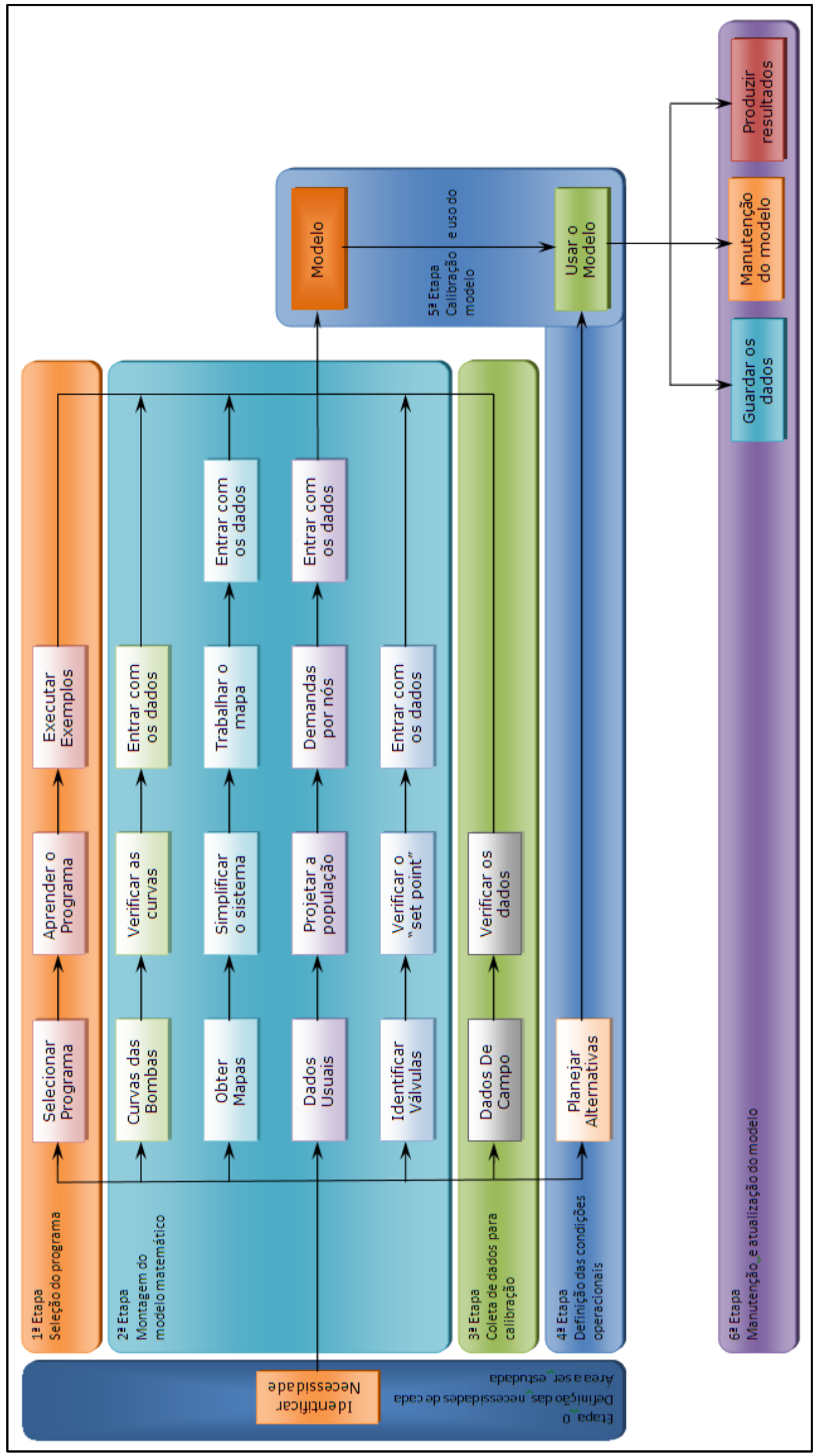

Figura 4.10 - Uma possível seqüência de etapas para a utilização de um aplicativo simulador hidráulico. (Walski et al., 2003) adaptada. 
. Existem dados que são influenciados por fatores complexos e aleatórios, e que terão de ser levantados em campo ou estimados, como por exemplo, o perfil de consumo (ou demanda horária), e o estado físico atuais da tubulação. As seguintes características devem ser levantadas nesta etapa:

Topografia: o levantamento planialtimétrico da área em estudo é obtido no cadastro técnico, com a consulta às plantas cadastrais da rede de distribuição existente. No caso de se tratar de uma área recém-implantada, pode existir a necessidade do levantamento no campo de algumas informações ainda inexistentes no cadastro. Com o levantamento planialtimétrico, toma-se conhecimento das cotas altimétrica envolvidas, e do caminhamento das redes de distribuição pela área em análise, bem como das válvulas existentes. Estas informações serão carregadas no modelo de simulação.

Extensão de rede: As informações referentes à rede de distribuição, ou seja, extensão, materiais, diâmetros, idade, válvulas e equipamentos que a compõem, são obtidas também no cadastro técnico das concessionárias.

Tubulações e seus materiais, diâmetros e idades: pela avaliação da idade e do material de cada trecho rede, é feita a avaliação das condições físicas do mesmo e seu efeito sobre o fluxo de água em seu interior. Para isso tomam-se como base as tabelas existentes e as equações de perda de carga distribuída e localizada, por exemplo, a rugosidade que é afetada diretamente pela incrustação existente em redes de ferro fundido com idades avançadas. Uma estimativa da espessura da camada de incrustação pode ser obtida pela equação de Colebrook-White, que estabeleceram uma relação linear para levar em conta o aumento da rugosidade, equações 4.1 e 4.2, como passar do tempo (Azevedo Netto, 1998).

$$
e=e_{0}+\alpha \cdot t \ldots(4.1)
$$

Onde: $e_{0}$ é a altura da rugosidade; $e$ é a altura da rugosidade após t anos; $t$ é o período de tempo em anos; $\alpha$ é a taxa de crescimento da aspereza, em m/ano.

$$
2 \cdot \log \alpha=6,6-p H \quad \ldots(4.2)
$$

Onde: $\alpha$ é taxa de crescimento da aspereza, em m/ano; $p H$ é o potencial hidrogeniônico médio das amostras de água coletadas.

Tipos de clientes: para modelar o comportamento da distribuição de água em uma determinada área, o comportamento da demanda horária de consumo deve ser obtido, pois é através de sua variação que os valores das vazões e pressões horárias existentes em cada trecho da rede são calculados. Os clientes são divididos, regularmente, em: Residenciais, Comerciais, Industriais e Públicos. E quanto ao seu 
porte em: Comuns e Especiais. Com o perfil de consumo, a demanda horária em cada trecho é calculada.

Demandas: a demanda horária é característica de cada cliente. Para sua determinação é necessário conhecer o perfil de consumo horário de cada cliente, para isso é necessário a coleta de dados individuais por meio de registradores eletrônicos instalados em cada ramal, a Figura 4.11 mostra alguns equipamentos utilizados no levantamento.

Pressões: a pressão estática é obtida pela diferença de cotas altimétricas mais a carga hidráulica do sistema.

$\mathrm{Na}$ etapa três é feita a calibração do modelo com o levantamento de dados em campo, que serão fornecidos ao modelo, e que por meio de ciclos de interações matemáticas, adéqua às diversas variáveis aos valores correspondentes em campo.

$\mathrm{Na}$ etapa quatro, depois que todas as informações relativas à área e de todas as características dos elementos e tubulações que compõem o sistema forem definidas, o modelo pode ser finalmente simulado. O modelo está pronto para o uso e planejam-se as alternativas previstas para o sistema de abastecimento, como por exemplo, a troca de redes, ampliação da malha de distribuição, a inclusão de um grande empreendimento imobiliário, etc. Criando assim diversos cenários que serão utilizados na etapa cinco e fornecerão os resultados que serão utilizados na análise da área e emissão de diagnóstico.

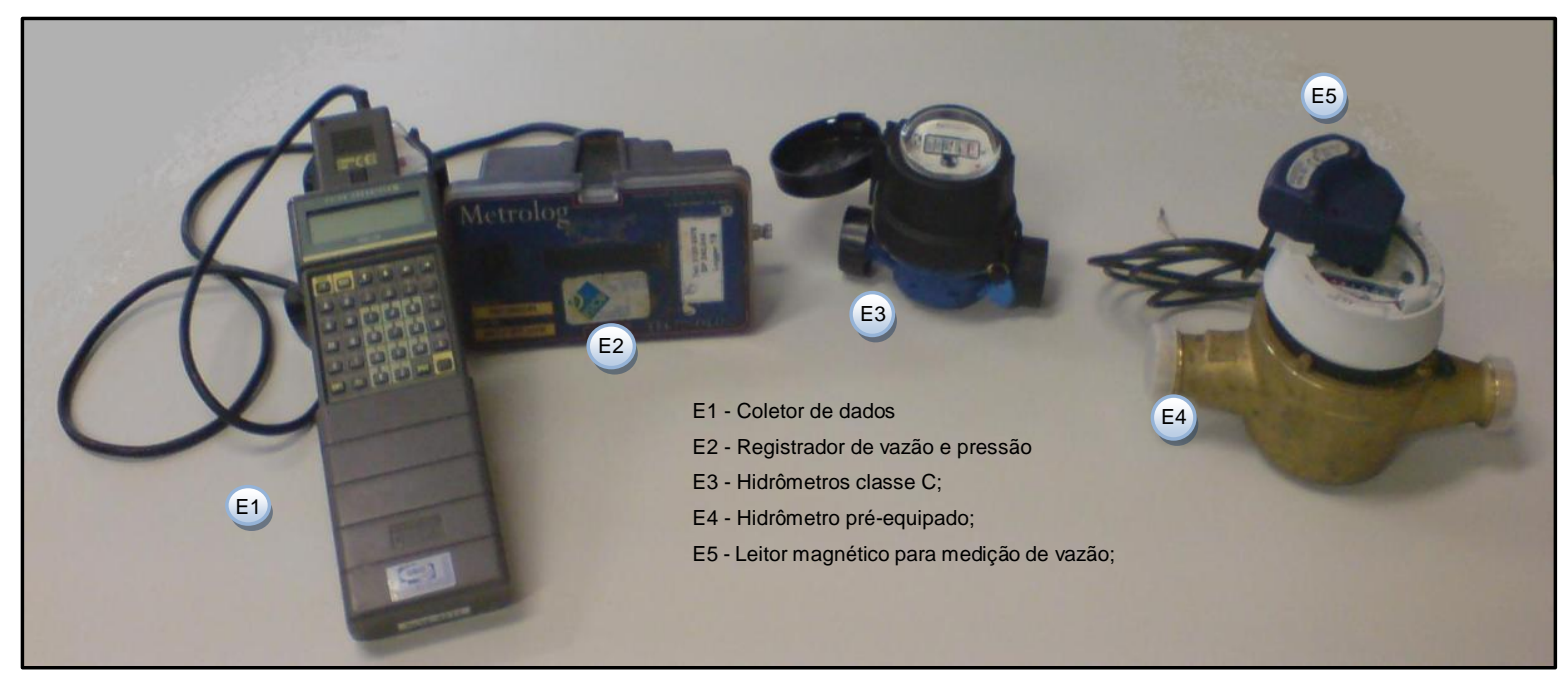

Figura 4.11 - Alguns Equipamentos utilizados na coleta de dados

Existem dois tipos básicos de simulação, que são: 
- Simulação em regime permanente (estático): onde são calculadas vazões, pressões, etc., considerando que as condições de contorno sejam estáticas, ou seja, não variam com o passar do tempo.

- Simulação em período estendido: onde o comportamento do sistema é levado em conta na simulação e as demandas e condições de contorno variam com o passar do tempo.

A etapa seis é a guarda e manutenção do modelo, pois este deve sempre estar atualizado para prover dados úteis à emissão de diagnósticos sempre que houver a necessidade de intervenções na área. É uma boa prática destinar uma equipe para esta função, visto que um sistema de abastecimento tende a crescer e tornar-se cada vez mais complexo.

\subsection{ALGORITIMOS GENÉTICOS}

O método foi desenvolvido por John Holland em 1975. Popularizou-se através de um de seus estudantes, David Goldberg, que foi capaz de solucionar um problema de difícil solução, envolvendo controle na transmissão de uma tubulação de gás, para sua dissertação de mestrado (Goldberg, 1989) apud (Ribeiro, 2005).

De acordo com Miranda (1998) apud Ribeiro (2005), os algoritmos evolucionários mais populares são:

- Programação evolucionária;

- Estratégias de evolução;

- Sistemas classificadores, e

- Algoritmos genéticos (AGs).

A teoria do AGs tem sua origem na genética natural e na ciência computacional e por esta razão os termos utilizados são uma mistura entre as duas ciências Ribeiro (2005). A Tabela 4.4, apresenta de forma resumida esta analogia, sugerida por Gen Cheng (1971) apud Ribeiro (2005). 
Tabela 4.4 - Terminologia dos AGs (Ribeiro, 2005)

Denominação genética

Cromossomo

Genes (bits)

Local ou Locus

Genes alelos

Fenótipo

Genótipo

\section{Denominação análoga}

Solução do problema

Unidade formadora da solução

Posição do gene no string

Valores de fato da variável de decisão

Solução decodificada (Ex.: $010 \Rightarrow 156$ )

Solução codificada (Ex.: $156 \Rightarrow 010)$

Para muitas aplicações de AGs, especialmente problemas do mundo da engenharia industrial, o AG simples é de difícil aplicação direta, pois os strings binários não são códigos ou representações naturais (Ribeiro, 2005).

Escolher a representação apropriada para as soluções candidatas do problema a ser tratado, é fundamental para a aplicação de AGs na solução de problemas reais.

Por exemplo, se o problema (cromossomo A) é escolher as vazões de entrada de um reservatório, a solução em código binário na base 10 é:

$A=[0011001000,1110000010,0100000010]$, na representação binária ou,

$A=[200,450,130]$, o mesmo cromossomo decodificado na representação real.

$\mathrm{Na}$ busca das soluções possíveis, as operações são realizadas de forma alternada entre os espaços de código (com strings codificados) e de soluções (valores numéricos de fato). As operações genéticas (cruzamentos e mutações) ocorrem no espaço de código, enquanto a avaliação da função objetivo e a seleção ocorrem no espaço solução. A Figura 4.12, mostra o ciclo de operações (Gen et al., 1997) apud (Ribeiro, 2005).

Para técnicas de decodificação sem strings (non-strings), segundo Gen et al. (1997) apud (Ribeiro, 2005)., existem três questões criticas na codificação e decodificação:

1. Viabilidade do cromossomo - ocorre quando a solução decodificada de um cromossom está situada na região viável de um dado problema;

2. Legalidade - quando um cromossomo representa uma solução para um dado problema;

3. Mapeamento - correspondência dos cromossomos (soluções codificadas) com as soluções de fato (decodificadas).

A Figura 4.13, ilustra as três questões levantadas. 


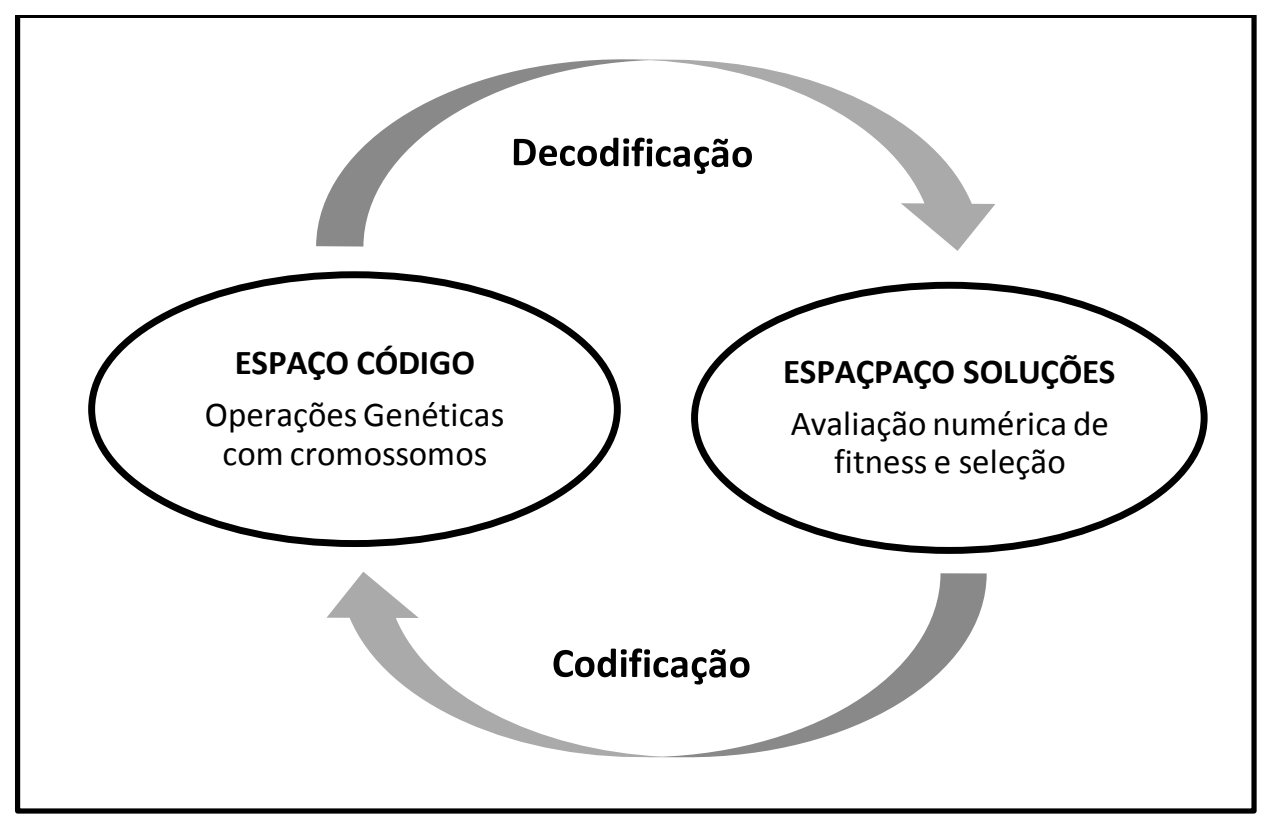

Figura 4.12 - Espaços de codificação e de solução

Muitos problemas de otimização tem sua região viável representada por sistemas de equações lineares ou não lineares. Em tais casos, deve ser utilizados métodos de penalidade, para tratar as soluções inviáveis. Estes casos ocorrem em situações de otimização restrita, onde o ótimo ocorre normalmente nos contornos. A penalidade na violação da restrição forçará a busca genética a aproximar o ótimo das áreas viáveis e

Figura 4.13 - Questões na codificação e decodificação (Ribeiro, 2005) Adaptada

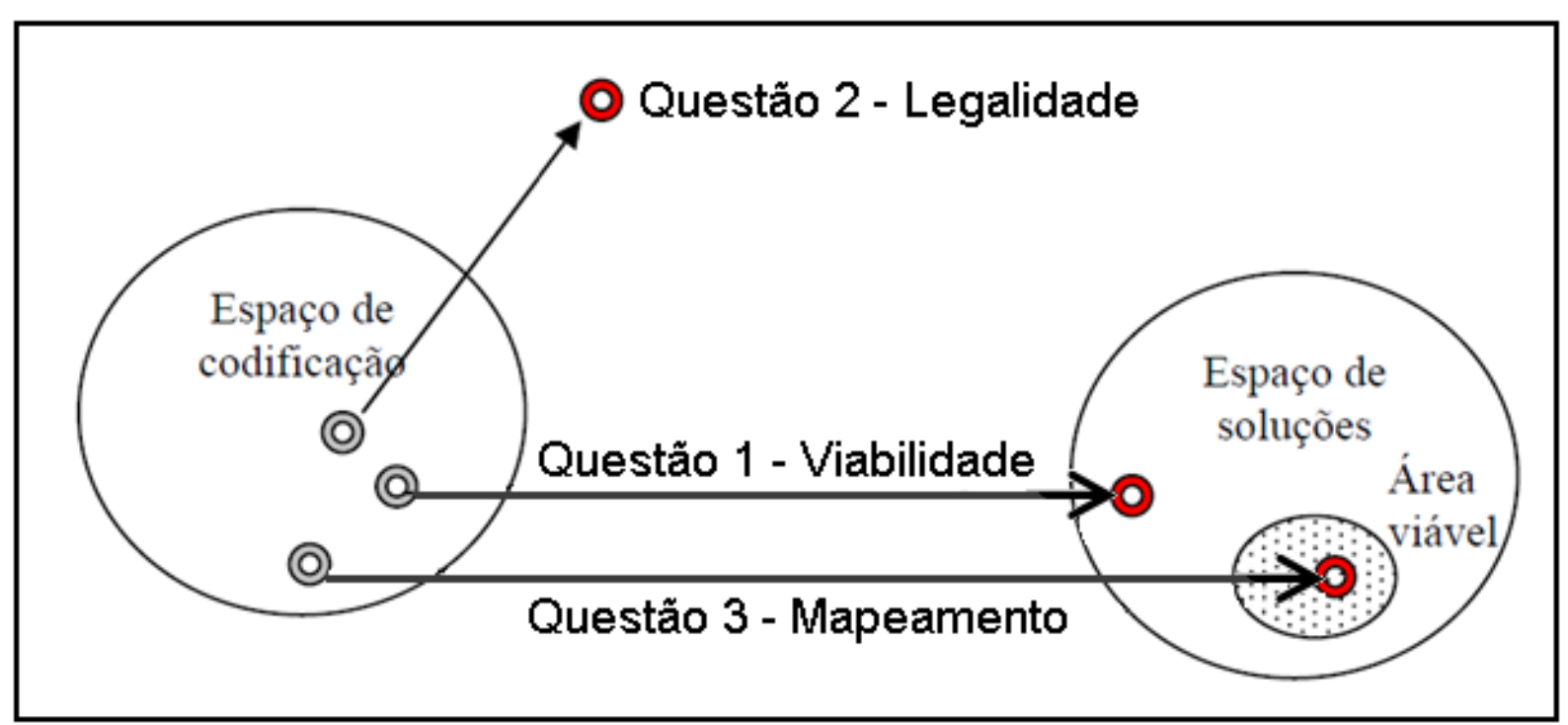

também das inviáveis. Nos problemas de otimização combinatória, os códigos específicos de determinados problemas, utilizados em outros de natureza diferente, 
produzem descendentes ilegais, que não poderão ser decodificados em solução. Assim, este descendente não poderá ser avaliado, o que torna a técnica de penalidade inaplicável. Uma forma de solução é introduzir estratégias de reparo combinadas com operadores de cruzamento, que são mais eficientes que as estratégias de rejeição ou de penalidades.

\subsubsection{Funcionamento dos AGs.}

Segundo Ribeiro (2005), um AG básico é um processo constituído de:

1. Uma população inicial: gerada a partir de números aleatórios (randômicos), dentro de limites estabelecidos de acordo com os limites mínimo e máximo definidos para as variáveis de decisão. Esta população constitui a primeira geração, que representa um conjunto inicial de possíveis soluções do problema.

2. Processo evolucionário: que é a busca do conjunto solução com os melhores valores. Este processo se divide em três etapas:

a. Determinação do fitness, isto é, valor numérico da função objetivo para todas as soluções da população, que classifica a solução como apta ou não, segundo a natureza do problema, de maximização ou minimização.

b. Aplicação do operador evolutivo, ou seja, os indivíduos que tiverem um nível de fitness, adequado ao problema, tem maior probabilidade de serem escolhidos para compor a geração seguinte.

c. Recombinação dos indivíduos selecionados, que consiste em aplicar as regras evolutivas predefinidas criando novas soluções que são submetidas às variações aleatórias de suas características (genes). Nesta etapa os operadores dos AGs atuantes são: os genéticos de cruzamento e mutação. $O$ conjunto solução obtido neste processo é chamado de segunda geração. Este processo é repetido gerando uma evolução artificial ao longo de gerações, as quais os melhores resultados são mantidos.

3. Finalização do processo, que é a interrupção das interações conforme definido nos critérios de convergência, ou por atingir o número de gerações especificado no início do processo.

A Figura 4.14 ilustra o funcionamento de um AG básico. 


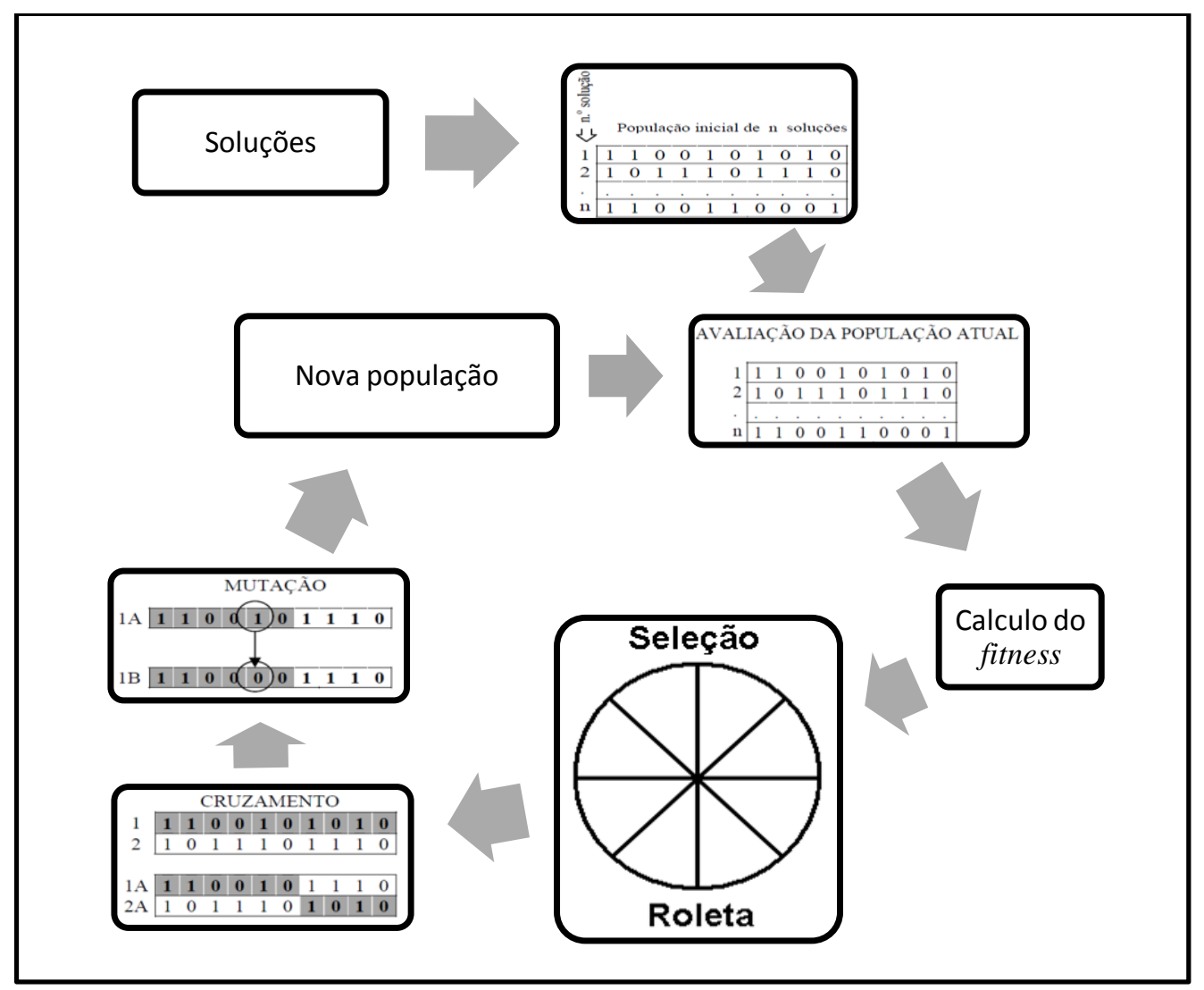

Figura 4.14 - Ciclo dos AGs Gen e Cheng (1997) apud Ribeiro (2005)

Ainda segundo Ribeiro (2005), as maiores vantagens dos AG em ralação a outras técnicas de otimização são:

1. Não necessitam de exigências matemáticas de implementação em relação aos problemas de otimização. Devido à sua natureza evolutiva, irão buscar por soluções sem levar em conta as características do problema, externas às soluções a serem obtidas;

2. Podem manipular qualquer tipo de função de aptidão e restrições (lineares ou não), definidas em espaços de busca de parâmetros discretos, contínuos ou misto;

3. Apresentam flexibilidade na hibridização com heurísticas dependentes de domínio, na reformulação eficiente de um problema específico.

4. Tratam grande número de parâmetros, podendo ser aplicados a problemas de grandès dimensões;

5. São bem ajustados para processamento paralelo, ou seja, microprocessadores que buscam as soluções ótimas paralelamente e simultaneamente e,

6. Otimizam funções com superfícies extremamente complexas, podendo saltar de 
um mínimo local (característica de uma meta-heurística) para região de soluções viáveis.

AGs são uma classe de métodos que conforme o tipo de busca de propósito geral não determinístico, combinando elementos de busca estocástica e direcionada, na qual o cruzamento será determinado pelo ambiente do sistema genético e não pelo operador em si.

\subsection{Modelagem matemática de perdas de água}

O volume de água perdida que ocorre numa companhia de saneamento pode ser aproximadamente calculado, empregando uma representação matemática. Segundo o tipo e natureza da perda (aparente ou real), o modelo pode ser uma simples planilha de cálculo ou uma complexa série de cálculos com uma coletânea de dados de entrada, para a determinação do volume de água perdida. A modelagem hidráulica da rede de distribuição e das demandas foi o foco central das análises com modelos de simulação hidráulica nos últimos 30 anos. Estes modelos, segundo Thornton et al.(2008), tratavam das perdas de água de maneira simplificadas, considerando-a como fixa ou residual.

A partir dos anos 90, após uma série de estudos efetuados em diversas partes do mundo, a perda de água foi divida em seus componentes. E surgiram os primeiros modelos matemáticos baseados em equações empíricas desenvolvidas a partir de avaliações estatísticas de dados, tais como: quantidade e tipos de vazamentos, períodos de detecção, material da tubulação, entre outros. A perda foi divida em três categorias, a saber:

- Perda real: se refere a vazamentos e extravasamentos.

- Perda aparente: se refere à imprecisão na medição dos volumes consumidos e fornecidos, erros sistêmicos na coleta e tratamento de dados no sistema comercial e consumos não autorizados.

No Reino Unido, entre 1990 e 1995, foi identificada a necessidade de se ter um método para a gestão de perdas. Assim, surgiu uma metodologia geral conhecida como burst and background estimates (BABE), que não é uma ciência precisa. Em princípio ela é 
baseada na análise de uma grande quantidade de dados e de ensaios de campo. Difere dos conceitos gerais de modelos matemáticos de sistemas hidráulicos, por utilizar uma mistura de dados obtidos por medições, estimativas e testes de campo. O objetivo da modelagem, pelo método BABE, é caracterizar individualmente cada componente da perda real e comparar com a estimativa de perda obtida do balanço hídrico $(\mathrm{BH})$, (também conhecido pelo nome em inglês "top-down water audit spreadsheet model"), ou do método da vazão mínima noturna (VMN), ou ainda o método do "fixed and variable area discharge" (FAVAD) (Farley et al., 2003).

O método BABE é aplicado à modelagem de perdas reais. Para perdas aparentes é utilizado o $\mathrm{BH}$ juntamente com a análise individual de seus componentes. A perda aparente tem sido modelada de diversas maneiras nos últimos anos. Entretanto, recentemente seus componentes têm sido modelados de maneira similar ao método aplicado às perdas reais, onde seus componentes são apresentados como múltiplos de uma perda inevitável anual (Thornton et al., 2008). Assim a perda total no sistema de abastecimento é dada pela equação 4.3:

$$
P=\sum P_{r}+\sum P_{a} \cdots
$$

Onde $P$ é a perda total, $P_{r}$ é a perda real e $P_{a}$ é a perda aparente, todas expressas em $\mathrm{m}^{3}$.

\subsubsection{Método "Fixed and Variable Area Discharge" (FAVAD)}

A pressão na rede é um dos fatores que influi diretamente no surgimento e na vazão dos vazamentos, daí a importância de seu controle e monitoramento.

A sua relação com a vazão dos vazamentos é função do material da tubulação, pois como é demonstrado pelo modelo FAVAD ('Fixed and Variable Area Discharge Paths'), desenvolvido no Reino Unido, apresenta um equacionamento para várias situações encontradas na rede de distribuição (Tsutiya, 2006).

A equação 4.4 relaciona a vazão dos vazamentos com a pressão.

$$
\frac{Q_{1}}{Q_{0}}=\left(\frac{P_{1}}{P_{0}}\right)^{N_{1}} \ldots
$$


Onde $Q_{0}$ é a vazão inicial em $\mathrm{L} / \mathrm{h}, Q_{1}$ é a vazão final em $\mathrm{L} / \mathrm{h}, P_{0}$ é a pressão inicial em $\mathrm{mH}_{2} \mathrm{O}, P_{1}$ é a pressão final em $\mathrm{mH}_{2} \mathrm{O}$, e $N_{1}$ é um expoente que depende do material do tubo.

Ensaios realizados em diversos países comprovaram os seguintes valores para $N_{l}$ :

- Para tubos metálicos $N_{l}=0,5$

- Para tubos plásticos $1,5<N_{l}<2,5$

Destes mesmos ensaios, foi obtido o valor de $N_{1} \cong 1,5$ para vazamentos inerentes, independente do material, pois são provenientes de pequenos vazamentos nas tubulações pressurizadas localizados geralmente nas juntas ou conexões, onde existe a presença de material vedante, cuja plasticidade é maior.

\subsubsection{Método Vazão mínima noturna (VMN)}

Este método consiste na medição das vazões e pressões horárias de uma área delimitada na qual todo o consumo e o volume disponibilizado são medidos. O pico de consumo é geralmente entre 11 e 14 horas, e o mínimo consumo é geralmente entre três e quatro horas, que é chamada de vazão mínima noturna que correspondente ao período de menor consumo (Lambert et al., 1998).

A Vazão Mínima $\left(Q_{\min }\right)$ tem importância na determinação das vazões de vazamentos $\left(Q_{v}\right)$, pois o consumo neste período é menor, e assim uma parcela significativa de seu valor refere-se a vazamentos (Figura 4.15). Como a vazão de vazamentos é influenciada pela pressão, o cálculo do volume perdido diário utilizando a vazão de vazamentos obtida na simples diferença entre a $Q_{\min }$ e o consumo mínimo horário $C_{\min }$ (equação 4.5), extrapola o volume perdido diário, pois a pressão no período onde ocorre a vazão mínima (geralmente entre as 3 e 4 horas), é maior que a pressão média ao longo das 24 horas, em áreas sem controle de pressão, e menor que a pressão média em áreas com controle de pressão, necessitando ser corrigida pelo Fator Noite-Dia $\left(F_{n d}\right)$.

$$
Q_{\min }=Q_{v}+C_{\min }
$$




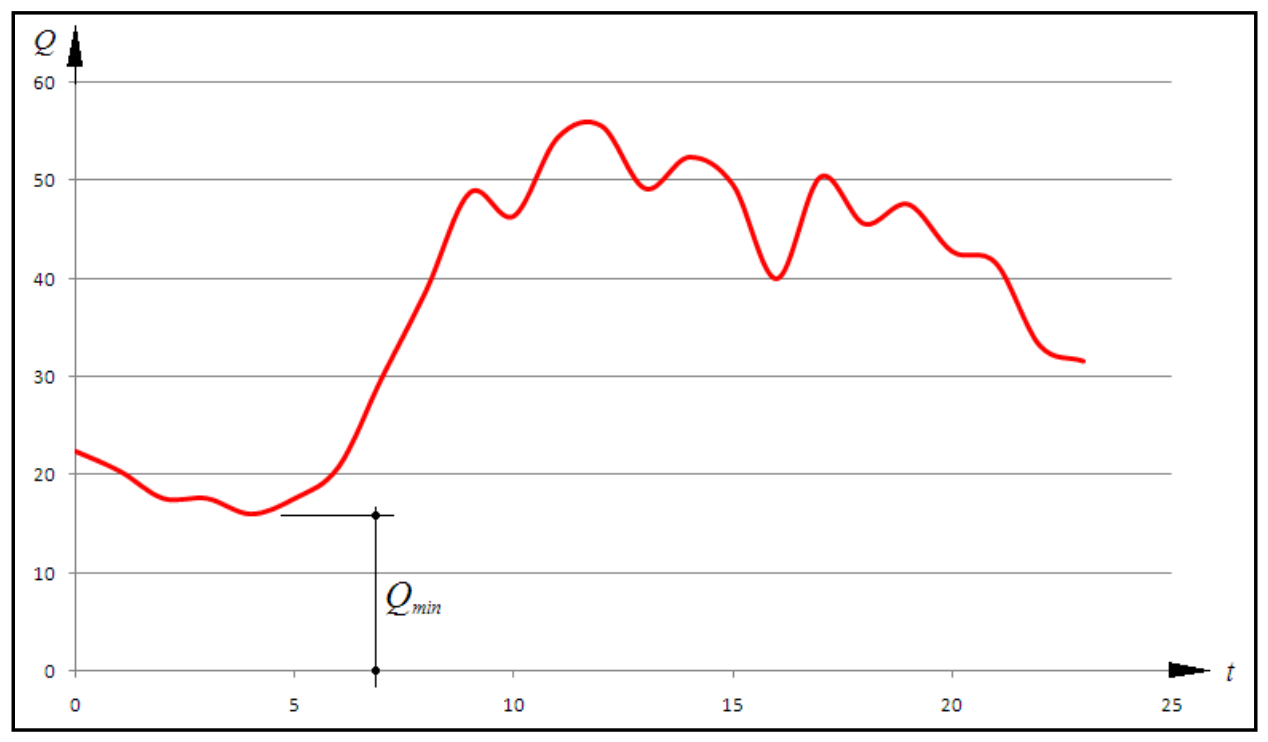

Figura 4.15 - Vazão mínima

O Fator Noite-Dia $\left(F_{n d}\right)$, que é obtido a partir de medição da pressão horária no ponto médio da área medida e calculado utilizando a relação entre pressão e vazão (equação 4.4) resultando na equação 4.6.

$$
F_{n d}=\sum_{n=1}^{24}\left(\frac{\bar{p}_{(n-1) \rightarrow n}}{\bar{p}_{3 \rightarrow 4}}\right)^{N_{1}} \ldots
$$

Onde $\bar{p}_{(n-1) \rightarrow n}$ é a pressão média horária entre à hora $(n-1)$ e $n$, em $\mathrm{mH}_{2} \mathrm{O}$. O valor de $F_{n d}$ pode ser menor que 24 em setores sem gerenciamento de pressões e maior que 24 em setores onde exista o gerenciamento de pressão.

Com o $F_{n d}$ obtém-se a vazão de perdas reais diárias $Q_{r d}$ pela correção do valor da vazão de vazamentos obtida trabalhando a equação 4.6. A equação 4.7, apresenta a correção do valor da vazão de vazamentos.

$$
Q_{r d}=F_{n d} \cdot Q_{v}
$$

Onde $Q_{r d}$ é a vazão de perdas reais diárias, e $Q_{v}$ é a vazão de vazamentos em $\mathrm{L} / \mathrm{h}$.

Vantagens do método são:

- Retrata a realidade física e operacional da área;

- Auxilia no conhecimento das características técnico/operacionais da área.

Desvantagens do método são:

- O ensaio é geralmente feito em áreas pequenas, cujo resultado pode diferir do 
setor de abastecimento como um todo, pois a avaliação neste método é feita sempre observando a área como um todo e o setor pode conter frações piores ou melhores que a área escolhida para o ensaio;

- Envolve custo com equipe e equipamentos para a realização do ensaio.

\subsubsection{Método do balanço hídrico $(\mathrm{BH})$}

Muitos avanços significativos ocorreram que permitiram melhor entendimento do comportamento das perdas e possibilitaram a criação de modelos que simulam seus componentes e ajudam a definir o nível econômico de perdas (NEP) em cada sistema individualmente. Apesar de existirem vários casos de sucesso no controle de perdas, a maioria dos sistemas de abastecimento ao redor do mundo continuava com altos índices de perdas. Parte do problema era devido à falta de padronização e de maior intercâmbio de informações sobre o controle e redução de perdas. Cada país tinha seu próprio método de balanço hídrico e de controle. Assim a International Water Association (IWA) estabeleceu uma estrutura e terminologia internacional para o $\mathrm{BH}$ (Liemberger et al., 2004). O cálculo do BH se aplica a uma área globalmente, seguindo o estabelecido pela IWA e isto proporciona o conhecimento das condições e das características da área, e auxilia na definição das ações a serem aplicadas para o combate as perdas (Tardelli Filho, 2006). As vantagens do método do BH são:

- Facilidade de aplicação em áreas de tamanhos variados;

- Os dados da macromedição e micromedição estarem disponíveis;

- As hipóteses para estimativa da perda aparente são baseadas em estudos de existentes ou em literatura;

- Seu custo é reduzido.

A desvantagem é a baixa precisão nos resultados, associada às hipóteses e estimativas.

A avaliação do volume perdido é relativamente simples sendo a diferença entre o volume disponibilizado para a distribuição e o volume consumido. Contudo, este volume representa a perda total. Para se determinar o valor da perda real e da aparente são necessários cálculos e adoção de hipóteses mais complexas e ainda execução de ensaios de campo. A Figura 4.16, ilustra os componentes do BH estabelecido pela IWA. Este formato foi adotado por inúmeras associações e companhias de saneamento. 


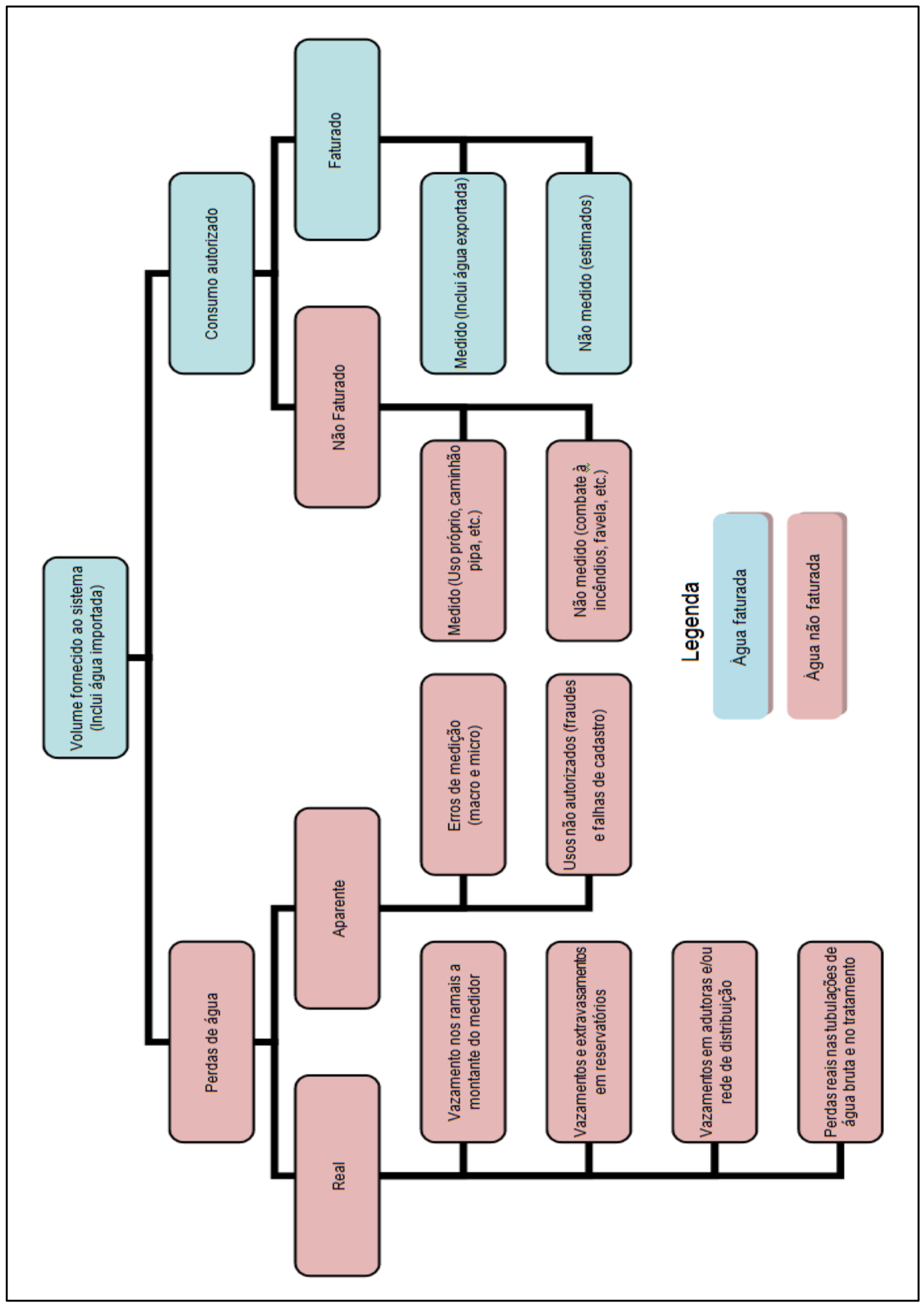

Figura 4.16 - Diagrama do Balanço Hídrico IWA 


\subsection{Métodos de avaliação de volume perdido}

Uma relação que constitui um indicador conceitualmente mais adequado para quantificar as perdas é o volume perdido. Se este for referenciado com os elementos físicos do sistema de abastecimento de água como, extensão de rede ou número de conexões, por exemplo, permitiria uma avaliação da efetiva perda total de água existente. Neste sentido foram desenvolvidas teorias que procuram quantificar a vazão de perdas reais, e depois, por diferença, a quantidade de perda aparente.

\subsubsection{Perda real inerente}

São pequenos vazamentos existentes nas tubulações cuja detecção pelos métodos

acústicos atuais é impossível e a aplicação de outros métodos mais sofisticados não tem justificativa econômica. A metodologia para a determinação da Perda Real Inerente anualizada segue a seguintes etapas (Lambert et al., 1998):

- Escolha do valor de referencia da IWA, equivalente a redes com baixa perda real inerente;

- Determinação do fator de condição da infraestrutura $\left(F_{c i}\right)$;

- Para as outras áreas que possuem similaridade de condições da infraestrutura com a área do ensaio do $F_{c i}$, obtém-se a vazão perdida inerente pela equação 4.8 .

$$
Q_{i}=Q_{v i} \cdot F_{c i} \cdots(4.8)
$$

Onde $Q_{i}$ é vazão média de perda inerente diária, $Q_{v i}$ é a vazão de vazamentos inerentes, em L/h.

Os valores de referência da IWA para $Q_{v i}$, a 50 mca de pressão, são:

- Para redes $=20 \mathrm{~L} /(\mathrm{h} \cdot \mathrm{km})$;

- Para ramais $=1,25 \mathrm{~L} /(\mathrm{h} \cdot \mathrm{ramal})$.

Assim $Q_{v i}$ é calculado pela equação 4.9 , a seguir.

$$
Q_{v i}=2,78 \cdot 10^{-4} \cdot\left(Q_{p r d} \cdot L+Q_{r p m} \cdot N\right) \cdot\left(\frac{\bar{p}}{50}\right)^{N_{1}} \ldots
$$


Onde $Q_{v i}$ em L/s para uma dada pressão média $\bar{p}$ em mca é dado pela equação 4.9 onde $Q_{p r d}$ e $Q_{p r m}$ são os valores de referência da IWA para $Q_{v i}$, a 50 mca de pressão, determinados para rede e ramal respectivamente em $\mathrm{L} / \mathrm{h}^{*} \mathrm{~km}, L$ é a extensão de rede em $\mathrm{km}, \bar{p}$ é a pressão média na rede em $\mathrm{mH}_{2} \mathrm{O}$ e $N$ é o número de ramais.

\subsubsection{Perda real anual inevitável}

Existem dois limites para a redução de perda num sistema de abastecimento: Custo e tecnologia. A perda real anual inevitável contém a perda real inerente e os vazamentos não visíveis, pois em ambos os casos, por razões econômicas, torna-se inviável a detecção destes vazamentos, ou seja, com a configuração atual das redes, nunca haverá perda "zero".

Para o cálculo da perda real anual inevitável utiliza-se a equação 4.10 levando em consideração os valores de referência da IWA feito com base anual, para os vazamentos inerentes, não visíveis e visíveis, em sistemas com boas condições infraestruturais, ou seja, $\mathrm{F}_{\mathrm{ci}} \cong 1$. Simplificando o cálculo se propôs o expoente $\mathrm{N}_{1} \cong 1$. $\mathrm{A}$ Tabela 4.5 apresenta os valores das perdas reais inevitáveis para cada componente da infraestrutura por tipo de vazamento, calculados a partir dos parâmetros da Tabela 4.6, assim obtém-se a equação 4.10 (Lambert et al., 1998):

$$
P_{\text {rai }}=\left(18 \cdot L+0,8 \cdot N+25 \cdot L_{P}\right) \cdot \overline{\bar{p}} \quad \cdots
$$

Onde $P_{r a i}$ é o volume de perda real anual inevitável em $\mathrm{m}^{3} / \mathrm{ano}, L$ a extensão de rede em km, $N$ número de ramais, $L_{P}$ a distância da testada do imóvel até o hidrômetro em $\mathrm{km}, \overline{\bar{p}}$ a pressão média de operação em $\mathrm{mH}_{2} \mathrm{O}$.

Tabela 4.5 - Valores de referência IWA - (Lambert et al., 1998) Adaptada

\begin{tabular}{ccrrr}
\hline \multirow{2}{*}{ Tipo de Vazamento } & $\begin{array}{c}\text { Componente } \\
\text { infraestrutura }\end{array}$ & Frequência & Vazão & Duração \\
\hline \multirow{2}{*}{ Inerente } & Rede & - & $20 \mathrm{~L} /(\mathrm{km} \cdot \mathrm{h})$ & - \\
\cline { 2 - 5 } & Ramal & - & $1,25 \mathrm{~L} /(\mathrm{ramal} \cdot \mathrm{h})$ & - \\
\hline \multirow{2}{*}{ Visível } & Rede & $0,124 /(\mathrm{km} \cdot \mathrm{ano})$ & $12 \mathrm{~m}^{3} / \mathrm{h}$ & 3 dias \\
\cline { 2 - 5 } & Ramal & $2,25 \% 0$ & $1,6 \mathrm{~m}^{3} / \mathrm{h}$ & 8 dias \\
\hline \multirow{2}{*}{ Detectável } & Rede & $0,006 /(\mathrm{km} \cdot \mathrm{ano})$ & $6 \mathrm{~m}^{3} / \mathrm{h}$ & 50 dias \\
\cline { 2 - 5 } & Ramal & $0,75 \% 0$ & $1,6 \mathrm{~m}^{3} / \mathrm{h}$ & 100 dias \\
\hline
\end{tabular}

Observação: Todas as vazões obtidas a $50 \mathrm{mH}_{2} \mathrm{O}$ 
Tabela 4.6 - Perda real anual inevitável - (Lambert et al., 1998) Adaptada

\begin{tabular}{|c|c|c|}
\hline $\begin{array}{c}\text { Tipo de } \\
\text { Vazamento }\end{array}$ & $\begin{array}{l}\text { Componente } \\
\text { infraestrutura }\end{array}$ & Vazão \\
\hline \multirow{2}{*}{ Inerente } & Redes & $9,6 \mathrm{~L} /\left(\mathrm{km} \cdot \mathrm{dia} \cdot \mathrm{mH}_{2} \mathrm{O}\right)$ \\
\hline & Ramais & $0,6 \mathrm{~L} /\left(\mathrm{ramal} \cdot \mathrm{dia} \cdot \mathrm{mH}_{2} \mathrm{O}\right)$ \\
\hline \multirow{2}{*}{ Visível } & Redes & $5,8 \mathrm{~L} /\left(\mathrm{km} \cdot \mathrm{dia} \cdot \mathrm{mH}_{2} \mathrm{O}\right)$ \\
\hline & Ramais & $0,04 \mathrm{~L} /\left(\mathrm{ramal} \cdot \mathrm{dia} \cdot \mathrm{mH}_{2} \mathrm{O}\right)$ \\
\hline \multirow{2}{*}{ Detectável } & Redes & $2,6 \mathrm{~L} /\left(\mathrm{km} \cdot\right.$ dia $\left.\cdot \mathrm{mH}_{2} \mathrm{O}\right)$ \\
\hline & Ramais & $0,16 \mathrm{~L} /\left(\mathrm{ramal} \cdot \mathrm{dia} \cdot \mathrm{mH}_{2} \mathrm{O}\right)$ \\
\hline \multirow{2}{*}{$P_{\text {rai }}$} & Redes & $18 \mathrm{~L} /\left(\mathrm{km} \cdot \mathrm{dia} \cdot \mathrm{mH}_{2} \mathrm{O}\right)$ \\
\hline & Ramais & $0,8 \mathrm{~L} /\left(\mathrm{ramal} \cdot \mathrm{dia} \cdot \mathrm{mH}_{2} \mathrm{O}\right)$ \\
\hline
\end{tabular}

A pressão média de operação é obtida multiplicando o valor da pressão média anual pela porcentagem de tempo pressurizado, ou seja, o tempo no qual o sistema esteve em operação.

$$
\overline{\bar{p}}=\bar{p} \cdot T_{p} \cdot 365 \quad \cdots(4.11)
$$

Onde $\overline{\bar{p}}$ é a pressão média de operação anual, e $\bar{p}$ é a pressão média diária ambas em $\mathrm{mH}_{2} \mathrm{O}, T_{p}$ é o fator de tempo pressurizado diário, varia de 0 a 1 .

Como no Brasil os hidrômetros são instalados junto à testada dos imóveis, considera-se a variável $L_{p}=0$, e para se estimar a vazão de perdas inevitáveis $\left(Q_{r i}\right)$ em litros por segundo a equação 4.10 fica então:

$$
Q_{r i}=1,16 \cdot 10^{-5} \cdot(18 \cdot L+0,80 \cdot N) \cdot \overline{\bar{p}}
$$

\subsubsection{Controle ativo de vazamentos}

O Controle Ativo de Vazamentos representa a ação sistemática desenvolvida no sentido de localizar os vazamentos não visíveis, através de métodos acústicos de pesquisa. $O$ principio básico de detecção acústica é ouvir o ruído do vazamento. São empregados para isso os equipamentos a seguir:

- Haste de Escuta;

- Geofone;

- Correlacionador de ruídos;

- Equipamentos auxiliares: que são complementares as atividades de detecção 
dos vazamentos tais como: barra de perfuração, manômetros, trena ou roda de medição, detector de massa metálica e detectores de tubulação.

Uma área é selecionada para detecção de vazamentos quando o Fator de Pesquisa, que é a relação entre a vazão mínima noturna e a vazão média, equação 4.13 , for maior do que $30 \%$.

$$
F_{p}=\frac{Q_{\min }}{\bar{Q}} \cdot 100 \cdots
$$

Onde $F_{p}$ é o fator de pesquisa, $Q_{\min }$ é a vazão mínima e $\bar{Q}$ é a vazão Média em L/s.

\subsection{AVALIAÇÃO DOS DADOS DE UMA ÁREA}

\subsubsection{MAPAS TEMÁTICOS}

Os mapas temáticos são elaborados, objetivando a melhor visualização e comunicação, representando os fenômenos de qualquer natureza, geograficamente distribuídos sobre a superfície da área em estudo. Os fenômenos podem ser tanto de natureza física como, por exemplo, a média anual de temperatura ou precipitação sobre uma área, de natureza abstrata, humana ou de outra característica qualquer, tal como a taxa de desenvolvimento, indicadores sociais, perfil de uma população segundo variáveis tais como sexo, cor e idade, dentre outros (Archela et al., 2008).

Cada mapa possui um objetivo específico, de acordo com os propósitos de sua elaboração, por isso, existem diferentes tipos de mapas. O mapa temático deve cumprir sua função, ou seja, dizer o quê, onde e, como ocorre determinado fenômeno geográfico, utilizando símbolos gráficos (signos) especialmente planejados para facilitar a compreensão de diferenças, semelhanças e possibilitar a visualização de correlações pelo usuário.

Na construção de um mapa temático, é estabelecida convenções de símbolos e linhas que representarão as variáveis do tema escolhido. A variável visual "tamanho" corresponde à variação do tamanho do ponto, de acordo com a informação quantitativa; a variável visual "valor" pressupõe a variação da tonalidade, ou em uma sequencia 
monocromática, a granulação, que corresponde a variação da repartição do preto no branco; a variável visual cor significa a variação das cores do arco-íris, sem variação de tonalidade, tendo as cores a mesma intensidade. Por exemplo: usar azul, vermelho e verde é usar a variável visual "cor". O uso do azul-claro, azul médio e azul escuro corresponde à variável "valor". A variável visual orientação corresponde às variações de posição entre o vertical, o oblíquo e o horizontal e, por fim, a forma, agrupa todas as variações geométricas ou não.

As variáveis visuais podem ser percebidas de modo diferente, conforme um conjunto de propriedades que podem ser: seletivas, associativas, dissociativas, ordenadas e quantitativas. São chamadas variáveis visuais seletivas, quando permitem separar visualmente as imagens e possibilitam a formação de grupos de imagens. A cor, a orientação, o valor, a granulação e o tamanho possuem essa propriedade. São associativas quando permitem agrupar espontaneamente, diversas imagens num mesmo conjunto; forma, orientação, cor e granulação possuem a propriedade de serem vistos como imagens semelhantes. Ao contrário, quando as imagens se separam espontaneamente, a variável é dissociativa; este é o caso do valor e do tamanho.

São chamadas variáveis ordenadas quando permitem uma classificação visual segundo uma variação progressiva. São ordenados o tamanho, valor e a granulação. Finalmente, são quantitativas quando se relacionam facilmente com um valor numérico. $A$ única variável visual quantitativa é o tamanho. Isto porque somente as figuras geométricas possuem uma área e um volume que pode ser visualizado com facilidade, permitindo relacionar imediatamente com uma unidade de medida e, portanto, com uma quantidade que é visualmente proporcional.

A combinação dessas variáveis, segundo os métodos padronizados, dará origem aos diferentes tipos de mapas temáticos, entre os quais os mapas de símbolos pontuais, mapas de isolinhas e mapas de fluxos; mapas zonais, ou coropléticos, mapas de símbolos proporcionais ou círculos proporcionais, mapas de pontos ou de nuvem de pontos.

Os métodos de mapeamento para os fenômenos qualitativos utilizam as variáveis visuais seletivas forma, orientação e cor, nos três modos de implantação: pontual, linear e zonal. Os fenômenos ordenados são representados em classes visualmente 
ordenadas e utilizam a variável valor na implantação zonal. Os mapas mais significativos para representar fenômenos ordenados são os mapas coropléticos. Estes são elaborados com dados quantitativos e apresentam sua legenda ordenada em classes conforme a regra própria de utilização da variável visual valor por meio de tonalidades de cores, ou ainda, por uma sequencia ordenada de cores que aumentam de intensidade conforme a sequencia de valores apresentados nas classes estabelecidas.

Os tipos de representação cartográfica estão relacionados ao objetivo da construção e a escala. Os mais comuns são o mapa e a carta. O mapa resulta de um levantamento preciso e exato, da superfície terrestre, e é apresentado em escala pequena (escalas inferiores a 1:1.000.000). A carta é uma representação de parte da superfície terrestre em escala média ou grande, dos aspectos artificiais e naturais de uma área, subdividida em folhas delimitadas por linhas convencionais - paralelos e meridianos - com a finalidade de possibilitar a avaliação de detalhes, com grau de precisão compatível com a escala.

Quanto ao conteúdo os mapas podem ser classificados em analítico ou de síntese. O mapa analítico mostra a distribuição de um ou mais elementos de um fenômeno, utilizando dados primários, com as modificações necessárias para a sua visualização. 0 mapa de síntese é mais complexo e exige profundo conhecimento técnico dos assuntos a serem mapeados. Representam o mapeamento da integração de fenômenos, feições, fatos ou acontecimentos que se interligam na distribuição espacial. Esses mapas permitem que se estabeleçam estudos conclusivos sobre a integração e interligação dos fenômenos.

Os mapas de síntese são construídos para mostrar ao leitor as relações existentes entre vários dados, tal como sua eventual aptidão para determinar conjuntamente outros fenômenos ou outras combinações. Os mapas de síntese devem ser objetivos e legíveis e comportar apenas dados essenciais (Archela et al., 2008).

\subsection{GRÁFICOS DE PARETO}

O diagrama de Pareto é uma forma especial do gráfico de barras verticais, que dispõe 
os itens analisados desde o mais frequente até o menos frequente.

Tem como objetivo estabelecer prioridades na tomada de decisão, a partir de uma abordagem estatística.

Principio de Pareto

Gráfico de Pareto tem origem em 1897, quando o economista italiano Vilfredo Pareto, analisando a distribuição da renda entre os cidadãos, concluiu que a maior parte da riqueza pertence a poucas pessoas. Em 1907, o economista americano M. C. Lorenz apresentou teoria semelhante, agora em forma de diagrama. Foi, porém, o Dr. J. M. Juran quem aplicou esses conceitos em Controle de Qualidade, aplicando o método do diagrama de Lorenz, denominando este método de Análise de Pareto (Bastos Filho, 1998). Essa relação que ficou conhecida como Principio de Pareto, ou a relação 20-80. Segundo esse princípio $20 \%$ das causas são responsáveis por $80 \%$ dos efeitos. Esse princípio demonstra que alguns poucos fatores são responsáveis pelas maiorias dos efeitos observados (Silva, 2002). A Figura 4.17, apresenta um exemplo de gráfico de Pareto.

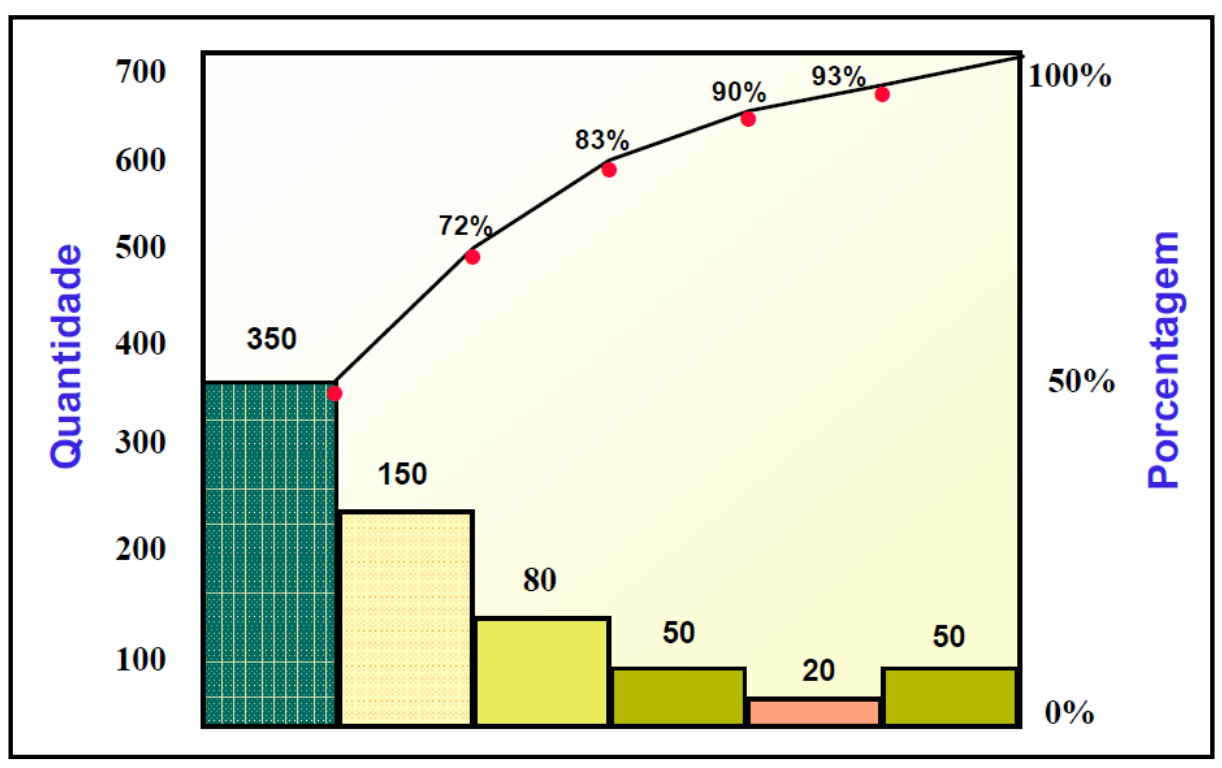

Figura 4.17 - Exemplo de gráfico de Pareto(Silva, 2002)

O gráfico de Pareto é usado sempre que for preciso classificar a importância relativa entre problemas ou condições, no sentido de:

- Selecionar problemas que serão projetos de melhoria de qualidade; 
- Identificar problemas, que é o primeiro passo do MASP;

- Identificar as causas fundamentais de um problema;

- Comparar o antes e o depois de uma ação corretiva.

Etapas para a construção do Gráfico de Pareto

- Estratificação;

- Levantamento de dados;

- Diagrama de Pareto propriamente dito. 


\section{MATERIAIS E MÉTODOS}

Neste capítulo serão apresentados os seguintes tópicos:

- Materiais utilizados em cada etapa da pesquisa;

- Procedimentos para a utilização do modelo de simulação hidráulica;

- Método para a calibração do modelo com dados de campo;

- Método para a verificação dos resultados obtidos com a simulação.

\subsection{Introdução}

A simulação hidráulica, por meio de modelagem matemática, exige o conhecimento do aplicativo que executará a simulação, e da operação real do sistema de abastecimento a ser modelado. Desta forma, precisa ser feito um estudo detalhado do aplicativo e de todas as funções e dados de entrada, necessários para simulação e calibração do modelo. O termo "calibração" na modelagem hidráulica refere-se à obtenção de parâmetros operacionais reais coletados em campo do sistema modelado, a fim de se ajustar o modelo para que este forneça resultados que coincidam com a realidade. Neste trabalho o termo "calibração" é utilizado no sentido de se ajustar o modelo de forma que este forneça resultados que estejam dentro de uma faixa de valores (máximos e mínimos) que representam o comportamento médio esperado do sistema real modelado.

As informações, tanto técnicas quanto comerciais, disponíveis nos respectivos arquivos e banco de dados, devem ser verificadas "in loco", para garantir confiabilidade na simulação feita por meio do modelo.

Os ensaios de campo devem ser conduzidos de modo criterioso, anotando-se todas as ocorrências que podem intervir nos resultados e no diagnóstico das condições operacionais da malha de distribuição.

A medida da eficácia da utilização dos resultados da simulação nos cálculos de perdas 
é obtida por meio da comparação entre o diagnostico obido a partir dos valores simulados e o constado "in loco".

As equações empíricas Lambert et al.(1998) simulam as perdas em uma base de dados anuais. Desta forma, observando a superposição dos valores dos indicadores de perdas calculados, o número de vazamentos detectados "in loco" e os resultados simulados por trecho, obtém-se a medida da eficácia procurada.

As etapas necessárias para a aplicação deste método em um modelo de sistema de abastecimento de água, para diagnóstico de perdas, são:

- Construção da topologia da rede no aplicativo de simulação hidráulica.

- Coleta de dados técnicos e comerciais;

- Coleta de dados de campo para a calibração;

- Cálculo das incertezas das medições;

- Ensaios e medições em campo, para obter dados para a calibração do modelo, o valor da rugosidade absoluta, e cálculo do $\mathrm{FCl}$ e do $\mathrm{N}_{1}$;

- Planejamento;

- Aviso aos clientes;

- Programação das equipes;

- Execução;

- Cálculos baseados nos dados levantados.

- Medições de pressão e vazão em campo.

- Definição dos pontos;

- Instalação de registradores eletrônicos;

- Coleta das leituras;

- Avaliação da incerteza das medidas.

- Avaliação dos resultados simulados e cálculo dos indicadores de perdas.

- Simulação em regime permanente, hora a hora, no modelo matemático;

- Cálculos, utilizando as equações empíricas de Lambert et al.,(1998);

- Análise dos resultados;

- Elaboração de mapas temáticos;

- Perdas reais;

- Perdas aparentes;

- Sobreposição de perdas reais e vazamentos detectados; 
- Análise da eficiência da previsão dada pelos resultados simulados.

- Comparativo entre as pressões simuladas e as pressões medidas;

- Comparativo entre o a perda real simulada e os vazamentos detectados;

- Comparativo entre o $\mathrm{FCl}$ simulado e o obtido pelo ensaio de campo.

\subsection{Materiais}

Os materiais necessários para execução de cada etapa em cada fase do trabalho devem estar em bom estado e os equipamentos de medidas calibrados. Seu manejo e instalação devem ser de domínio dos técnicos que executarão as etapas, garantindo assim a confiabilidade nos dados obtidos.

\subsubsection{Microcomputadores e aplicativos utilizados}

No desenvolvimento dos trabalhos, foi empregado um microcomputador e aplicativos descritos a seguir:

- Microcomputador com sistema operacional Microsoft Windows XP Professional® versão, 5.1.2600 Service Pack 3, compilação 2600, com processador x86 Family 6 Model 15 Stepping 11 Genuine Intel $2400 \mathrm{MHz}$. Memória física total 2.048,00 MB, Memória virtual total 2,00 GB, espaço do arquivo de paginação 3,85 GB.

- Notebook Assus com sistema operacional Microsoft Windows XP Professional® versão, 5.1.2600 Service Pack 3.

- WaterGEMS® versão 8.11.00.30 da Bentley Systems.

- ArcView® Gis versão 3.2 da Environmental Systems Research Institute Inc.

- Aplicativo Microsoft Office® Excel e Word, versão 12.0, compilação 6341.5001, idioma português (Brasil);

5.2.2 Construção do modelo no aplicativo de simulação hidráulica

Na construção do modelo no aplicativo escolhido são necessários os seguintes materiais, equipamentos e aplicativos: 
- Plantas cadastrais da rede de distribuição de água;

- Plantas cadastrais das ligações de água;

- Banco de dados comercial contendo:

- Consumos,

- Tipos e quantidade de: ligação, cliente e economia.

\subsubsection{Ensaios e medições de campo}

Para a calibração do modelo, é necessária a execução de medições e de dois ensaios de campo. Um para a obtenção do valor da rugosidade absoluta, e outro para o fator de condição de infraestrutura e $N_{1}$. A rugosidade absoluta entrará como parâmetro físico da malha de distribuição, e o $F C I$ e $N_{1}$, nos caçulos de perdas. Os materiais, equipamentos e aplicativos utilizados são:

- Plano de trabalho (formulário);

- Aviso aos clientes;

- Programação das equipes;

- Na avaliação da incerteza das medidas:

- Microcomputador e aplicativos item 5.2.1.

- Mapa da área com a locação dos pontos de medição e dos registros limítrofes;

- Registradores de pressão;

- Registradores de vazão;

- Chaves de manobra;

- Hidrômetros pulsados;

- Cabos para comunicação entre hidrômetro e o registrador de vazão;

- Conexões e mangueira para instalação do registrador de pressão no ramal predial.

- Ferramentas manuais para conexão dos equipamentos;

- Microcomputador portátil para coleta dos dados dos registradores;

- Cabo para comunicação entre o microcomputador e os registradores;

- Lista das ligações para o fechamento dos registros dos cavaletes e verificação das leituras inicial e final;

- Tubo PEAD $\varnothing 32 \mathrm{~mm}$;

- Adaptadores para PEAD rosca $\varnothing 32 \mathrm{~mm}$;

- Trena de $30 \mathrm{~m}$; 
- Duas balizas;

- Nível;

- Mira;

- Cronômetro;

- Rádios comunicadores;

- Ferramentas manuais para conexão dos equipamentos;

- Microcomputador portátil para coleta dos dados dos registradores;

- Lacres para hidrômetro;

5.2.4 Tratamento de dados, simulação e análise.

Para a simulação das condições operacionais do DMC no aplicativo, elaboração dos mapas temáticos, avaliação da eficiência, comparação entre os dados medidos em campo e os simulados, utilizou-se:

- Microcomputador e aplicativos descritos no item 5.2.1.

\subsection{Método}

O método proposto a seguir, orienta a utilização de modelos de simulação hidráulicas na obtenção de informações para diagnóstico de perdas de água. É abordado o carregamento das demandas, a calibração com a ferramenta "Darwin Calibrator" disponível no aplicativo de simulação hidráulica WaterGEMS®, e a utilização dos resultados modelados, como entrada para os cálculos de perdas de água e a criação de mapas temáticos, elaborados com o auxílio do aplicativo ArcView® Gis.

Para detalhes sobre a construção de modelos no WaterGEMS $\Theta$, e da calibração com a ferramenta "Darwin Calibrator", recomenda-se a leitura do manual do usuário, que se encontra no $C D$ anexo a este trabalho.

\subsubsection{Carregamento das demandas}

Após a construção da topologia da rede no aplicativo de simulação, é necessário o 
carregamento e a definição do padrão horário de variação das demandas nas junções. Isto auxiliará a na primeira estimativa de correção das demandas feita pelo algoritmo genético. No estudo de caso, apresentado neste trabalho, foi adotado como padrão de variação horária de consumo, o perfil residencial médio, obtido por Barreto (2008) apresentado na Figura 5.1, mas o método de carregamento apresentado se aplica a qualquer perfil de consumo.

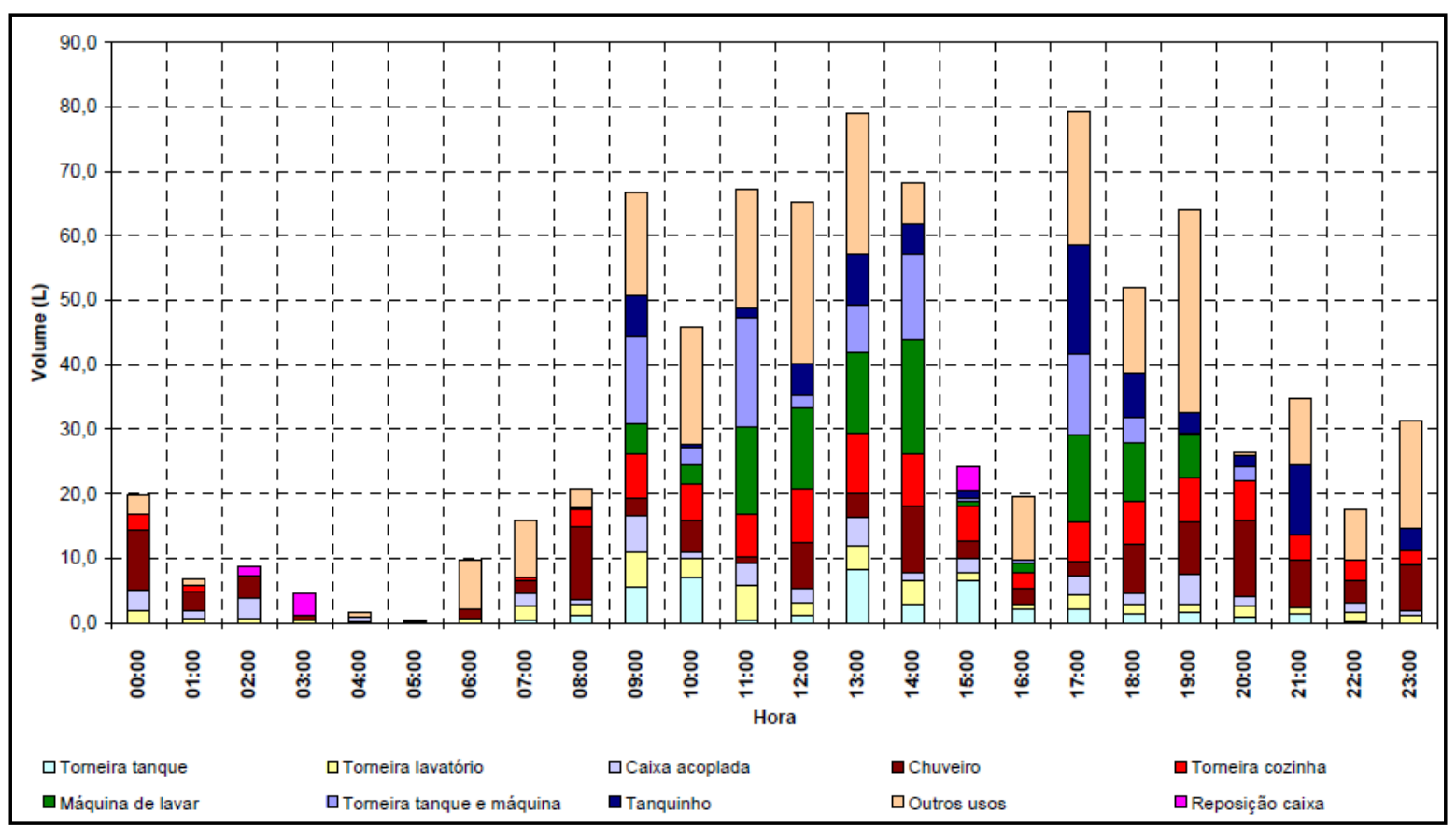

Figura 5.1 - Consumo horário desagregado por pontos de utilização fonte: (Barreto, 2008)

O perfil definido por Barreto refere-se a uma única ligação domiciliar, mas considerando:

1. Que a maioria dos imóveis são residenciais, e com características urbanas semelhantes;

2. Existência de amortecimento na vazão individual de cada imóvel, causado pela caixa d'água, faz com que os consumos horários médios do DMC apresentem pouca diferença com o perfil individual, permitindo assim, esta simplificação.

3. Estudo realizado por Galvão (2007) que demonstrou que o efeito da caixa d'água na rede de distribuição reduz o impacto das diferenças de consumo e pressões.

Obtém-se o fator horário das demandas efetuando a razão entre a vazão horária e a vazão média do perfil, ou seja:

$$
f_{d}=\frac{Q_{h_{\text {Barreto }}}}{\bar{Q}_{\text {Barreto }}}
$$


Onde $f_{d}$ é o fator horário de demanda, $Q_{h}$ a vazão horária média e $\bar{Q}$ a vazão média estas últimas por Barreto (2008). A Tabela 5.1 apresenta os valores calculados e a Figura 5.2 apresenta o gráfico do fator horário de demanda obtido.

As demandas são obtidas das leituras mensais, efetuadas para a emissão de contas, e serão à base de cálculo das vazões fornecidas. Logo, devem referir-se ao mesmo mês de realização dos ensaios de campo, pois o volume lido nos hidrômetros dos clientes está relacionado as mesmas condições ambientais e operacionais que os dados coletados pelos registradores eletrônicos, permitindo assim uma avaliação correta das vazões horárias simuladas em função das pressões medidas.

As vazões médias das demandas das junções são obtidas pela transformação das demandas mensais expressas em $\mathrm{m}^{3}$ para $\mathrm{L} / \mathrm{s}$, dividindo o consumo mensal pela quantidade de segundos do período considerado, como apresentado a seguir.

$$
\bar{Q}_{J}=\frac{C_{m} \cdot 1000}{(30 \cdot 24 \cdot 60 \cdot 60)}=\frac{C_{m}}{\left(2,59 \cdot 10^{3}\right)}=3,86 \cdot 10^{-4} \cdot C_{m}
$$

Tabela 5.1 - Valores do fator horário obtido de (Barreto, 2008)

\begin{tabular}{lll}
\hline Hora & $Q_{h}(\mathrm{~L})$ & $f_{d}$ \\
\hline $0: 00$ & 20,03 & 0,5723 \\
\hline $1: 00$ & 6,63 & 0,1893 \\
\hline $2: 00$ & 8,68 & 0,2481 \\
\hline $3: 00$ & 4,51 & 0,1288 \\
\hline $4: 00$ & 1,54 & 0,0440 \\
\hline $5: 00$ & 0,42 & 0,0119 \\
\hline $6: 00$ & 9,76 & 0,2789 \\
\hline $7: 00$ & 16,20 & 0,4628 \\
\hline $8: 00$ & 21,21 & 0,6061 \\
\hline $9: 00$ & 67,69 & 1,9340 \\
\hline $10: 00$ & 46,29 & 1,3225 \\
\hline $11: 00$ & 68,27 & 1,9505 \\
\hline $12: 00$ & 66,26 & 1,8932 \\
\hline $13: 00$ & 80,06 & 2,2876 \\
\hline $14: 00$ & 68,93 & 1,9694 \\
\hline $15: 00$ & 24,48 & 0,6994 \\
\hline $16: 00$ & 19,83 & 0,5667 \\
\hline $17: 00$ & 80,44 & 2,2983 \\
\hline $18: 00$ & 52,65 & 1,5042 \\
\hline $19: 00$ & 64,65 & 1,8471 \\
\hline $20: 00$ & 26,96 & 0,7703 \\
\hline $21: 00$ & 35,19 & 1,0053 \\
\hline $22: 00$ & 17,65 & 0,5043 \\
\hline $23: 00$ & 31,68 & 0,9051 \\
\hline $\bar{Q} \Rightarrow$ & 35,00 & - \\
\hline & &
\end{tabular}




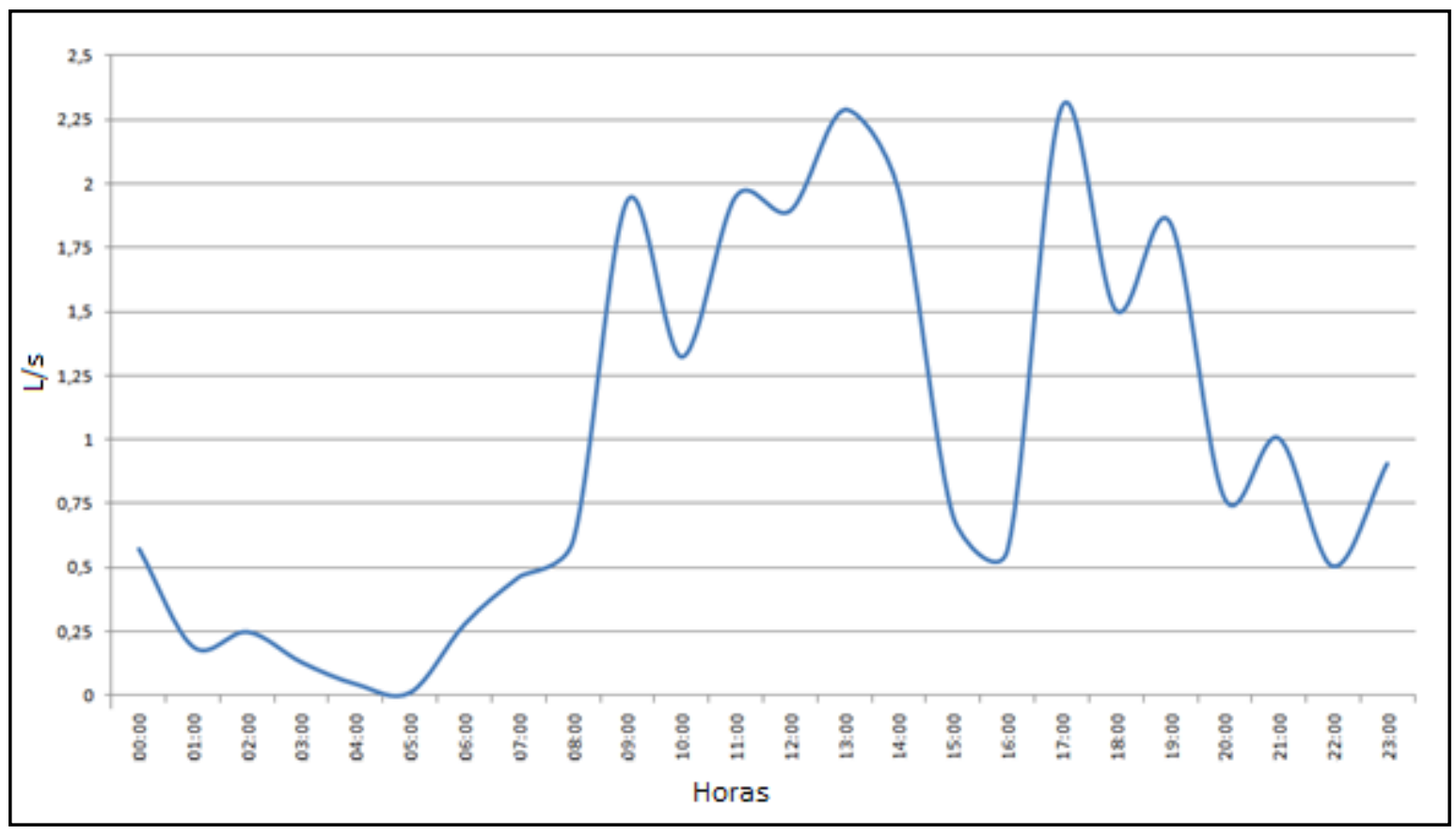

Figura 5.2 - Gráfico de fator horário obtido do estudo de (Barreto, 2008).

Onde $\bar{Q}_{J}$ é a vazão média em L/s numa determinada junção, $C_{m}$ representa a somatória dos consumos mensais lidos nos hidrômetros de cada ligação agrupada na junção em questão.

Aplicando o fator horário à vazão média da junção, obtém-se a variação horária da demanda, como segue:

$$
Q_{h}=f_{d} \cdot \bar{Q}_{J}
$$

Onde $Q_{h}$ é a demanda horária numa determinada junção. As demandas são agrupadas nas junções em função de sua proximidade a ela, ou quando representa um grande consumidor pode ser considerada como uma junção, Figura 5.3. Esse agrupamento de demandas servirá de parâmetro inicial de cada junção que será utilizada pelo algoritmo genético em sua primeira estimativa das demandas reais.

Caso sejam conhecidos diversos padrões de consumo, estes devem ser aplicados nas junções às quais eles sejam representativos, e com isso, a simulação logo de início se aproximará das condições do sistema de abastecimento real, otimizando a utilização do algoritmo genético. 


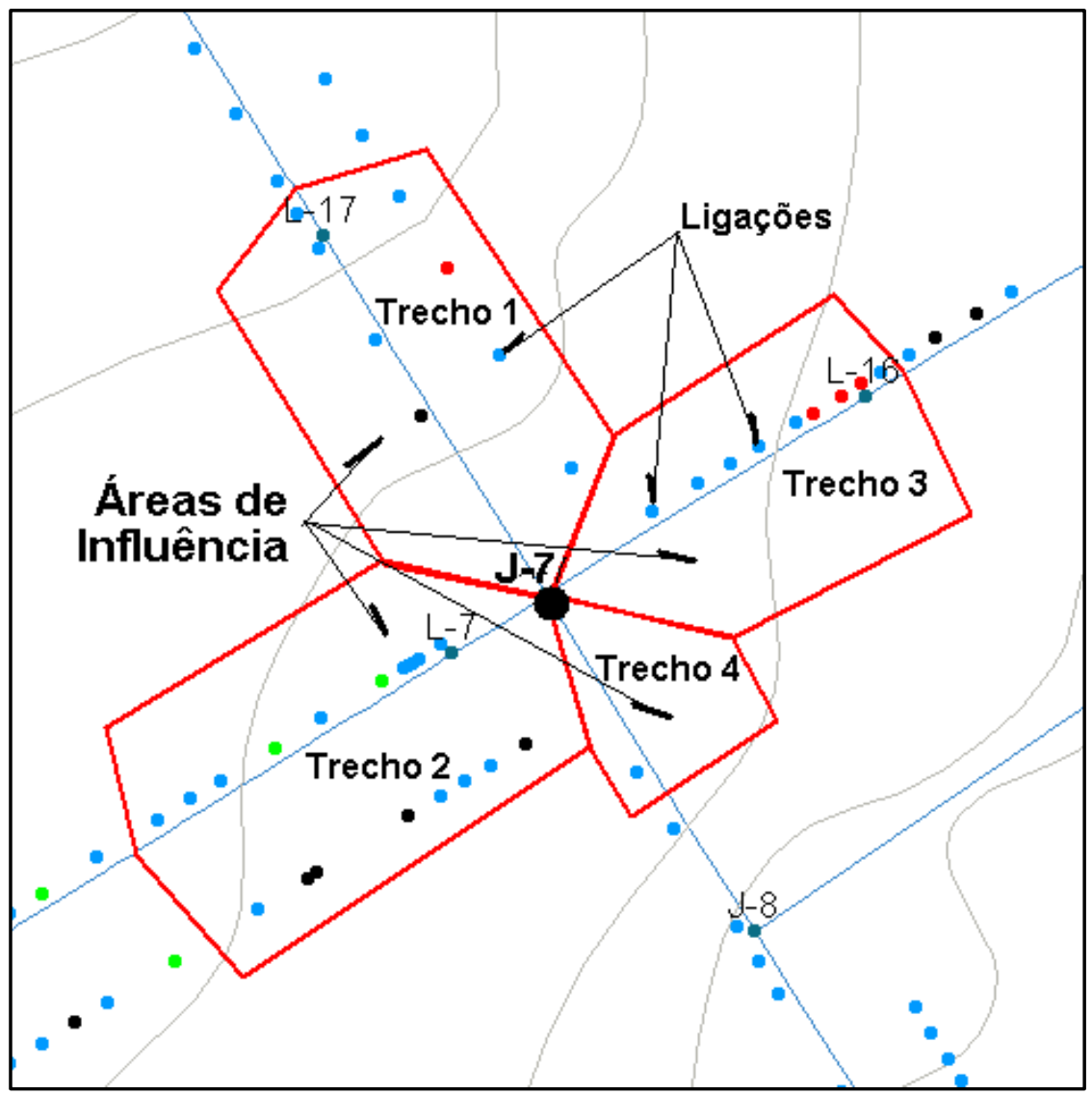

Figura 5.3 - Agrupamento de demandas nas junções por área de influência

\subsubsection{Ensaios e medições em campo}

A calibração é executada em duas etapas: ensaio de campo e simulação dos resultados por meio de algoritmo genéticos. O ensaio de campo é realizado para a obtenção de dois parâmetros físicos utilizados na modelagem: a rugosidade absoluta $\varepsilon$, utilizada na equação universal da perda de carga, fator de condição da infraestrutura (FCI) e o expoente N1, utilizados no cálculo das perdas inerentes.

Antes da execução do ensaio é necessário um preparo da área para assegurar que os dados obtidos são relativos às condições reais de abastecimento e operação do sistema.

São realizadas as seguintes atividades:

1) Verificação das condições de operação dos registros, limítrofes e interiores, reparos de falhas, e a garantia da estanqueidade da área (Figura 5.4); 


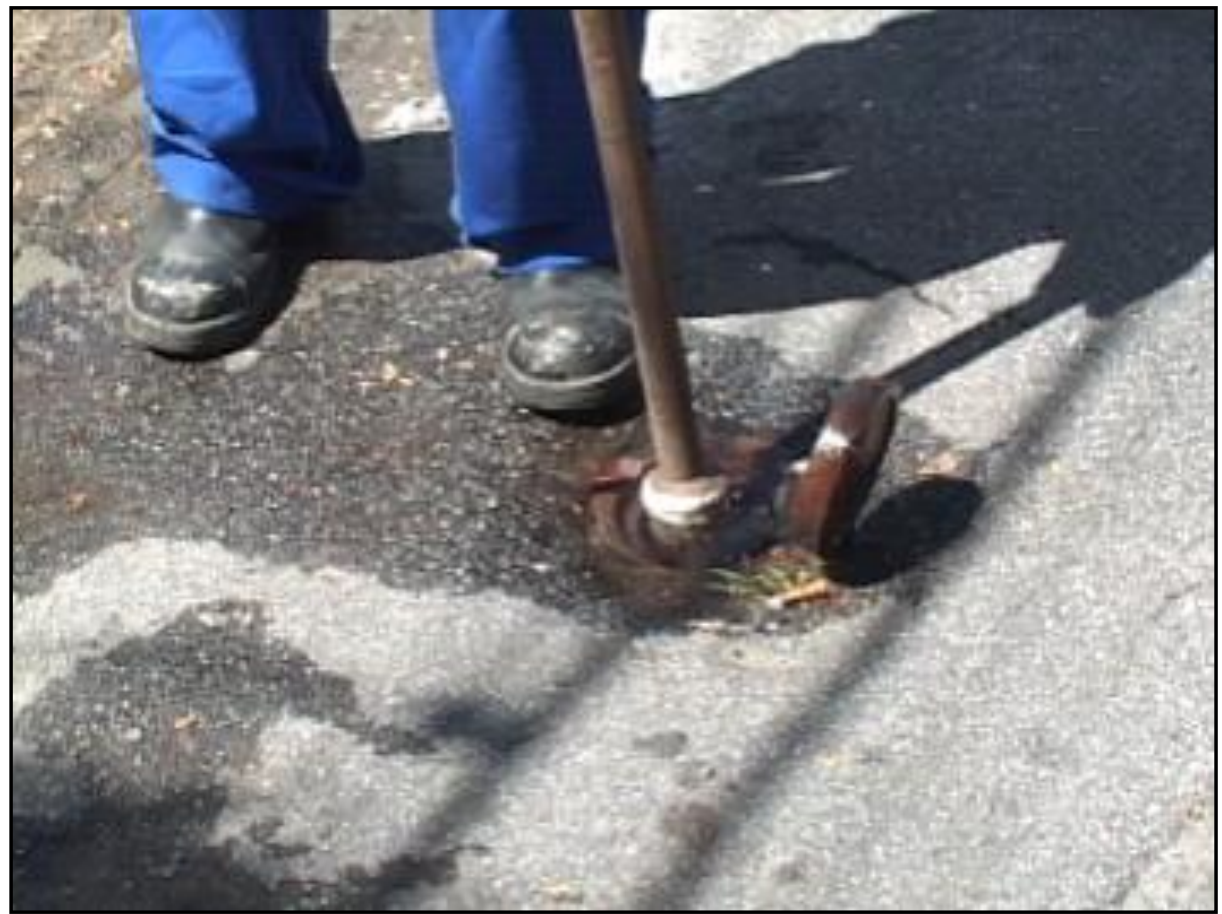

Figura 5.4 - Verificação dos registros

2) Detecção de vazamentos, efetuadas em três varreduras consecutivas (Figura 5.5), após cada reparo dos vazamentos detectados anteriormente (Figura 5.6);

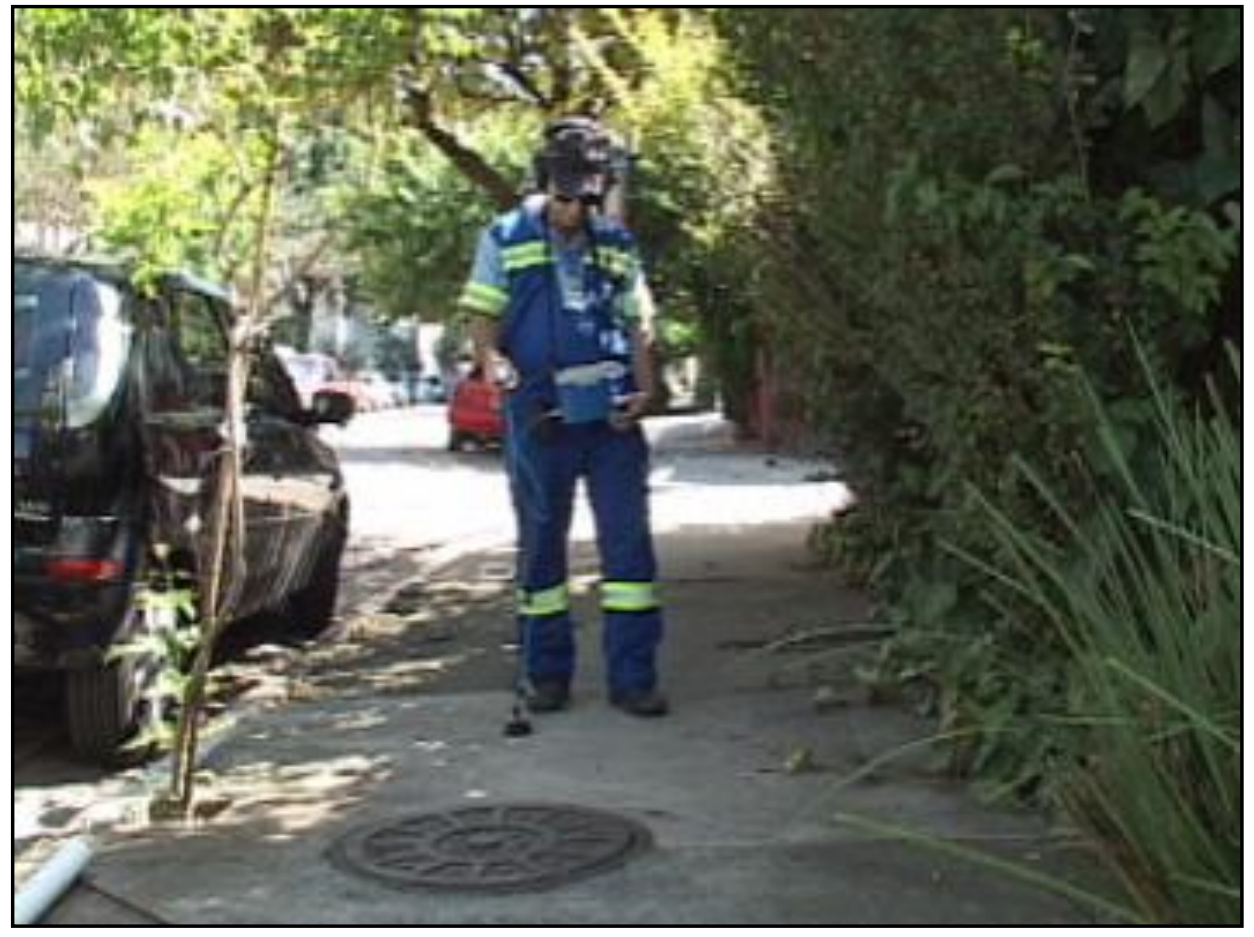

Figura 5.5 - Detecção de vazamentos (geofone eletrônico) 


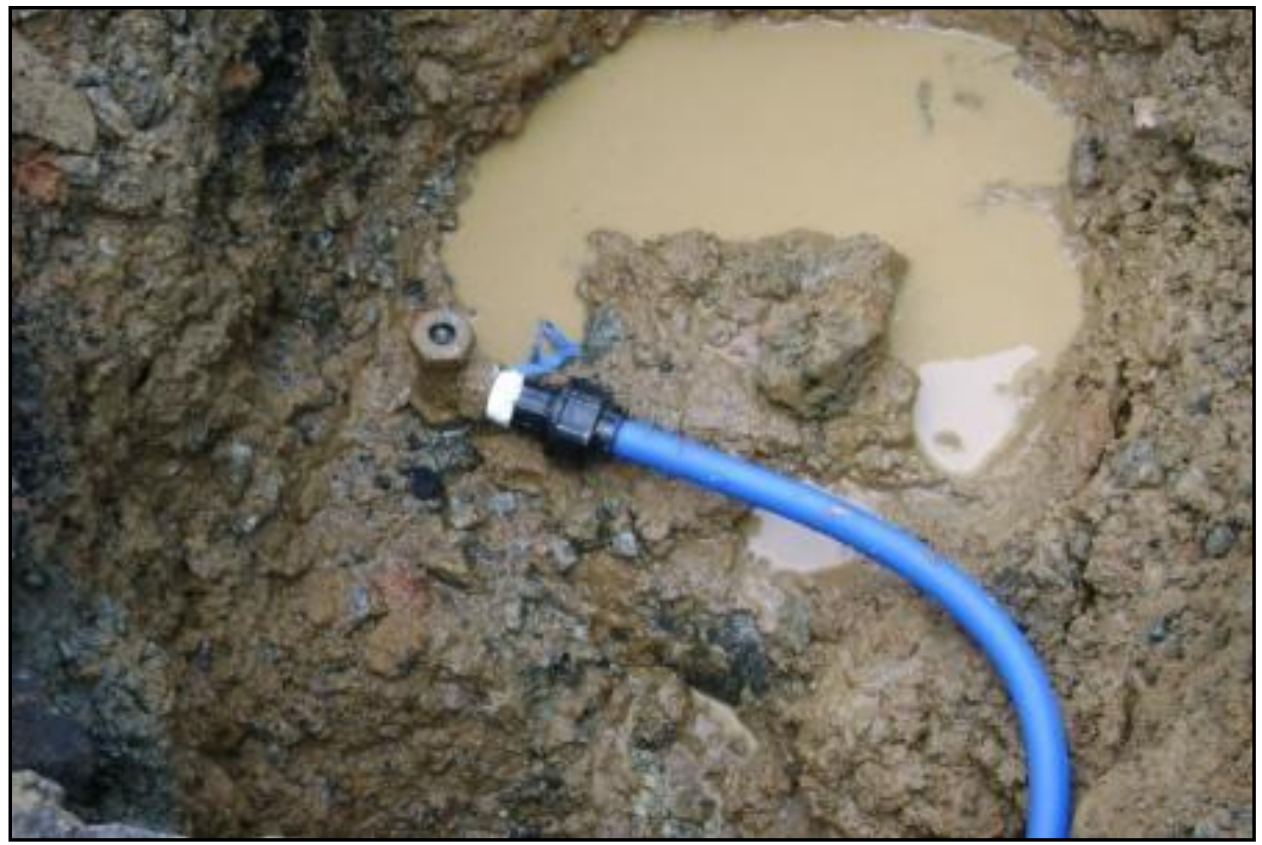

Figura 5.6 - Conserto de vazamento em ferrule

3) Nivelamento topográfico para a obtenção das cotas de terreno e da tubulação no ponto de montante e jusante do trecho a ser estudado, Figura 5.7.

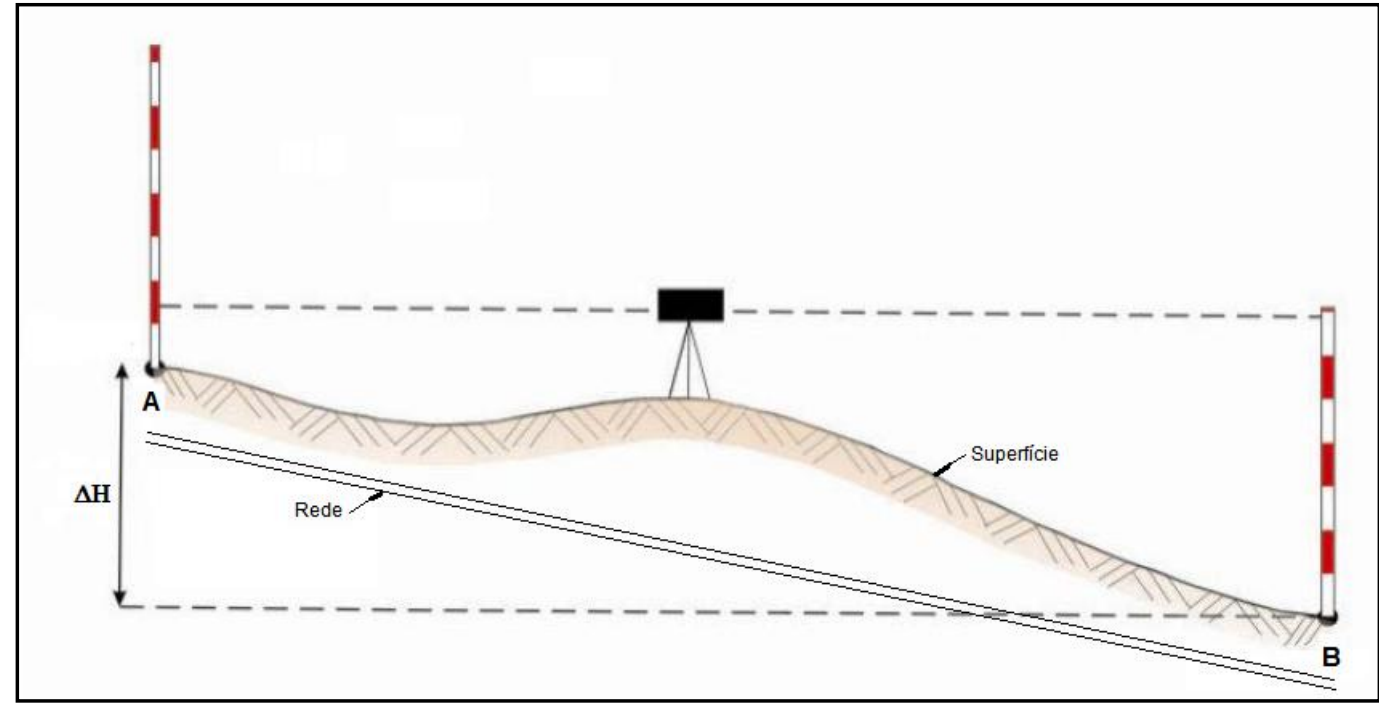

Figura 5.7 - Esquema de nivelamento geométrico - Fonte: (Jelinek, 2010)

Escolhido o trecho para a execução do teste, deve ser construído um poço de visita (PV), que permita a instalação de dois ferrules, um a montante e outro a jusante de um dos registros que fecham o trecho, ver Figura 5.8. 


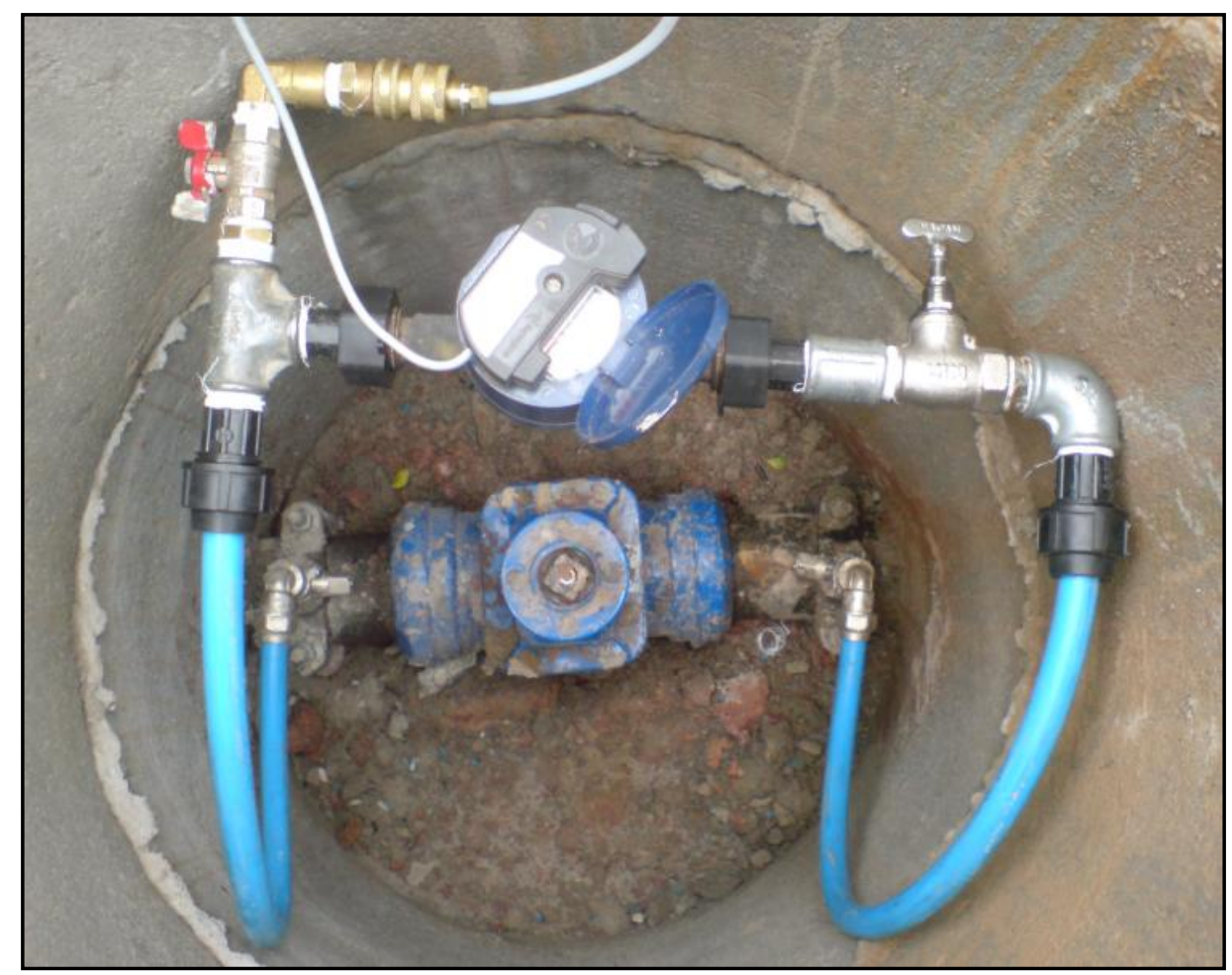

Figura 5.8 - Detalhe do interior do PV

É feita a instalação de um hidrômetro pulsado entre eles, o qual fornecerá as medidas de vazão de entrada durante todo o teste. Este PV deve estar pronto até a data de execução do ensaio.

A realização do ensaio inicia com a montagem da sinalização de segurança e de trânsito, a colocação dos EPIs e o posicionamento das equipes. Uma equipe é responsável pela montagem do hidrômetro e dos registradores de pressão e vazão no PV e a operação de abertura e fechamento do registro durante todo o ensaio, a Figura 5.9 ilustra a área ao redor do PV no qual as leituras são coletadas e o controle das vazões é feito. Outra equipe executa o fechamento e a lacração dos registros das ligações dos clientes para evitar consumos durante a realização do ensaio, ver Figura 5.10 .

Também é feito o levantamento dos clientes conectados à rede, para o encaminhamento do comunicado informando sobre o ensaio que será executado. Este comunicado deve conter: o objetivo do ensaio, a data de realização, horário de inicio e de término, e também informar que haverá falta de água na residência durante o período de execução do ensaio, pois os registros dos cavaletes serão lacrados para evitar que consumos interfiram nas medições. 


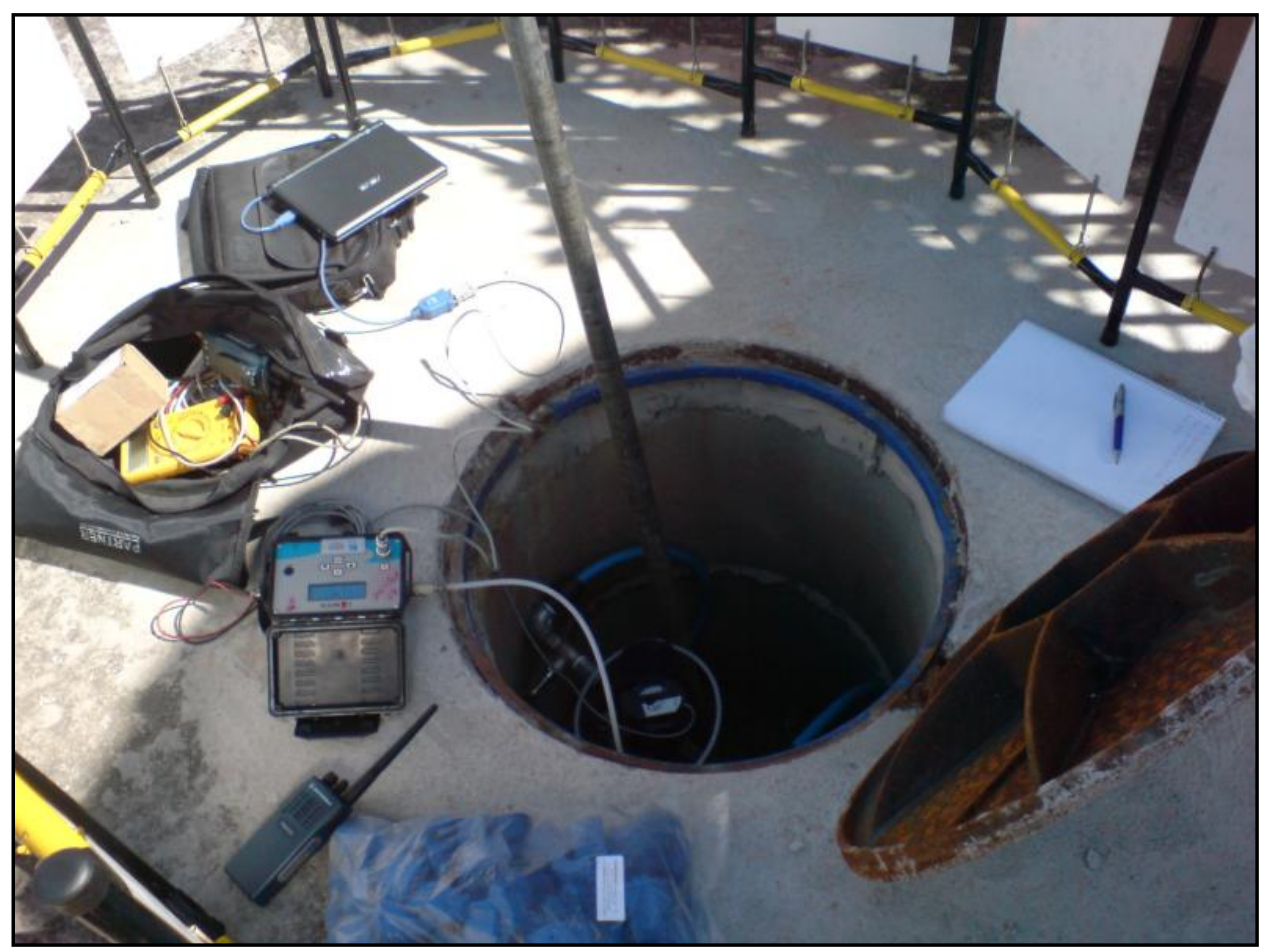

Figura 5.9 - Equipamentos instalados no PV

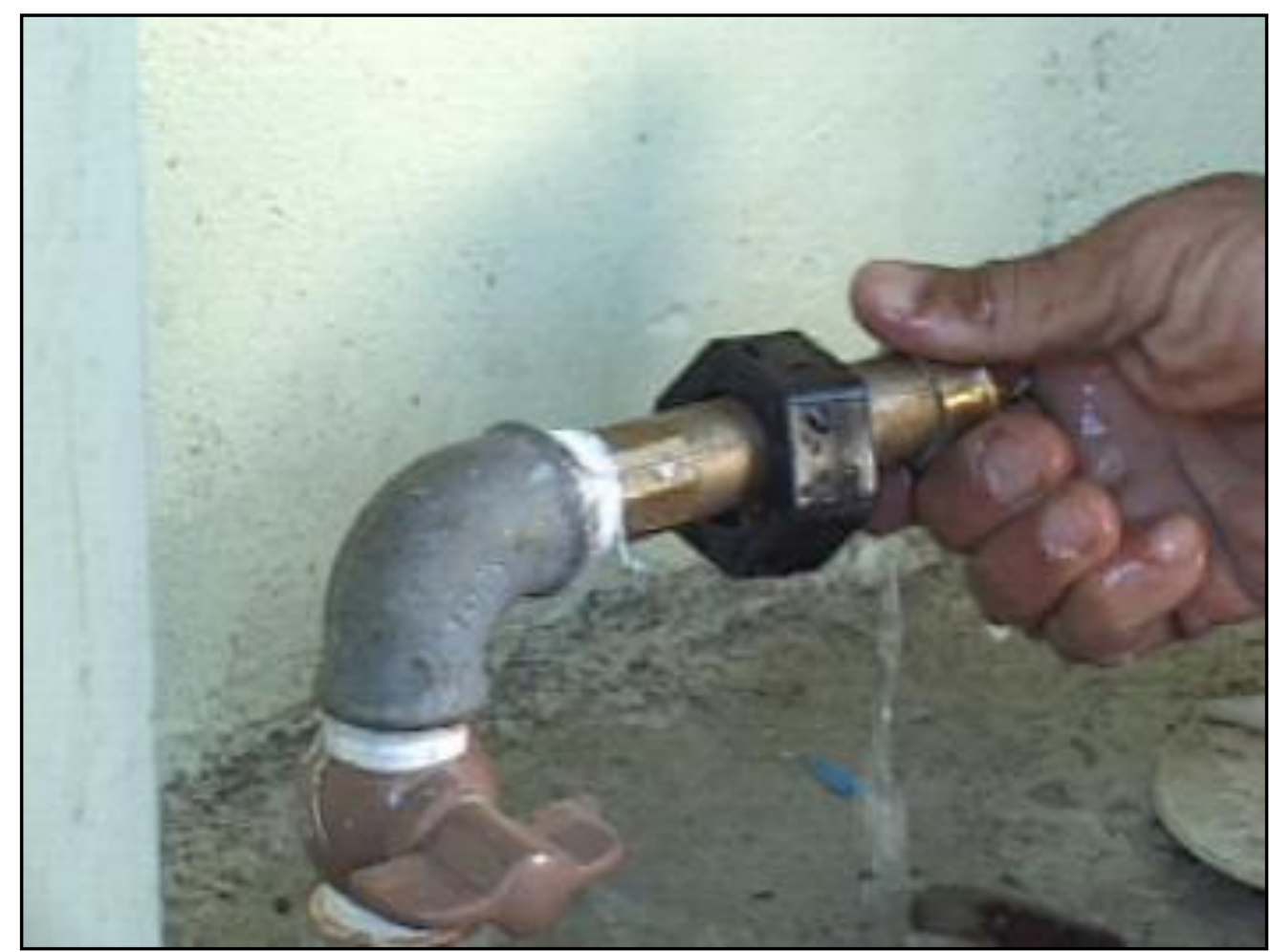

Figura 5.10 - Fechamento e lacração dos registros

O comunicado deve ser entregue com uma antecedência mínima de cinco dias úteis. Durante este período, é feito o planejamento e a convocação dos técnicos e auxiliares 
que participarão do ensaio. No planejamento deve ser avaliado:

a) A disponibilidade de materiais e equipamentos necessários;

b) Comunicar todas as pessoas envolvidas;

c) Verificar a logística no local de execução do ensaio, ou seja, como as equipes se movimentarão, posicionamento das viaturas, equipamentos, e a montagem da sinalização de trânsito.

Uma equipe fica encarregada dos pontos de descarga e de medição da pressão. Para estes pontos são desmontados cinco cavaletes de ligações próximas e consecutivas para a instalação de registradores de pressão e vazão, ver Figura 5.11.

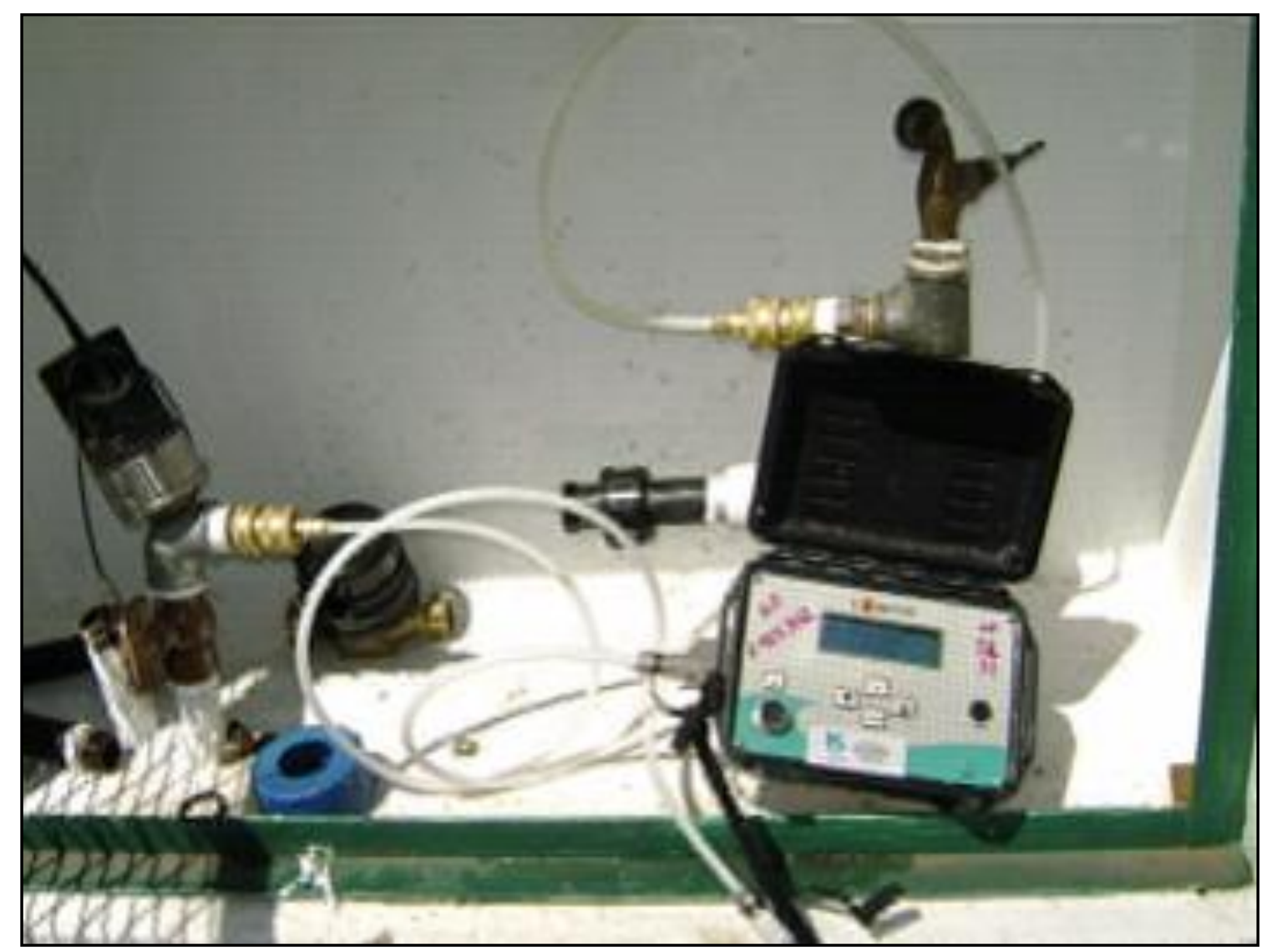

Figura 5.11 - Ponto de medição de pressão

Efetuadas estas atividades, dá-se inicio ao ensaio, começando pela obtenção da rugosidade específica $\varepsilon$. Em seguida, é feita a avaliação das vazões mínimas para a obtenção do FCl.

Pelo rádio, as equipes se orientam e se posicionam para o início do ensaio. Os 
registradores de pressão e vazão são verificados para certificar que estão todos com os horários sincronizados. É feita a constatação de consumo zero, observando as leituras nos registradores, e constatando que é obtido o valor igual a zero, antes do início do ensaio.

\section{Obtenção da rugosidade absoluta $\varepsilon$}

O ensaio de rugosidade absoluta consiste em medir a vazão e pressão a montante e a pressão a jusante do trecho, variando a vazão abrindo as descargas. Isto é necessário para obter velocidades de escoamento suficientes para garantir o regime turbulento, que é o regime normamente encontrado nas redes de distribuição de água tratada.

Os registros, do PV entre os ferrules e o da extremidade oposta, permanecem fechados durante todo o ensaio. O registro auxiliar instalado antes do hidrômetro no PV é aberto e todas as quatro descargas também. Aguarda-se a estabilização da vazão e efetua-se o registro das vazões por no mínimo dez minutos. Ao término do período, fecha-se uma das descargas, aguarda-se a estabilização da vazão e efetua-se o registro das vazões por mais dez minutos, e assim até à última descarga ser fechada (Figura 5.12).

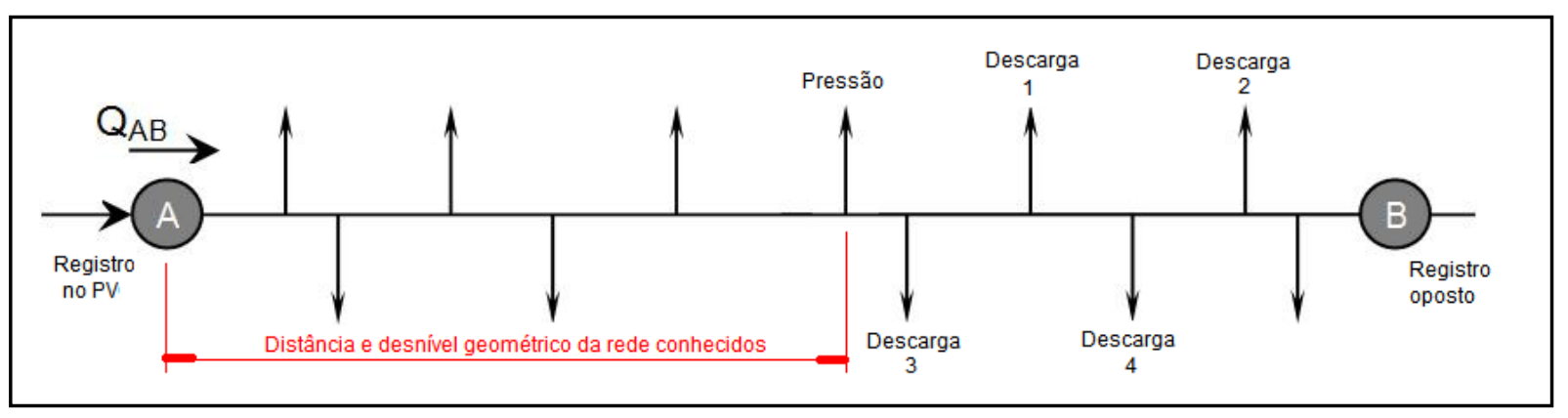

Figura 5.12 - Esquema do ensaio da rugosidade absoluta

Os dados armazenados nos registradores durante o ensaio são descarregados em um microcomputador e sua incerteza de medição é determinada (ver subitem 5.3.3), e então é feita a avaliação da rugosidade absoluta $\varepsilon$, executando uma combinação entre as equações de Darcy-Weisbach da perda de carga, e a equação de Colebrook-White. Para os cálculos foi utilizada a equação explícita de Sousa (1999), em uma planilha eletrônica como apresentado na Figura 5.13 e Tabela 5.2. O valor da incrustação obtido experimentalmente no tubo valida o uso das equações citadas. 


$$
\begin{gathered}
\Delta H=f \cdot \frac{8 \cdot L \cdot Q^{2}}{\pi^{2} \cdot g \cdot D^{5}} \quad \ldots(5.4) \\
\frac{1}{\sqrt{f}}=-2 \cdot \log _{10}\left(\frac{\varepsilon}{3,7 \cdot D}+\frac{2,51}{R_{e} \cdot \sqrt{f}}\right) \quad \ldots(5.5) \\
\frac{1}{\sqrt{f}}=-2 \cdot \log _{10}\left(\frac{\varepsilon}{3,7 \cdot D}-\frac{5,16}{R_{e}} \cdot \log _{10}\left(\frac{\varepsilon}{3,7 \cdot D}+\frac{5,09}{R_{e}^{0,87}}\right)\right)
\end{gathered}
$$

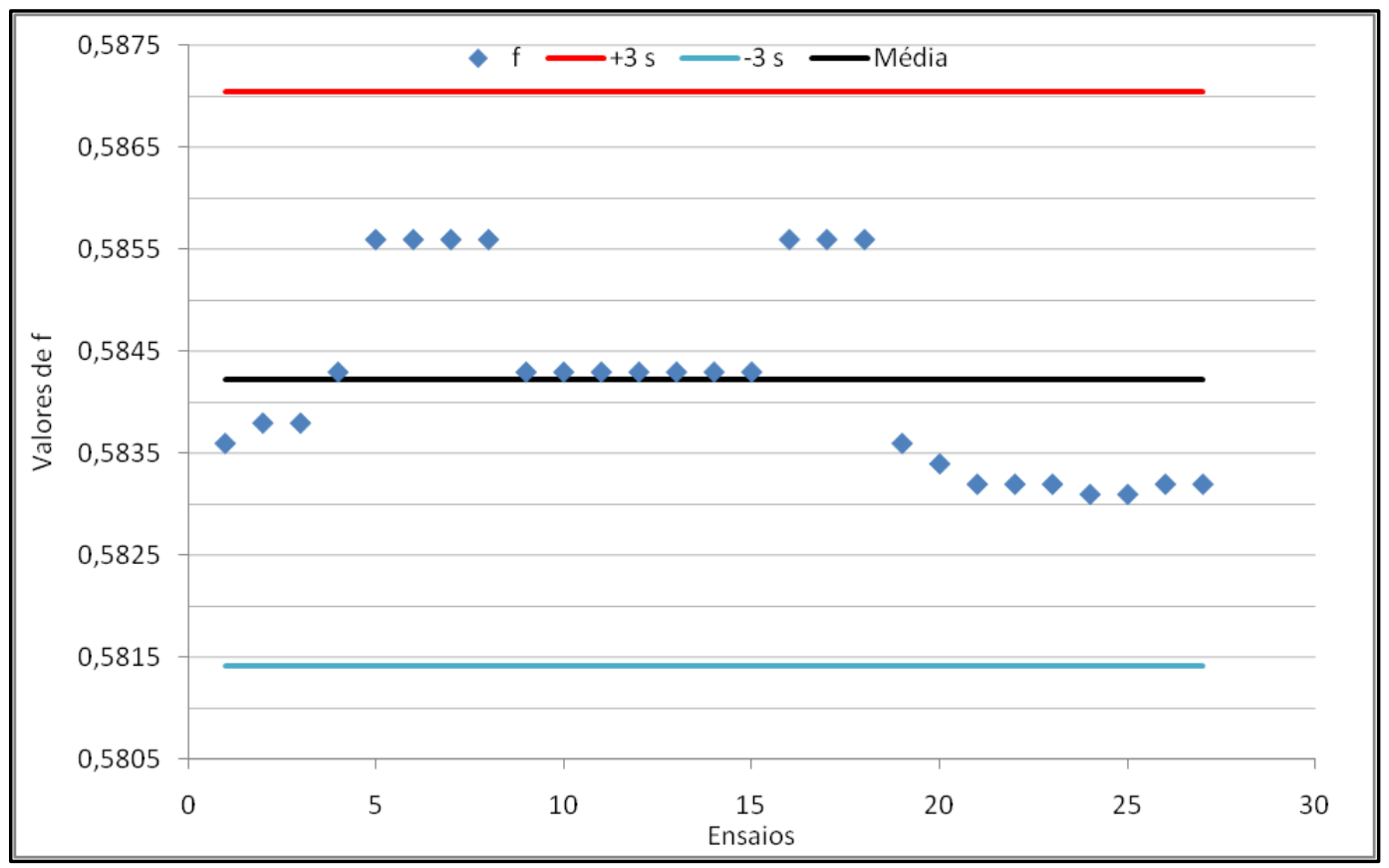

\begin{tabular}{|c|c|c|c|c|c|c|c|c|c|c|}
\hline Dado & DATA & HORA & $\begin{array}{l}P 0 \\
\mathrm{mH} 20\end{array}$ & $\frac{P 1}{\mathrm{mH} 20}$ & $\begin{array}{l}V A Z \tilde{A} O \\
\mathrm{~L} / \mathrm{s}\end{array}$ & $D P$ & $R e$ & $f$ & $\begin{array}{l}\varepsilon \\
m m\end{array}$ & ${ }_{\text {médio }}^{f}$ \\
\hline 1 & $19 / 11 / 2009$ & 09:31:00 & 22,14 & 25,24 & 0,144 & 3,1 & 28539 & 0,5836 & \multirow{7}{*}{10} & \multirow{7}{*}{0,5842} \\
\hline 2 & $19 / 11 / 2009$ & $09: 32: 00$ & 22,37 & 19,21 & 0,108 & 3,16 & 21404 & 0,5838 & & \\
\hline 3 & $19 / 11 / 2009$ & 09:33:00 & 23,2 & 19,22 & 0,108 & 3,98 & 21404 & 0,5838 & & \\
\hline 4 & $19 / 11 / 2009$ & 09:34:00 & 23,42 & 20,5 & 0,072 & 2,92 & 14270 & 0,5843 & & \\
\hline$\vdots$ & $\vdots$ & $\vdots$ & $\vdots$ & $\vdots$ & $\vdots$ & $\vdots$ & $\vdots$ & $\vdots$ & & \\
\hline 26 & $19 / 11 / 2009$ & 09:56:00 & 21,19 & 22,94 & 0,432 & 1,75 & 85618 & 0,5832 & & \\
\hline 27 & $19 / 11 / 2009$ & 09:57:00 & 20,83 & 23,95 & 0,396 & 3,12 & 78483 & 0,5832 & & \\
\hline
\end{tabular}

Figura 5.13 - Exemplo de gráfico com valores de $f$ calculados

Tabela 5.2 - Exemplo de dados trabalhados e calculo de $\varepsilon$ 
Avaliação do fator de condição de infraestrutura $\mathrm{FCl}$ e $\mathrm{N}_{1}$

O ensaio para obtenção do fator de condição da infraestrutura consiste em medir a vazão na entrada do trecho, variando a pressão na rede pelo fechamento gradual do registro auxiliar, e tendo o consumo igual à zero. Nestas condições as vazões registradas são devidas a existência de vazamentos inerentes (Figura 5.14).

O ensaio inicia após o fechamento de todas as descargas, utilizadas no ensaio anterior. Após aguardar no mínimo quinze minutos para estabilização, começa-se a registrar as vazões e pressões obtidas.

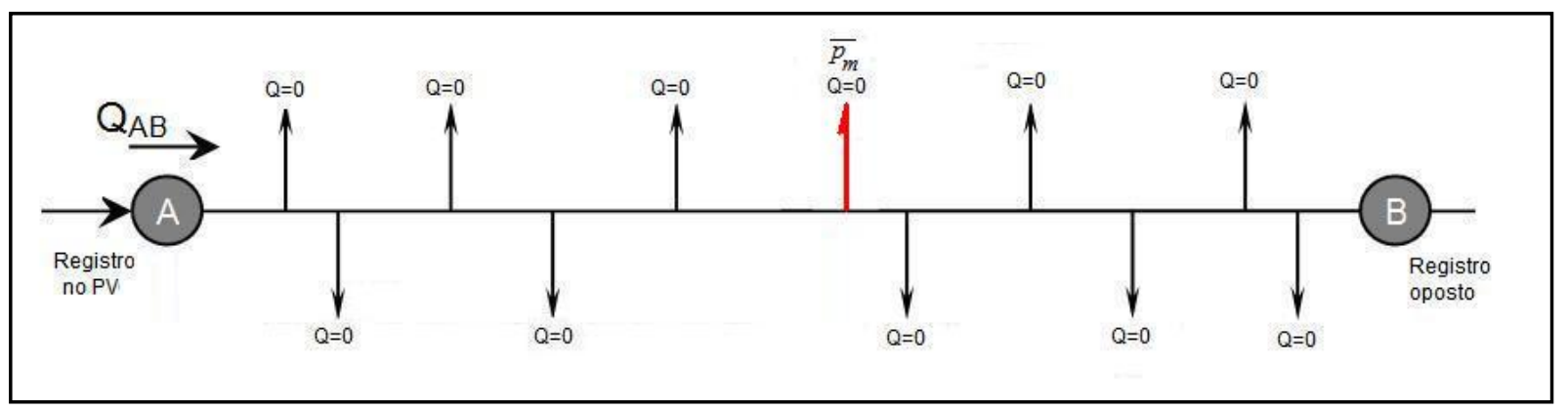

Figura 5.14 - Esquema do ensaio de $\mathrm{FCl}$ e N1

Devem ser feitas no mínimo dez leituras. O registro auxiliar deve ser fechado de modo a causar uma diminuição de um décimo da pressão total em cada período de leitura. Os dados devem ser colhidos após aguardar, por um período de no mínimo quinze minutos, a estabilização da vazão e a coleta de dados deve durar igual período, no mínimo.

Os dados armazenados nos registradores durante o ensaio são descarregados em um microcomputador e sua incerteza de medição é determinada (ver subitem 5.3.3), e então é feita a avaliação do $F_{c i}$ e do $N_{1}$ através das equações empíricas de Lambert et al. (1998) equações 4.5 e 4.9, da relação entre a variação de vazão e pressão equação 4.2 .

$$
\begin{aligned}
\frac{Q_{1}}{Q_{0}} & =\left(\frac{P_{1}}{P_{0}}\right)^{N_{1}} \cdots(4.2) \\
Q_{i} & =Q_{v i} \cdot F_{c i} \cdots(4.8)
\end{aligned}
$$




$$
Q_{v i}=2,78 \cdot 10^{-4} \cdot\left(Q_{p r d} \cdot L+Q_{r p m} \cdot N\right) \cdot\left(\frac{\bar{p}}{50}\right)^{N_{1}} \ldots
$$

Para a avaliação do $F_{c i}$ efetuam-se os cálculos, isolando o $F_{c i}$ em 4.8 e substituindo $Q_{v i}$ pela equação 4.9 , e os valores de referência da IWA para $Q_{v i}$, a 50 mca de pressão, são:

- Para redes $=20 \mathrm{~L} /(\mathrm{h} \cdot \mathrm{km})$;

- Para ramais $=1,25 \mathrm{~L} /(\mathrm{h} \cdot \mathrm{ramal})$.

Assim tem-se:

$$
F_{c i}=\frac{Q_{i}}{Q_{v i}} \Rightarrow F_{c i}=\frac{Q_{i}}{2,78 \cdot 10^{-4} \cdot(20 \cdot L+1,25 \cdot N) \cdot\left(\frac{\overline{p_{m}}}{50}\right)^{N_{1}}}
$$

Onde $Q_{i}$, representa a vazão média medida em cada período $p$ do ensaio em $\mathrm{L} / \mathrm{s}, L$, a extensão de rede no trecho em $\mathrm{km}, N$ é o número de conexões na rede, $\bar{p}_{m}$, é a pressão média no ponto médio do trecho em $\mathrm{mH}_{2} \mathrm{O}$, e $N_{1}$ é o expoente que depende do material do tubo. $O N_{1}$ é o coeficiente angular da reta média obtida por regressão linear no gráfico com escala di-logarítmica, calculado pela transformação da equação 4.2 escrita de na forma logarítmica (equação 5.8).

$$
\begin{aligned}
\log \left(\frac{Q_{1}}{Q_{0}}\right) & =N_{1} \cdot \log \left(\frac{P_{1}}{P_{0}}\right) \\
N_{1} & =\frac{\log \left(\frac{Q_{1}}{Q_{0}}\right)}{\log \left(\frac{P_{1}}{P_{0}}\right)}
\end{aligned}
$$

A partir de uma tabela com dados obtidos do ensaio de campo, é elaborado o gráfico da Figura 5.15, no qual a inclinação da reta é numericamente igual ao valor de $N_{1}$.

O $F_{c i}$ é calculado utilizando o $N_{1}$ obtido.

$$
F_{c i}=\frac{Q_{i}}{2,78 \cdot 10^{-4} \cdot(20 \cdot L+1, N) \cdot\left(\frac{\bar{p}_{m}}{50}\right)^{N_{1}}}
$$




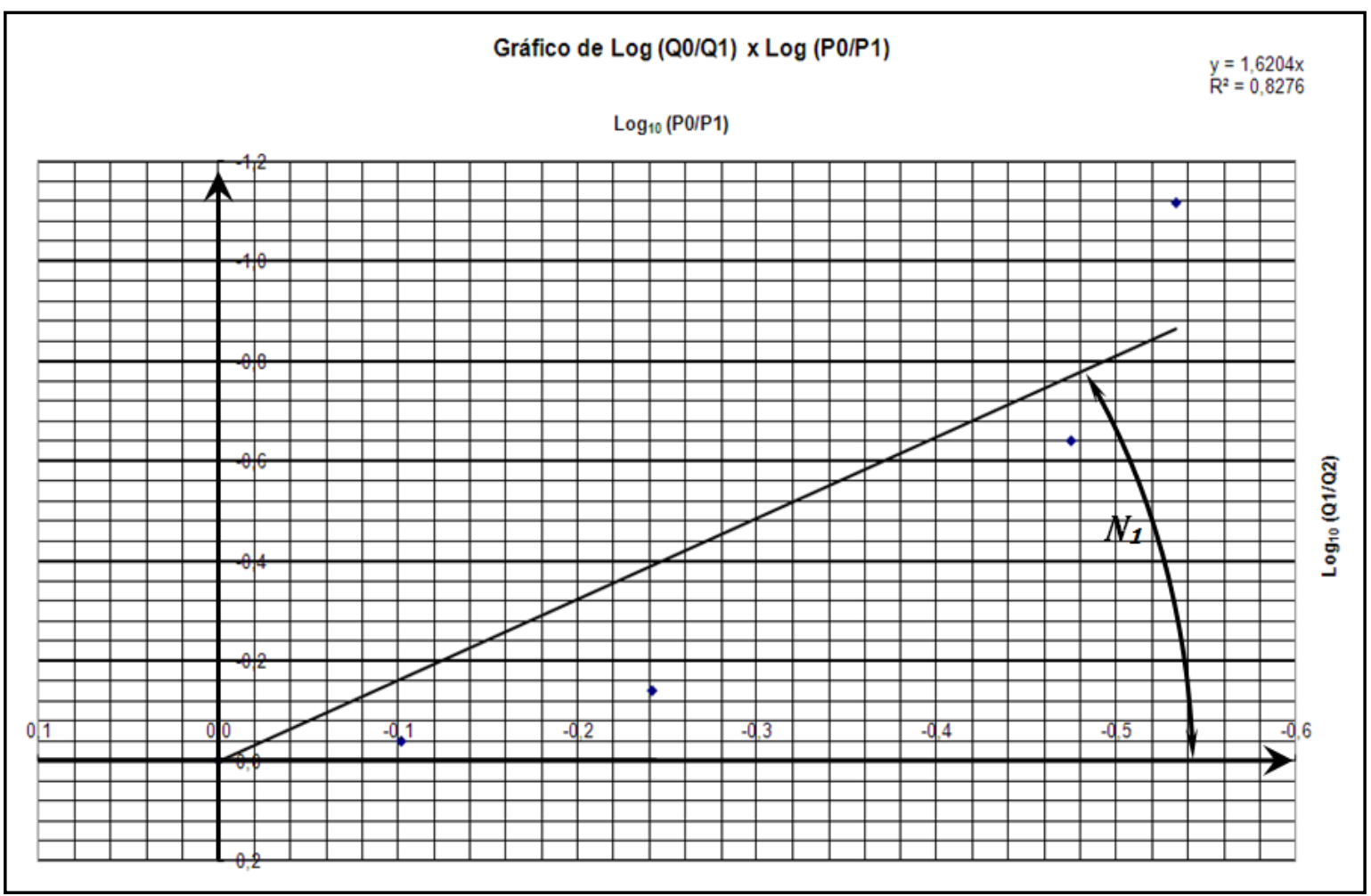

Figura 5.15 - Gráfico de $\mathrm{N}_{1}$

Obtenção das pressões para a calibração do modelo

$\mathrm{Na}$ calibração do modelo de simulação hidráulica, são necessários valores reais de pressão ou de demandas, ou ambos. Para a obtenção destes valores é necessária à instalação de registradores de pressão e vazão, no maior número de ligações de água dos clientes, Figura 5.16, e se possível ter um registrador em cada trecho de rede. $O$ número de registradores necessários para a realização de uma boa calibração foi discutido em estudo realizado por Gambale (2000). Na prática se estabelece cinco pontos mínimos para a coleta de dados de pressão, são eles:

1. Entrada da área;

2. Ponto médio da malha de distribuição;

3. Ponto crítico de pressão mínima;

4. Ponto crítico de pressão máxima;

5. Ponto mais distante da entrada de abastecimento;

Esta coleta de dados permitirá a calibração do modelo por meio de algoritmo genético, resultando em uma série de dados que se aproximam das condições reais de operação. $\mathrm{Na}$ instalação, deve ser identificado o imóvel, no qual está o registrador para o correto posicionamento do mesmo na topologia da rede utilizada no modelo. 


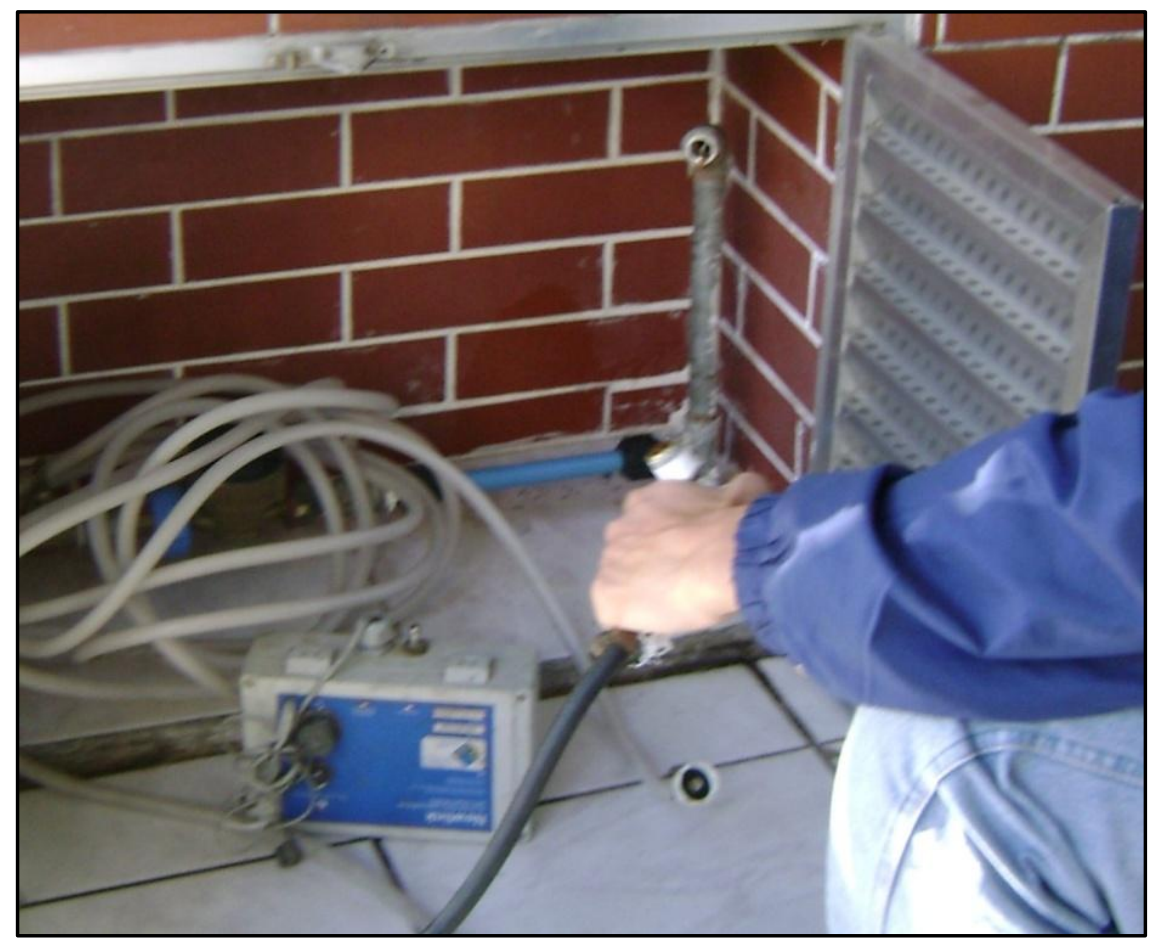

Figura 5.16 - Instalação de registrador de pressão

Os registradores de pressão e vazão devem permanecer instalados por um período mínimo de quinze dias, e devem estar com seus horários sincronizados.

\subsubsection{Tratamento dos dados coletados e determinação das incertezas}

Após o descarregamento dos dados registrados, é feita a avaliação da incerteza associada ao processo de medição, e com isso a determinação das faixas cuja probabilidade de ocorrência dos valores mais provável. O método para a determinação da incerteza está apresentado no APËNDICE A.

Analisando os valores registrados, observa-se a oscilação deles em torno de um valor médio a cada hora. Então a faixa de probabilidade de ocorrência de um valor medido é dada pela equação:

$$
x \in\left[x_{m} \pm s_{r}\right]
$$

Onde $x$ representa o valor observado, e $\left[x_{m} \pm s_{r}\right]$ o intervalo ou faixa de probabilidade determinado por $x_{m}$, que é o valor médio horário, e $s_{r}$ que é a incerteza da série de registros naquele horário. O gráfico da Figura 5.17, ilustra um exemplo de faixa de probabilidade dos valores obtidos em campo, que será utilizado para a comparação 
com os valores simulados, sejam eles de vazão ou pressão. Espera-se que os valores simulados estejam dentro da faixa determinada.

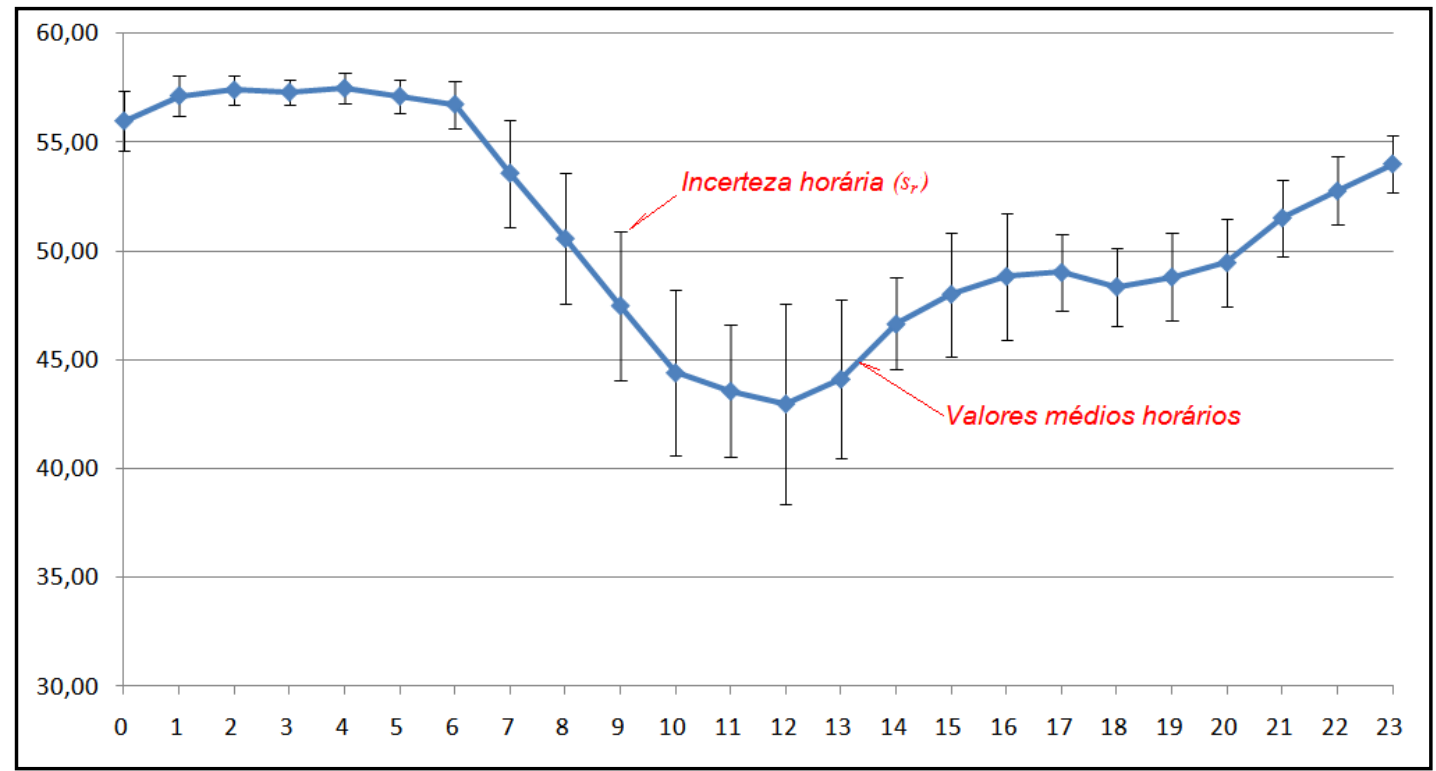

Figura 5.17 - Exemplo de gráfico com a faixa de probabilidade dos valores

Os resultados são então apresentados resumidos por hora. A Tabela 5.3 ilustra a forma como os dados são descarregados dos registradores, e a

Tabela 5.4, apresenta um exemplo de resultado da avaliação das incertezas.

Tabela 5.3 - Exemplo de dados coletados em campo

\begin{tabular}{ccc}
\hline Data/Hora & \multicolumn{2}{l}{$\begin{array}{l}\text { Pressão } \\
\text { mH2O }\end{array}$} \\
\hline 16/7/2009 00:15 & 54 \\
\hline $18 / 7 / 200900: 00$ & 53 & \\
\hline$\vdots$ & & $\vdots$ \\
\hline $19 / 7 / 200900: 00$ & 55 & \\
\hline $19 / 7 / 2009$ & $00: 15$ & 55 \\
\hline
\end{tabular}

Tabela 5.4 - Exemplo de resultado da avaliação da incerteza

\begin{tabular}{|c|c|c|c|c|c|c|c|}
\hline Hora & $\begin{array}{l}\text { Pressão } \\
\mathrm{mH}_{2} \mathrm{O}\end{array}$ & $s$ & $\overline{\boldsymbol{s}}_{m}$ & $E$ & $E^{2}$ & $E_{c}$ & $E_{R}$ \\
\hline 0 & 55,97 & 1,38 & 0,25 & 1,15 & 1,31 & \multirow{7}{*}{5,43} & \multirow{7}{*}{$10,65 \%$} \\
\hline$\overline{1}$ & 57,13 & 0,91 & 0,16 & 1,15 & 1,33 & & \\
\hline$\overline{2}$ & 57,39 & 0,68 & 0,12 & 1,15 & 1,33 & & \\
\hline \multirow[t]{2}{*}{3} & 57,29 & 0,57 & 0,10 & 1,15 & 1,32 & & \\
\hline & $\vdots$ & $\vdots$ & $\vdots$ & $\vdots$ & $\vdots$ & & \\
\hline$\overline{22}$ & 52,76 & 1,57 & 0,28 & 1,09 & 1,19 & & \\
\hline 23 & 54,00 & 1,28 & 0,23 & 1,10 & 1,22 & & \\
\hline
\end{tabular}




\subsubsection{Calibração do modelo com uso da ferramenta "Darwin Calibrator"}

Após o tratamento dos dados registrados em campo, inicia-se 0 aplicativo WaterGEMS® e no arquivo referente à área de interesse. Insere-se no modelo as junções que simularão as medições feitas pelos registradores eletrônicos instalados nos trechos de rede. Na Figura 5.18, as junções de cor vermelha representam os registradores que foram adicionados ao modelo. Existem parâmetros que devem ser fornecidos ao software antes que seja executada a simulação. Estes são:

1. Limite de gerações criadas;

2. Quantidade de interações máxima;

3. Diferença máxima entre o valor real e o simulado (fitness);

4. Escolha das variáveis a serem ajustadas (demandas, pressões, fator de atrito etc.).

Neste trabalho para os itens de 1 a 3 foram utilizados os valores fornecidos por padrão no software, e no item 4 adotou-se a demanda como variável a ser ajustada. Esta decisão foi tomada tendo em vista a avaliação prática do modelo, para testar os efeitos das simplificações e dos valores sugeridos nos resultados da calibração.

Em cada nova junção é necessário informar ao aplicativo a cota altimétrica e a demanda média para o caso de registrador de vazão. Para as junções que representam pontos de medição de pressão as demandas são nulas, e as pressões serão carregadas no "Darwin Calibrator".

No WaterGEMS® existe uma ferramenta para a calibração de modelos, baseada em algoritmos genéticos, chamada de "Darwin Calibrator". Esta ferramenta possui uma interface amigável e necessita dos dados levantados em campo e dos padrões horários de variação das demandas para efetuar a calibração. Para o objetivo deste método, são utilizados os valores do atributo: carga hidráulica ou as pressões medidas. Embora a simulação em período extensivo forneça uma série de resultados com maior representatividade do comportamento do sistema hidráulico, o regime permanente foi escolhido para as simulações, pois o algoritmo genético será executado para cada hora separadamente, evitando-se a demora desnecessária de processamento e tendo-se maior controle sobre as variáveis simuladas. Após o término dos ciclos de cálculos, 
todas as demandas foram avaliadas e corrigidas para aproximarem-se dos valores medidos de pressão e vazão do sistema real. Concluídas as calibrações, criam-se novos cenários no modelo, um para cada hora, e são feitas simulações, cada uma utilizando um cenário, ou seja, serão simuladas as vinte e quatro horas. Ao término de cada simulação as tabelas tubos e junções, são exportadas no formato texto, e importadas em planilhas eletrônicas, nas quais serão efetuados os cálculos de perdas.

As tabelas após importadas para as planilhas serão tabuladas e fornecerão os dados para os cálculos de perdas e a elaboração dos mapas temáticos. A Tabela 5.5 apresenta a forma da planilha de dados das junções e a Tabela 5.6 a planilha de dados dos tubos.

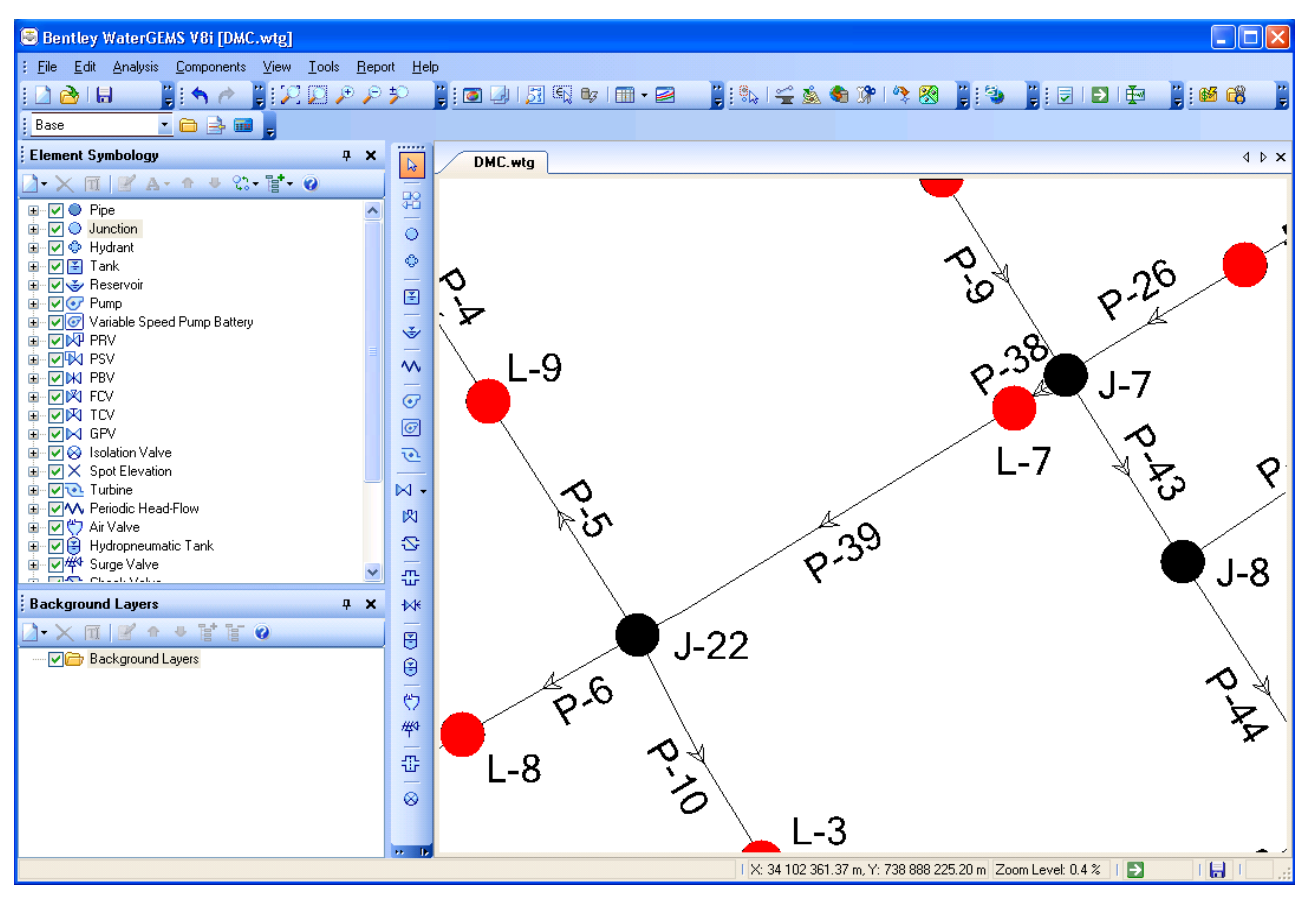

Figura 5.18 - Junções inseridas para representar os registradores eletrônicos WaterGEMS $\AA$

Tabela 5.5 - Exemplo de planilha de junções

\begin{tabular}{|c|c|c|c|c|c|}
\hline Hora & Label & Elevation (m) & Demand (L/s) & Hydraulic Grade (m) & Pressure (m H2O) \\
\hline 0 & L-10 & 779.03 & 0 & 810.19 & 31.093 \\
\hline 0 & $\mathrm{~J}-26$ & 751.63 & 0.1819 & 810.95 & 59.199 \\
\hline 0 & $\mathrm{~J}-27$ & 753.24 & 0.48852 & 819.6 & 66.226 \\
\hline 0 & $\mathrm{~J}-28$ & 753.04 & 0.11615 & 813.16 & 60.003 \\
\hline 0 & $\mathrm{~J}-29$ & 758.23 & 0.30186 & 813.59 & 55.249 \\
\hline r. & . & $\vdots$ & $\vdots$ & 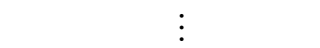 & $\vdots$ \\
\hline
\end{tabular}


Tabela 5.6 Exemplo da planilha de tubos

\begin{tabular}{|c|c|c|c|c|c|c|c|c|c|c|c|c|c|}
\hline Hora & a Label & $\begin{array}{l}\text { Start } \\
\text { Node }\end{array}$ & $\begin{array}{l}\text { Stop } \\
\text { Node }\end{array}$ & $\begin{array}{l}\text { Diameter } \\
(\mathrm{mm})\end{array}$ & Material & $\begin{array}{l}\text { Minor Loss } \\
\text { Coefficient } \\
\text { (Local) () }\end{array}$ & Flow (L/s) & $\begin{array}{l}\text { Velocity } \\
(\mathrm{m} / \mathrm{s})\end{array}$ & $\begin{array}{l}\text { Headloss } \\
\text { Gradient } \\
(\mathrm{m} / \mathrm{m})\end{array}$ & $\begin{array}{l}\text { Has User } \\
\text { Defined } \\
\text { Length? }\end{array}$ & $\begin{array}{l}\text { Length } \\
\text { (User } \\
\text { Defined) } \\
\text { (m) }\end{array}$ & $\begin{array}{l}\text { Darcy- } \\
\text { Weisbach } \\
\text { (Initial) () }\end{array}$ & $\begin{array}{l}\text { Darcy- } \\
\text { f Weisbach } \\
\text { e (mm) }\end{array}$ \\
\hline 0 & P-1 & R-1 & L-1 & 1000.0 & $\begin{array}{l}\text { Ductile } \\
\text { Iron }\end{array}$ & 0.000 & 7.83019 & 0.01 & 0 & True & 1 & 0.000 & 0.0001 \\
\hline 1 & P-1 & $\mathrm{R}-1$ & L-1 & 1000.0 & $\begin{array}{l}\text { Ductile } \\
\text { Iron }\end{array}$ & 0.000 & 7.37002 & 0.01 & 0 & True & 1 & 0.000 & 0.0001 \\
\hline 2 & P-1 & $\mathrm{R}-1$ & $\mathrm{~L}-1$ & 1000.0 & $\begin{array}{l}\text { Ductile } \\
\text { Iron }\end{array}$ & 0.000 & 12.13056 & 0.02 & 0 & True & 1 & 0.000 & 0.0001 \\
\hline$\vdots$ & $\vdots$ & $\vdots$ & $\vdots$ & $\vdots$ & $\vdots$ & $\vdots$ & $\vdots$ & $\vdots$ & $\vdots$ & $\vdots$ & $\vdots$ & $\vdots$ & $\vdots$ \\
\hline
\end{tabular}

O modelo de simulação hidráulica deve ser salvo e arquivado. Sua manutenção deverá ser freqüente, pois permite de modo rápido avaliar o comportamento hidráulico da área por meio da comparação entre os resultados modelados e os de uma nova calibração. Isto possibilita agilidade na deteç̧ão de problemas operacionais e a verificação de anomalias no comportamento hidráulico do sistema.

$\mathrm{Na}$ rotina de manutenção são prementes as atualizações cadastrais, técnicas e comerciais, tais como ampliações na rede de distribuição em áreas de expansão, novas ligações, demandas, padrões de consumo, etc.

\subsubsection{Avaliação de perdas}

A análise se inicia com o cálculo da vazão fornecida ao trecho de rede, pois a simulação hidráulica fornece a vazão total que passa por ele, e que abastece também aos demais trechos a ele conectados. A Figura 5.19 ilustra a situação.

E a vazão fornecida ao trecho se divide em duas porções: a demanda consumida no trecho e as perdas de água. A vazão fornecida ao trecho, $Q_{\overline{A B}}$ deve ser entendida como aquela que abastece apenas ao trecho analisado, como mostra o esquema representado na Figura 5.20. Ou seja:

$$
Q_{\overline{A B}}=\sum_{i=1}^{n} q_{i}+P
$$




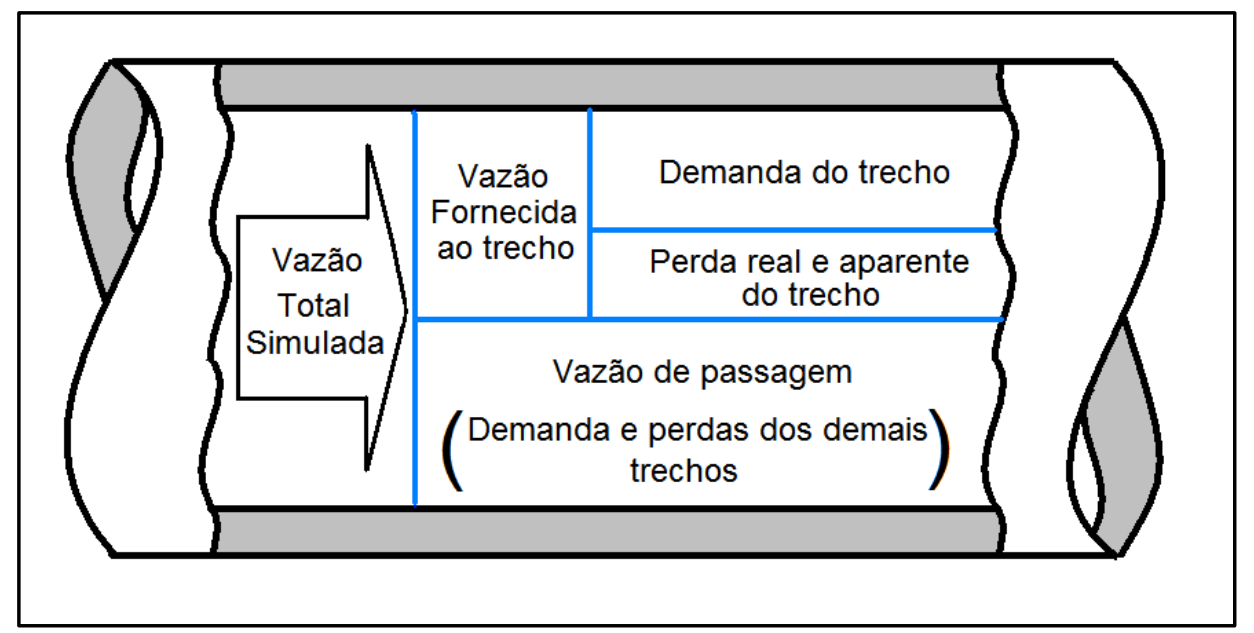

Figura 5.19 - Esquema da estratificação da vazão simulada

Onde, $Q_{\overline{A B}}$ é a vazão fornecida, $q_{i}$ são as demandas consumidas, e $P$ são as perdas totais, no trecho considerado.

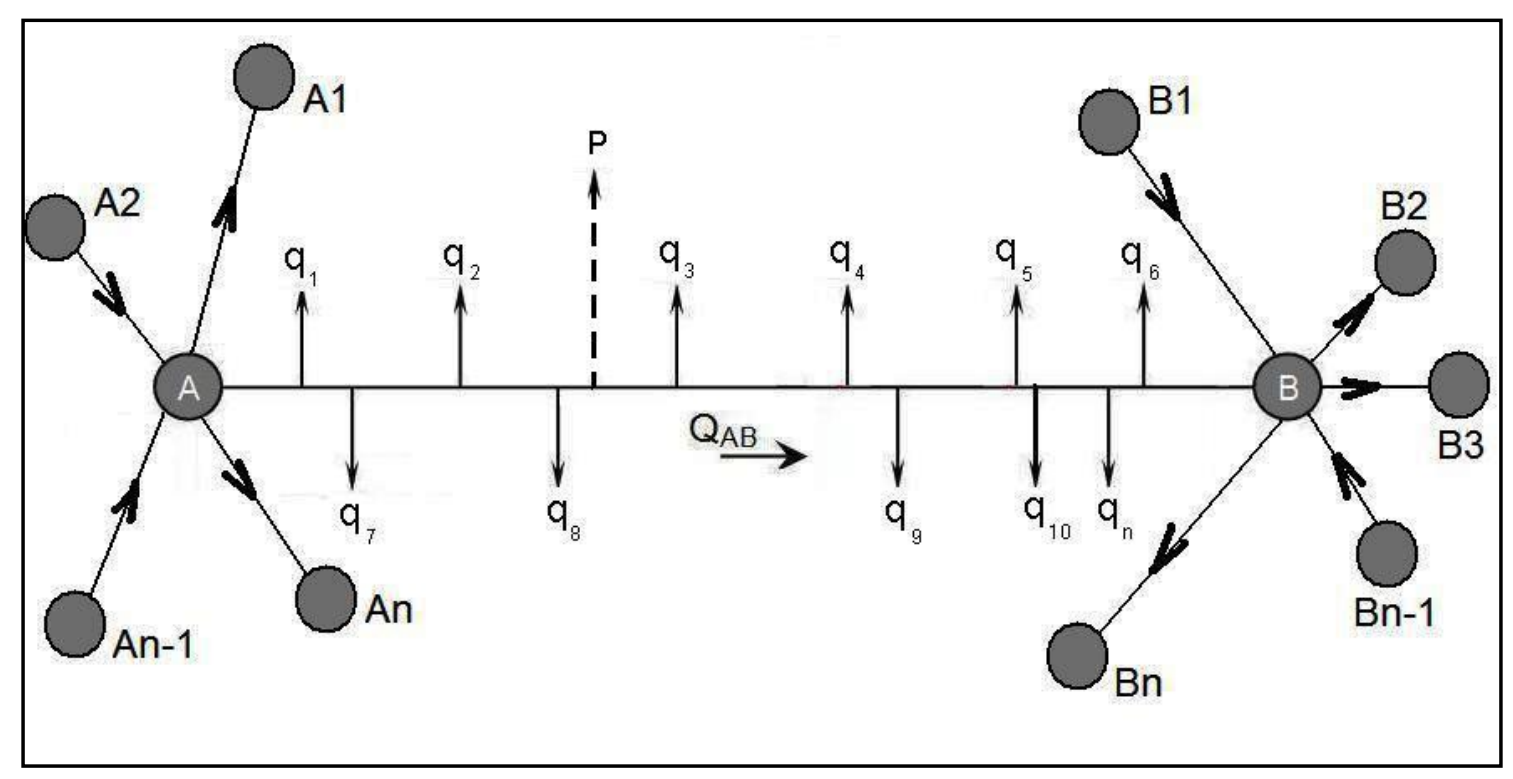

Figura 5.20 - Esquema do balanço de vazões

A vazão fornecida ao trecho $\left(Q_{\overline{A B}}\right)$ é obtida, efetuando dois balanços de vazões, um em cada extremidade do trecho considerado. $O$ balanço de vazões é feito, tomando-se as vazões que entram e que saem de cada extremidade. Por exemplo, a vazão fornecida ao trecho $A B$ da Figura 5.20, é obtida pela soma dos balanços de vazões dos pontos $A$ e B. O balanço de vazões nos pontos é dado pela equação 5.17 . 


$$
\begin{gathered}
\mathrm{B}_{A}=\sum_{i=1}^{n} Q E_{A}-\sum_{i=1}^{n} Q S_{A}-Q_{\overline{A B}}=0 \\
\mathrm{~B}_{B}=\sum_{i=1}^{n} Q E_{B}-\sum_{i=1}^{n} Q S_{B}=0
\end{gathered}
$$

Onde, $Q E_{A}, Q E_{B}, Q S_{A}$, e $Q S_{B}$ são as vazões que entram e saem dos pontos $\mathrm{A}$ e $\mathrm{B}$, respectivamente. $E_{A} B_{A}$ e $B_{B}$ são os balanços de vazões em $A$ e $B$ respectivamente. Assim, a vazão fornecida ao trecho é a soma dos balanços de vazão de cada extremidade. A equação 5.19 demonstra o cálculo.

$$
Q_{\overline{A B}}=\sum_{i=1}^{n} Q E_{A}-\sum_{i=1}^{n} Q S_{A}+\sum_{i=1}^{n} Q E_{B}-\sum_{i=1}^{n} Q S_{B}
$$

Onde $Q_{\overline{A B}}$ é a vazão fornecida ao trecho.

A vazão total por hora em cada trecho é o único parâmetro que o modelo de simulação hidráulica nos dá de forma direta, com as expressões anteriores obtém-se o valor da vazão fornecida a cada trecho de rede.

5.3.6 Análise da eficácia dos resultados no diagnóstico de perdas de água

A verificação da eficácia do uso dos resultados simulados, na criação do diagnóstico de perdas de água, é feita pela classificação dos trechos (do pior para o melhor) com base nos cálculos de perdas executados considerando os resultados da simulação hidráulica, e comparando com os valores verificados no sistema de abastecimento real.

Os valores a serem comparados são:

- Acertos e erros na previsão de vazamentos;

- Pressões simuladas corrigidas pelo AG e as medidas no sistema real;

- Vazão fornecida determinada pela simulação e a medida na entrada do sistema real;

- Rugosidade absoluta utilizada e a obtida no ensaio de campo; 
Entre os acertos e erros na previsão de vazamentos, foi necessária a criação de uma classificação das vazões de perdas reais em função dos valores simulados. Esta classificação tem o seguinte critério:

- Vazamentos classe A, são aqueles que possuem vazões teóricas acima da média interna dos valores simulados, isto é, excluindo-se os valores extremos.

- Vazamentos classe B, são aqueles que possuem vazões teóricas entre a vazão de perdas reais inevitáveis e a média interna dos valores simulados.

- Vazamentos classe C, são aqueles que possuem vazões teóricas iguais ou menores que a perda real inevitável.

Classificados os trechos, os resultados podem ser tabulados como o apresentado na Tabela 5.7 .

Tabela 5.7 - Exemplo de tabulação de resultados

\begin{tabular}{|l|c|r|c|c|c|}
\hline Classificação & Selecionados & \% Extensão Rede & Quantidade & Recuperação em L/s & \%Relativa à Perda Total \\
\hline Classe A & 12 & $27,18 \%$ & 2 & 6,29 & $40,70 \%$ \\
\hline Classe B & 29 & $52,50 \%$ & 7 & 1,04 & $6,75 \%$ \\
\hline Classe C & 7 & $10,49 \%$ & 1 & 0,0035 & $0,02 \%$ \\
\hline Sem classificação * & 5 & $9,83 \%$ & 0 & - & - \\
\hline
\end{tabular}

* Refere-se a trechos teóricos ou colocados para garantir a calibração da simulação hidráulica

A classe "A" abrange as maiores vazões de perda real, representam vazamentos de rede, e sua detecção faz uma redução significativa na perda real. A classe "B" representa as vazões de vazamentos detectáveis que compreendem a forma mais comum de vazamentos nos sistemas reais. A classe " $\mathrm{C}$ " é composta por vazamentos muito pequenos que tornam sua detecção inviável economicamente.

O comparativo entre os valores simulados de pressão e vazão, e os observados no sistema real, obedece a um critério prático utilizado nas avaliações cotidianas das medidas em campo. Este critério define o valor fornecido pela simulação como aceitável se o valor simulado esteve dentro do intervalo de confiança definido. A Figura 5.21 mostra um exemplo da avaliação das pressões.

Os intervalos de confiança adotados neste critério são os seguintes:

- Para a vazão:

- Duas vezes o desvio padrão dos valores medidos na hora avaliada; 
- Para as pressões:

- Se a valor medido for menor ou igual a $20 \mathrm{mH} 2 \mathrm{O}$, o intervalo é de \pm 2 $\mathrm{mH} 2 \mathrm{O}$;

- Se a valor medido for maior que $20 \mathrm{mH} 2 \mathrm{O}$, o intervalo é de $\pm 10 \%$ do valor medido em $\mathrm{mH} 2 \mathrm{O}$;

Do ensaio realizado para a obtenção do fator de atrito, é possível obter a rugosidade absoluta utilizando a equação explicita de Sousa (1999). Quanto mais próximos os resultados, melhor a confiança nos dados para a simulação.

\subsubsection{Mapas temáticos}

As informações existentes na planilha resultado por si só, já permite a definição e a priorização de onde e como agir para a redução das perdas de água na área em estudo. Entretanto, pelo fato das ações passarem antes por aprovações em reuniões com grupos heterogêneos, onde nem sempre todos entendem os detalhes técnicos do combate e redução de perdas, o mapa temático ilustra onde as ações serão aplicadas. Permitindo desta forma, a priorização, definições de recursos, e principalmente o planejamento da execução.

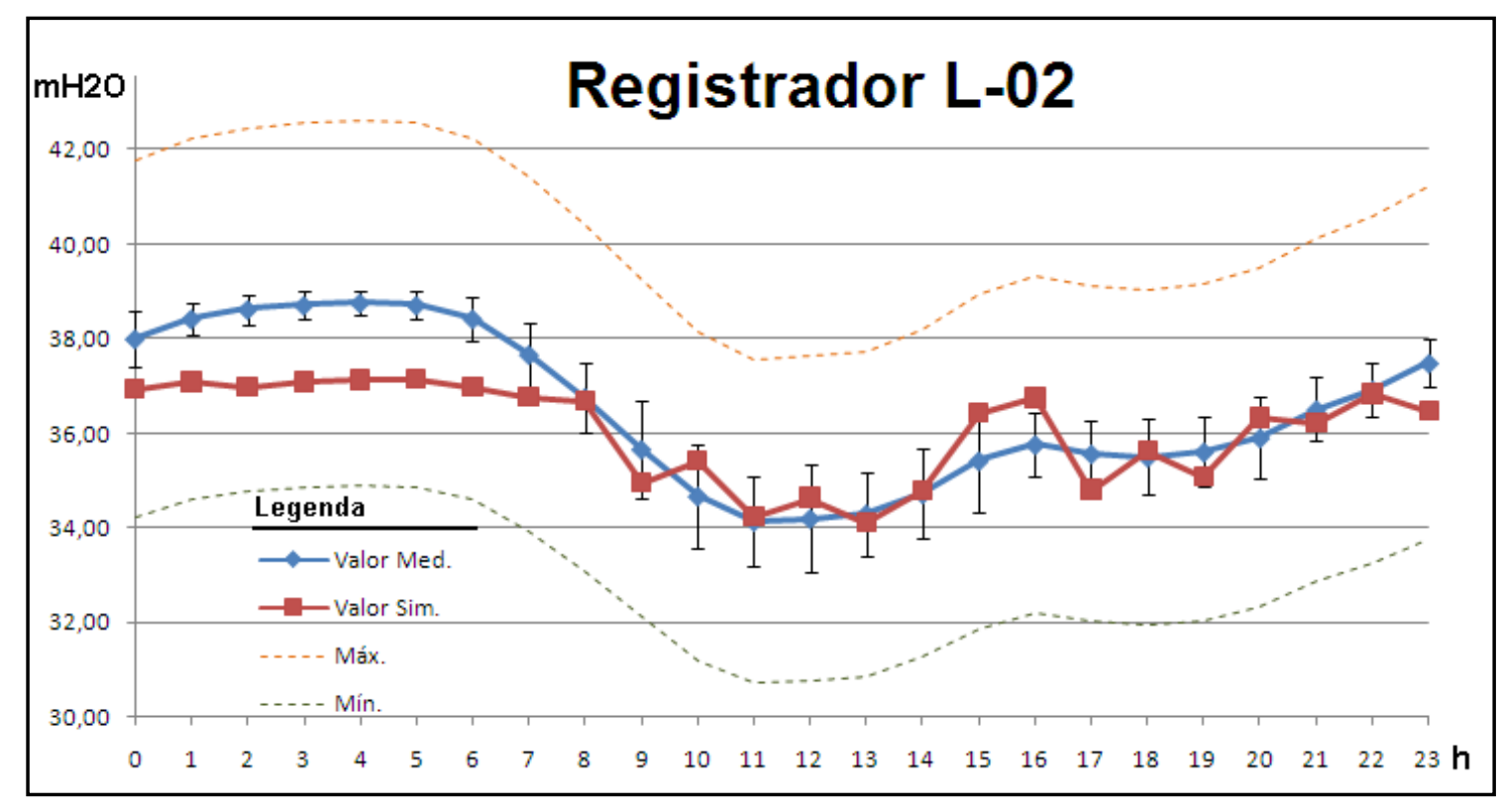

Figura 5.21 - Exemplo da avaliação das pressões 
O mapa temático é feito em qualquer aplicativo de espacialização de informações. Neste trabalho foi utilizado o $\operatorname{ArcView}{ }^{\circledR}$. O primeiro passo, para a criação do mapa é a exportação da topologia da rede criada no WaterGEMS® no formato shp (shp é shapefile desenvolvido pela ESRI para dados espaciais em um sistema de informação geográfica) aceito pelo ArcView ${ }^{\circledR}$. Com a base importada no ArcView ${ }^{\circledR}$, importam-se os dados da planilha resultado salva no formato de arquivo dbf. Com estes passos realizados, os mapas temáticos são feitos rapidamente.

A Figura 5.22, apresenta um exemplo de mapa feito no ArcView® Versão 3.2. 


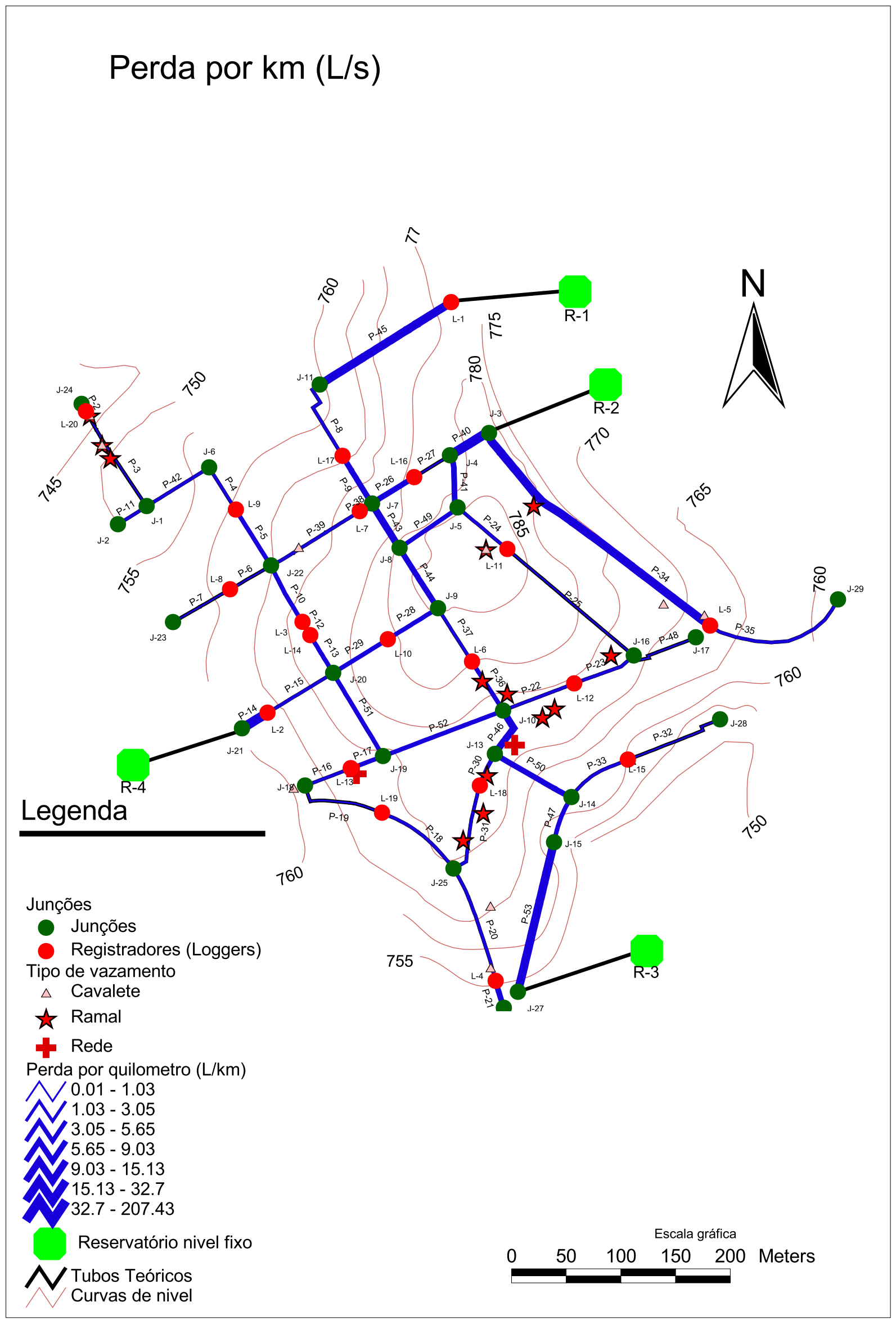

Figura 5.22 - Exemplo de mapa temático - ArcView ${ }^{\circledR}$ 


\section{ESTUDO DE CASO - APLICAÇÃO EM UM DISTRITO DE MEDIÇÃO E CONTROLE}

Neste capítulo serão apresentados os seguintes tópicos:

- Característica geográfica;

- Característica física;

- Característica operacional;

- Ensaios de campo;

- Simulação hidráulica.

O método descrito neste trabalho foi aplicado em uma pequena área que corresponde a um distrito de medição e controle (DMC), cujas características e etapas realizadas são apresentadas a seguir. $O$ tamanho da área foi definido pela disponibilidade de recursos humanos e de equipamentos. O método se vale da simulação hidráulica do sistema de abastecimento, desta forma, não há limite para o tamanho da área a ser estuda, desde que existam equipamentos e mão-de-obra suficientes para a coleta de dados.

\subsection{CARACTERISTICA GEOGRÁFICA}

Este DMC situa-se na zona leste do município de São Paulo, no estado de São Paulo, Brasil (Figura 6.1).

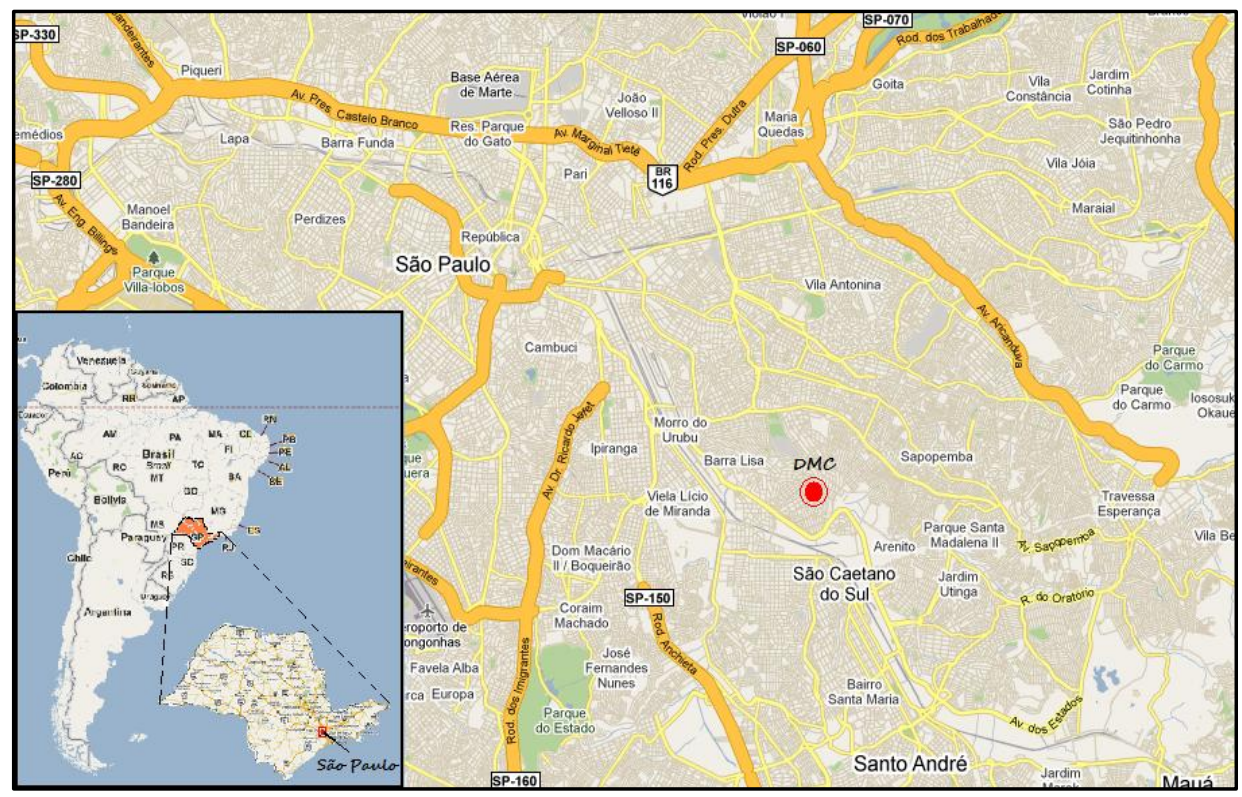

Figura 6.1 - Localização geográfica do DMC Fonte: Google Maps (2009) 
São Paulo é a quarta maior cidade do mundo, e a maior do hemisfério sul, possui $1.522,99 \mathrm{~km}^{2}$ de área, com uma população de 11.037 .593 habitantes. Com uma densidade demográfica de 7.247 habitantes por km², e a altitude de $760 \mathrm{~m}$. Seu clima é tropical de altitude, caracterizado por chuvas de verão e temperatura média anual entre $19^{\circ} \mathrm{C}$ e $27^{\circ} \mathrm{C}$ (IBGE, 2010). É uma área urbana composta predominantemente por residências uni familiares (Sabesp, 2009).

\subsection{CARACTERISTICA FISICA}

Sua topografia é irregular, com cotas altimétricas variando de 785 a 745 m, ver Figura 6.2. Possui uma extensão de rede $3,64 \mathrm{~km}$, com diâmetros variando entre 80 e $150 \mathrm{~mm}$ e idade de 48 anos, composta de tubos de ferro fundido sem revestimento interno.

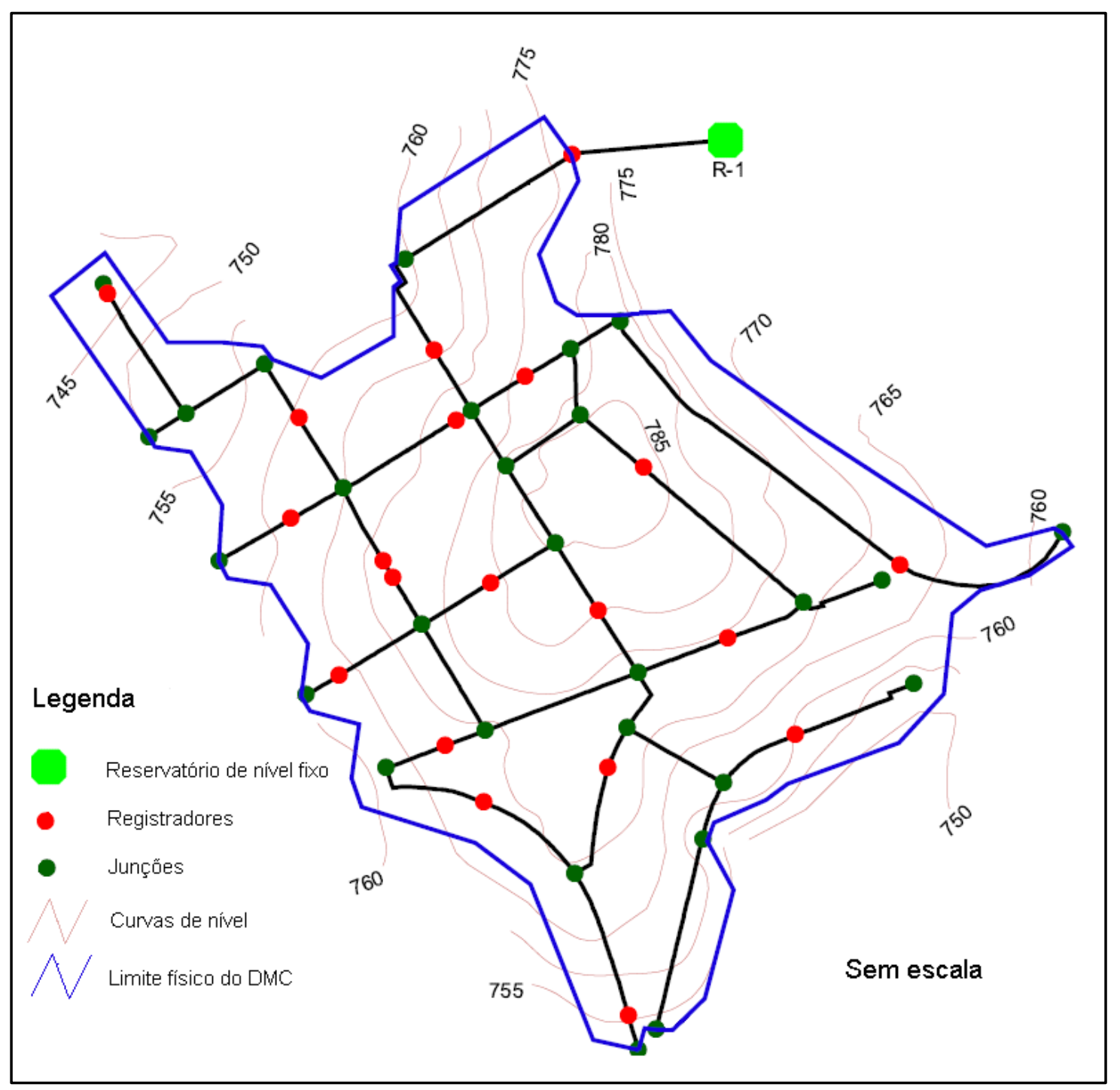

Figura 6.2 - Altimetria do distrito de medição e controle (DMC) 
A rede apresenta incrustações, e seu estado estrutural é bom com ausência de corrosão com diminuição da espessura da parede do tubo. A Figura 6.3 apresenta uma amostra da seção da rede existente. A densidade de ramais por $\mathrm{km}$ de rede é de 264 . $\mathrm{O}$ comprimento médio de cada ramal é de aproximadamente 3,5 m, ou seja, um acréscimo de $3,37 \mathrm{~km}$ de extensão de tubulação composta de ramais em PEAD Ø32mm.

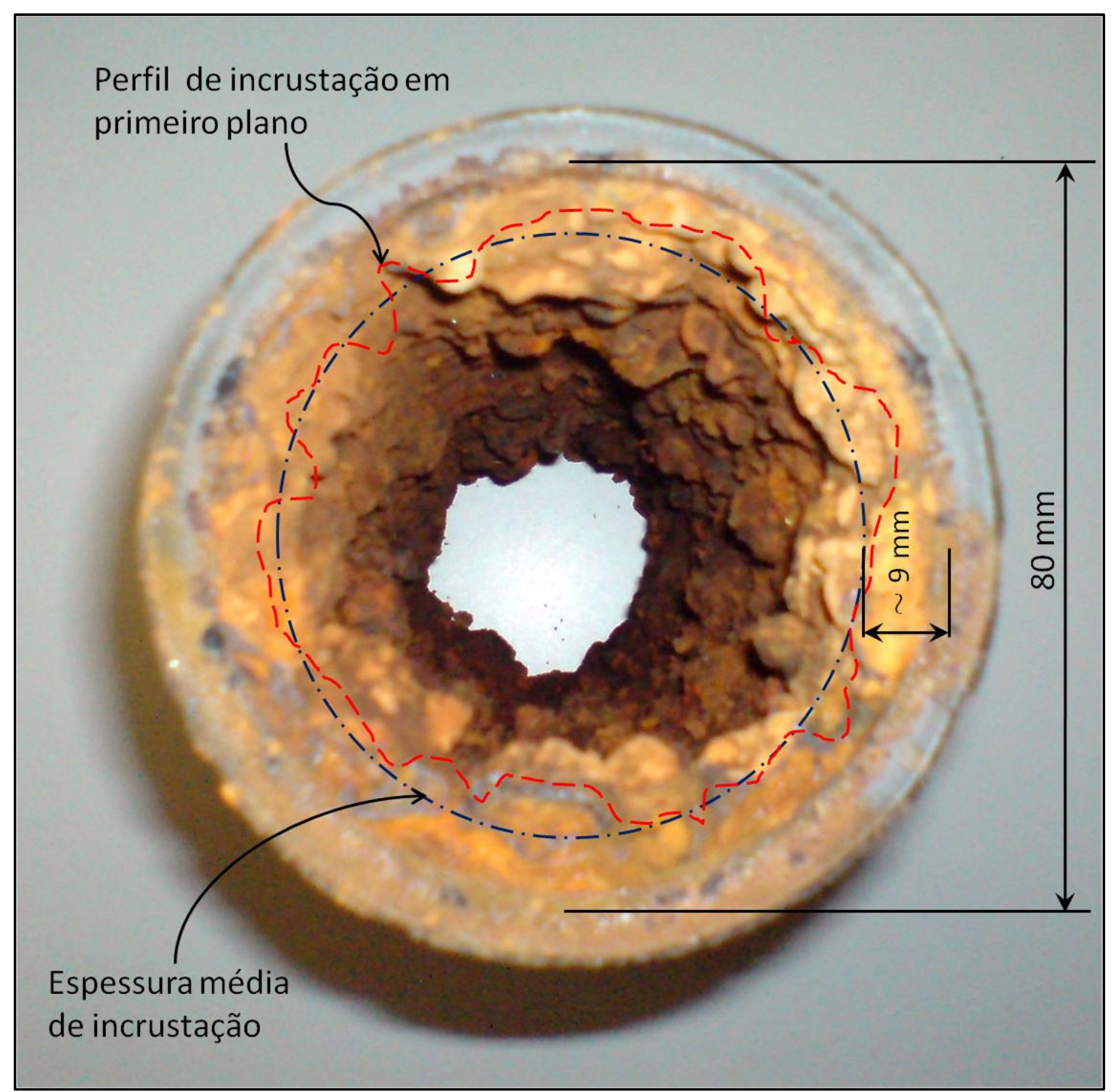

Figura 6.3 - Amostra da rede existente no $\mathrm{DMC}$ material $\mathrm{F}^{\circ} \mathrm{F}^{\circ} \mathrm{e}$ idade de 48 anos

A qualidade da água na distribuição é monitorada diariamente. Assim, é possível obter os parâmetros físico-químicos da água fornecida à área, como o valor do pH médio, que influencia na espessura média da camada de incrustação. Pelos dados obtidos das amostras de água coletadas, o valor que melhor representa o $\mathrm{pH}$ médio da área do DMC é 8,3. A Tabela 6.1 apresenta os dados fornecidos. 
Tabela 6.1 - Dados fornecidos pelo controle sanitário Fonte:(Sabesp, 2009)

\begin{tabular}{cccccccccccc}
\hline Data & Hora & Amostra & pH & Data & Hora & Amostra & pH & Data & Hora & Amostra & pH \\
\hline $07 / 07 / 09$ & $09: 57$ & 8850 & 8,1 & $26 / 08 / 09$ & $12: 00$ & 10270 & 8 & $06 / 10 / 09$ & $14: 18$ & 13134 & 8,9 \\
\hline $07 / 07 / 09$ & $11: 00$ & 8851 & 8 & $26 / 08 / 09$ & $12: 52$ & 10271 & 8,2 & $22 / 10 / 09$ & $09: 20$ & 13640 & 8,8 \\
\hline $07 / 07 / 09$ & $11: 13$ & 8852 & 8,4 & $03 / 09 / 09$ & $09: 38$ & 11702 & 8,3 & $22 / 10 / 09$ & $11: 19$ & 13641 & 8,4 \\
\hline $07 / 07 / 09$ & $11: 58$ & 8849 & 8 & $03 / 09 / 09$ & $11: 45$ & 11701 & 8 & $22 / 10 / 09$ & $13: 16$ & 13639 & 8,3 \\
\hline $21 / 07 / 09$ & $08: 50$ & 9304 & 8,6 & $03 / 09 / 09$ & $12: 40$ & 11703 & 8,4 & $08 / 11 / 09$ & $15: 12$ & 14489 & 8,5 \\
\hline $21 / 07 / 09$ & $10: 00$ & 9302 & 8,3 & $03 / 09 / 09$ & $13: 15$ & 11704 & 8,3 & $08 / 11 / 09$ & $16: 05$ & 14487 & 8,2 \\
\hline $21 / 07 / 09$ & $11: 00$ & 9303 & 8,4 & $25 / 09 / 09$ & $10: 24$ & 12255 & 8,3 & $08 / 11 / 09$ & $16: 28$ & 14490 & 8,1 \\
\hline $06 / 08 / 09$ & $12: 37$ & 10137 & 8,4 & $25 / 09 / 09$ & $10: 24$ & 12256 & 8,5 & $08 / 11 / 09$ & $17: 15$ & 14488 & 8,2 \\
\hline $06 / 08 / 09$ & $13: 36$ & 10138 & 8,1 & $25 / 09 / 09$ & $10: 25$ & 12257 & 8,2 & $17 / 11 / 09$ & $09: 52$ & 14957 & 8,4 \\
\hline $06 / 08 / 09$ & $14: 09$ & 10139 & 8 & $06 / 10 / 09$ & $11: 10$ & 13132 & 8,3 & $17 / 11 / 09$ & $10: 53$ & 14959 & 8,1 \\
\hline $06 / 08 / 09$ & $14: 18$ & 10136 & 8,3 & $06 / 10 / 09$ & $11: 44$ & 13135 & 8,5 & $17 / 11 / 09$ & $11: 16$ & 14958 & 8 \\
\hline $26 / 08 / 09$ & $10: 27$ & 10272 & 8,1 & $06 / 10 / 09$ & $13: 57$ & 13133 & 8,9 & $17 / 11 / 09$ & $11: 37$ & 14956 & 8,1 \\
\hline
\end{tabular}

Substituindo o valor do $\mathrm{pH}$ médio e a idade da rede, nas equações 4.1 e 4.2, a espessura média das incrustações são estimadas como segue.

$$
\begin{gathered}
2 \cdot \log \alpha=6,6-8,3 \Rightarrow \alpha=10^{\frac{6,6-8,3}{2}}=0,1365 \mathrm{~mm} / \text { ano } \\
e=0,85+0,1365 \cdot 48 \Rightarrow e=7,63 \mathrm{~mm}
\end{gathered}
$$

Onde: $e_{0}=0,85 \mathrm{~mm}$ é a altura da rugosidade de um tubo novo; $e=7,63 \mathrm{~mm}$ é a altura da rugosidade após 48 anos; $t=48$ é o período de tempo em anos; $\alpha=0,1365$ é a taxa de crescimento da aspereza, em mm/ano. A amostra apresenta uma espessura média de incrustação da ordem de $9 \mathrm{~mm}$, ou seja, 1,37 mm maior que o teoricamente esperado. Devido à grandeza da incrustação existente, é correto reduzir o diâmetro da tubulação na simulação, porém neste estudo, foi utilizado o diâmetro interno sem incrustação. Esta decisão foi tomada para verificar o impacto desta simplificação nos resultados da simulação, pois na maioria das situações práticas, não é feito ensaio de campo nem estimativa da incrustação.

\subsection{CARACTERISTICA OPERACIONAL}

O setor de abastecimento que fornece água para o DMC é o setor Vila Alpina. O DMC é delimitado por 11 registros, e para simular o fornecimento de água ao DMC, o setor foi representado, simplificadamente, pelo reservatório $\mathrm{R} 1$, que abastece o trecho $\mathrm{P}-45$ do esquema hidráulico. O fornecimento de água é constante e sem interrupções. As pressões máxima e mínima são aproximadamente 67,8 e 22,55 $\mathrm{mH}_{2} \mathrm{O}$ respectivamente. E as vazões máxima e mínima são aproximadamente 12,50 e $0,0384 \mathrm{~L} / \mathrm{s}$ respectivamente. Ligados à malha de distribuição existem 962 clientes sendo agrupados em termos de uso da água em 875 residências, 56 comércios, 18 indústrias 
e 13 mistos. Classificando as ligações em termos de economias, existem 1.174 economias sendo: 1.087 residências, 21 indústrias, 66 comerciais, ou seja, 92,59\% de residências; $5,62 \%$ de comércios; e 1,79\% de indústrias. A maioria do uso da água é doméstico o que permitiu a adoção do perfil residencial para todas as ligações. As ruas pavimentadas e as construções são térreas em sua maioria. A Figura 6.4, apresenta o esquema hidráulico do DMC. Para simular o fornecimento constante de água foi adotado um reservatório de nível fixo. Esta simplificação garantiu que houvesse sempre água na entrada do sistema sem afetar a simulação.

\subsection{ENSAIOS DE CAMPO}

Para simular as condições operacionais reais do sistema de abastecimento, foi realizada a calibração do modelo de simulação, por meio de medições e ensaios de campo, determinando alguns dos valores reais para uso na simulação.

Foram realizados as seguintes medições e ensaios:

1 Determinação das variações de vazão na entrada e pressões nos trechos;

2 Ensaio para determinação do fator de atrito;

3 Ensaio para determinação do fator de condição da infraestrutura;

4 Ensaio para determinação do expoente $\mathrm{N}_{1}$.

As pressões nos trechos foram coletadas durante um período de vinte e nove dias, em dezenove pontos, representados como junções de cor vermelha, no esquema hidráulico, e que cobriram noventa por cento dos trechos da rede. Resultando em quinze dias com dados sincronizados. O registrador 15 apresentou problemas e forneceu dados durante cinco dias, e o registrador 19 , que foi o último a ser instalado, registrou dados por um período de dez dias. A Figura 6.5 apresenta o cronograma de coleta dos dados. 


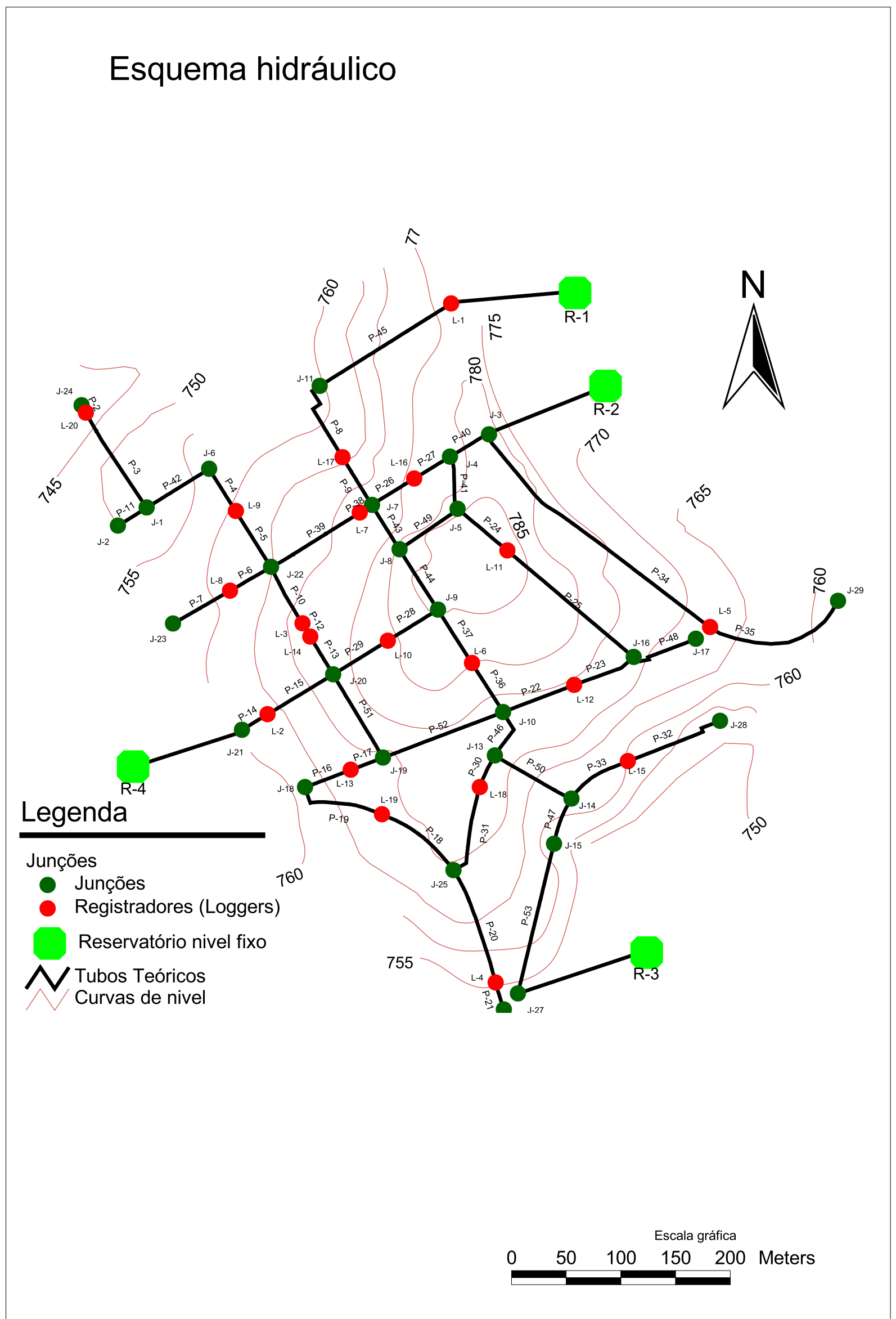

Figura 6.4 - Esquema hidráulico - ArcView ${ }^{\circledR}$ 


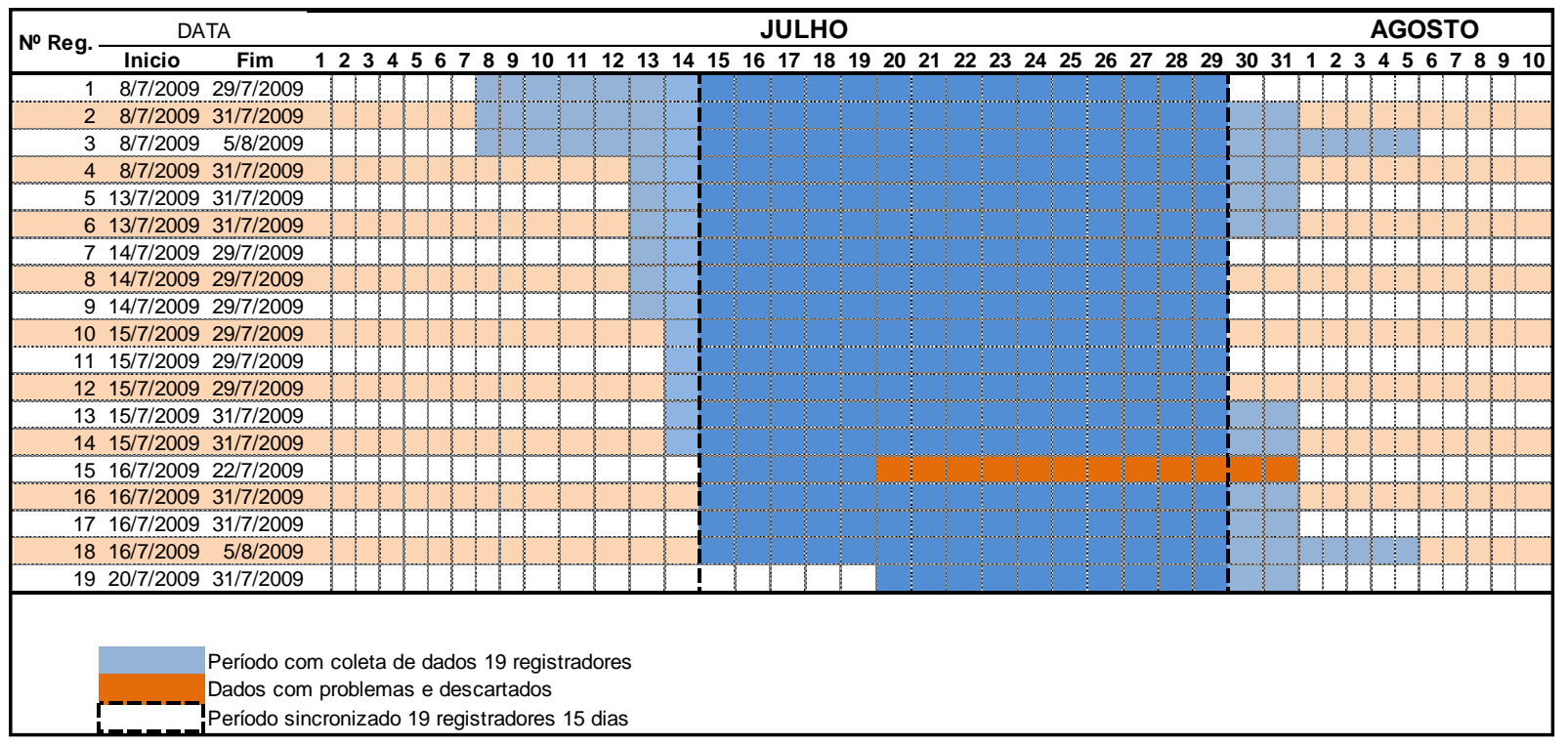

Figura 6.5 - Período de coleta de dados

Como a simulação utiliza o perfil médio de cada registrador, todos os pontos medidos foram utilizados. Os que possuíram maior quantidade de leituras são os pontos com melhor estimativa de comportamento, porém nenhum ponto teve menos de sete dias de dados coletados (que é o mínimo adotado na prática), o que permite dizer que o comportamento médio das pressões, na época da coleta de dados, está bem definido.

Os dados foram coletados conforme o método descrito no item 5.3.2 e trabalhados como o descrito no item 5.3.3. Um exemplo dos dados trabalhados para as 12 horas é apresentado na Tabela 6.2. Os valores horários de cada registrador são encontrados no $\mathrm{CD}$ anexo no caminho Arquivos/DadosCampo/EnsaiosCampo.

Os ensaios de campo foram realizados nos trechos de rede P-24 e P-25, do esquema hidráulico. Somente estes trechos foram escolhidos devido à dificuldade de execução do teste, e para evitar a interrupção no fornecimento de água a um número maior de clientes. O ensaio ocorreu no mês de novembro de 2.009. Para a sua execução, foram realizadas as atividades, conforme o cronograma apresentado na Figura 6.6. 
Tabela 6.2 - Resumo dos valores médios e as 12 horas

\begin{tabular}{|c|c|c|c|c|c|}
\hline Registrador & Variável & Valor $12 \mathrm{~h}$ & Incerteza & Valor Médio & Incerteza \\
\hline L-01 & Vazão & 53,73 & 1,50 & 21,62 & 5,41 \\
\hline L-02 & Pressão & 0,00 & 0,20 & 38,02 & 0,59 \\
\hline L-03 & Pressão & 37,04 & 0,98 & 49,36 & 4,87 \\
\hline L-04 & Pressão & 47,54 & 1,22 & 62,72 & 6,02 \\
\hline L-05 & Pressão & 47,63 & 0,99 & 52,98 & 5,16 \\
\hline L-06 & Pressão & 28,92 & 0,75 & 39,17 & 3,86 \\
\hline L-07 & Pressão & 36,18 & 0,88 & 46,67 & 4,66 \\
\hline L-08 & Pressão & 43,00 & 1,19 & 55,83 & 5,26 \\
\hline L-09 & Pressão & 41,94 & 1,02 & 54,67 & 5,26 \\
\hline L-10 & Pressão & 26,97 & 0,74 & 38,33 & 3,76 \\
\hline L-11 & Pressão & 19,42 & 0,57 & 29,33 & 2,92 \\
\hline $\mathrm{L}-12$ & Pressão & 33,53 & 0,80 & 44,30 & 4,20 \\
\hline $\mathrm{L}-13$ & Pressão & 36,63 & 0,95 & 50,58 & 4,82 \\
\hline L-14 & Pressão & 35,29 & 1,75 & 47,83 & 11,43 \\
\hline $\mathrm{L}-15$ & Pressão & 43,74 & 1,21 & 57,43 & 5,48 \\
\hline L-16 & Pressão & 31,89 & 3,22 & 40,89 & 18,68 \\
\hline $\mathrm{L}-17$ & Pressão & 43,85 & 0,99 & 51,17 & 5,07 \\
\hline $\mathrm{L}-18$ & Pressão & 33,87 & 1,09 & 45,79 & 4,67 \\
\hline L-19 & Pressão & 40,16 & 1,03 & 50,26 & 5,21 \\
\hline
\end{tabular}

\begin{tabular}{|c|c|c|c|c|c|c|c|c|c|c|c|c|c|c|c|c|c|c|c|c|}
\hline \multirow{2}{*}{ Atividade } & \multicolumn{2}{|c|}{ DATA } & \multicolumn{3}{|c|}{ Junho } & \multicolumn{3}{|c|}{ Julho } & \multicolumn{3}{|c|}{ Agosto } & \multicolumn{3}{|c|}{ Setembro } & \multicolumn{3}{|c|}{ Outubro } & \multicolumn{3}{|c|}{ Novembro } \\
\hline & Inicio & Fim & 1 & 15 & 30 & 1 & 15 & 31 & 1 & 15 & 31 & 1 & 15 & 30 & 1 & 15 & 31 & 1 & 15 & 30 \\
\hline 1.0 Verificação dos registros limítrofes & $1 / 3 / 2009$ & $15 / 3 / 2009$ & & & & & & & & & & & & & & & & & & \\
\hline 2.0 Detecção de vazamentos & $15 / 8 / 2009$ & $15 / 10 / 2009$ & & & & & & & & & & & & & & & & & & \\
\hline 3.0 Reparo dos vazamentos & $20 / 8 / 2009$ & $20 / 10 / 2009$ & & & & & & & & & & & & & & & & & & \\
\hline 4.0 Nivelamento geométrico do trecho & $15 / 9 / 2009$ & $30 / 9 / 2009$ & & & & & & & & & & & & & & & & & & \\
\hline 5.0 Execução do ensaio & $19 / 11 / 2009$ & $19 / 11 / 2009$ & & & & & & & & & & & & & & & & & & \\
\hline $5.1 \quad \mathrm{FCl} / \mathrm{N} 1$ & 09:00 & $09: 30$ & & & & & & & & & & & & & & & & & & \\
\hline 5.2 Fator de atrito & $09: 40$ & $11: 00$ & & & & & & & & & & & & & & & & & & \\
\hline
\end{tabular}

Figura 6.6 - Cronograma de atividades realizadas nos ensaios

Na avaliação da rugosidade absoluta $\varepsilon$ foi utilizada a equação explícita de SOUSA (1999), equação 5.6 .

$$
\frac{1}{\sqrt{f}}=-2 \cdot \log _{10}\left(\frac{\varepsilon}{3,7 \cdot D}-\frac{5,16}{R_{e}} \cdot \log _{10}\left(\frac{\varepsilon}{3,7 \cdot D}+\frac{5,09}{R_{e}{ }^{0,87}}\right)\right)
$$

O fator de condição da infraestrutura é avaliado através das equações empíricas de (Lambert et al., 1998) equações 4.6 e 4.5, da relação entre a variação de vazão e pressão equação 4.4 . 


$$
F_{n d}=\sum_{n=1}^{24}\left(\frac{\bar{p}_{(n-1) \rightarrow n}}{\bar{p}_{3 \rightarrow 4}}\right)^{N_{1}} \ldots(4.6) ; Q_{\min }=Q_{v}+C_{\min } \ldots(4.5) ; \frac{Q_{1}}{Q_{0}}=\left(\frac{P_{1}}{P_{0}}\right)^{N_{1}} \ldots
$$

Para o calculo do $F_{c i}$, é necessária a determinação do $N_{1}$, que é obtido após trabalhar os dados coletados em campo, pela aplicação da equação 5.9.

$$
N_{1}=\frac{\log \left(\frac{Q_{1}}{Q_{0}}\right)}{\log \left(\frac{P_{1}}{P_{0}}\right)}
$$

O $F_{c i}$ é obtido pela aplicação da equação 5.7 .

$$
F_{c i}=\frac{Q_{i}}{Q_{v i}} \Rightarrow F_{c i}=\frac{Q_{i}}{2,78 \cdot 10^{-4} \cdot(20 \cdot L+1,25 \cdot N) \cdot\left(\frac{\overline{p_{m}}}{50}\right)^{N_{1}}}
$$

\subsection{SIMULAÇÃO HIDRÁULICA}

Após a obtenção do valor referente à rugosidade absoluta, por meio dos ensaios de campo. Por existir similaridade nas condições físicas da rede tais como: idade, material, $\mathrm{pH}$ da água fornecida, este valor foi adotado para todos os trechos de rede do modelo. A calibração foi feita em regime permanente hora a hora, utilizando o aplicativo "Darwin Calibrator" do WaterGEMS $\AA$, como o descrito no item 5.3.4. A calibração corrigiu as vazões dos trechos e as demandas das junções, produzindo series horárias de vazões e pressões. Estes resultados foram exportados para planilhas eletrônicas nas quais foram efetuados os cálculos de perdas para cada trecho de rede.

As tabelas com todos os resultados simulados estão no $C D$ anexo na pasta Arquivos/ModeloHidraulico/Simulacoes.zip. 


\section{RESULTADOS E DISCUSSÕES}

Neste capítulo será apresentado:

- As dificuldades e soluções adotadas na realização dos ensaios;

- O comparativo entre os dados medidos e os simulados;

- A avaliação das perdas;

- Discussão sobre o uso dos resultados no diagnóstico de perdas de água.

- Análise com gráficos de Pareto;

- Análise com mapas temáticos.

Após realizar todas as etapas descritas no capítulo cinco e efetuar as simulações hora a hora, foi gerado um conjunto de resultados inter-relacionados que representa de forma simplificada a realidade operacional da área em estudo. Mas para chegar neste resultado algumas dificuldades tiveram que ser resolvidas.

São elas:

1 Dificuldade na coleta de dados de campo;

2 Dificuldade de realização de ensaios de campo.

3 Falha na estanqueidade da área;

4 Demora excessiva na simulação em período estendido pelo WaterGEMS®;

\subsection{AS DIFICULDADES E AS SOLUÇÕES ADOTADAS}

A reprodução aproximada da realidade depende diretamente da confiabilidade das informações obtidas em campo. Assim, toda a coleta de dados proveniente de medições ou ensaios, deve ser tratada com o máximo rigor possível, agindo como se estivesse em um grande laboratório. Todas as ocorrências e providências tomadas devem ser apontadas. Quaisquer observações podem ser de grande valia no momento da simulação ou na análise dos resultados. 


\subsubsection{Dificuldade na coleta de dados de campo}

Os pontos amostrados com medições de pressão e vazão deveriam cobrir a maior extensão de rede possível. Na medição de vazão, o único ponto existente foi na entrada do DMC. Seria de grande valor a medição de vazões em outros trechos, pois permitiria um melhor conhecimento do comportamento das demandas, e além disso, é mais um item que contribuiria na sua calibração. Porém devido à falta de equipamentos e a dificuldade de instalação de mais medidores de vazão, neste trabalho utilizou-se apenas o medidor existente.

A falta de registradores eletrônicos, de vazão e pressão, em número suficiente para coletar os dados simultaneamente, nos pontos escolhidos, fez com que a coleta se alongasse por vinte e nove dias. Esta dificuldade foi resolvida ao longo do período de coleta, resultando em quinze dias com medições simultâneas. A solução foi aguardar a disponibilidade de mais equipamentos. Os dados de dois registradores $L-15$ e o L-19, que mediam pressão, tiveram um menor número de leituras em função de problemas na coleta dos dados e atraso na instalação respectivamente. No L-20 todos os dados formam perdidos por falha do equipamento. Outra dificuldade encontrada na coleta de dados de pressão foi à colaboração do cliente em ceder espaço em seu cavalete para a instalação do registrador eletrônico. Mesmo tendo sido conscientizado e informado da importância e necessidade da realização da medição, alguns clientes se achavam monitorados pela Sabesp e temiam aumento em suas contas, desta forma não permitiam a instalação do equipamento.

\subsubsection{Dificuldade de realização de ensaios de campo}

Alguns fatores dificultam a execução dos ensaios de campo. São eles:

A. Preparação do trecho: compreende construir PV para a instalação dos medidores de vazão e pressão, e a detecção e reparos de vazamentos.

B. Agendamento do ensaio: consiste em avisar o cliente e reservar equipe de técnicos e equipamentos para o ensaio de campo.

C. Controle das condições do ensaio: monitorar todas as ligações para evitar uso de água durante a realização do teste, acompanhar a variação das pressões e vazões detectando anomalias e observar alteração no padrão dos dados lidos. 
No preparo do trecho, as atividades dependeram da equipe de manutenção que atende à área para a execução do PV, porém sem prejudicar ou interferir na operação normal dos serviços diários. Desta forma, os serviços foram agendados conforme a disponibilidade de equipes para a execução. Na detecção e reparo dos vazamentos, houve a participação da equipe de detecção, e os reparos ocorreram na medida em que os vazamentos eram informados. Foram feitas três varreduras consecutivas na área. $\mathrm{E}$ foi necessário aguardar a disponibilidade da equipe de detecção de vazamentos, para a entrega dos avisos e posterior execução do ensaio.

No ensaio em campo aberto é necessário criar as condições para a obtenção dos dados, e isso requer a definição das variáveis que se deseja obter, e em como estabelecer e monitorar as condições em campo, permitindo medi-las. No ensaio realizado, as variáveis pesquisadas foram: pressão a montante e no ponto médio do trecho, e a vazão na entrada e na descarga. Estas variáveis são utilizadas no cálculo da rugosidade específica da tubulação e na determinação do $N_{1}$ e do $F C I$, como descrito no capítulo quatro item 4.5 equações 4.1 , 4.2, 4.4, 4.6, 4.7, 4.9 e 4.10 .

A instalação dos equipamentos de medição de pressão geralmente é feita nos cavaletes do cliente, a utilização de água pode interferir nas medições, por que causa variação na pressão, e também afeta a vazão medida na entrada do trecho. O controle dos consumos dos clientes difícil, uma vez que o número de pessoas envolvidas é limitado, e o número de ligações a controlar é grande. Os técnicos se empenham em manter sob controle o maior numero de ligações possível.

A quantidade de equipamentos, e de materiais, a serem utilizados deve estar disponível no momento da realização do ensaio. E isto não ocorreu, pois o ensaio prevê a instalação de quatro descargas para a determinação da rugosidade absoluta, mas só houve condição para a instalação de uma única descarga. Desta maneira, houve prejuízo nos resultados do ensaio, pois as vazões obtidas se situaram no regime de transição. Assim, os resultados dos cálculos, da rugosidade absoluta, ficaram comprometidos. Nada se pode concluir dos valores encontrados, embora próximos do valor real observado na amostra retirada da rede. 


\subsubsection{Falha na estanqueidade da área}

A confirmação da estanqueidade da área é a primeira ação a ser realizada em todo o trabalho, e influi diretamente nos resultados medidos. Cabe ter total confiança na informação obtida quanto à estanqueidade ou não da área. Basta saber se a área está ou não estanque, e no caso negativo saber qual o registro está aberto permitindo afluxo ou efluxo da água na área. Isto porque os dados reais serão simulados pelo modelo hidráulico, permitindo até a melhoria do desempenho do abastecimento local. No caso deste trabalho houve falha na estanqueidade da área, mas a mesma só foi detectada após várias simulações mal sucedidas no modelo hidráulico. Após duas verificações no local foi constatado que três registros limítrofes estavam abertos. Dois permitiam afluxo e um o efluxo de água.

\subsubsection{Demora na simulação em período estendido pelo WaterGEMS®}

Para a execução da calibração do modelo foi utilizado o aplicativo "Darwin Calibrator", existente no software WaterGEMS ${ }^{\circledR}$, como apresentado no capítulo cinco item 5.3.4. Originalmente seriam utilizados todos os dados existentes e executar o aplicativo em regime estendido. Porém ao se tentar este procedimento, o programa ficou horas processando e não apresentou nenhum resultado.

A solução encontrada foi simular em regime permanente (ou estático), hora a hora. $\mathrm{O}$ resultado foram 24 simulações, que foram utilizadas na obtenção dos resultados finais.

\subsection{COMPARATIVO ENTRE AS GRANDEZAS MEDIDAS E SIMULADAS}

Os dados coletados em campo por meio de medições e pelos ensaios, compõem a base na qual o modelo de simulação hidráulica se apoia para efetuar a calibração das variáveis de calculo.

$\mathrm{Na}$ modelagem, foi utilizado um perfil de consumo padrão para todas as ligações. Isto não ocorre na realidade, mas esta simplificação foi adota em face das similaridades dos usos da água no DMC e da existência da caixa d'água que interfere na simultaneidade 
dos consumos. Desta forma, em junções onde o comportamento do perfil de consumo real se aproximou da somatória de perfis teóricos, os valores tiveram variações aceitáveis, já em pontos onde o perfil era muito diferente, os valores apresentam variações maiores. Porém o comportamento hidráulico de todos os pontos simulados é semelhante ao real medido. A seguir é apresentada a análise dos dados de vazão e pressão levantados em campo.

\subsubsection{Medição de vazão}

A vazão foi medida na entrada da área onde existe um hidrômetro pré-equipado com saída pulsada, na qual se conectou um registrador eletrônico de vazão. A comparação entre a vazão medida e a vazão simulada, demonstrou valores coerentes e plenamente aceitáveis. A Figura 7.1 mostra o gráfico comparativo dos valores medidos e simulados.

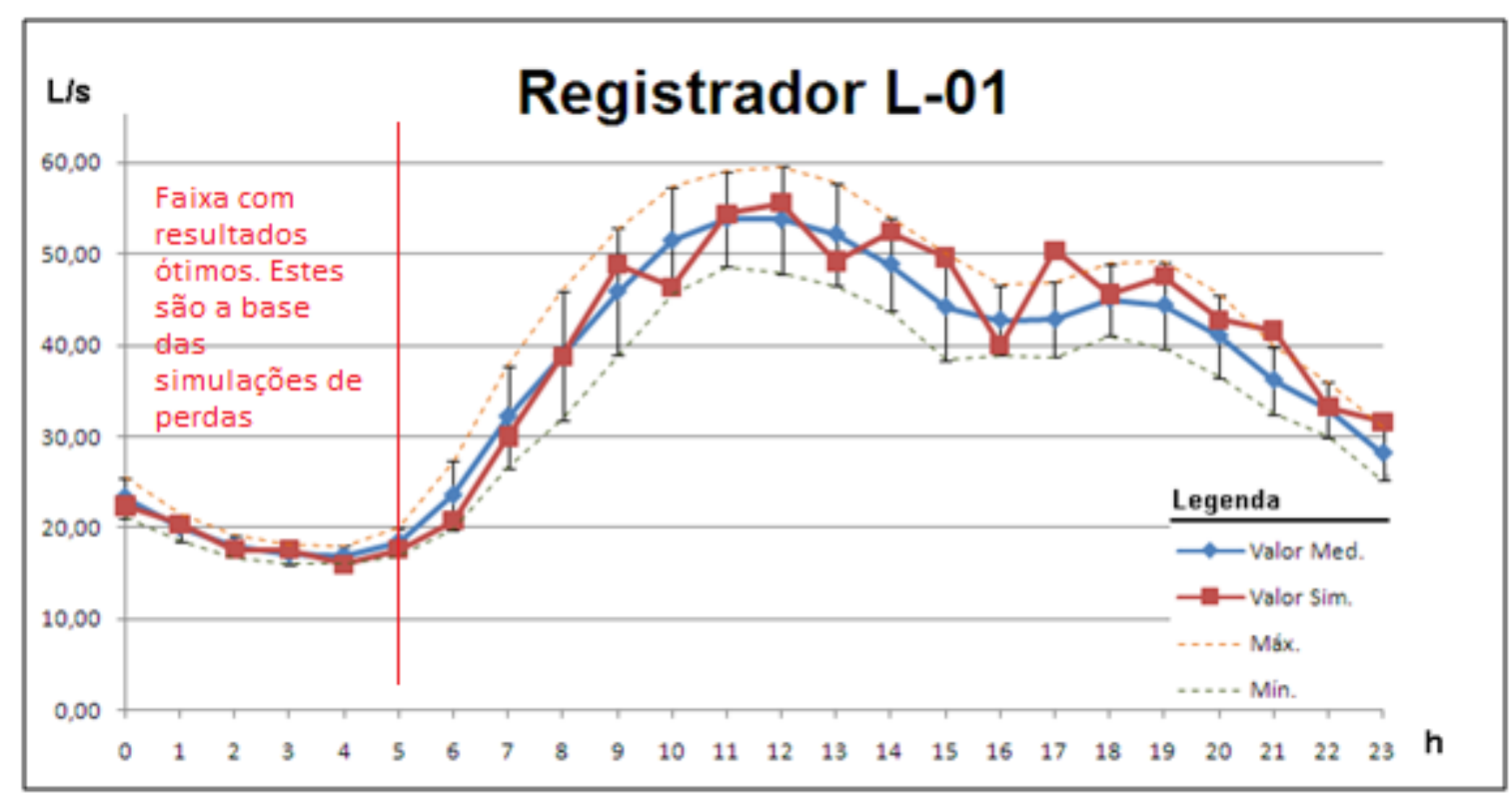

Figura 7.1 - Gráfico comparativo da vazão medida e simulada

A vazão obtida na modelagem refletiu bem as condições operacionais, pois como a área escolhida possui a característica predominante a residencial, a vazão resultante ficou bem definida e dentro dos limites esperados. Demonstrando que a correção das demandas obtida pela aplicação do algoritmo genético forneceu bons resultados na correção da vazão total da área em estudo. A faixa demarcada na Figura 7.1, ilustra a coincidência do comportamento dos dados simulados e dos valores médios medidos no 
sistema real. Este período é o utilizado na estimativa da vazão mínima noturna que é a base para a determinação das vazões de vazamentos.

\subsubsection{Medição de pressão}

$\mathrm{Na}$ prática, observa-se que, numa área sem gerenciamento de pressão, o comportamento da pressão é inverso ao da vazão, ou seja, quando a pressão é máxima a vazão é mínima e vice-versa. As pressões foram medidas em dezoito pontos. A comparação dos valores medidos, com os modelados, apresentaram configurações bem distintas. Mas o comportamento hidráulico do sistema virtual foi semelhante ao do sistema real. A Figura 7.2, mostra em forma de gráfico o comportamento dos valores simulados. Nota-se que em cada hora, a distribuição dos valores é irregular. $\mathrm{Na}$ cor verde estão os valores dentro da faixa criada pelos limites superior e inferior, e na cor cinza os valores fora dos limites definidos. Na média os valores obtidos ficaram $45 \%$ dentro dos limites definidos, representada pela linha de cor vermelha na Figura 7.3, e a linha ondulada de cor azul mostra a variação horária da quantidade de registradores simulados que ficaram dentro dos limites. Este resultado pode ser melhorado com a simulação em regime estendido, pois permite uma uniformização maior nos valores estimados pelo AG. Fica aqui uma recomendação para novos trabalhos neste sentido.

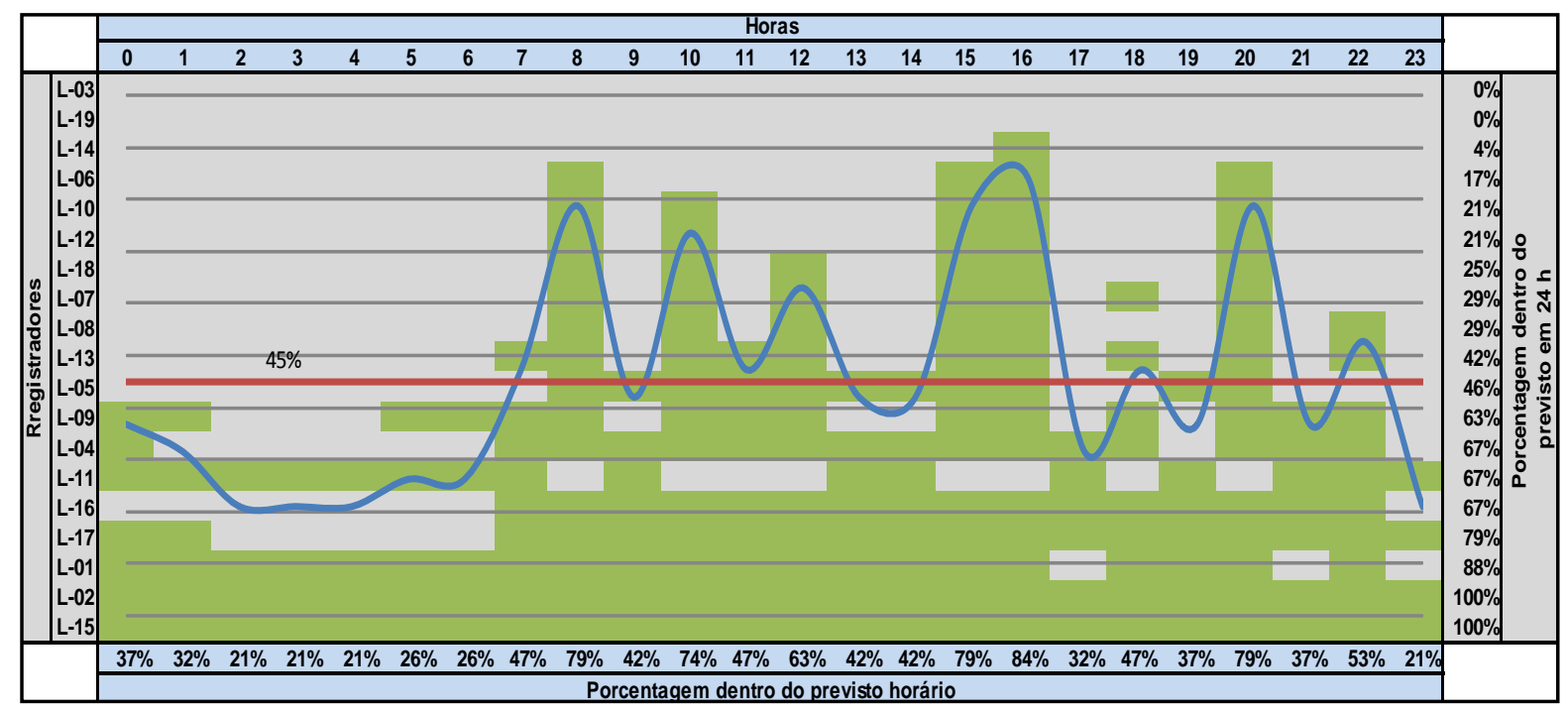

Figura 7.2 - Comparação entre valores horários medidos e simulados

A simulação dos registradores $L-02$ e $L-15$, forneceram valores dentro da faixa em todas as 24 simulações realizadas. Já a simulação dos registradores L-03 e L-19, forneceram 
valores fora dos limites definidos, mas o comportamento das variações de pressão são semelhantes ao real. As 8, 10, 15, 16 e 20 horas apresentaram o maior número de valores dentro da faixa simultaneamente. Sendo que às 16 horas é a melhor estimativa, com $84 \%$ dos valores dentro da faixa simultaneamente, e o período entre as 23 e 7 horas, apresenta o menor número. Este comportamento pode ter sua origem no fato de ter sido adotado, os valores de precisão e de aproximação, padrões do aplicativo.

Isto pode ter diminuído a sensibilidade às variações da pressão, que em alguns períodos, foi pequena. Não houve novas tentativas de calibração alterando-se os parâmetros padrões do aplicativo.

A Figura 7.3, apresenta o comportamento da simulação do registrador L-02, comparado aos valores reais, e com os limites superior e inferior. O comportamento da variação de pressão ao longo do dia foi representado com boa aproximação.

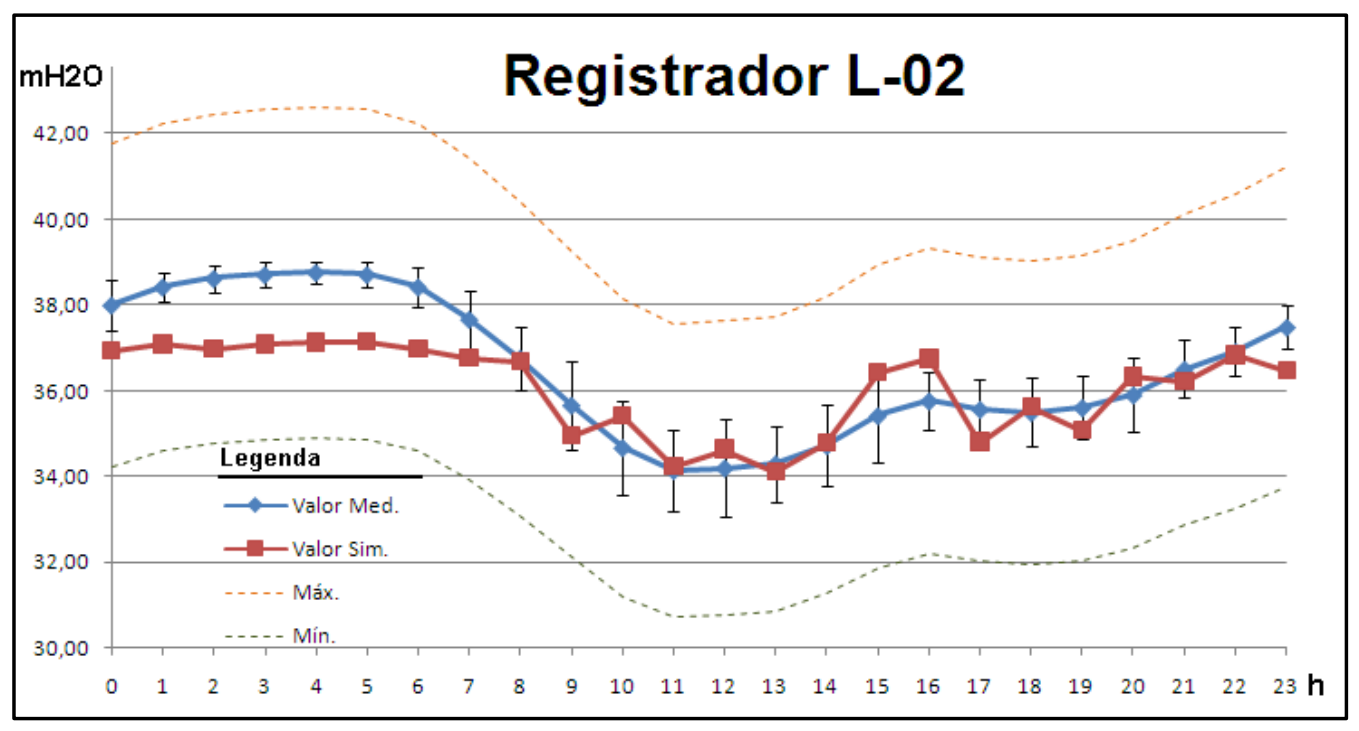

Figura 7.3 - Gráfico comparativo dos valores L-02

$\mathrm{Na}$ Figura 7.4, é apresentado o comportamento dos valores simulados do registrador L03 . Embora seus valores, comparados com os reais, estejam fora dos limites definidos, o comportamento das variações de pressão, ao longo das 24 horas, semelhante ao real. Estudando os valores simulados, pode se constatar que as variações de pressão simuladas tem o mesmo comportamento das variações reais de pressão do sistema. $E$ 
se todos os valores simulados, que se apresentam fora dos limites, forem multiplicados por uma constante, o resultado situa-se entre os limites definidos, como mostra a Figura 7.5 , que apresenta os valores do L-03 multiplicados por 1,28.

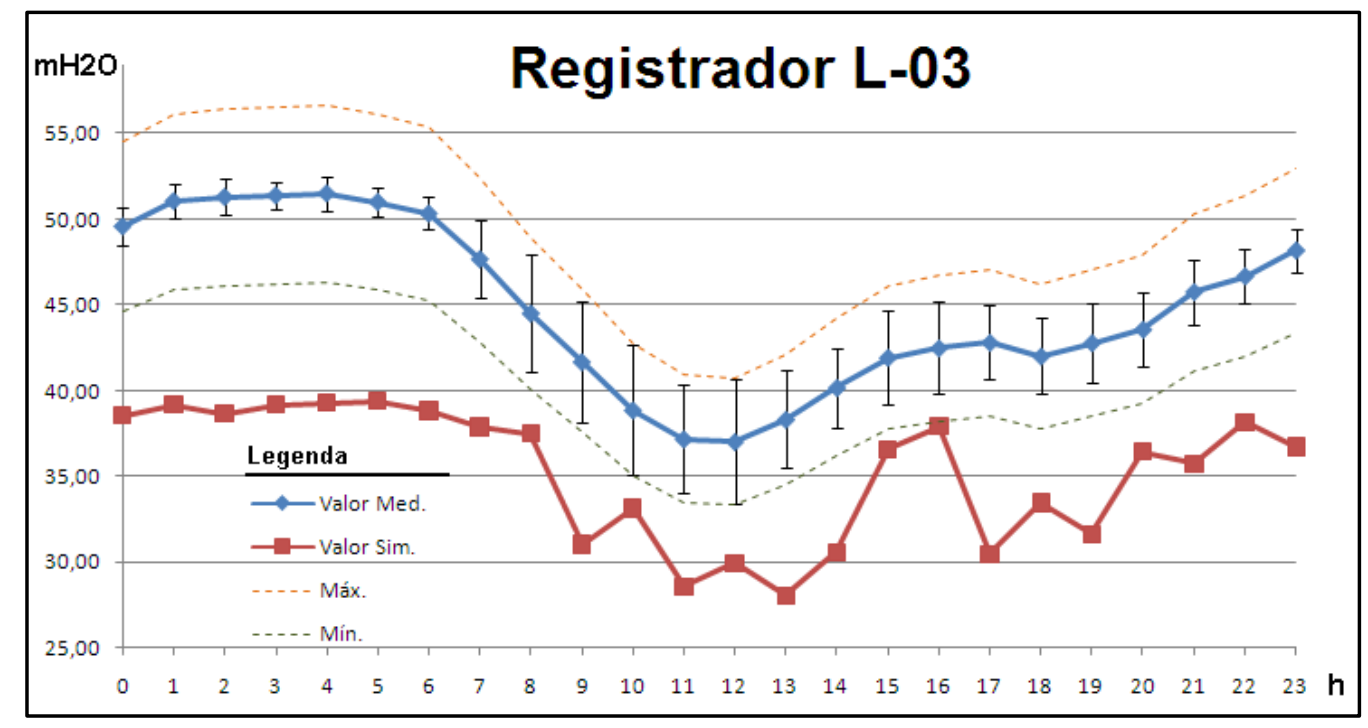

Figura 7.4 - Gráfico comparativo L-03

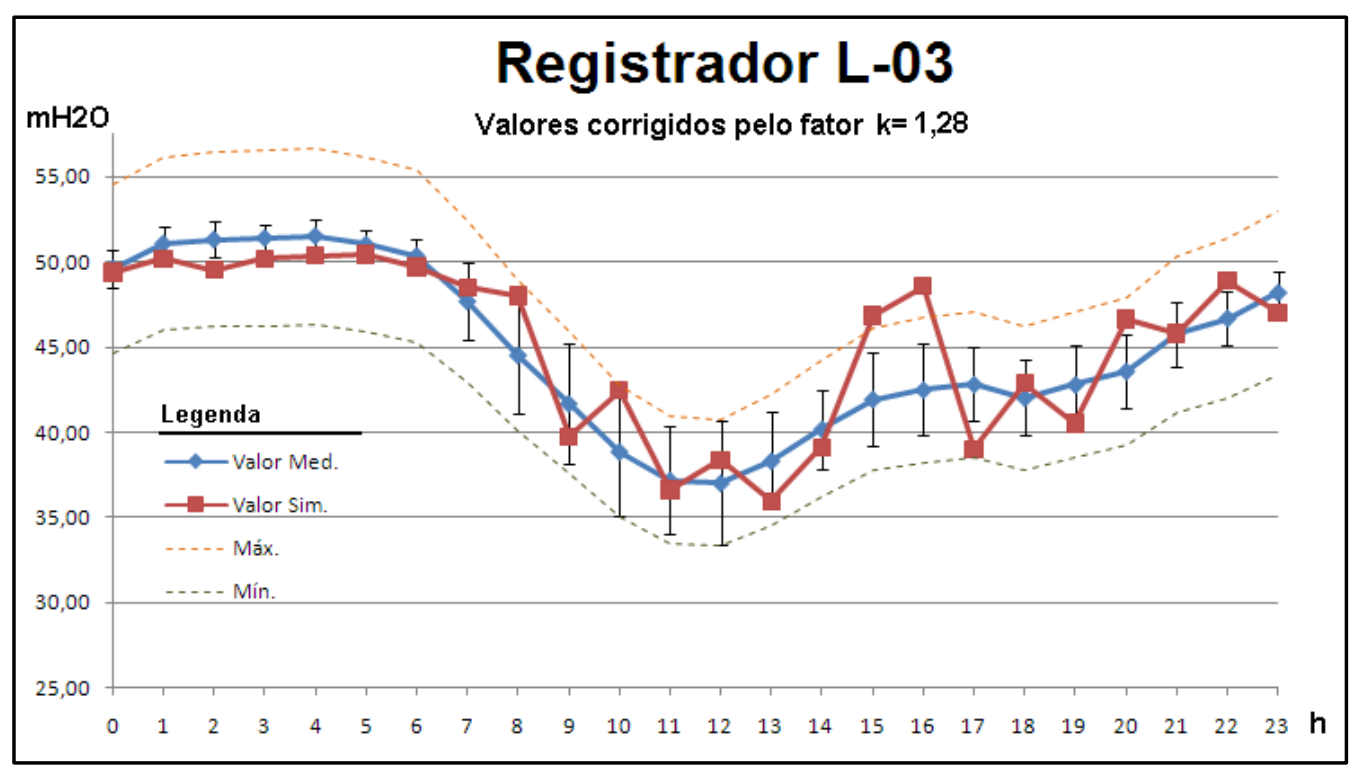

Figura 7.5 - Valores do registrador L03 simulados corrigidos pelo fator $k=1,28$

Desta forma nota-se que as simplificações aplicadas na calibração do sistema virtual, produzem resultados finais que representam o comportamento existente no sistema real, mas sem com isso, expressar o valor exato das grandezas existentes. Desta 
forma, os valores corrigidos das demandas incorporam os vazamentos no trecho, mas as vazões dos vazamentos podem ser bem diferentes no sistema real. Contudo, seu valor representa a perda real no trecho, em termos de grandeza, o que para 0 diagnóstico é útil.

Um dos parâmetros que certamente está influindo no resultado é a rugosidade absoluta. Este parâmetro teve seu valor obtido no ensaio de campo e foi considerado igualmente em todos os trechos de rede, como já comentado anteriormente, o que não acontece no sistema real, onde cada trecho tem uma rugosidade específica própria.

A calibração do modelo hidráulico se dá partindo das variações de pressão medidas no sistema real, e corrigindo as demandas de cada junção, ou a rugosidade específica de cada trecho de rede. A primeira opção foi escolhida, por estarem contidas nas demandas das junções as vazões dos vazamentos. E para a calibração do modelo, fazse a variação de vazão em todas as junções, na busca de valores que melhor representem o comportamento hidráulico, representado pelas pressões medidas. Se a opção fosse corrigir as rugosidades, seria necessário adotar que os vazamentos estivessem contidos nas demandas totais de cada junção, pois as demandas ficariam inalteradas durante a calibração da rugosidade específica, e isso prejudicaria o diagnóstico das perdas.

\subsection{A AVALIAÇÃO DAS PERDAS}

Após as simulações, os resultados são importados para as planilhas de pressões, vazões e trechos de rede. Os cálculos de todos os componentes de perdas por trecho são efetuados em planilha eletrônica, na qual fica caracterizado o balanço hídrico e os componentes da vazão mínima. Na Erro! Fonte de referência não encontrada.Figura .5 é apresentado um exemplo da planilha calculada para o trecho P-20 do modelo de simulação hidráulica. A planilha é composta por quatro quadros. O primeiro situado acima e à esquerda, denominado 'Resumo do trecho avaliado', o segundo, situado acima e à direita, denominado 'Valores IWA', o terceiro, situado ao lado do segundo, denominado 'Dados', e o quarto, com os cálculos, abaixo dos quadros citados. 

O primeiro quadro possui em seu conteúdo, um resumo das informações do trecho, nele é apresentado:

- Na linha 1, a denominação atribuída ao trecho;

- Na linha 2, a extensão de rede expressa em metros,

- Na linha 3, o número de ligações existentes,

- Na linha 4, o material que constitui a tubulação,

- Na linha 5, a vazão média da demanda, obtida pela média calculada com os valores da coluna 5 , no intervalo da linha 9 a linha 32 ,

- Na linha 6, a vazão média fornecida total, obtido pela média calculada com os valores da coluna 3 , no intervalo da linha 9 a linha 32 ,

- Na linha 7, a vazão média fornecida ao trecho, obtida pela média calculada com os valores da coluna 4, no intervalo da linha 9 a linha 32,

- Na linha 8, a vazão média transferida, obtida pela diferença entre a vazão média fornecida ao trecho e a vazão média fornecida total, todas as vazões expressas em litros por segundo.

No segundo quadro, são apresentados os valores padronizados de vazão de vazamentos, pela IWA. Estes são utilizados nos cálculos das vazões de vazamentos inerentes. Nele é apresentado:

- Na linha 1, o valor padrão de vazão para vazamentos em rede, expressa em litros por hora por quilometro de rede, e;

- Na linha 2, o valor padrão de vazão de vazamentos em ramais, expressa em litros por hora por ramal.

No terceiro quadro, são apresentados:

- Na linha 1, a vazão média mínima, expressa em litros por segundo;

- Na linha 2, a vazão média máxima, expressa em litros por segundo;

- Na linha 3, a pressão à vazão mínima, expressa em metros de coluna de água;

- Na linha 4, a pressão à vazão máxima, expressa em metros de coluna de água;

- Na linha 5, vazão mínima, expressa em litros por segundo;

- Na linha 6, o consumo médio mínimo obtido à vazão mínima, expresso em litros por segundo. 
O quarto quadro, é composto de 20 colunas, nas quais são apresentados os dados simulados por hora obtidos do modelo de simulação, e os cálculos de perdas, baseado nas equações teóricas apresentadas no capítulo 4. Nas colunas tem-se:

- Coluna 1, da linha 9 a 32, as horas simuladas;

- Coluna 2, da linha 9 a 32, o fator horário das demandas baseado no trabalho de Barreto, (2008);

- Coluna 3, da linha 9 a 32, a vazão horária simulada total, expressa em litros por segundo;

- Coluna 4, da linha 9 a 32, a vazão horária simulada fornecida ao trecho, expressa em litros por segundo;

- Coluna 5, da linha 9 a 32, as demandas horárias corrigidas pelo algoritmo genético, expressa em litros por segundo;

- Coluna 6, da linha 9 a 32, as pressões horárias simuladas, na extremidade inicial do trecho, expressa em metros de coluna de água;

- Coluna 7, da linha 9 a 32, as pressões horárias simuladas, na extremidade final do trecho, expressa em metros de coluna de água;

- Coluna 8, da linha 9 a 32, as pressões horárias no ponto médio, obtida pela média aritmética entre as pressões apresentadas nas Colunas 6 e 7;

- Coluna 9, da linha 9 a 32, as razões entre a pressão horária média e a pressão mínima, adimensional;

- Coluna 10, o valor de $\mathrm{N}_{1}$, calculado pela equação 5.9, obtido graficamente com os valores obtidos dos ensaios de campo;

- Coluna 11, o valor do fator noite dia (FND), calculado pela equação 4.6;

- Coluna 12, o valor da vazão de perda real inevitável, obtida pela equação 4.12;

- Coluna 13, o valor da vazão de vazão de vazamentos inerentes, calculada pela equação 4.9;

- Coluna 14, o valor da vazão de vazamentos, obtida pela diferença entre a vazão mínima, apresentada no terceiro quadro na linha 5, e o consumo mínimo ocorrido à vazão mínima, expressa em litros por segundo;

- Coluna 15, o valor da vazão de vazamentos corrigida pelo fator noite dia, (equação 4.7), expressa em litros por segundo;

- Coluna 16, o valor do fator de condição da infraestrutura (FCI), calculado pela equação 5.15 , adimensional; 
- Coluna 17, o valor do indicador de perdas na distribuição (IPDT), calculado pela equação 4.14, expresso em litros por ligação por dia.

- Coluna 18, o valor estimado da vazão de perdas reais, expresso em litros por segundo, e abaixo na mesma coluna a porcentagem em relação à perda total;

- Coluna 19, o valor estimado da vazão de perdas aparente, expresso em litros por segundo, e abaixo na mesma coluna a porcentagem em relação à perda total;

- Coluna 20, o valor da vazão perdida por quilometro de rede, expressa em litros por segundo por quilometro.

Cabe salientar que em alguns trechos de rede, o resultado do cálculo da vazão de perda real, resultou em um valor negativo. Isto porque, a distribuição das demandas reais existentes no trecho, atribuídas às junções de suas extremidades, acaba sendo influenciada pelas demandas dos demais trechos unidos na mesma junção. Desta forma, quando o algoritmo genético executa as adequações nas vazões das junções, provoca algum desvio em relação ao balanço de vazões originais, o que pode gerar valores de vazão fornecida ao trecho, menores que a vazão perdida total. Como não existe perda nula ou negativa, para efeito de cálculo, foi considerada nestes casos a perda real igual à perda real inevitável.

Todas as planilhas podem ser consultadas no CD anexos na pasta Arquivos/ModeloPerdas. Com as planilhas trecho a trecho, os resultados são compilados em uma planilha resumo (ver Tabela 7.1), a qual será a base para a elaboração dos gráficos de Pareto e os mapas temáticos para o diagnóstico de perdas da área.

Com os mapas será possível conhecer a característica da distribuição de água nos trechos, e a escolha das ações. E também dará um direcionamento às ações, aplicando os recursos acertadamente nos trechos críticos, bem como prever o comportamento posterior do sistema, prevendo novas ocorrências de problemas operacionais.

\subsection{DISCUSSÃO SOBRE O USO DOS RESULTADOS NO DIAGNÓSTICO DE PERDAS DE ÁGUA.}

Com os resultados calculados por trecho de rede e tabulados como apresentado na Tabela 7.1 foi feita a comparação dos valores obtidos e os valores efetivos do sistema 
real. Os valores comparados foram:

- Acertos e erros na previsão de vazamentos;

- Pressões simuladas com as medidas no sistema real;

- Vazão fornecida simulada e a medida na entrada do sistema real;

- Rugosidade absoluta teórica com a obtida no ensaio de campo;

\subsubsection{Comprovações na previsão de vazamentos.}

$\mathrm{Na}$ Tabela 7.1, pode ser observada a classificação dos trechos e a priorização sugerida. Observa-se que, foram selecionados 12 trechos de classe "A", e constada a existência vazamentos em dois deles, isso resultaria numa economia de 6,29 L/s, representando $40,70 \%$ da perda real total do DMC, e atuando em apenas $27,18 \%$ da extensão total de rede. A tabela 7.3, apresenta os trechos classificados e selecionados, mas onde não houve comprovação de vazamentos.

Tabela 7.1 - Trechos com vazamentos comprovados

\begin{tabular}{|l|c|r|c|c|c|}
\hline Classificação & Selecionados & \% Extensão Rede & Quantidade & Recuperação em L/s & \%Relativa à Perda Total \\
\hline Classe A & 12 & $27,18 \%$ & 2 & 6,29 & $40,70 \%$ \\
\hline Classe B & 29 & $52,50 \%$ & 7 & 1,04 & $6,75 \%$ \\
\hline Classe C & 7 & $10,49 \%$ & 1 & 0,0035 & $0,02 \%$ \\
\hline Sem classificação * & 5 & $9,83 \%$ & 0 & - & - \\
\hline
\end{tabular}

* Refere-se a trechos teóricos ou colocados para garantir a calibração da simulação hidráulica

Avaliando ainda os trechos selecionados de classe "A", tem-se que a média da vazão por vazamentos constatados é de 3,14 L/s por. Se os demais vazamentos de classe "A" fossem detectados, haveria um acréscimo de $0,43 \mathrm{~L} / \mathrm{s}$ por vazamento. Desta maneira, a eficácia do modelo é comprovada, pois direciona a atenção nos trechos onde o retorno será maior.

Tabela 7.2 - Trechos com vazamentos não comprovados

\begin{tabular}{|l|c|r|c|c|c|}
\hline Classificação & Selecionados & \% Extensão Rede & Quantidade & Recuperação em L/s & \%Relativa à Perda Total \\
\hline Classe A & 12 & $27,18 \%$ & 10 & 4,34 & $28,12 \%$ \\
\hline Classe B & 29 & $52,50 \%$ & 22 & 3,35 & $21,71 \%$ \\
\hline Classe C & 7 & $10,49 \%$ & 6 & 0,42 & $2,70 \%$ \\
\hline Sem classificação * & 5 & $9,83 \%$ & 5 & - & - \\
\hline
\end{tabular}

* Refere-se a trechos teóricos ou colocados para garantir a calibração da simulação hidráulica

7.4.2 As pressões simuladas com as medidas no sistema real. 
Com a comparação dos valores medidos e simulados, observa-se que em média $45 \%$ dos valores simulados estiveram dentro dos limites estipulados. É difícil predizer as causas que levaram os resultados a se afastarem dos valores esperados. Eles podem ter sido afetados por diversos fatores. Como exemplo, pode-se citar:

- O perfil de consumo, que por ser determinante das variações horárias de vazão, influi diretamente na determinação dos valores nos trechos;

- A cota altimétrica, por ter sido obtida de plantas cadastrais com intervalos entre cotas de cinco metros, e sem a verificação das cotas reais no local;

- A rugosidade absoluta, cujo valor escolhido foi o obtido na amostra e aplicado igualmente a todos os trechos da rede.

Mesmo assim, o comportamento físico dos fluxos de água nas tubulações foi representado de modo aceitável, e permitiu a avaliação das perdas de água no DMC. Desta forma, as informações fornecidas pelo modelo de simulação, podem ser utilizadas para a definição dos trechos que, são os mais críticos, e assim, determinar as ações de perdas a serem aplicadas.

\subsubsection{A vazão fornecida simulada e a medida na entrada do sistema real.}

Os valores simulados para a vazão de entrada do DMC ficou dentro dos limites esperados. Isto pode ter sua explicação no comportamento hidráulico do sistema real ser definido pelo uso residencial em sua quase totalidade.

7.4.4 A rugosidade absoluta teórica e a obtida no ensaio de campo.

A rugosidade absoluta das tubulações foi determinada pelo cálculo teórico com a equação de Colebrook-White, e pelo ensaio de campo. Uma amostra da rede foi obtida pela necessidade de se instalar uma válvula de manobra no trecho do ensaio, o que permitiu a verificação visual da rugosidade. Isto possibilitou a comparação entre o valor teórico obtido com a equação de Colebrook-White, e a espessura real medida na amostra, uma vez que o resultado obtido com o ensaio foi prejudicado pela falta de equipamento, como já exposto. Na pratica é utilizado apenas a equação de ColebrookWhite, sem se avaliar a real situação da incrustação, este ensaio permite dizer que o uso da equação é válido para tubos de ferro fundido que conduzem água potável. 


\subsubsection{Análises com gráficos de Pareto}

Com o gráfico de Pareto é possível realizar analises de custo benefício, e com elas obter quais os trechos de rede receberão ações. Dentre todos os dados simulados serão apresentado alguns exemplos de análises para ilustrar a aplicação dos resultados de modelos de simulação hidráulica. Isto permite potencializar os recursos.

\section{Volumes perdidos}

A Figura 7.6, apresenta um gráfico de Pareto da porcentagem de perda real em função dos trechos de redes, direcionando ações em P-34, P-43, P-52, P-46 e P-50, ou seja, atuando em apenas cinco trechos é possível atacar $50 \%$ da perda total da área, que representa aproximadamente $17 \%$ da extensão de rede.

\section{Recursos disponíveis}

Para avaliar o uso de recursos, aplicam-se os gráficos de Pareto relacionando variáveis, desta maneira é possível determinar os itens potenciais que aumentam a probabilidade do retorno ser maior. A Figura 7.7 mostra um gráfico de Pareto com a relação porcentual de perda total relacionada com a extensão de rede. Nota-se que se houverem recursos para investir em troca ou revitalização de rede e ramais, em torno de $50 \%$ da extensão total, estará sendo combatidas $85 \%$ da perda total.

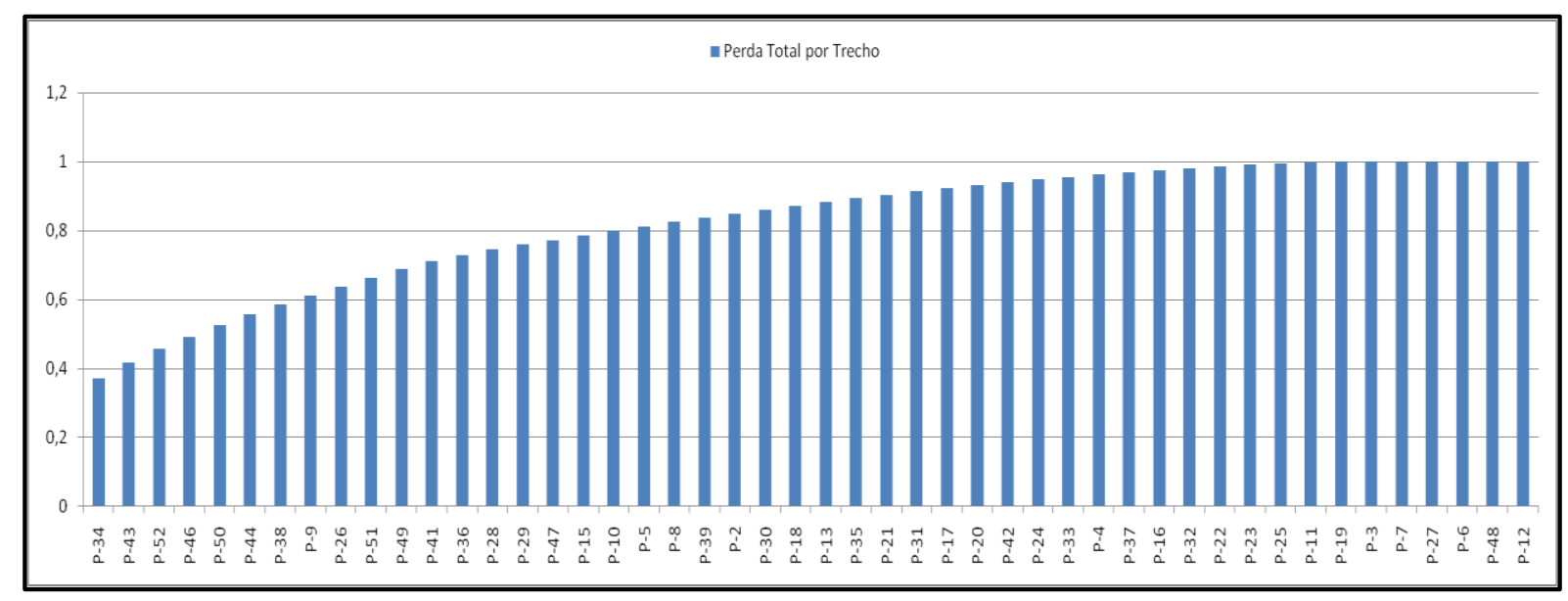

Figura 7.6 - Gráfico de Pareto da porcentagem de perda total por trecho. 


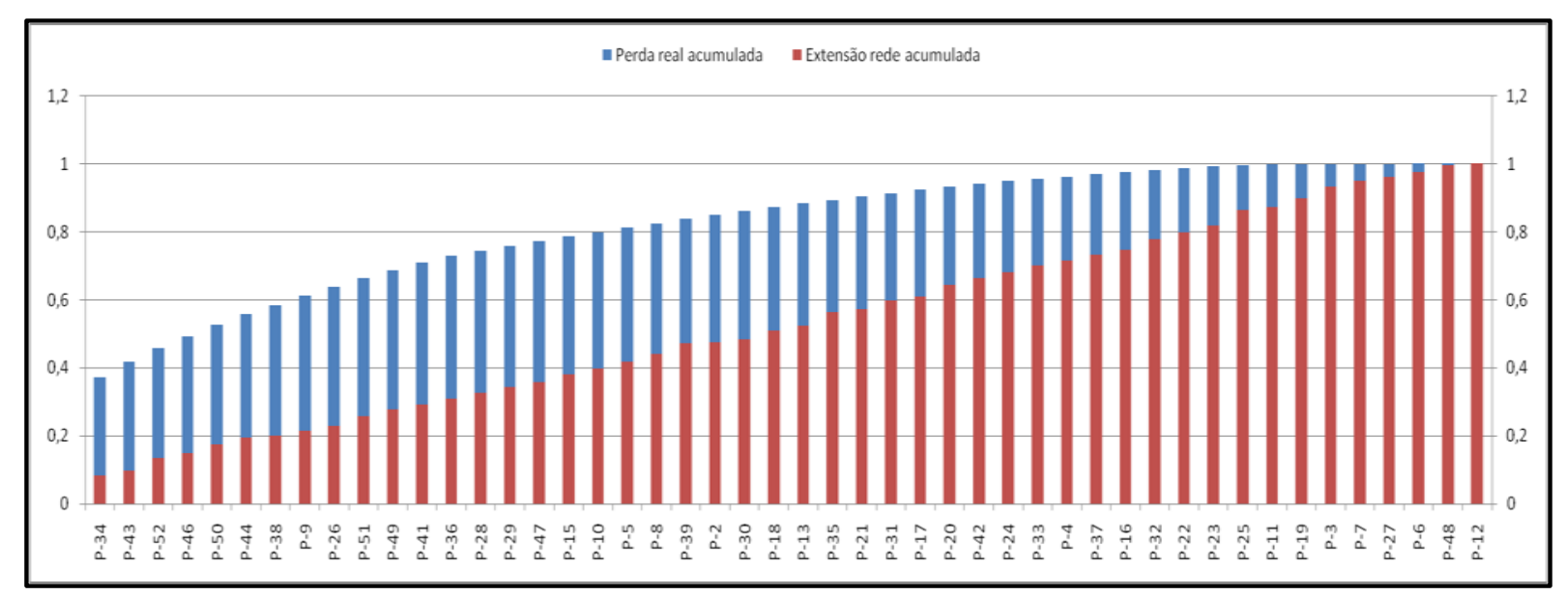

Figura 7.7 Gráfico de Pareto da perda total e extensão de rede acumuladas

A Figura 7.8, demonstra que se existirem recursos para agir sobre $40 \%$ das ligações, será combatida em torno de $76 \%$ da perda aparente.

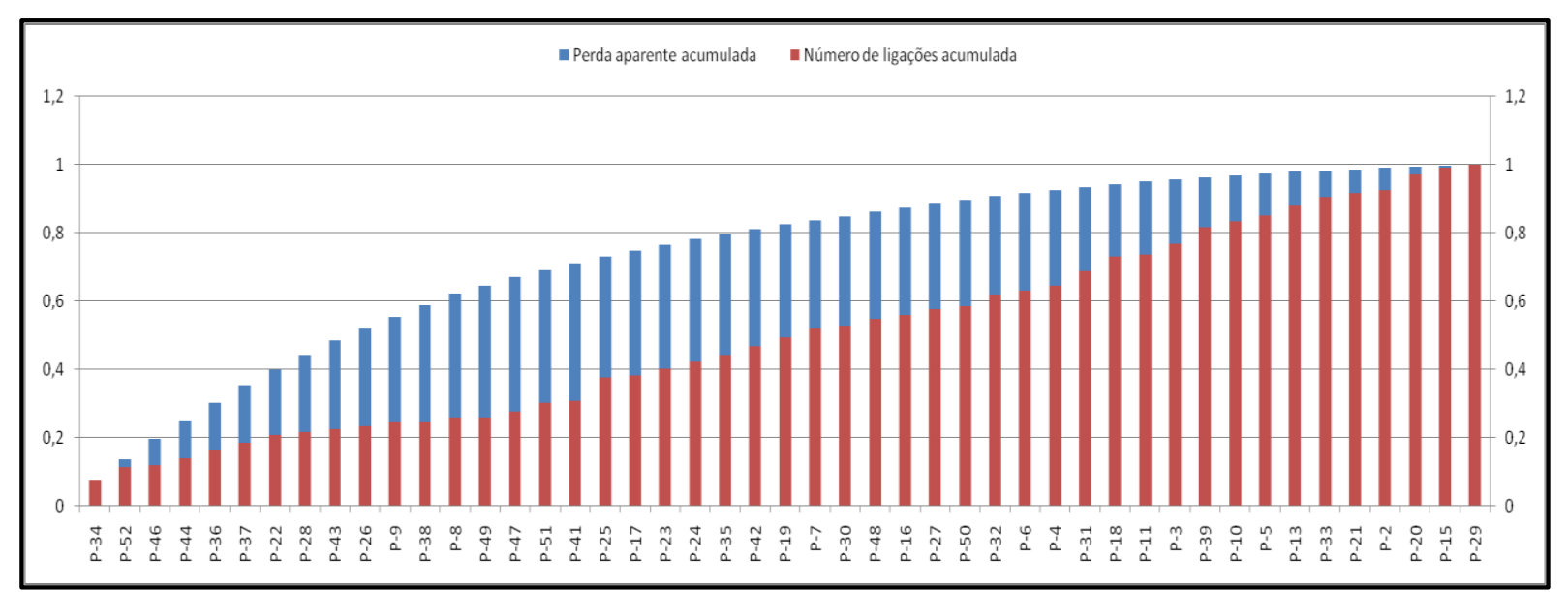

Figura 7.8 Gráfico de Pareto Perda aparente x Núm. de ligações acumuladas

\subsubsection{Os mapas temáticos}

O uso de mapas temáticos alavanca as análises com a espacialização das informações. É possível elaborar vários mapas temáticos, por exemplo: $F C I, L / k m, P_{a}$ e $P_{r}$. Os mapas temáticos servem para orientação, base para o planejamento, e também conhecimento da área em estudo.

Cada mapa elaborado tem como função, apresentar como um determinado tema se distribui sobre a área em estudo. Isto permite a superposição de informações, 
facilitando compreender o comportamento das variáveis. O mapa utilizado é o quantitativo, que representa de forma resumida a distribuição de um tema nos trechos de rede. $O$ estudo de caso permitiu comparar os dados de perdas por trecho de rede, com o número e tipo de vazamento real detectado antes do ensaio de campo. Desta forma, pode ser feita a comparação e observação dos acertos na previsão fornecida pelo modelo hidráulico. Neste trabalho, foram preparados três mapas temáticos que caracterizam o perfil de perdas de água existente na área. E um analítico sintético que auxilia no entendimento das perdas que ocorrem na área dando uma visão global da área.

No mapa da Figura 7.10, são apresentados os vazamentos detectados e o valor do $\mathrm{FCl}$ por trecho de rede. $\mathrm{O}$ a espessura dos trechos está variando de acordo com o valor calculado do $\mathrm{FCl}$, sendo o mais fino o menor e o mais espesso o maior. O FCl compara a vazão de perda real inerente atual com a admissível estipulada pela IWA, a qual é baseada na perda inerente encontrada em setores de abastecimento com uma infraestrutura em boas condições. Os trechos onde a condição da infraestrutura é pior, também foram detectados vazamentos. Embora este indicador forneça apenas um quantitativo de vazamentos inerentes, em redes com uma condição de infraestrutura muito ruim, a presença de vazamentos detectáveis é esperada.

No mapa da Figura 7.11, é apresentada a perda por km de rede. Este mapa mostra a variação da vazão de vazamentos por quilometro de rede. Nos trechos onde o indicador é maior, pode haver vazamentos, mas também pode ser um trecho no qual a vazão está fortemente afetada por vazamentos em sua vizinhança. Isto pode ser observado, por exemplo, nos trechos P-50 e P-52. Já nos trechos P-45, P-40, P-53 e P-14, são afetados pela existência de afluxo de água, na entrada do abastecimento ( $\mathrm{P}-45$ e P-40), e efluxo de água, causado por falha na estanqueidade ( $\mathrm{P}-53$ e P-14), que causam um acréscimo nas vazões dos trechos que contribuem para alimentar as demandas e os vazamentos.

O mapa da Figura 7.12, mostra a distribuição da perda real nos trechos de rede. Pode ser observado, que a maioria dos vazamentos detectados, está nos trechos demarcados com os maiores índices de perda real. Este é um bom orientador para a detecção de vazamentos, pois reflete o volume real perdido em cada trecho de rede. Também permite a seleção de trechos provavelmente comprometidos, nos quais pode 
ser prevista somente a troca de ramais, e/ou troca ou reabilitação da rede.

A perda real por trecho demonstra melhor a distribuição dos vazamentos, pois o volume perdido é representativo dos trechos afetados pelas vazões de vazamentos. Pode ser observado que os trechos P-30, P-31, P-50, P-46, P-52, P-51, P36, P-28 e P-29, são afetados pelos vazamentos existentes em torno da junção $\mathrm{J}-10$. O trecho P-22, embora tenha vazamentos locados no sistema real, apresentou perda menor que o trecho P-52, que não possui vazamentos detectados. O que não implica dizer que no trecho P-52, não há vazamentos.

A perda aparente é obtida pela diferença entre as perdas total e real calculada, desta forma o mapa da Figura 7.13, apresenta a perda aparente por trecho de rede. $\mathrm{Na}$ avaliação das perdas aparentes, é necessária a estratificação das causas, e com o auxílio deste mapa, é possível selecionar os trechos de maior incidência de perda aparente, e efetuar um estudo para verificar qual ação será mais eficaz.

Para a análise do comportamento das perdas de água na área, é utilizado um mapa analítico sintético, no qual é apresentada a perda real e aparente comparada com o FCl dos trechos de rede. Este mapa é apresentado na Figura 7.14, e auxilia na visualização das características das perdas da área, em conjunto com as condições da infraestrutura. 


\section{$\mathrm{FCl} \times$ Vazamentos}

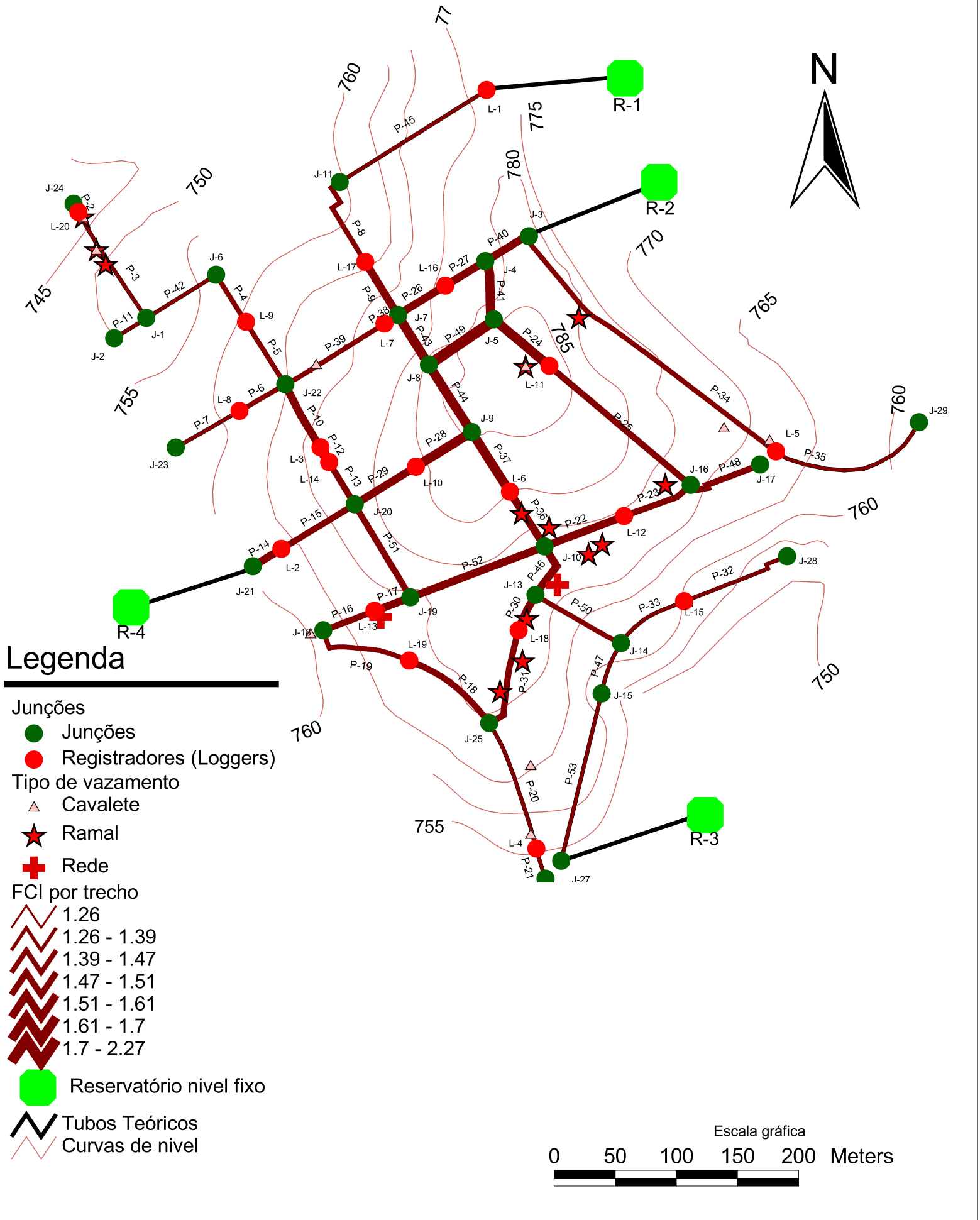

Figura 7.10 - FCl x Vazamentos - ArcView ${ }^{\circledR}$ 


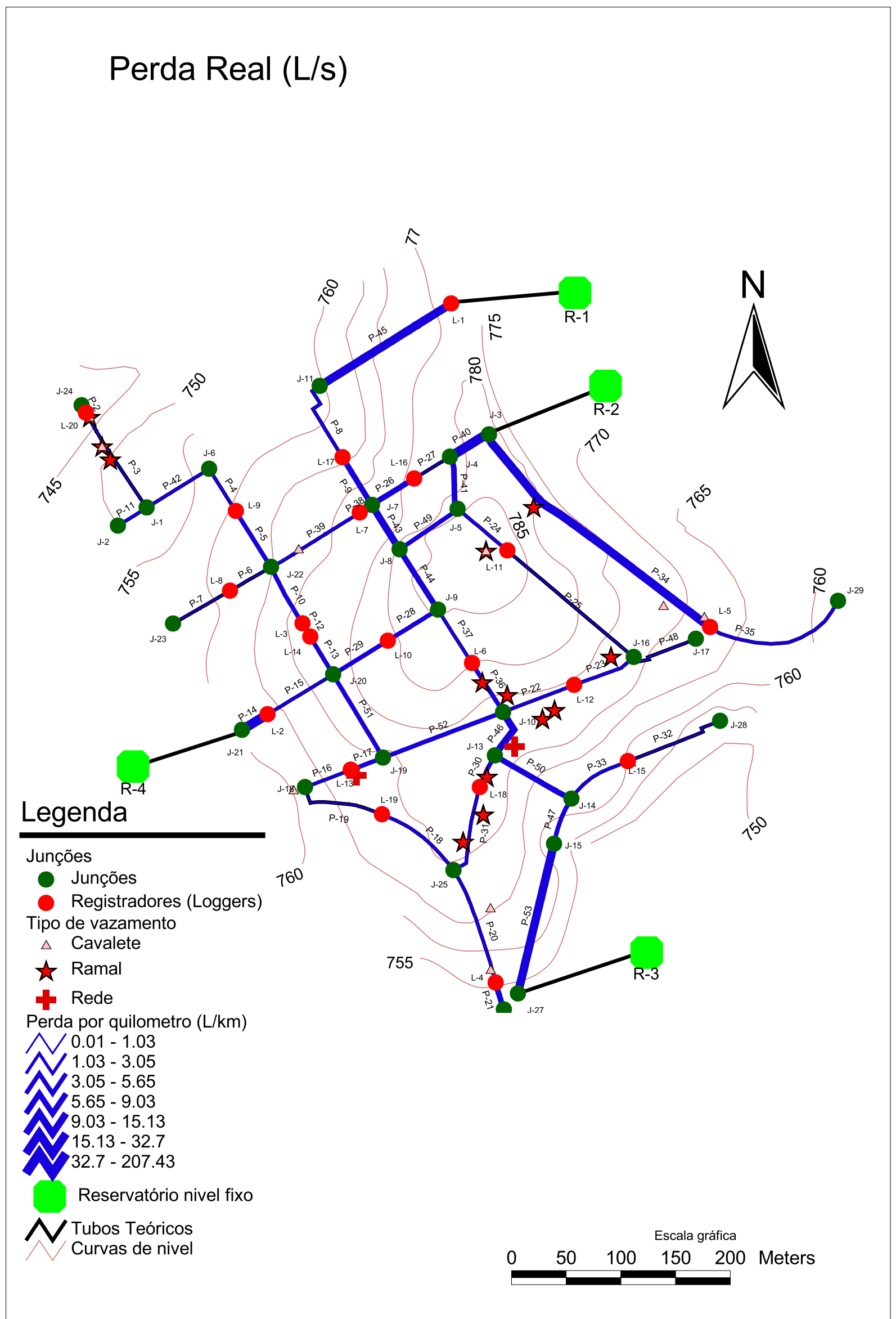

Figura 7.11 - Perda por km (L/s) - ArcView® 


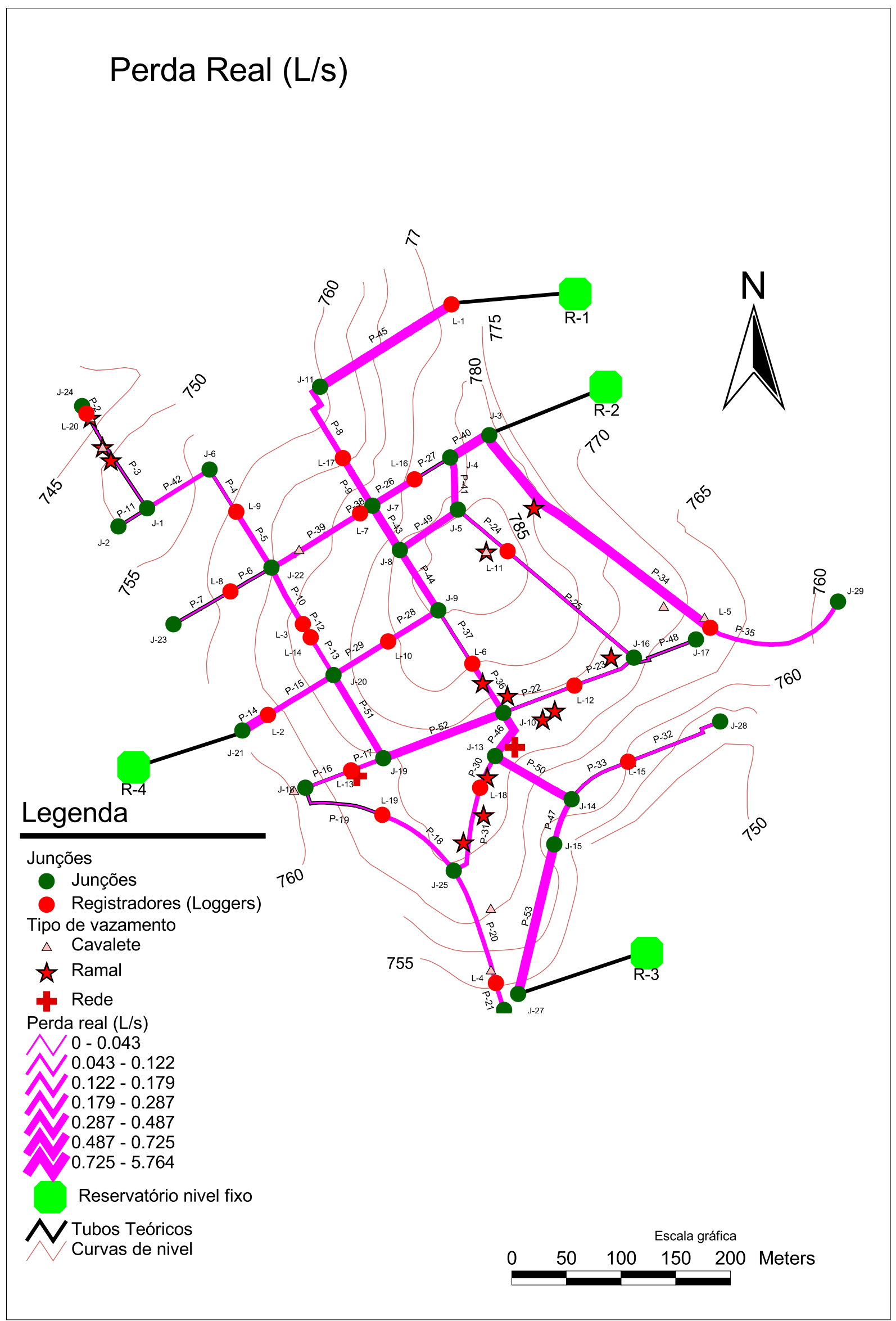

Figura 7.12 - Perda Real (L/s) - ArcView ${ }^{\circledR}$ 


\section{Perda Aparente (L/s)}

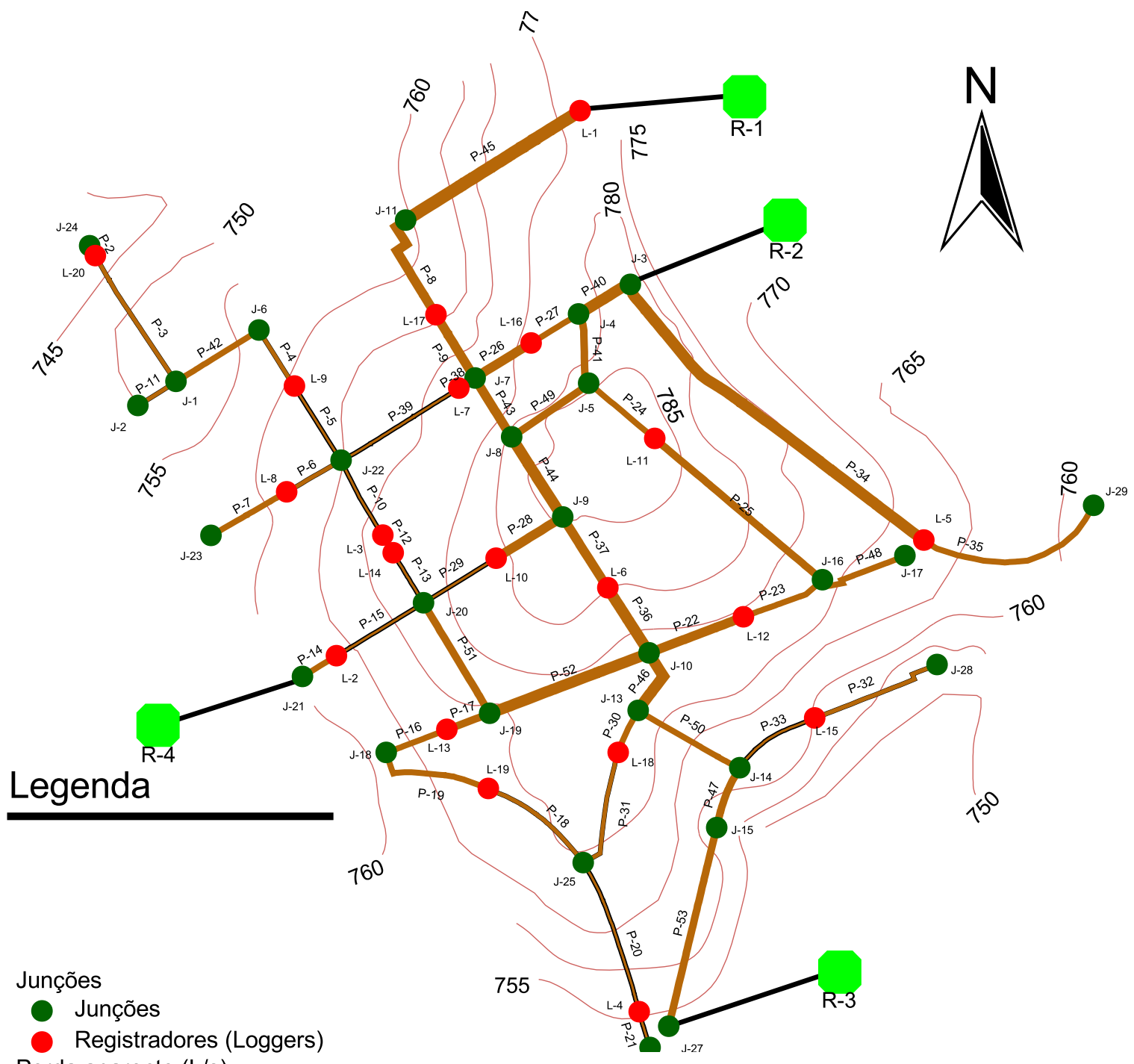

Perda aparente (L/s)

N0 - 0.171

$0.171-0.326$

$0.326-0.524$

$0.524-0.778$

$0.778-1.576$

$1.576-2.405$

$2.405-4.884$

Reservatório nivel fixo

NTubos Teóricos

Curvas de nivel

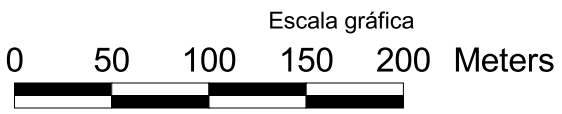

Figura 7.13 - Perda Aparente (L/s) - ArcView ${ }^{\circledR}$ 


\section{$\mathrm{FCl} \times$ Vazamentos x Perdas}

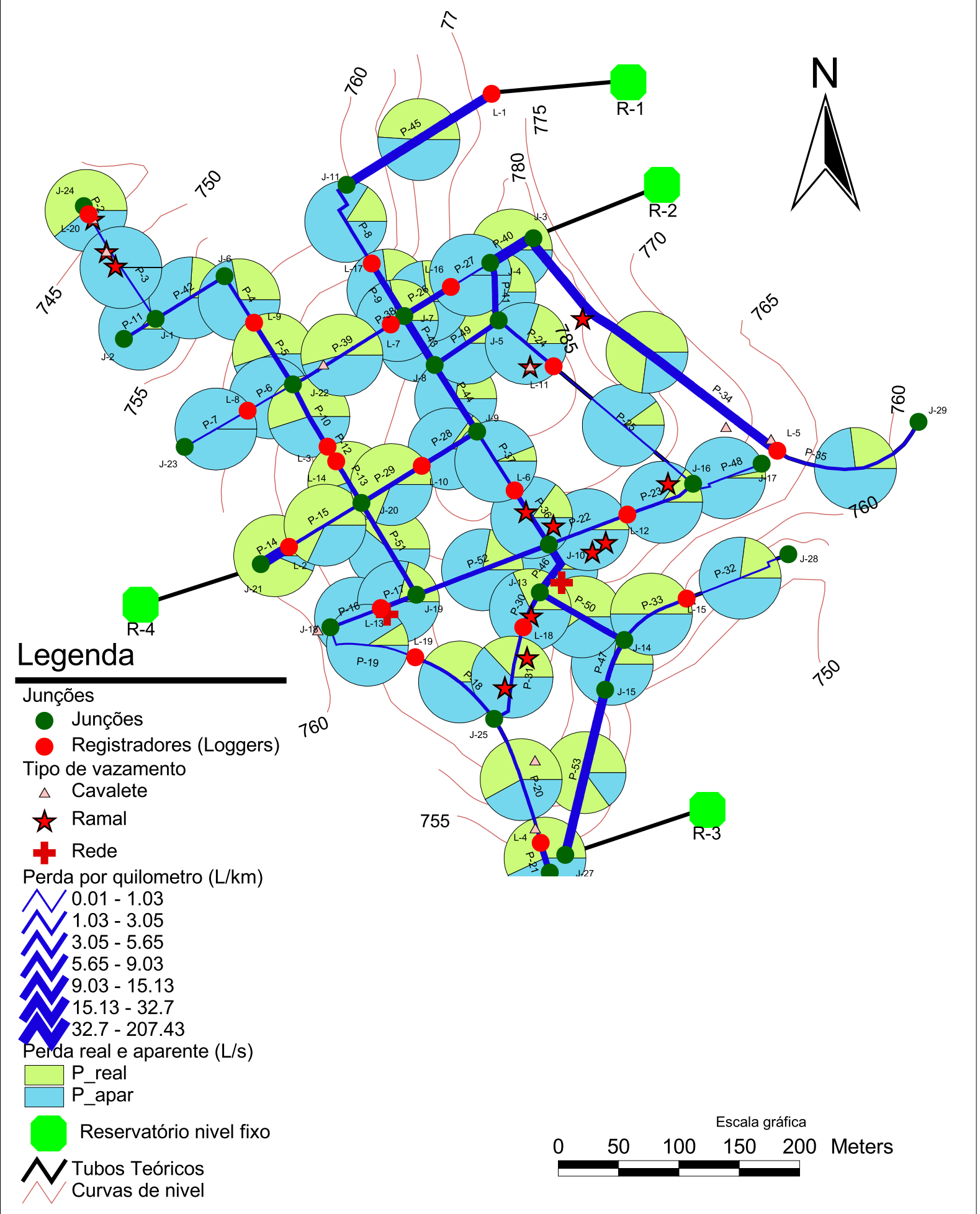

Figura 7.14 - FCl x Vazamentos x Perdas - ArcView ${ }^{\circledR}$ 


\section{CONCLUSÕES}

O presente trabalho demonstra a eficácia da utilização de modelos de simulação hidráulica no fornecimento de informações para a elaboração de um diagnóstico de perdas de água em um sistema de distribuição de água.

Apresenta uma metodologia para o uso da simulação hidráulica de uma forma prática para a obtenção de dados para análise operacional de uma malha de distribuição de água, visando à eficiência na operação e redução de perdas de água.

A classificação dos trechos em três categorias A, B e C permitiu, de forma inovadora, a escolha dos trechos mais críticos da rede e permitiu a priorização dos mesmos por meio de gráficos de pareto e mapas temáticos. 


\section{REFERENCIA BIBLIOGRÁFICA}

ABENDE. 2003. Apostila do Curso de Detecção de Vazamentos Não Visíveis: Métodos Acústicos. 1aㅡ Edição. São Paulo : ABENDE - Associação Brasileira de Ensaios Não Destrutivos, 2003.

ABNT, Associação Brasileira de Normas Técnicas. 2007. NBR 12.218 - ABNTProjeto de Rede de Distribuição de Água para Abastecimento Público. São Paulo : ABNT, 2007. Alegre, Helena, et al. 2006. Performance indicators for water supply services. 2.ed. London : International Water Association - IWA, 2006. p. 289. 1943390515.

Archela, Rosely Sampaio e Théry, Hervé. 2008. Orientação metodológica para construção e leitura de mapas temáticos. Confins. [Online] 23 de 06 de 2008. [Citado em: 01 de 03 de 2010.] http://confins.revues.org/index3483.html.

AWWA, American Water Works Association. 1999. AWWA Manual M36. Denver : AWWA, 1999. ISBN 0-89867-485-0.

AWWA, American Water Works Association. 2009. Manual of water supply practices - M36. [ed.] Melissa Valentine. 3를 Edição. Denver : IWWA, 2009. p. 285. Vol. 1. 1-58321631-6.

Azevedo Netto, José Martiniano de. 1998. Manual de Hidráulica. 8ª Edição. São Paulo : Edgard Blucher Ltda, 1998. p. 669.

Barreto, Douglas. 2008. Perfil do consumo residencial e usos finais da água. [A. do livro] Associação Nacional de Tecnologia do Ambiente Construído. Ambiente Construído. Porto Alegre : Associação Nacional de Tecnologia do Ambiente Construído, 2008.

Bentley Systems, Incorporated. 2008. WaterGEMS $\AA^{\circledR}$. 7.107.280 e 7.013.248 e outras US e Internacionais patentes pendentes. Estados Unidos da América, 06 de 11 de 2008. Software.

Carrijo, Ivaltemir Barros. 2004. Extração de regras operacionaisótimas de sistemas de distribuição de água atraves da utilização de algoritmos genéticos muiltobjetivos e aprendizado de máquina. São Carlos : Tese (Doutorado) - Escola de Engenharia São Carlos da Universidade de São Paulo, 2004.

EPANET2, Brasil. 2009. Aplicativo para simulação hidráulica Versão 2.00.12. [www.lenhs.ct.ufpb.br/html/downloads/epanet] [trad.] Laboratório de Eficiência Energética e Hidráulica em Saneamento da UFPB. João Pessoa, Paraíba, Brasil : U.S. 
Environmental Protection Agency, 04 de 08 de 2009.

ESRI, Environmental Systems Research Institut Inc. 1992-1999. ArcView Gis V3.2. EUA, 1992-1999. Software.

Farley, Malcolm and Trow, Stuart. 2003. Losses in water distribution networks: a practitioner's guide to assessment, monitoring and control. 1'a . London : International Water Association - IWA, 2003. p. 282. 1-900222-11-6.

Fontanazza, C. M., Freni, G. e La Loggia, G. 2009. Implementation of a Numerical Model for the Evaluation of Potential Apparent Losses in a Distribution Network. [ed.] IWA - International Water Association. Cape Town, Soulth Africa : IWA - International Water Association, 2009. 978-1-920017-38-5.

Galvão, José Ricardo Bueno. 2007. Avaliação Relação Pressão x Consumo, emáreas controladas por válvulas redutoras de pressão (VRP's). Estudo de caso: Rede de distribuição de água da RMSP. São Paulo : Dissertação (Mestrado) - Escola Politécnica da Universidade de São Paulo. Departamento de Engenharia Hidráulica e Sanitária. 2007. p. 249.

Gambale, Sérgio Ricardo. 2000. Aplicação de algoritmo genético na calibração de redes de água. São Paulo: Dissertação (Mestrado) - Escola Politécnica da Universidade de São Paulo, Departamento de Engenharia Hidráulica e Sanitária. 2000. p. 266.

Gomes, Heber Pimentel, Garcia, Rafael Péres e Rey, Pedro L. Iglesias. 2007. Abastecimento de Água. João Pessoa : UFPB, 2007. ISBN 978-85-7745-078-3.

Haestad, et al. 2003. Advanced Water Distribution Modeling and Management. [ed.] Adam Strafaci, Colleen Totz e Kristen Dietrich. $1^{1}$ Edição. Waterbury : Haested Methods Inc., 2003. p. 751. ISBN 0-9714141-2-2.

IBGE, Instituto Brasileiro de Geografia e Estatística. 2010. IBGE - Cidades@. IBGE Instituto Brasileiro de Geografia e Estatística. [Online] 2010. [Citado em: 15 de 03 de 2010.] http://www.ibge.gov.br/cidadesat/topwindow.htm?1.

IWA, International Water Association. 2007. DMA Management Guidance Notes. London : IWA, 2007.

Jelinek, Andréa Ritter. 2010. Topografia I. Universidade Federal do Rio Grande do Sul - UFRGS. [Online] 2010. [Citado em: 13 de 02 de 2010.] http://www.ufrgs.br/geodesia/trabalhosdidaticos/Topografia_IProfa_\%20Andrea_Jelinek/ Teoria/Altimetria.pdf.

Lambert, Allan, Myers, Stephen e Trow, Stuart. 1998. Managing Water Leakage. London : Financial Times Energy, 1998. ISBN 1-84083-011-5. 
Liemberger, Roland and Farley, Malcolm. 2004. Developing a Non-Revenue Water Reduction Strategy. Liemberger.cc. [Online] 9 1, 2004. [Cited: 9 16, 2007.] http://www.liemberger.cc/default.htm?http://www.liemberger.cc/who_is_who/roland_liem berger.htm.

Mecaltec. Mecaltec Produtos Página 2. Mecaltec Home. [Online] Mecaltec Industria e Comercio Ltda. [Citado em: 18 de Setembro de 2009.] http://www.mecaltec.com.br/produtos/produto_2.htm.

Ribeiro, Gracione Picanço. 2005. Operação otimizada do sistema adutor metropolitano utilizando algoritmos genéticos: estudo de caso: SAM Leste da Região Metropolitana de São Paul. São Paulo : Tese (Doutorado) - Escola Politécnica da Universidade de São Paulo. Departamento de Engenharia Hidráulica e Sanitária., 2005. Rios, Jorge Luiz Paes. 1982. IMPORTÂNCIA DO EFLUENTE NA ESCOLHA DO LOCAL DE IMPLANTAÇÃO DE UMA USINA NUCLEAR. PANAMÁ : ASSOCIACION INTERAMERICANA DE INGENIERIA SANITARIA Y AMBIENTAL (AIDIS), 1982.

Silva, Carlos $\quad$ Eduardo $\quad$ Sanches 2002.

http://www.iem.unifei.edu.br/sanches/Ensino/pos\%20graduacao/Ferramentas\%20qualid ade/Aulas/apostila-R1.pdf. IEM - Instituto de Engenharia Mecânica - UNIFEI Universidade Federal de Itajubá. [Online] 2002. [Citado em: 01 de 05 de 2010.] http://www.iem.unifei.edu.br/sanches/Ensino/pos\%20graduacao/Ferramentas\%20qualid ade/Aulas/apostila-R1.pdf.

Soares, Alexandre Kepler. 2003. Calibração de modelos de redes de distribuição de água para abastecimento considerando vazamentos e demandas dirigidas pela pressão. São Carlos : Dissertação (Mestrado) - Escola de Engenharia de São Carlos da Universidade de São Paulo, 2003. p. 178.

Tardelli Filho, Jairo. 2006. Controle e Redução de Perdas. [A. do livro] Milton

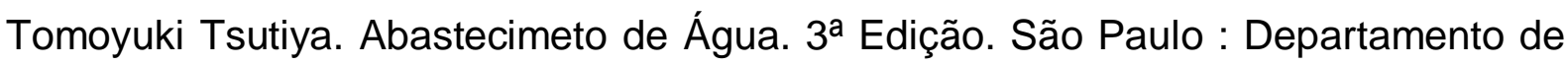
Engenharia Hidráulica e Sanitária da Escola Politécnica da Universidade de São Paulo, 2006, Vol. 1, p. 643.

Thornton, Julian, Sturn, Reinhard and Kunkel, George. 2008. Water loss control. 2. New York : McGraw-Hill, 2008. 978-0-07-149918-7.

Tsutiya, Milton Tomoyuki. 2006. Abastecimeto de Água. $3^{\underline{a}}$ Edição. São Paulo : Departamento de Engenharia Hidráulica e Sanitária da Escola Politécnica da Universidade de São Paulo, 2006. p. 643. Vol. 1. ISBN 85-900823-6-9.

Walski, Thomas M., et al. 2003. Advanced Water Distribution Modeling and 
Management. [ed.] Adam Strafaci, Colleen Totz e Kristen Dietrich. 1를 Edição. Waterbury : Haested Methods Inc., 2003. p. 751. ISBN 0-9714141-2-2. 


\section{BIBLIOGRAFIA CONSULTADA}

Alves, Castilho Wolney, et al. 2004. PNCDA - Programa Nacional de Combate ao Desperdício de Água. Ministério das Cidades. [Online] 01 de Janeiro de 2004. [Citado em: 18 de Julho de 2009.] http://www2.cidades.gov.br/pncda/Dtas/Arq/DTA_D2.pdf.

Bastos Filho, Fernando José Caldeira. 1998. Index - Fernando José Caldeira Bastos Filho. Departamento de Engenharia de Produção e Sistemas - CTC UFSC. [Online] 1998. [Citado em: 01 de 05 de 2010.] Dissertação (mestrado) . http://www.eps.ufsc.br/disserta98/bastos/.

Falkenberg, Alex Vieira. 2005. PREVISÃO DE CONSUMO URBANO DE ÁGUA EM CURTO PRAZO. Departamento de Construção Civil, UFPR, Universidade Federal do Paraná. Curitiba, PR : UFPR, 2005. p. 88, Dissertação. Dissertação apresentada como requisito parcial à obtenção do grau de Mestre no Curso de Pós-Graduação em Métodos Numéricos em Engenharia, Universidade Federal do Paraná.

Helene, Otaviano A. M. e Vanin, Vitor R. 1991. Tratamento Estatístico de Dados em Física Experimental. São Paulo : Edigard Blücher Ltda, 1991.

SOUSA, J. J., CUNHA, M.C., SÁ MARQUES J. A. A. e FRANCISCO, F. F. 1999. Dimensionamento Optimizado de Redes de Distribuição de Água Assistido por Computador. Coimbra, Portugal : s.n., 1999. IV SILUSBA, Simpósio de Hidráulica e Recursos Hídricos dos Países de Língua Oficial Portuguesa.

Thornton, Julian. 2002. Water Loss Control Manual. New York : McGraw-Hill, 2002. ISBN 0-07-137434-5.

IWA, Water Loss Task Force. 2005. Leakage 2005 Papers. [Online] 2007. [Citado em: 01 de 03 de 2008.] http://waterloss2007.com/Leakage2005.com/index.php? page $=$ conference_summary.

IWA, Water Loss Task Force. 2007. [Online] 2007. [Citado em: 01 de 03 de 2008.] http://waterloss2007.com/pdf vortraege/overview.html Jager, Carla de. 2009. Water Loss 2009. [CD-ROM] Cape Town - South Africa : Carlamani Conferences and Events (Pty) Ltd, 04 2009. 978-1-920017-38-5. 


\section{A. APÊNDICE A - CÁLCULO E PROPAGAÇÃO DE INCERTEZAS}

Para a correta avaliação da eficácia na utilização das informações geradas pelo modelo de simulação, nas estimativas dos valores reais, é necessário conhecer as incertezas existentes no processo e determinar o grau de confiança dos valores encontrados.

\section{A.1 CÁLCULO DE INCERTEZAS DE MEDIDAS}

Todo instrumento de medida possui uma incerteza, e no caso dos medidores de vazão esta incerteza está associada a sua escala de leitura e sua faixa de operação (curva de erro característico).

O conhecimento da curva de erro de cada medidor permite determinar qual a incerteza associada a cada observação de vazão. Atualmente são desconhecidas as curvas de erros dos medidores instalados. Desta forma foi utilizado o erro teórico à vazão máxima, no cálculo da incerteza total.

A incerteza total é composta pela incerteza do instrumento de medida mais a incerteza da medida, esta representada por seu desvio padrão médio.

A propagação das incertezas é feita pela avaliação das operações matemáticas envolvidas na obtenção da grandeza desejada, no caso, a vazão média do período em estudo. A vazão média é calculada pela soma das vazões observadas dividida pelo número de observações realizadas. O número de observações é um número puro cujo valor é conhecido, assim a incerteza fica restrita apenas a somatória das vazões.

Com a incerteza da vazão média de cada ponto de entrega, se faz necessária a propagação da incerteza dos pontos que compõem a vazão média de cada área. São utilizadas neste cálculo as fórmulas de macromedição de cada área para obter os pontos que entram na composição da vazão da área, e é feita a propagação das incertezas dos mesmos. 
O volume fornecido é calculado pelo produto da vazão média pelo intervalo de tempo desejado. O tempo é tomado como um valor conhecido, desconsiderando-se a incerteza em sua medição. Desta forma a incerteza final é a da vazão média.

A incerteza associada a cada setor de abastecimento fornece a magnitude das variações no volume fornecido, que entra no balanço hídrico, sendo assim de grande importância na análise da influência sobre os seus componentes.

\section{A.2 ALGARISMOS SIGNIFICATIVOS}

Para obter-se a medida de uma grandeza utilizam-se instrumentos de medição. Estes possuem uma escala que nos permite a estimar uma medida com exatidão até um número determinado de casas decimais. O último algarismo fica afetado pela incerteza. Desta forma o número de algarismos significativos é igual ao número de algarismos cujo valor é conhecido. Por exemplo, na medida de um comprimento obtém-se 0,60 m, pode-se afirmar que o valor real se encontra entre 0,55 e 0,65 m, ou seja, dois algarismos significativos (Helene et al., 1991).

Por convenção a incerteza de um instrumento de medida é a metade da menor divisão de sua escala de medida (Helene et al., 1991).

Se as medidas utilizadas em operações aritméticas, possuírem quantidades diferentes de algarismos significativos, para preservar a acurácia no resultado final, o resultado será expresso com um algarismo significativo a menos do que o da medida com menor quantidade, ou no máximo com a mesma quantidade.

\section{A.3 LEITURA DOS DADOS}

Quando é feita a leitura em um instrumento de medição, deve-se levar em consideração, fatores que geram variações no intervalo entre dois valores mínimos de sua escala. Podem ser fatores do ambiente como temperatura e umidade, interferências elétricas, ou causadas pelo próprio método de fabricação do instrumento. Desta forma deve ser conhecido o intervalo de confiança que o 
instrumento nos garante. Por exemplo, ao se medir a tensão elétrica é obtido o valor de 12,5 V. Pela definição anterior é de se esperar que o valor real esteja entre 12,45 e 12,55 V. Porem o instrumento possui uma escala dividida de 5 em 5 V. Daí nosso intervalo de confiança é de 2,5 V. Assim a medida real está dentro do intervalo entre 10 e $15 \mathrm{~V}$. Muito maior que quando aplicada a convenção anterior (Helene et al., 1991). A representação usual desta grandeza é $12,5 \pm 2,5 \mathrm{~V}$.

\section{A.4 TIPOS DE ERROS}

Segundo (Helene et al., 1991) os erros são usualmente classificados em:

a) Sistemáticos: aqueles relacionados ao manuseio incorreto do instrumento de medida, procedimento errôneo ou falha conceitual.

b) Estatísticos: causados por variações incontroláveis e aleatórias dos instrumentos de medida, ou condições externas tais como: temperatura, umidade, etc., ou ambas.

Os primeiros se relacionam ao conceito de acurácia e os segundos ao de precisão.

\section{A.5 INDEPENDÊNCIA DOS DADOS}

Para a correta estimativa da real medida da grandeza, realiza-se uma série de medições, com o intuito de determinar qual o erro cometido. Mas para que isso possa ser possível, é necessário que as observações sejam independentes entre si, ou seja, a obtenção de cada um dos valores não interfere nos demais (Vuolo, 1992). Ainda segundo (Vuolo, 1992), para existir a independência completa entre as várias observações, cada uma deve ser efetuada com um instrumento, por um observador, em um local, em um dia, e tudo mais que se possa imaginar diferente dos demais.

\section{A.6 MEDIA E DESVIO PADRÃO}

Utiliza-se a média de uma série de medidas como valor que melhor representa uma grandeza. 


$$
\bar{x}=\frac{1}{n} \sum_{i=1}^{n} x_{i}
$$

Onde $x_{i}$ são os dados obtidos nas $n$ observações e $\bar{x}$ é o valor médio.

A chance de um dado estar dentro de um intervalo de largura $\Delta x$ em torno de $x$ é dado por:

$$
\Delta P \cong F(x) \cdot \Delta x
$$

A quantidade de dados esperada neste intervalo é:

$$
\Delta n=n \cdot \Delta P \cong n \cdot F(x) \cdot \Delta x
$$

Com este último resultado, a média pode ser reescrita em função de $F(x)$ como:

$$
\bar{x} \cong \frac{1}{n} \sum_{i=1}^{n} x_{i} \cdot n \cdot F(x) \cdot \Delta x
$$

Onde a soma é sobre todos os intervalos $\Delta x$ possíveis. Assim levando a equação 4 ao limite tem-se:

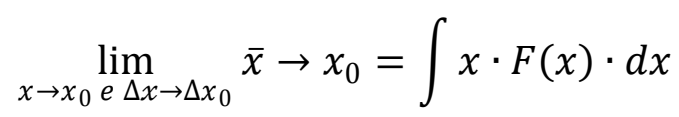

Onde a integral e feita sobre o intervalo onde $F(x)$ é definida. $\mathrm{O}$ valor $x_{0}$ é a verdadeira média e não deve ser confundido com a $\bar{x}$ que é uma aproximação da média.

Como o valor verdadeiro de uma grandeza é desconhecido, as diferenças existentes entre os diversos dados obtidos, se devem as variações ocorridas nas diversas observações realizadas. Desta forma o desvio padrão ou desvio quadrático médio $\sigma$, é uma informação muito importante, pois nos permite conhecer a dispersão dos dados, e é definido pela equação:

$$
s^{2}=\sum_{i=1}^{n} \frac{\left(x_{i}-\bar{x}\right)^{2}}{n-1} \cdots
$$


O desvio padrão da média é uma estimativa da dispersão que seria obtida em médias de diferentes conjuntos de medidas, efetuadas nas mesmas condições, e é definido por:

$$
s_{m}^{2}=\sum_{i=1}^{n} \frac{\left(x_{i}-\bar{x}\right)^{2}}{n(n-1)}=\frac{\sigma^{2}}{n} \cdots
$$

O resultado da medida é representado pela média mais a sua incerteza definida por seu desvio padrão médio $s_{m}^{2}$. Todavia, o desvio padrão pode ser feito tão pequeno quanto se queira, efetuando-se um número cada vez maior de observações. Isto levaria a uma condição de imaginar que a incerteza seria nula. Porém ainda leva-se em conta a incerteza do instrumento de medida. A incerteza de fica então definida pela equação:

$$
s_{r}=\sqrt{s_{m}^{2}+\sigma_{c}^{2}} \ldots
$$

Onde $s_{r}$ é a incerteza do resultado da medida e $\sigma_{c}$ é a incerteza do instrumento de medida nas condições da observação (Helene et al., 1991).

\section{A.7 ERRO ABSOLUTO E RELATIVO}

Segundo (Helene et al., 1991) defini-se como erro absoluto a diferença entre o valor exato de uma grandeza e sua aproximação.

$$
E=x_{0}-\bar{x} \cdots
$$

Como é conhecida apenas a aproximação e sua incerteza, toma-se esta última como o módulo do erro absoluto. Assim tem-se:

$$
E=s_{r} \cdots(20)
$$

Defini-se como erro relativo a razão entre o erro absoluto e o valor aproximado de uma grandeza. É expresso em porcentagem.

$$
E_{R}=\frac{s_{r}}{\bar{x}} \times 100
$$

\section{A.8 CÁlCULO E PROPAGAÇÃO DE INCERTEZAS}

No desenvolver de um trabalho, regularmente a utilização de operações matemáticas é necessária para a determinação do valor de uma grandeza. Deste 
modo, quando uma grandeza tem seu valor obtido em função de cálculos envolvendo grandezas cujos valores são resultados de medidas, há a necessidade de se obter a incerteza ao final dos cálculos.

Segundo (Vuolo, 1992) dada uma grandeza $g$ dada por $g=f\left(x_{1}, x_{2}, \cdots, x_{n}\right.$ ), com as respectivas incertezas $\left\{\sigma_{1}, \sigma_{2}, \cdots, \sigma_{n}\right\}$, independentes entre si, determina-se a incerteza em $\bar{z}=f\left(\bar{x}_{1}, \bar{x}_{2}, \cdots, \bar{x}_{n}\right)$ como:

$$
\sigma_{z}^{2}=\left(\frac{\partial f}{\partial x_{1}} \sigma_{1}\right)^{2}+\left(\frac{\partial f}{\partial x_{2}} \sigma_{2}\right)^{2}+\cdots+\left(\frac{\partial f}{\partial x_{n}} \sigma_{n}\right)^{2}
$$

Onde as derivada parciais são definidas nos pontos $x_{1}=\bar{x}_{1} ; x_{2}=\bar{x}_{2}$; etc..

Os casos particulares mais importantes desta forma geral são:

\section{Adição ou Subtração:}

Se $z= \pm x \pm y,|\partial z / \partial x|=1$ e $|\partial z / \partial y|=1$, assim tem-se:

$$
\sigma_{z}^{2}=\sigma_{x}^{2}+\sigma_{y}^{2} \cdots
$$

\section{Multiplicação ou Divisão:}

Se $z=x y$ ou $z=x / y,|\partial z / \partial x|=|z / x|$ e $|\partial z / \partial y|=|z / y|$, assim tem-se:

$$
\left(\frac{\sigma_{z}}{z}\right)^{2}=\left(\frac{\sigma_{x}}{x}\right)^{2}+\left(\frac{\sigma_{y}}{y}\right)^{2}
$$




\section{B APÊNDICE B - RESUMO EXECUTIVO}

\section{B.1 OBJETIVO}

O presente trabalho tem por objetivo, avaliar a eficácia da utilização de modelos de simulação hidráulica de sistemas de abastecimento, apoiados em levantamentos de dados hidráulicos de campo, na obtenção de informações para elaboração do diagnóstico de perdas de um sistema de distribuição de água.

\section{B.2 INTRODUÇÃO}

Atualmente a avaliação das perdas de água, nos sistemas de distribuição, é feita com base em equações empíricas, que utilizam informações, agrupadas e totalizadas, da uma área. Isto torna necessária sua subdivisão em frações cada vez menores, na busca da fração mais crítica.

Com o acelerado avanço da computação, o crescimento físico e a complexidade das malhas de distribuição, torna-se premente a utilização de métodos eficazes de diagnóstico de perdas, direcionando as ações de modo a obter a melhor relação de custo benefício.

Um modelo matemático representa ou interpreta simplificadamente a realidade, apresenta uma visão ou cenário baseado nas informações coletadas em campo. Assim, a aplicação dos modelos permite o estudo do comportamento hidráulico nos mais diversos cenários, e permite a análise em situações nas quais é impossível testar ou medir as diversas soluções possíveis.

Neste trabalho, é apresentada uma avaliação da eficácia do uso de modelos de simulação hidráulica na obtenção das informações necessárias para a elaboração de um diagnóstico de perdas de água, bem como, uma metodologia para o uso de modelos com este objetivo. 
Este trabalho contribui para a adoção da simulação hidráulica no estudo das causas de perdas de água nos sistemas de abastecimento. A utilização dos modelos permitirá as empresas de saneamento, uma melhoria na gestão operacional, na busca da excelência na distribuição de água, garantindo a sustentabilidade da empresa, a economia dos recursos humanos, econômicos, e principalmente, os hídricos.

\section{B.3 CONCEITOS}

Segundo Tardelli Filho (2006), as perdas de água se dividem em dois grupos:

a) A perda real corresponde ao volume de água produzido que não chega ao consumidor final devido à ocorrência de vazamentos nas adutoras, redes de distribuição e reservatórios, bem como de extravasamentos em reservatórios setoriais.

b) A perda aparente são volumes efetivamente consumidos que por algum motivo não foram contabilizados pela companhia de saneamento.

Até 1994 havia poucas técnicas disponíveis para a modelagem de perdas. Segundo Farley et al. (2003), existiam alguns fatores que dificultavam a modelagem de perdas, eram eles:

- O desconhecimento sobre o processo dos vazamentos;

- O conhecimento empírico somente do relacionamento entre a ocorrência de vazamentos e a pressão;

A perda era considerada como uma entidade única, desconhecendo suas componentes. No Reino Unido, entre 1990 e 1995, foi identificada a necessidade de se ter um método para a gestão de perdas. Assim surgiu uma metodologia geral conhecida como burst and background estimates (BABE), que não é uma ciência precisa, em princípio, ela é baseada na análise de uma grande quantidade de dados e de ensaios de campo. Difere dos conceitos gerais de modelos matemáticos de sistemas hidráulicos, por utilizar uma mistura de dados obtidos por medições, estimativas e testes de campo. O objetivo da modelagem, pelo método BABE, é caracterizar individualmente cada componente da perda real e comparar com a estimativa de perda obtida do balanço hídrico $(\mathrm{BH})$, (também conhecido pelo nome em inglês "top-down water audit spreadsheet model"), ou do método da vazão 
mínima noturna (VMN), ou ainda o método do "fixed and variable area discharge" (FAVAD) (Farley et al., 2003). A perda total no sistema de abastecimento é dada pela equação 3.1 :

$$
P=\sum P_{r}+\sum P_{a} \cdots
$$

Onde $P$ é a perda total, $P_{r}$ é a perda real e $P_{a}$ é a perda aparente todas expressas em $\mathrm{m}^{3}$. Onde $P$ é a perda total, $P_{r}$ é a perda real e $P_{a}$ é a perda aparente todas expressas em $\mathrm{m}^{3}$. O modelo FAVAD ('Fixed and Variable Area Discharge Paths'), desenvolvido no Reino Unido, apresenta um equacionamento para várias situações encontradas na rede de distribuição (Tsutiya, 2006). Sua equação (3.2) relaciona a vazão dos vazamentos com a pressão.

$$
\frac{Q_{1}}{Q_{0}}=\left(\frac{P_{1}}{P_{0}}\right)^{N_{1}} \ldots
$$

Onde $Q_{0}$ é a vazão inicial em $\mathrm{L} / \mathrm{h}, Q_{1}$ é a vazão final em $\mathrm{L} / \mathrm{h}, P_{0}$ é a pressão inicial em $\mathrm{mH}_{2} \mathrm{O}, P_{1}$ é a pressão final em $\mathrm{mH}_{2} \mathrm{O}$, e $N_{l}$ é um expoente que depende do material do tubo.

O método da vazão mínima noturna (VMN ou $\left.Q_{\text {min }}\right)$ tem importância na determinação das vazões de vazamento $\left(Q_{v}\right)$, pois o consumo neste período é menor e assim uma parcela significativa de seu valor refere-se a vazamentos.

$$
Q_{\min }=Q_{v}+C_{\min }
$$

$Q_{\min }$ é a vazão mínima noturna, e $C_{\min }$ o consumo mínimo horário no mesmo instante de $Q_{\min }$. Como a pressão neste instante é maior que a pressão média ao longo das 24 horas, torna-se necessária à correção do valor pelo fator noite/dia $\left(F_{n d}\right)$ dado pela equação 3.4 .

$$
F_{n d}=\sum_{n=1}^{24}\left(\frac{\bar{p}_{(n-1) \rightarrow n}}{\bar{p}_{3 \rightarrow 4}}\right)^{N_{1}} \ldots
$$

Onde $\bar{p}_{(n-1) \rightarrow n}$ é a pressão média horária entre à hora $(n-1)$ e $n$, em $\mathrm{mH}_{2} \mathrm{O}$. O valor de $F_{n d}$ pode ser menor que 24 em setores sem gerenciamento de pressões e maior que $24 \mathrm{em}$ setores onde exista o gerenciamento de pressão. Com o $F_{n d}$ obtem-se a vazão de perdas reais diárias $Q_{r d}$ pela equação 3.5 .

$$
Q_{r d}=F_{n d} \cdot Q_{v}
$$

Onde $Q_{r d}$ é a vazão de perdas reais diárias, e $Q_{v}$ é a vazão de vazamentos em L/h. 
O método de avaliação pelo volume perdido constitui um indicador conceitualmente mais adequado para quantificar as perdas. É composto por três equações básicas, apresentadas a seguir.

$$
Q_{i}=Q_{v i} \cdot F_{c i} \cdots
$$

Onde $F_{c i}$ é o fator de condição da infraestrutura, $Q_{i}$ é vazão média de perda inerente diária, $Q_{v i}$ é a vazão de vazamentos inerentes, em $\mathrm{L} / \mathrm{h}$. E $Q_{v i}$ é calculado pela equação 3.7 .

$$
Q_{v i}=2,78 \cdot 10^{-4} \cdot\left(Q_{p r d} \cdot L+Q_{r p m} \cdot N\right) \cdot\left(\frac{\bar{p}}{50}\right)^{N_{1}} \ldots
$$

Onde $Q_{v i}$ em L/s para uma dada pressão média $\bar{p}$ em $\mathrm{mH} 2 \mathrm{O}, Q_{p r d}$ e $Q_{p r m}$ são os valores de referência da IWA para $Q_{v i}$, a 50 mca de pressão, determinados para rede e ramal respectivamente em $L / h^{*} k m, L$ é a extensão de rede em $\mathrm{km}, \bar{p}$ é a pressão média na rede em $\mathrm{mH}_{2} \mathrm{O}$ e $N$ é o número de ramais.

Existem dois limites para a redução de perda num sistema de abastecimento: Custo e tecnologia. Assim, a perda real anual inevitável $\left(P_{\text {rai }}\right)$ contém a perda real inerente e os vazamentos não visíveis, pois em ambos os casos por razões econômicas torna-se inviável a detecção destes vazamentos. Tem-se assim que conviver com eles, sabendo que nunca haverá perda "zero". Para simplificação do cálculo se propôs o expoente $\mathrm{N}_{1} \cong 1$. A Tabela B.1, apresenta os valores das perdas reais inevitáveis para cada componente da infraestrutura por tipo de vazamento, calculados a partir dos parâmetros da Tabela B.2, assim obtém-se a equação 3.8 (Lambert et al., 1998):

$$
P_{\text {rai }}=\left(18 \cdot L+0,8 \cdot N+25 \cdot L_{P}\right) \cdot \overline{\bar{p}} \quad \cdots
$$

Onde $P_{\text {rai }}$ é o volume de perda real anual inevitável em $\mathrm{m}^{3} / \mathrm{ano}, L$ a extensão de rede em $\mathrm{km}, N$ número de ramais, $L_{P}$ a distância da testada do imóvel até 0 hidrômetro em km, $\overline{\bar{p}}$ a pressão média de operação em $\mathrm{mH}_{2} \mathrm{O}$.

Como no Brasil os hidrômetros são instalados junto à testada dos imóveis, considera-se a variável $L_{p}=0$, e para estimarmos a vazão de perdas inevitáveis $\left(Q_{r i}\right)$ em litros por segundo, a equação 2.8 fica então:

$$
Q_{r i}=1,16 \cdot 10^{-5} \cdot(18 \cdot L+0,80 \cdot N) \cdot \overline{\bar{p}}
$$


Tabela B.1 -Valores de referência IWA - (Lambert et al., 1998) Adaptada

\begin{tabular}{ccrrr}
\hline Tipo de Vazamento & $\begin{array}{c}\text { Componente } \\
\text { infraestrutura }\end{array}$ & Frequência & Vazão & Duração \\
\hline \multirow{2}{*}{ Inerente } & Rede & - & $20 \mathrm{~L} /(\mathrm{km} \cdot \mathrm{h})$ & - \\
\cline { 2 - 5 } & Ramal & - & $1,25 \mathrm{~L} /(\mathrm{ramal} \cdot \mathrm{h})$ & - \\
\hline \multirow{2}{*}{ Visível } & Rede & $0,124 /(\mathrm{km} \cdot \mathrm{ano})$ & $12 \mathrm{~m}^{3} / \mathrm{h}$ & 3 dias \\
\cline { 2 - 5 } & Ramal & $2,25 \% 0$ & $1,6 \mathrm{~m}^{3} / \mathrm{h}$ & 8 dias \\
\hline \multirow{2}{*}{ Detectável } & Rede & $0,006 /(\mathrm{km} \cdot \mathrm{ano})$ & $6 \mathrm{~m}^{3} / \mathrm{h}$ & 50 dias \\
\cline { 2 - 5 } & Ramal & $0,75 \% 0$ & $1,6 \mathrm{~m}^{3} / \mathrm{h}$ & 100 dias \\
\hline
\end{tabular}

Observação: Todas as vazões obtidas a $50 \mathrm{mH}_{2} \mathrm{O}$

Tabela B.2 - Perda real anual inevitável - (Lambert et al., 1998) Adaptada

\begin{tabular}{|c|c|c|}
\hline $\begin{array}{c}\text { Tipo de } \\
\text { Vazamento }\end{array}$ & $\begin{array}{l}\text { Componente } \\
\text { infraestrutura }\end{array}$ & Vazão \\
\hline \multirow{2}{*}{ Inerente } & Redes & $9,6 \mathrm{~L} /\left(\mathrm{km} \cdot \mathrm{dia} \cdot \mathrm{mH}_{2} \mathrm{O}\right)$ \\
\hline & Ramais & $0,6 \mathrm{~L} /\left(\mathrm{ramal} \cdot \mathrm{dia} \cdot \mathrm{mH}_{2} \mathrm{O}\right)$ \\
\hline \multirow{2}{*}{ Visível } & Redes & $5,8 \mathrm{~L} /\left(\mathrm{km} \cdot \mathrm{dia} \cdot \mathrm{mH}_{2} \mathrm{O}\right)$ \\
\hline & Ramais & $0,04 \mathrm{~L} /\left(\mathrm{ramal} \cdot \mathrm{dia} \cdot \mathrm{mH}_{2} \mathrm{O}\right)$ \\
\hline \multirow{2}{*}{ Detectável } & Redes & $2,6 \mathrm{~L} /\left(\mathrm{km} \cdot \mathrm{dia} \cdot \mathrm{mH}_{2} \mathrm{O}\right)$ \\
\hline & Ramais & $0,16 \mathrm{~L} /\left(\mathrm{ramal} \cdot \mathrm{dia} \cdot \mathrm{mH}_{2} \mathrm{O}\right)$ \\
\hline \multirow{2}{*}{$P_{\text {rai }}$} & Redes & $18 \mathrm{~L} /\left(\mathrm{km} \cdot \mathrm{dia} \cdot \mathrm{mH}_{2} \mathrm{O}\right)$ \\
\hline & Ramais & $0,8 \mathrm{~L} /\left(\mathrm{ramal} \cdot \mathrm{dia} \cdot \mathrm{mH}_{2} \mathrm{O}\right)$ \\
\hline
\end{tabular}

\section{B.4 MODELO MATEMÁTICO}

Um modelo matemático é uma representação (ou interpretação), simplificada da realidade de um sistema (ou fragmento deste), segundo uma estrutura de conceitos teóricos e experimentais. A modelagem matemática ou computacional permite criar modelos computacionais para situações nas quais é impossível testar ou medir as diversas soluções possíveis ou o custo para a criação de modelos experimentais ou a solução analítica é inviável. Em Teoria de modelos, um modelo é uma estrutura composta por um conjunto universo e por constantes, relações e funções definidas 
neste conjunto universo (Rios, 1982). No caso da simulação de sistemas de distribuição de água, as leis físicas que regem o fenômeno de escoamento do fluido sob pressão, são utilizadas para este fim. (Carrijo, 2004).

A topologia da rede é composta de: nós, os quais representam características de um local específico dentro do sistema, e de linhas retas, que definem as relações entre os nós, ver Tabela B.3e Figura B.1.

Tabela B.3 - Elementos comuns em modelagem (Walski et al., 2003)

\begin{tabular}{lll}
\hline Elemento & Tipo & Função no modelo \\
\hline Reservatório & Nó & Prover água ao sistema. \\
\hline Tanque & Nó & $\begin{array}{l}\text { Estoca o excesso de água do sistema e devolve nos } \\
\text { horários de pico de consumo. }\end{array}$ \\
\hline Junção & Nó & Retira ou coloca vazão de água no sistema. \\
\hline Tubulação & Linha & Conduz água de uma junção a outra. \\
\hline Bombas & Nó ou linhas & $\begin{array}{l}\text { Aumenta a carga hidráulica para sobrepor desníveis } \\
\text { geométricos ou perda de carga. }\end{array}$ \\
\hline Válvulas de Controle & Nó ou linhas & $\begin{array}{l}\text { Controla a pressão ou vazão no sistema de acordo com } \\
\text { critérios definidos. }\end{array}$ \\
\hline
\end{tabular}

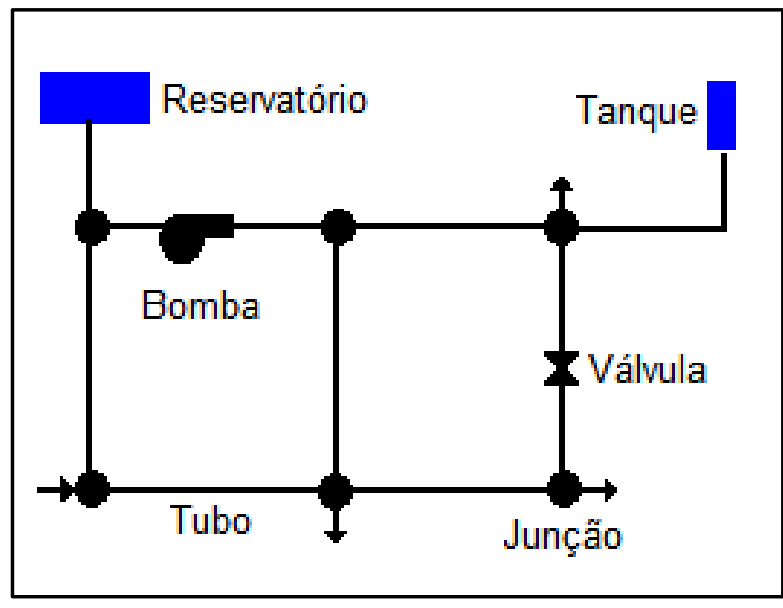

Figura B.1 - Exemplo dos elementos do modelo hidráulico. (EPANET2, 2009)

A calibração de modelos com o uso de algoritmo genético (AG) foi desenvolvido por John Holland em 1975, e popularizou-se através de um de seus estudantes, David Goldberg, que foi capaz de solucionar um problema de difícil solução, envolvendo controle na transmissão de uma tubulação de gás, para sua dissertação de mestrado (Goldberg, 1989) apud (Ribeiro, 2005). 
$\mathrm{Na}$ busca das soluções possíveis, as operações são realizadas de forma alternada entre os espaços de código (com strings codificados) e de soluções (valores numéricos de fato). As operações genéticas (cruzamentos e mutações) ocorrem no espaço de código, enquanto a avaliação da função objetivo e a seleção ocorrem no espaço solução. A Figura B.2, mostra o ciclo de operações (Gen et al., 1997) apud (Ribeiro, 2005).

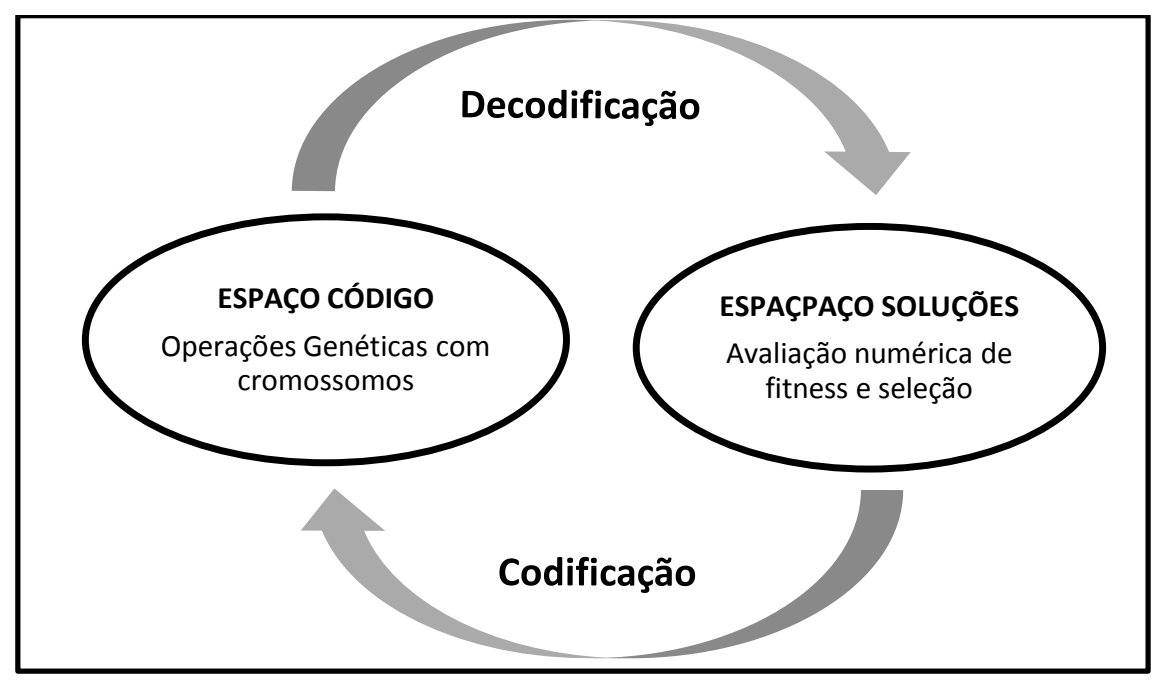

Figura B.2 - Espaços de codificação e de solução

\section{B.5 METODOLOGIA}

O método proposto a seguir, orienta a utilização de modelos de simulação hidráulicas na obtenção de informações para diagnóstico de perdas de água. É abordado o carregamento das demandas, a calibração com a ferramenta "Darwin Calibrator" disponível no aplicativo de simulação hidráulica WaterGEMS®, e a utilização dos resultados modelados, como entrada para os cálculos de perdas de água e a criação de mapas temáticos, elaborados com o auxílio do aplicativo ArcView ${ }^{\circledR}$ Gis.

Após a construção da topologia da rede no aplicativo de simulação, é necessário o carregamento e a definição do padrão horário de variação das demandas nas junções. Neste trabalho foi adotado como padrão de variação horária de consumo, o perfil residencial médio, obtido por Barreto (2008). O perfil definido por Barreto, refere-se a uma única ligação domiciliar. Considerando que a maioria dos imóveis 
são residenciais, e com caracteristicas urbanas semelhantes, a existência de amortecimento na vazão individual de cada imóvel, causado pela caixa d'água, faz com que os consumos horários médios do DMC apresente pouca diferença com o perfil individual, permitindo assim, esta simplificação. Desta maneira, pelo perfil obtido por (Barreto, 2008) é possível obter o fator horário das demandas efetuando a razão entre a vazão horária e a vazão média do perfil, ou seja:

$$
f_{d}=\frac{Q_{h}}{\bar{Q}}
$$

Onde $f_{d}$ é o fator horário de demanda, $Q_{h}$ a vazão horária média e $\bar{Q}$ a vazão média. As demandas são obtidas das leituras mensais, efetuadas para a emissão de contas, e serão à base de cálculo das vazões fornecidas. As vazões médias das demandas das junções são obtidas pela transformação das demandas mensais expressas em $\mathrm{m}^{3}$ para $\mathrm{L} / \mathrm{s}$, dividindo o consumo mensal pela quantidade de segundos do período considerado, como apresentado a seguir.

$$
\bar{Q}_{J}=\frac{C_{m} \cdot 1000}{(30 \cdot 24 \cdot 60 \cdot 60)}=\frac{C_{m}}{\left(2,59 \cdot 10^{3}\right)}=3,86 \cdot 10^{-4} \cdot C_{m}
$$

Onde $\bar{Q}_{J}$ é a vazão média em L/s numa determinada junção, $C_{m}$ representa a somatória dos consumos mensais lidos nos hidrômetros de cada ligação agrupada na junção em questão. Aplicando o fator horário à vazão média da junção, obtém-se a variação horária da demanda, como segue:

$$
Q_{h}=f_{d} \cdot \bar{Q}_{J} \quad \ldots(5.3)
$$

Onde $Q_{h}$ é a demanda horária numa determinada junção. As demandas são agrupadas nas junções em função de sua proximidade a ela, ou quando representa um grande consumidor pode ser considerada como uma junção.

A calibração é executada em duas etapas: ensaio de campo e simulação dos resultados por meio de algoritmo genéticos. $O$ ensaio de campo é realizado para a obtenção de dois parâmetros físicos utilizados na modelagem: a rugosidade absoluta $\varepsilon$, utilizada na equação universal da perda de carga, fator de condição da infraestrutura $(\mathrm{FCl})$ e o expoente $\mathrm{N} 1$, utilizados no cálculo das perdas inerentes. 


\section{B.6 AVALIAÇÃO DE PERDAS}

A análise se inicia com o cálculo da vazão fornecida ao trecho de rede, pois a simulação hidráulica fornece a vazão total que passa por ele, e que abastece também aos demais trechos a ele conectados. $E$ a vazão fornecida ao trecho se divide em duas porções: a demanda consumida no trecho e as perdas de água. A Figura B.3 ilustra a situação.

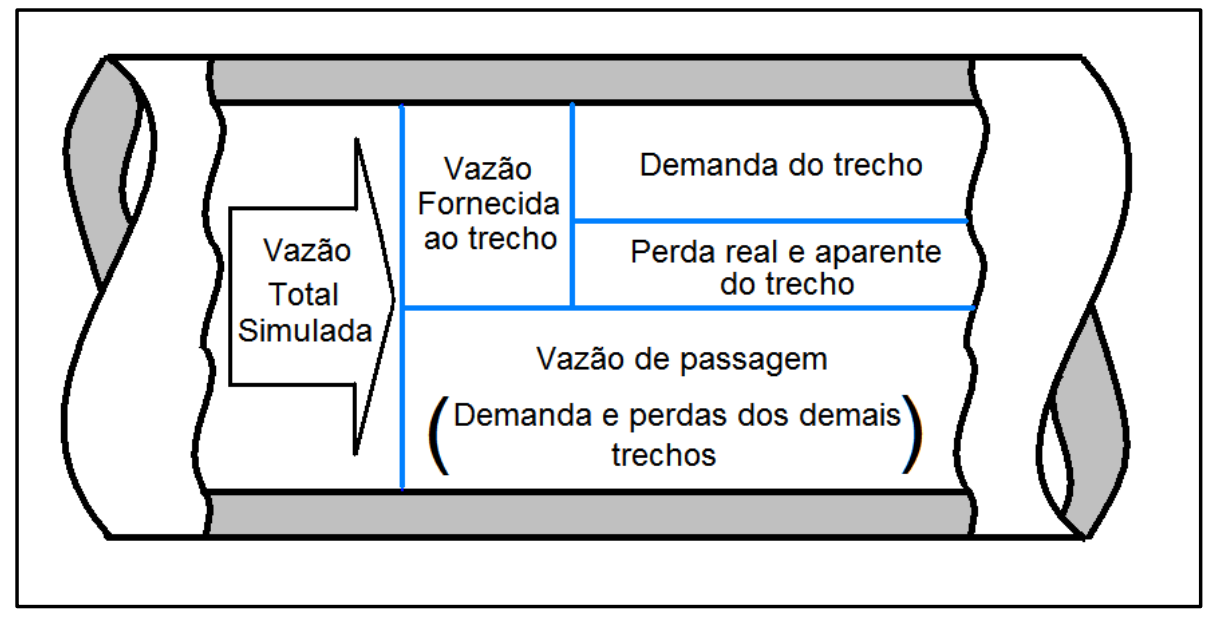

Figura B.3 - Esquema da estratificação da vazão simulada

A vazão fornecida ao trecho, $Q_{\overline{A B}}$ deve ser entendida como aquela que abastece apenas ao trecho analisado, como mostra o esquema representado na Figura B.4. Ou seja:

$$
Q_{\overline{A B}}=\sum_{i=1}^{n} q_{i}+P
$$

Onde, $Q_{\overline{A B}}$ é a vazão fornecida, $q_{i}$ são as demandas consumidas, e $P$ são as perdas totais, no trecho considerado.

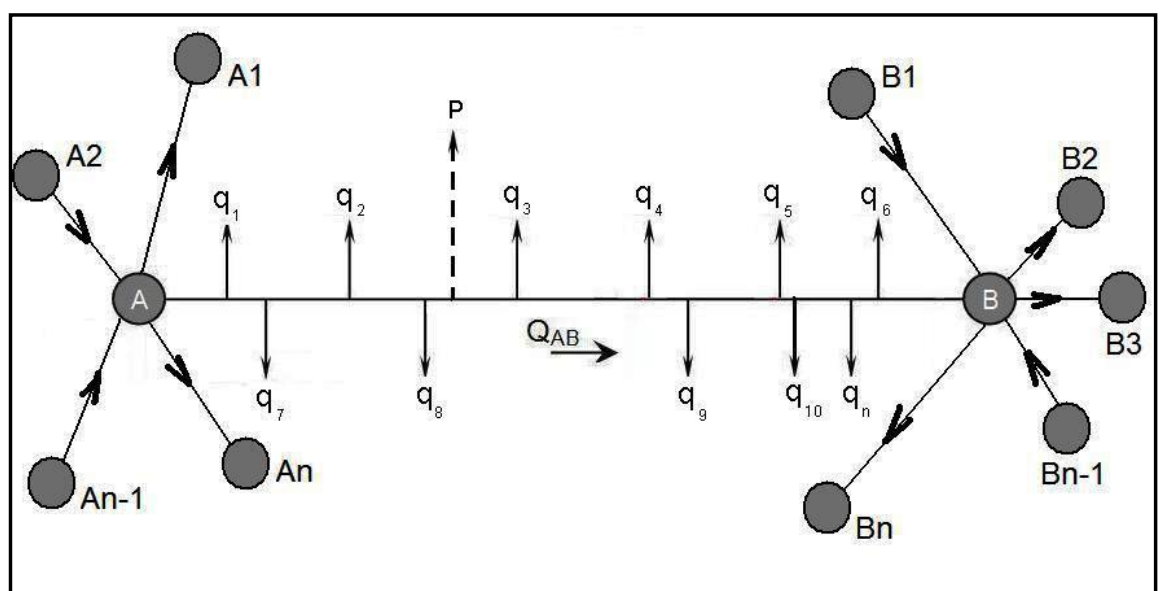

Figura B.4 - Esquema do balanço de vazões 
A vazão fornecida ao trecho $\left(Q_{\overline{A B}}\right)$ é obtida, efetuando dois balanços de vazões, um em cada extremidade do trecho considerado. $O$ balanço de vazões é feito, tomandose as vazões que entram e que saem de cada extremidade. Por exemplo, a vazão fornecida ao trecho $A B$ da Erro! Fonte de referência não encontrada., é obtida pela soma dos balanços de vazões dos pontos $A$ e $B$. O balanço de vazões nos pontos é dado pela equação 6.2 e 6.3 .

$$
\begin{gathered}
\mathrm{B}_{A}=\sum_{i=1}^{n} Q E_{A}-\sum_{i=1}^{n} Q S_{A}-Q_{\overline{A B}}=0 \\
\mathrm{~B}_{B}=\sum_{i=1}^{n} Q E_{B}-\sum_{i=1}^{n} Q S_{B}=0
\end{gathered}
$$

Onde, $Q E_{A}, Q E_{B}, Q S_{A}$, e $Q S_{B}$ são as vazões que entram e saem dos pontos $\mathrm{A}$ e $\mathrm{B}$, respectivamente. $E_{A} B_{A}$ e $B_{B}$ são os balanços de vazões em $A$ e $B$ respectivamente. Assim, a vazão fornecida ao trecho é a soma dos balanços de vazão de cada extremidade. A equação 5.4 demonstra o cálculo.

$$
Q_{\overline{A B}}=\sum_{i=1}^{n} Q E_{A}-\sum_{i=1}^{n} Q S_{A}+\sum_{i=1}^{n} Q E_{B}-\sum_{i=1}^{n} Q S_{B}
$$

Onde $Q_{\overline{A B}}$ é a vazão fornecida ao trecho.

A vazão total por hora em cada trecho é o único parâmetro que o modelo de simulação hidráulica nos dá de forma direta, com as expressões anteriores obtem-se o valor da vazão fornecida a cada trecho de rede.

\section{B.7 ESTUDO DE CASO}

O método descrito neste trabalho foi aplicado em uma pequena área que corresponde a um distrito de medição e controle (DMC), cujas características e etapas realizadas são apresentadas a seguir. Este DMC situa-se na zona leste do município de São Paulo, no estado de São Paulo, Brasil. Sua topografia é irregular, com cotas altimétricas variando de 785 a $745 \mathrm{~m}$. Possui uma extensão de rede 3,64 $\mathrm{km}$, com diâmetros variando entre 80 e $150 \mathrm{~mm}$ e idade de 48 anos, composta de tubos de ferro fundido sem revestimento interno. A rede apresenta incrustações, e 
seu estado estrutural é bom com ausência de corrosão com diminuição da espessura da parede do tubo. A densidade de ramais por $\mathrm{km}$ de rede é de 264 . O comprimento médio de cada ramal é de aproximadamente $3,5 \mathrm{~m}$, ou seja, um acréscimo de $3,37 \mathrm{~km}$ de extensão de tubulação composta de ramais em PEAD $\varnothing 32 \mathrm{~mm}$. É possível obter os parâmetros físico-químicos da água fornecida à área, como o valor do $\mathrm{pH}$ médio, que influencia na espessura média da camada de incrustação. Pelos dados obtidos das amostras de água coletadas, o valor que melhor representa o $\mathrm{pH}$ médio da área do $\mathrm{DMC}$ é 8,3. Com o valor do $\mathrm{pH}$ médio e a idade da rede, a espessura média das incrustações são estimadas como segue.

$$
\begin{gathered}
2 \cdot \log \alpha=6,6-8,3 \Rightarrow \alpha=10^{\frac{6,6-8,3}{2}}=0,1365 \mathrm{~mm} / \text { ano } \\
e=0,85+0,1365 \cdot 48 \Rightarrow e=7,63 \mathrm{~mm}
\end{gathered}
$$

Onde: $e_{0}=0,85 \mathrm{~mm}$ é a altura da rugosidade de um tubo novo; $e=7,63 \mathrm{~mm}$ é a altura da rugosidade após 48 anos; $t=48$ é o período de tempo em anos; $\alpha=$ 0,1365 é a taxa de crescimento da aspereza, em mm/ano. A amostra apresenta uma espessura média de incrustação da ordem de $9 \mathrm{~mm}$, ou seja, $1,37 \mathrm{~mm}$ maior que o teoricamente esperado. O setor de abastecimento que fornece água para o DMC é o setor Vila Alpina. O DMC é delimitado por 11 registros, e para simular o fornecimento de água ao DMC, o setor foi representado, simplificadamente, pelo reservatório $\mathrm{R} 1$, que abastece o trecho P-45 do esquema hidráulico. O fornecimento de água é constante e sem interrupções. As pressões máxima e mínima são aproximadamente 67,8 e 22,55 $\mathrm{mH}_{2} \mathrm{O}$ respectivamente. $\mathrm{E}$ as vazões máxima e mínima são aproximadamente 12,50 e $0,0384 \mathrm{~L} / \mathrm{s}$ respectivamente. Ligados à malha de distribuição existem 962 clientes sendo agrupados em termos de uso da água em 875 residências, 56 comércios, 18 indústrias e 13 mistos. Classificando as ligações em termos de economias, existem 1.174 economias sendo: 1.087 residências, 21 indústrias, 66 comerciais. As ruas pavimentadas e as construções são térreas em sua maioria.

Para simular as condições operacionais reais do sistema de abastecimento, foi realizada a calibração do modelo de simulação, por meio de medições e ensaios de campo, determinando alguns dos valores reais para uso na simulação. Foram realizados as seguintes medições e ensaios:

- Determinação das variações de vazão na entrada e pressões nos trechos; 
- Ensaio para determinação do fator de atrito;

- Ensaio para determinação do fator de condição da infraestrutura;

- Ensaio para determinação do expoente $N_{1}$.

As pressões nos trechos foram coletadas durante um período de vinte e nove dias, em dezenove pontos, e que cobriram noventa por cento dos trechos da rede. Resultando em quinze dias com dados sincronizados. O registrador 15 apresentou problemas e forneceu dados durante cinco dias, e o registrador 19, que foi o último a ser instalado, registrou dados por um período de dez dias.

$\mathrm{Na}$ avaliação da rugosidade absoluta $\varepsilon$ foi utilizada a equação explícita de SOUSA (1999), equação 7.1 .

$$
\frac{1}{\sqrt{f}}=-2 \cdot \log _{10}\left(\frac{\varepsilon}{3,7 \cdot D}-\frac{5,16}{R_{e}} \cdot \log _{10}\left(\frac{\varepsilon}{3,7 \cdot D}+\frac{5,09}{R_{e}{ }^{0,87}}\right)\right)
$$

O fator de condição da infraestrutura é avaliado através das equações empíricas de (Lambert et al., 1998) equações 3.6, 3.7, 3.9, da relação entre a variação de vazão e pressão equação 3.2. Para o calculo do $F_{c i}$, é necessária a determinação do $N_{1}$, que é obtido após trabalhar os dados coletados em campo, pela aplicação da equação 7.2 .

$$
N_{1}=\frac{\log \left(\frac{Q_{1}}{Q_{0}}\right)}{\log \left(\frac{P_{1}}{P_{0}}\right)}
$$

O $F_{c i}$ é obtido pela aplicação da equação 7.3 .

$$
F_{c i}=\frac{Q_{i}}{Q_{v i}} \Rightarrow F_{c i}=\frac{Q_{i}}{2,78 \cdot 10^{-4} \cdot(20 \cdot L+1,25 \cdot N) \cdot\left(\frac{\bar{p}_{m}}{50}\right)^{N_{1}}}
$$

\section{B.7.1 ANÁLISE DA EFICÁCIA DO USO DOS RESULTADOS NO DIAGNÓSTICO DE PERDAS DE ÁGUA}

A verificação da eficácia do uso dos resultados simulados, na criação do diagnóstico de perdas de água, é feito pela comparação entre os valores calculados, com base nos resultados da simulação hidráulica, e os verificados no sistema de abastecimento real.

Os valores a serem comparados são: 
- Os acertos e erros na previsão de vazamentos;

- As pressões simuladas com as medidas no sistema real;

- A vazão fornecida simulada e a medida na entrada do sistema real;

- A rugosidade absoluta teórica com a obtida no ensaio de campo;

Para a comparação entre os acertos e erros na previsão de vazamentos, com os resultados obtidos na simulação, é necessária a criação de uma classificação das vazões de perdas reais em função dos valores simulados. Esta classificação tem o seguinte critério:

- Vazamentos classe A, são aqueles que possuem vazões teóricas acima da média interna dos valores simulados, isto é, excluindo-se os valores extremos.

- Vazamentos classe B, são aqueles que possuem vazões teóricas entre a vazão de perdas reais inevitáveis e a média interna dos valores simulados.

- Vazamentos classe C, são aqueles que possuem vazões teóricas iguais ou menores que a perda real inevitável.

Classificados os trechos, os resultados podem ser tabulados como o apresentado na Tabela B.4 -Exemplo de tabulação de resultados.

Tabela B.4 -Exemplo de tabulação de resultados

\begin{tabular}{|l|c|r|r|c|c|}
\hline Classificação & Selecionados & \% Extensão Rede & Quantidade & Recuperação em L/s & \%Relativa à Perda Total \\
\hline Classe A & 12 & $27,18 \%$ & 2 & 6,29 & $40,70 \%$ \\
\hline Classe B & 29 & $52,50 \%$ & 7 & 1,04 & $6,75 \%$ \\
\hline Classe C & 7 & $10,49 \%$ & 1 & 0,0035 & $0,02 \%$ \\
\hline Sem classificação * & 5 & $9,83 \%$ & 0 & - & - \\
\hline
\end{tabular}

* Refere-se a trechos teóricos ou colocados para garantir a calibração da simulação hidráulica

É considerada assertiva a escolha dos trechos, se o resultado da detecção de vazamentos realizada, demonstrar um índice de acertos da ordem de $30 \%$ do total de vazamentos detectados de classe $A$. Esta classe abrange as maiores vazões de perda real, e sua detecção faz uma redução significativa na perda real.

O comparativo entre os valores simulados de pressão e vazão, e os observados no sistema real, obedece ao seguinte critério: a quantidade de tempo que o valor 
simulado esteve dentro do intervalo de confiança definido. Os intervalos de confiança adotados são os seguintes:

- Para a vazão:

- Duas vezes o desvio padrão dos valores medidos na hora avaliada;

- Para as pressões:

- Se a valor medido for menor ou igual a $20 \mathrm{mH} 2 \mathrm{O}$, o intervalo é de \pm 2 $\mathrm{mH} 2 \mathrm{O}$;

- Se a valor medido for maior que $20 \mathrm{mH} 2 \mathrm{O}$, o intervalo é de $\pm 10 \%$ do valor medido em $\mathrm{mH} 2 \mathrm{O}$;

A Figura B.5 mostra um exemplo da avaliação das pressões. Do ensaio realizado para a obtenção do fator de atrito, é possível obter a rugosidade absoluta. Este valor deve ser comparado com o valor obtido no cálculo teórico. Quanto mais próximos os resultados, melhor a confiança nos dados para a simulação. Na Figura B.6 é apresentado o comportamento dos valores simulados do registrador L-03. Embora seus valores, comparados com os reais, estejam fora dos limites definidos, o comportamento das variações de pressão, ao longo das 24 horas, semelhante ao real.

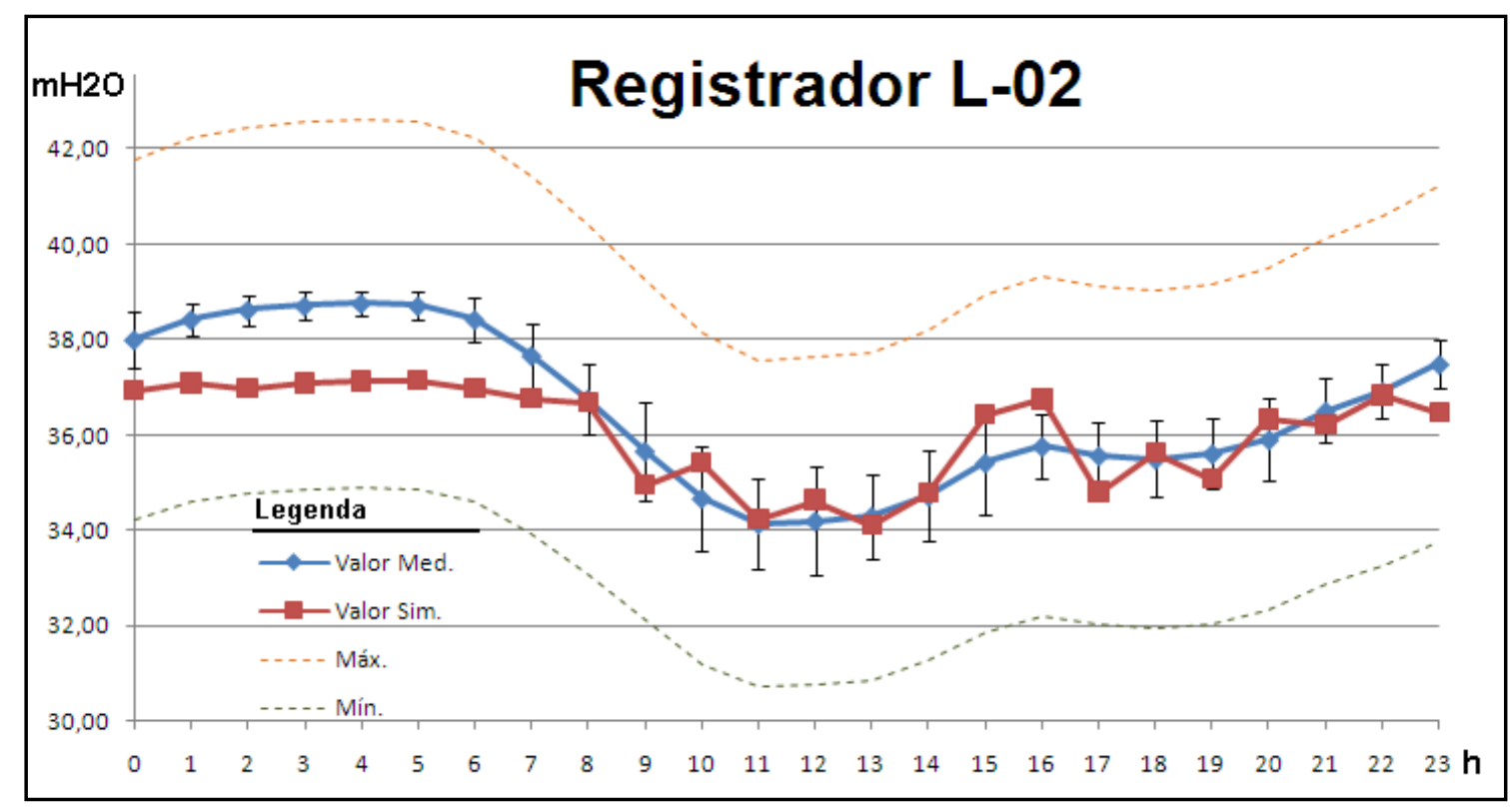

Figura B.5 - Exemplo da avaliação das pressões

Estudando os valores simulados, pode se constatar que as variações de pressão simuladas tem o mesmo comportamento das variações reais de pressão do sistema. 
E se todos os valores simulados, que se apresentam fora dos limites, forem multiplicados por uma constante, o resultado situa-se entre os limites definidos, como mostra a Figura B.7, que apresenta os valores do L-03 multiplicados por 1,28. Um dos parâmetros que certamente está influindo no resultado é a rugosidade absoluta. Este parâmetro teve seu valor obtido no ensaio de campo e foi considerado igualmente em todos os trechos de rede, o que não acontece no sistema real, onde cada trecho tem uma rugosidade específica própria e variável.

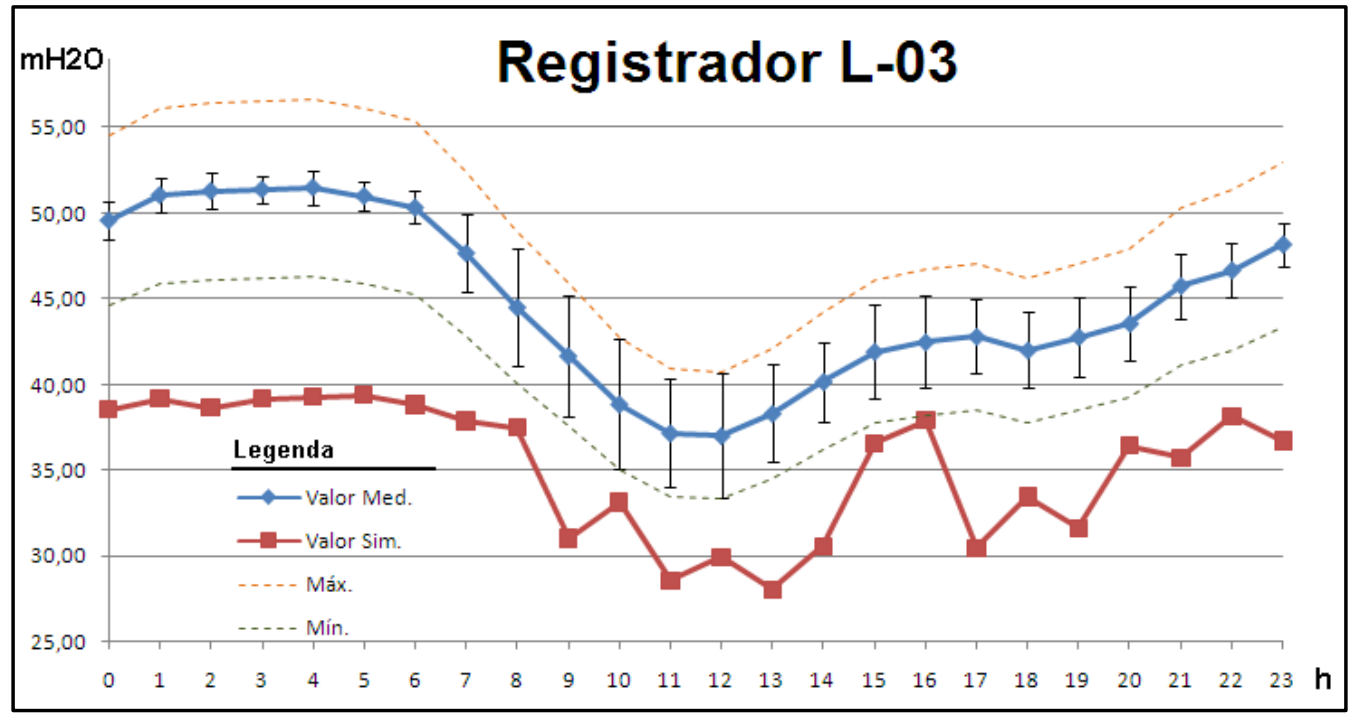

Figura B.6 - Gráfico comparativo L-03

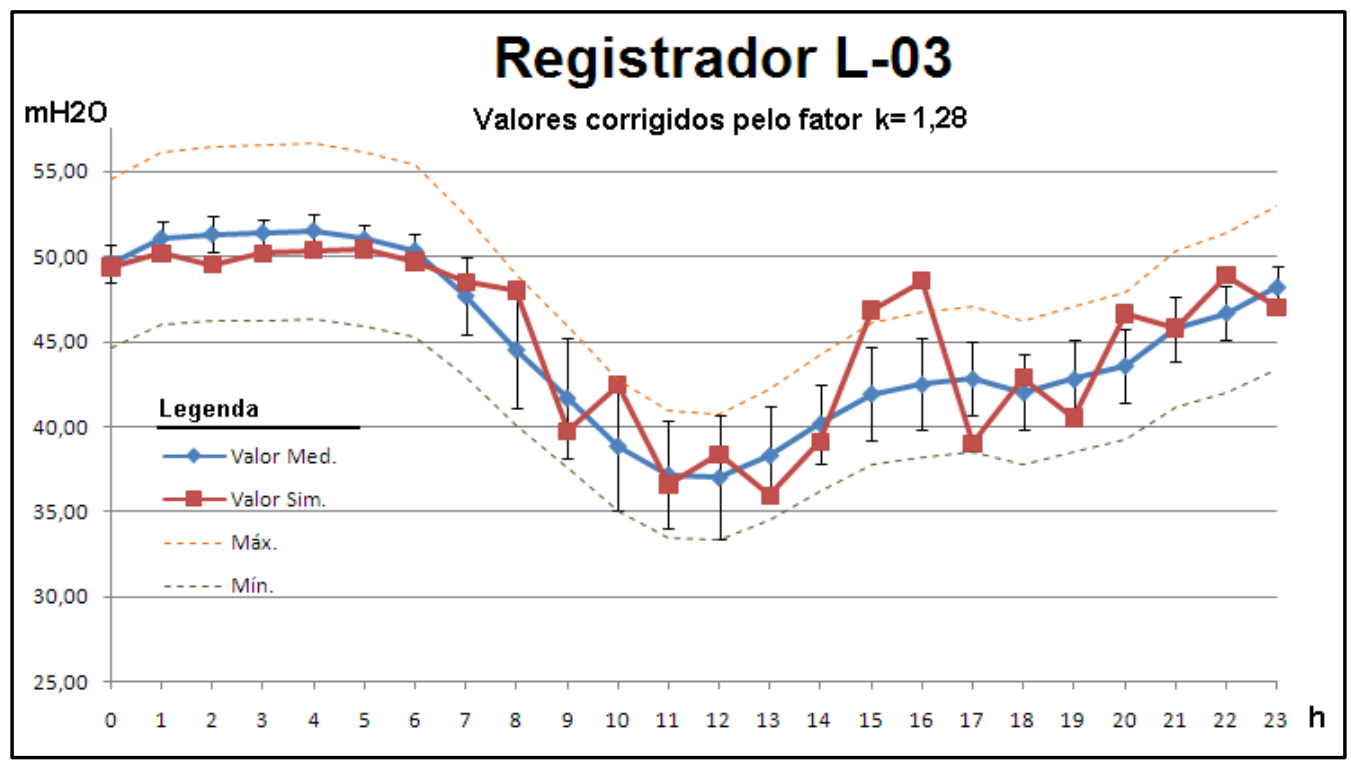

Figura B.7 - Valores do registrador L03 simulados corrigidos pelo fator $k=1,28$ 
Após as simulações, os resultados são importados para as planilhas de pressões, vazões e trechos de rede. Os cálculos de todos os componentes de perdas por trecho são efetuados em planilha eletrônica, na qual fica caracterizado o balanço hídrico e os componentes da vazão mínima. Na Figura B.8 é apresentado um exemplo da planilha calculada para o trecho P-20 do modelo de simulação hidráulica.

Cabe salientar que em alguns trechos de rede, o resultado do cálculo da vazão de perda real, resultou em um valor negativo. Isto porque, a distribuição das demandas reais existentes no trecho, atribuídas às junções de suas extremidades, acaba sendo influenciada pelas demandas dos demais trechos unidos na mesma junção. Desta forma, quando o algoritmo genético executa as adequações nas vazões das junções, provoca algum desvio em relação ao balanço de vazões originais, o que pode gerar valores de vazão fornecida ao trecho, menores que a vazão perdida total. Como não existe perda nula ou negativa, para efeito de cálculo, foi considerada nestes casos a perda real igual à perda real inevitável. 


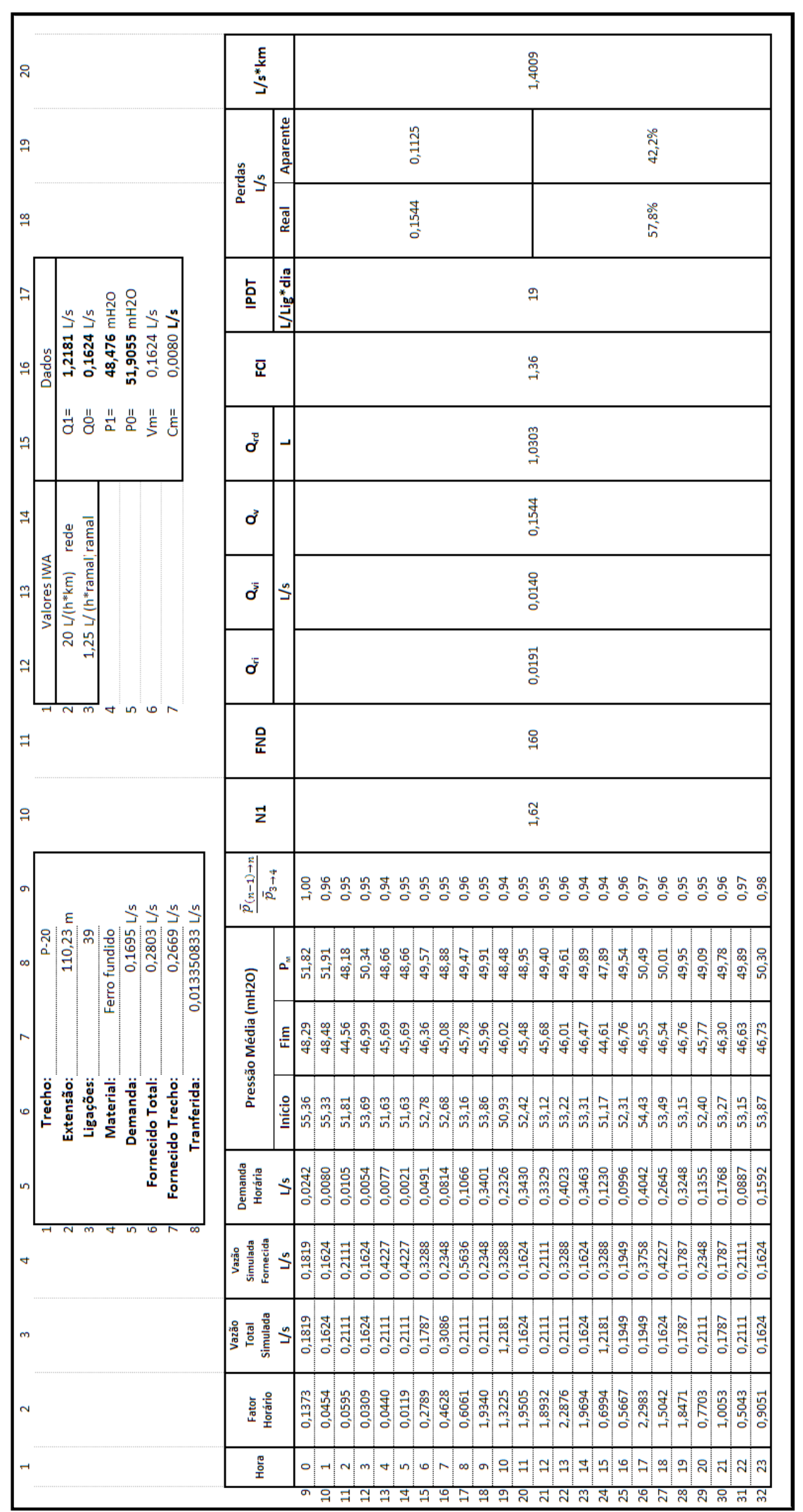

Figura B.8 - Exemplo da planilha de calculo 


\section{B.8 CONCLUSÕES}

- Os modelos de simulação hidráulica são eficazes no fornecimento de informações para a elaboração de um diagnóstico de perda de água em um sistema de distribuição, desde que se obtenham dados confiáveis, e representativos, das características da área a ser estudada.

- Possibilita a análise e avaliação das condições operacionais do sistema em estudo, proporcionando detectar desvios da realidade causados por alterações das condições operacionais (fechamentos de registros, alteração de demandas, novos empreendimentos, etc.), com a sua calibração com dados hidráulicos levantados em campo.

- As simplificações da realidade efetuadas no modelo, não afetaram os resultados críticos. Desta forma, o comportamento do sistema real foi reproduzido, o que permite a elaboração do diagnóstico operacional do sistema.

- O modelo pode apoiar as estratégias de investimento por meio de uma análise de custo benefício, apoiada nos resultados simulados. Isto porque aplicando os resultados na elaboração de gráficos de Pareto e mapas temáticos, facilitam a identificação de trechos de rede nos quais são necessárias, a detecção de vazamentos ou recuperação estrutural. Como exemplo, para reduzir em $40,70 \%$ a perda total, atua-se em apenas doze trechos, que representam $27,18 \%$ da extensão total de rede, o que gera uma economia de recursos financeiros e humanos.

- O modelo permite o cálculo das variáveis necessárias para estimar as perdas pelo método da IWA, o que permite avaliar as perdas reais e aparentes por trecho de rede.

- A simplificação das equações empíricas de Lambert et al. (1998) deram bons resultados, mesmo aplicados a valores simulados de um único dia. As previsões por trecho forneceram resultados representativos da realidade da área.

- O método aplicado no estudo de caso pode ser seguido em outra área em estudo, pois foi demonstrada sua eficácia na obtenção das informações necessárias para elaboração de diagnóstico e definições de ações para a 
redução de perdas de água no sistema de distribuição analisado.

- O método tem boa eficiência, pois reduziu a necessidade de pesquisar toda a extensão de rede da área, mas não elimina a necessidade de um segundo levantamento ou pesquisa de campo complementar.

- Em áreas cujas características são desconhecidas é um belo início. 


\section{B.9 RECOMENDAÇÕES}

- Atentar para as seguintes dificuldades encontradas e nas soluções aplicadas, pois servem de orientador para trabalhos futuros:

- Dificuldade na coleta de dados de campo;

- Dificuldade de realização de ensaios de campo.

- Falha na estanqueidade da área;

- Demora excessiva na simulação em período estendido pelo WaterGEMS $\AA$;

- São indispensáveis, o bom planejamento da execução do ensaio e a obtenção prévia de todos os equipamentos e materiais.

- A disponibilidade de uma equipe de técnicos e ajudantes treinados em perdas é necessária e deve ser requisitada, pois os testes devem ser conduzidos com o máximo rigor e confiabilidade.

- As instalações de medidores, válvulas e acessórios nos trechos de rede que serão ensaiados deve ser solicitada com antecedência evitando atrasos e complicações no abastecimento de água aos clientes.

Este trabalho apresentou a eficácia do uso do modelo apenas em função da localização de vazamentos, mas a redução de perdas é muito mais que isso. Fica a recomendação para novos estudos de verificação da eficácia em todas as decisões tomadas, baseadas nas previsões apontadas pela simulação, e com acompanhamento rigoroso durante a execução. 


\section{APÊNDICE C - ORGANIZAÇÃO DOS ARQUIVOS NO CD-ROM}

Pastas

Arquivos

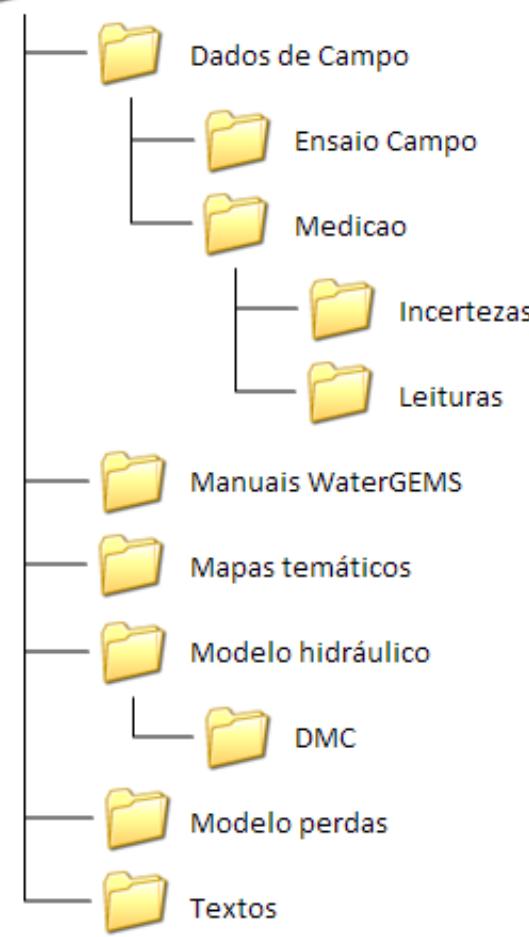

\section{Conteúdo}

Pasta raiz

Todos os arquivos de dados coletados no campo

Arquivos do ensaio de campo

Todos os arquivos das medições de pressão e vazão

Cálculos das incertezas das medições

Arquivos das leituras coletadas no local

Manuais do software WaterGEMS e Darwin Calibrator

Arquivo no formato ArcView $(8)$ V 3.2

Todos os arquivos que compõem o modelo hidráulico e as simulações

Arquivos que compõem o modelo hidráulico para WaterGEMS ${ }^{\odot}$

Arquivo com as tabelas calculadas para cada trecho de rede

Texto da dissertação e do artigo 